\title{
Advanced Fuels Campaign FY 2010 Accomplishments Report
}

December 2010

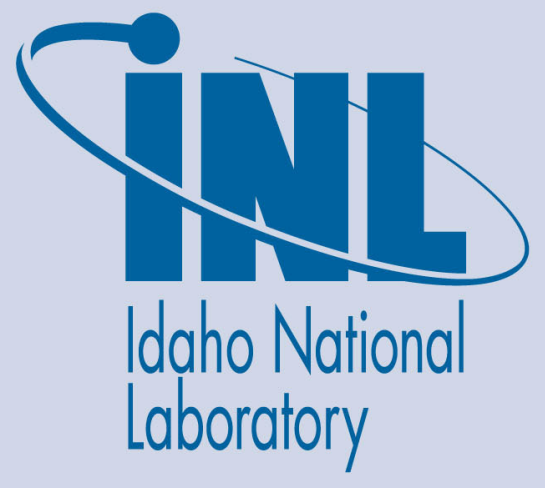

The INL is a U.S. Department of Energy National Laboratory operated by Battelle Energy Alliance 
INL/EXT-10-20566

FCRD-FUEL-2011-000015

\title{
Advanced Fuels Campaign FY 2010 Accomplishments Report
}

December 2010

\author{
Idaho National Laboratory \\ Fuel Cycle Research and Development \\ Idaho Falls, Idaho 83415
}

http://www.inl.gov

Prepared for the

U.S. Department of Energy

Office of Nuclear Energy

Under DOE Idaho Operations Office

Contract DE-AC07-05ID14517 


\section{DISCLAIMER}

This information was prepared as an account of work sponsored by an agency of the U.S. Government. Neither the U.S. Government nor any agency thereof, nor any of their employees, makes any warranty, expressed or implied, or assumes any legal liability or responsibility for the accuracy, completeness, or usefulness, of any information, apparatus, product, or process disclosed, or represents that its use would not infringe privately owned rights. References herein to any specific commercial product, process, or service by trade name, trade mark, manufacturer, or otherwise, does not necessarily constitute or imply its endorsement, recommendation, or favoring by the U.S. Government or any agency thereof. The views and opinions of authors expressed herein do not necessarily state or reflect those of the U.S. Government or any agency thereof. 


\title{
Fuel Cycle Research and Development
}

\section{Advanced Fuels Campaign FY 2010 Accomplishments Report}

\author{
INL/EXT-10-20566 \\ FCRD-FUEL-2011-000015 \\ Revision 0
}

December 2010

Compiled and edited by:

Lori Braase (lori.braase@inl.gov)

Douglas Hamelin (douglas.hamelin@inl.gov)

INL Systems Engineering

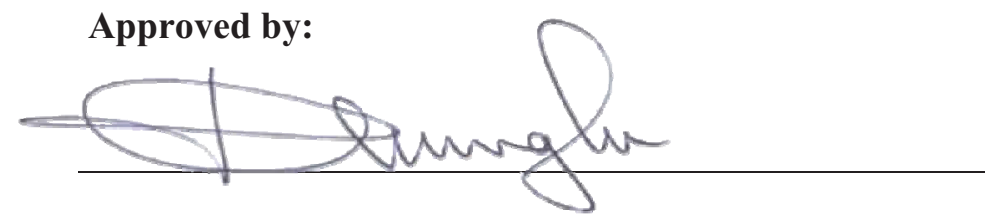

Kemal Pasamehmetoglu

FCRD AFC National Technical Director 


\section{EXECUTIUE SUMMARY}

The Advanced Fuels Campaign (AFC) under the Fuel Cycle Research and Development (FCRD) program is responsible for developing fuels technologies to support the various fuel cycle options defined in the DOE Nuclear Energy Research and Development Roadmap, Report to Congress, April 2010. The fiscal year 2010 (FY 2010) accomplishments report provides a highlight of the results of the research and development (R\&D) efforts performed within AFC in FY 2010. Each section contains a high-level overview of the activities, results, technical point of contact and applicable references. In this report, the word fuel is used to include fissile and fertile fuels, targets, and their associated cladding materials.

While this report provides a brief summary of the campaign management and integration activities, the focus is on the technical accomplishments. In FY 2010, the AFC transitioned to a "goal-oriented science-based approach" as opposed to a rapid, empirically-based demonstration program that was the focus of the campaign activities in the previous years. The science-based approach is aimed at a fundamental understanding of the fuel fabrication methods and fuel performance in the reactor, enabling the pursuit of multiple fuel forms for the future fuel cycle options. The science-based approach comprises fundamental experiments, theory and advanced modeling and simulation. The modeling and simulation activities for fuel performance are carried out under the Nuclear Energy Advanced Modeling and Simulation (NEAMS) program and the AFC activities are closely coordinated with the NEAMS team.

AFC management and integration activities included continued support for International collaborations, primarily with France, Japan, European Union, Republic of Korea and China. Various working group and expert group activities in International Agencies (OECD/NEA, IAEA) also were supported. Campaign management documents (implementation and execution plans) were published, along with a separate effects testing R\&D plan. In this category, the major accomplishment was the solicitation of innovative fuel ideas from National laboratories and selection of 10 concepts for feasibility R\&D plan development. Funding was provided for the top-ranking three concepts after an independent peer review. Quarterly campaign meetings focused on monitoring the progress in transitioning to the science-based approach and in assuring that a balanced approach is being applied to the development of evolutionary and revolutionary methods for fuel development.

The technical accomplishments are reported under the following R\&D categories:

- Metal-Based Fuels Technologies

- Ceramic-Based Fuels Technologies

- Coated Particle Fuels Technologies

- Core Materials Technologies

- Irradiation Testing Technologies.

Under Metal-Based Fuels Technologies, activities continued for high-purity neptunium (Np) and Americium (Am) metal feedstock preparation. A high temperature apparatus was fabricated and tested with surrogate (manganese) for Am feedstock preparation. High purity (97\% pure) Np metal was produced in small quantities. Fuel casting studies continued to minimize the losses (with an objective of achieving less than $0.1 \%$ losses which is a campaign grand-challenge). A laboratory scale continuous 
casting apparatus was designed. The experimental activities for casting were supported by casting modeling performed by the TRUCHAS code. To determine the phase, microstructure and thermo-physical properties of metal fuel samples, and to study the fuel-clad chemical interaction (FCCI) characterization activities continued. In addition, characterization technique development (which applies to metal fuels as well as other fuel forms) were conducted with major accomplishments in laser-based thermo-physical properties measurements at micron scale (Scanning Thermal Diffusivity Measurements - STDM). The methods development included adaptation of Focused Ion Beam (FIB) and micro-X-Ray Diffraction (MXRD) to measurements with radioactive materials.

Under Ceramic-Based Fuels Technologies, the emphasis
Metal-Based Fuels Technologies major accomplishments include:

- World's first measurement of thermal diffusivity on fresh and irradiated fuels with a 50 micrometer resolution

- Successful testing of the benchscale casting system to reduce Am volatility and design of a continuous casting system

- Production of $97 \%$ pure $\mathrm{Np}$ metal feedstock at research scale was on a fundamental understanding of feedstock and process parameters for the production of highquality fuel pellets with minimal losses. Process testing and dynamic oxygen-to-metal $(\mathrm{O} / \mathrm{M})$ ratio control studies were conducted using uranium and surrogates, which provided valuable data in

Ceramic-Based Fuels Technologies major accomplishments include:

- Fundamental understanding of sintering kinetics, O/M control, and feedstock effects on oxide fuel fabrication and characterization processes

- Diffusivity measurements during sintering to quantify the thermal-transport induced densification understanding the fabrication processes. Process testing using transuranic (TRU) elements and characterization of the MOX and Minor Actinide MOX (MA-MOX) samples continued. Process development studies were supported by detailed thermo-chemical modeling of binary oxides (U-O, Pu-O, Am$\mathrm{O})$, which will later be combined to understand the actinide oxide thermo-chemistry. Characterization development continued with studies of micro-structural characterization, thermal properties measurements and melt point determination. Diffusivity measurements were performed during sintering to quantify the thermal-transport induced densification, which is critical in understanding the sintering kinetics. The effects of rare-earths on the decomposition of resin particles were investigated as a continuation of sphere-pac fuel technology development.

The management of the NGNP "Deep Burn" program was transferred to AFC in FY 2010. The program evaluates the use of coated particle fuel (TRISO) technology for TRU transmutation. The associated studies on the system level fuel cycle assessments, the spent fuel disposition, and separation techniques for the TRISO fuel were concluded at the end of FY 2010.

Accomplishments for Coated Particle Fuels Technologies include the procurement of a thermal analyzer and mass spectrometer to produce fundamental actinide thermo chemical properties data to support model development. A thermochemical database was populated to support the TRU-bearing TRISO fuel development. Analysis shows that the inclusion of $\mathrm{SiC}$ or $\mathrm{ZrC}$ getters in the kernel reduces the $\mathrm{CO}$ pressure in the kernel considerably. For kernel fabrication, gettered kernels using surrogates $\left(\mathrm{ZrO}_{2}\right)$ for kernel material were fabricated successfully. A kernel fabrication laboratory for TRU

Coated Particle Fuels Technologies major accomplishments include:

- Analytic assessment of gettering concepts to suppress the CO pressure in the kernels

- Completion of the hot kernel fabrication laboratory

- Preliminary design of the coating laboratory

- Assessment of ZrC as a replacement for SiC as a coating layer 
materials was completed and should be operable in FY 2011. Preliminary designs of the coating laboratory were completed and the laboratory is expected to be operational in FY 2011. Because $\mathrm{ZrC}$ is being considered as a potential substitute for $\mathrm{SiC}$ for deep burn applications, considerable studies were conducted for $\mathrm{ZrC}$ mechanical properties, Palladium (Pd) $-\mathrm{ZrC}$ interactions, and silver $(\mathrm{Ag})-\mathrm{ZrC}$ interactions. Proton irradiation studies on $\mathrm{ZrC}$ to assess the irradiation effects on mechanical properties were also conducted. In addition, a patent was submitted for a new fully ceramic microencapsulated fuel designed to be the first microencapsulated fuel capable of irradiation in light water reactors.

Core Materials Technologies major accomplishments include:

- Testing of the FFTF/ACO3 duct (HT-9) samples (tensile, fracture toughness, Charpy impact; annealing, microstructure)

- Fabrication of multiple 14YWT heat (radiation tolerant nanostrengthened ferritic alloy)

- Fabrication coated cladding samples for irradiation testing
For Core Materials Technologies, the cladding coating and lining studies to mitigate the FCCI in metal fuels were continued. For coating, 50 samples with TiN, TiN/TaN, SiC, $\mathrm{ZrN}$ coating were prepared for irradiation testing. For liners, $\mathrm{Zr}$ liners were investigated and they were shown not to be susceptible to decarburization as were the sample with vanadium lining tested previously. Multiple studies were conducted on test samples cut from the high-dose ACO-3 duct irradiated in FFTF. These studies included tensile testing, facture toughness and Charpy impact testing, thermal annealing and damage recovery, and micro-structural assessment. In addition, fracture toughness testing on FFTF/MOTA HT-9 specimen were completed and provided consistent results with the ACO-3 samples' tests. Samples were cut for testing high-dose MA-957 Steel (ODS steel) also recovered from FFTF/MOTA. These samples will be tested in FY 2011. The fabrication of 14YWT (a leading radiation resistant nanostrengthened ferritic alloy - NFA) and characterization studies were very successful. The fracture toughness of the NFA as a function of temperature was investigated and was shown to be lower than HT9. Options to increase the fracture toughness are being investigated.

Finally, for Irradiation Testing Technologies, nondestructive examinations were completed on rodlets from experiments $\mathrm{AFC}-1 \mathrm{D}, 1 \mathrm{G}, 1 \mathrm{H}$, and $2 \mathrm{~A}$, including neutron radiography and gamma scanning. AFC-2C experiments (MA-MOX at low burnup) were completed and shipped to HFEF for PIE along with the AFC-2B tests that were previously discharged. AFC-2D (high burnup MA-MOX test) and AFC-2E (metal fuel test) are continuing. Analyses to support AFC-3 series of testing in the outboard 'A' position were completed. Experiments AFC-2B and $2 \mathrm{C}$ were shipped from ATR to HFEF in July 2010 and non-destructive PIE was initiated with visual exam, neutron radiography, and gamma scanning of the capsules.

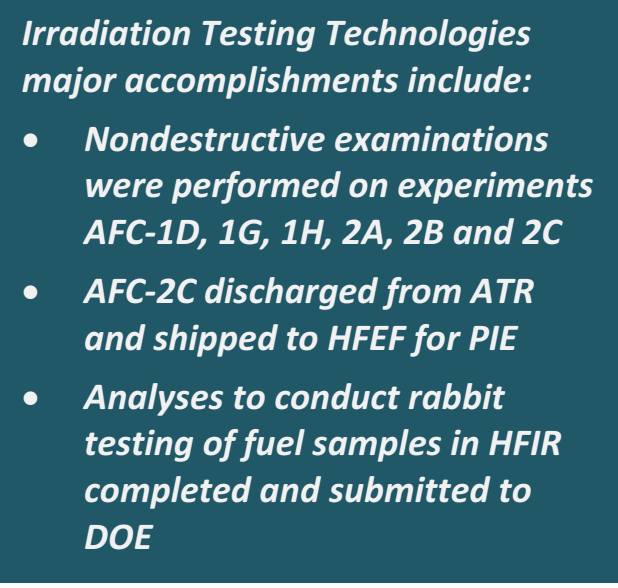

Several components were designed and fabricated to support the receipt of the FUTURIX-FTA experiments from Phénix reactor in a TN-106 shipping cask. Finally, all the supporting analyses for rabbit irradiations in HFIR were completed and submitted to DOE for approval. Once approved, rabbit irradiations of TEM disks containing TRU materials are expected to begin in FY 2011. 
Intentionally left Blank 


\section{CONTENTS}

Executive Summary $\mathrm{V}$

Acronyms $\mathrm{XV}$

1 Introduction 1

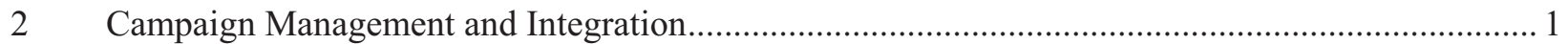

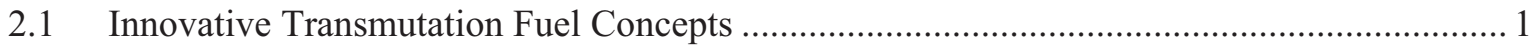

2.2 Advanced Fuels Separate Effects Tests R\&D Plan.............................................................. 3

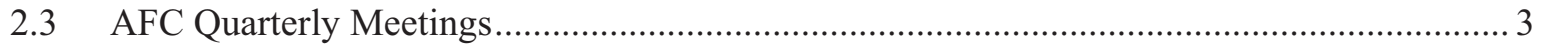

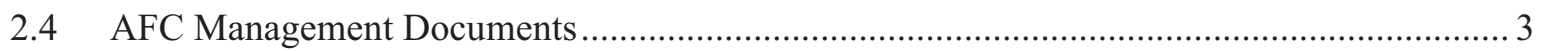

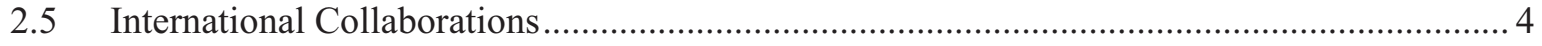

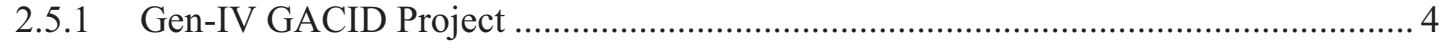

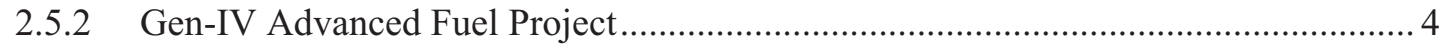

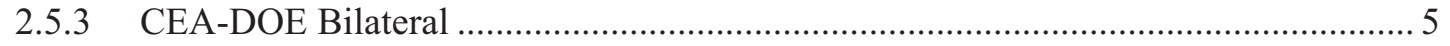

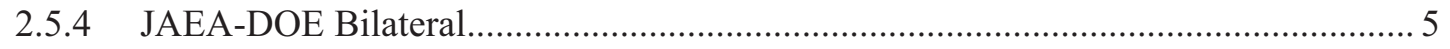

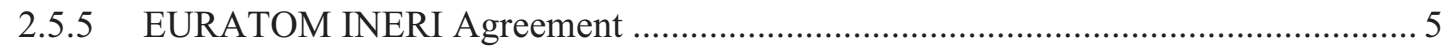

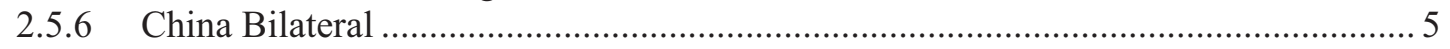

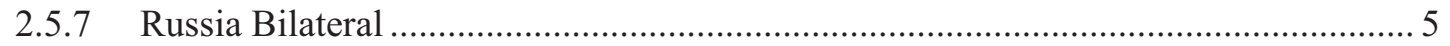

2.5.8 OECD/NEA Expert Group on Innovative Fuels ................................................... 5

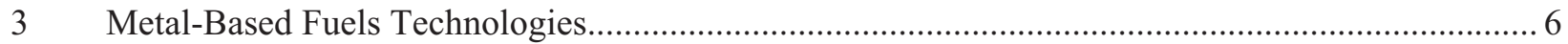

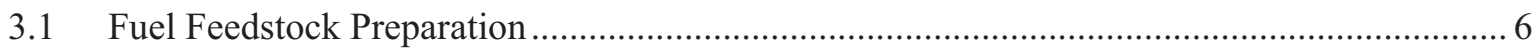

3.2 Fuel Fabrication and Casting Process Development.......................................................... 9

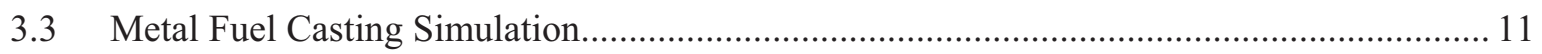

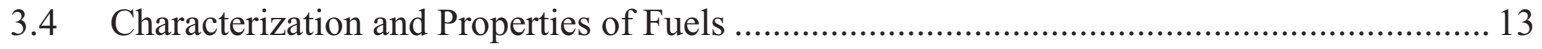

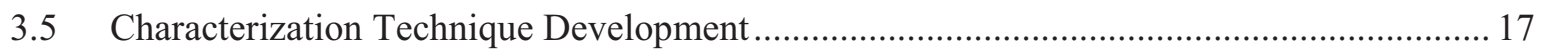

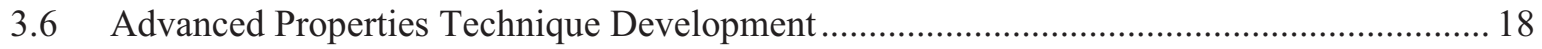

3.7 Modeling of Interdiffusion between U-based Fuels and Fe-based Claddings ...................... 21

3.8 Innovative Fuel Concept: Advanced Metallic Fuel Concept for Reliable

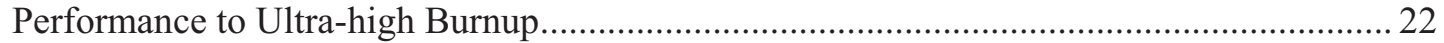

3.8.1 General Limits on Achieving Ultra-High Burnup ............................................... 22

3.8.2 Core Neutronics and Design for Ultra-high Burnup Metal Fuels ............................. 23

3.8.3 Alloy Additions to Control Fuel Constituent Migration ............................................2 24

3.8.4 Burnup Effect on Fuel Operating Temperature ........................................................2 26

3.8.5 Vented-fuel Impacts on Reactor Maintenance, Operations, and Safety..................... 27

3.9 Innovative Fuel Concept: Uranium Alloy Metal Fuel for Light Water Reactors ................. 27

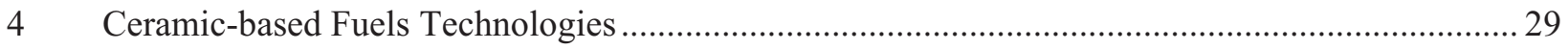

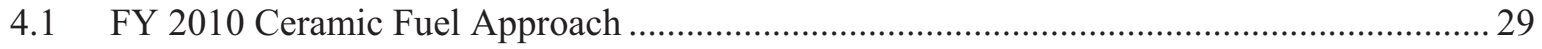

4.2 Decomposition of Rare Earth Loaded Resin Particles ....................................................... 30

4.3 Decomposition and Sulfur Removal from Nd-Loaded Resin ............................................. 31 
4.4 Uranium Oxide Based Processing Studies .......................................................................... 32

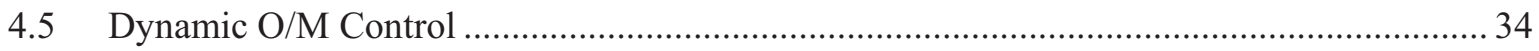

4.6 MOX and MA-MOX Fabrication and Process Development............................................. 37

4.7 Microstructural Characteristics of Sintered Urania ................................................................. 39

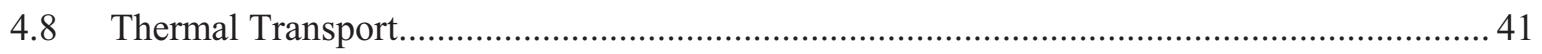

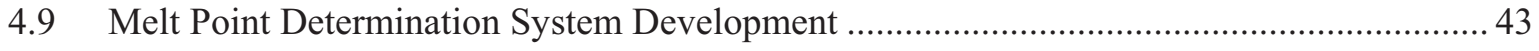

4.10 Oxide Thermochemical Modeling .................................................................................. 45

4.11 Innovative Fuel Concept: BNL Fuel Design \& Analysis - The Vented Fuel Pellet/Getter Concept for High Burnup Fuel........................................................................ 47

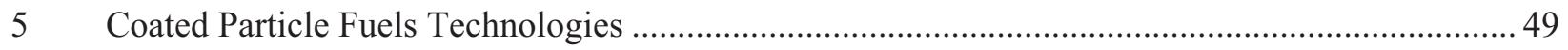

5.1 Deep Burn Simultaneous Thermal Analyzer Update ......................................................... 49

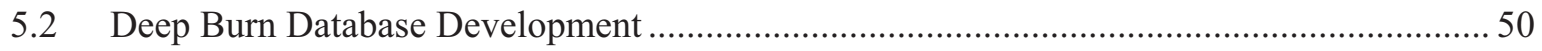

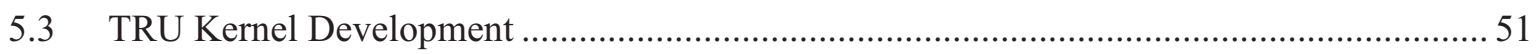

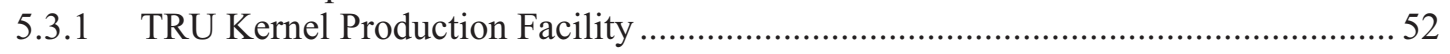

5.4 Deep Burn TRU Particle Coating Laboratory .............................................................. 53

5.5 Fully Ceramic Fuel for Waste Destruction ..................................................................... 57

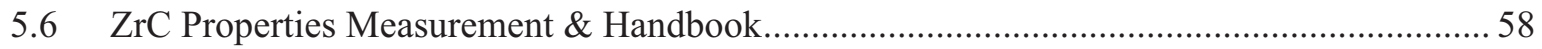

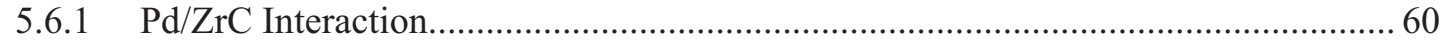

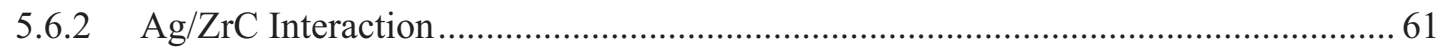

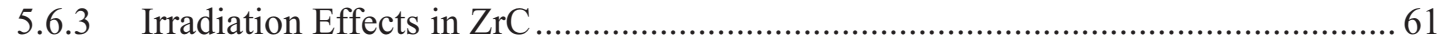

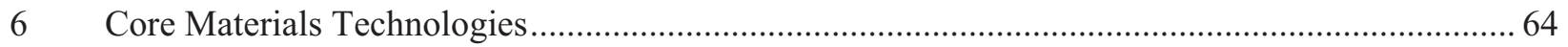

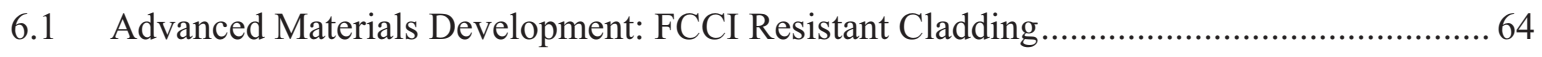

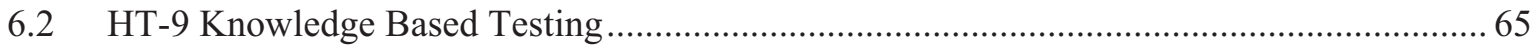

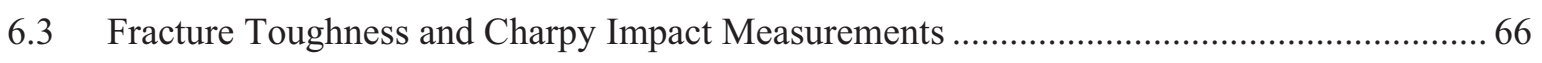

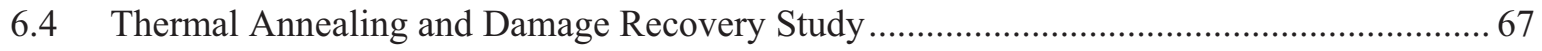

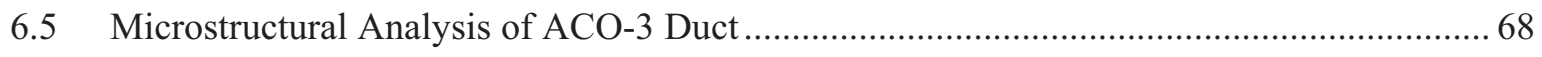

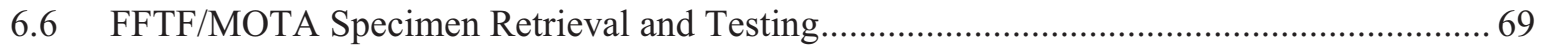

6.7 Tensile Testing and Microstructure of High Dose MA-957 ODS Steel .............................. 69

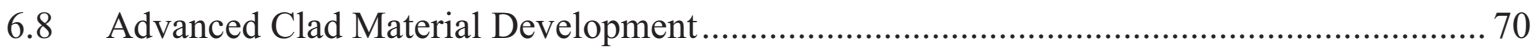

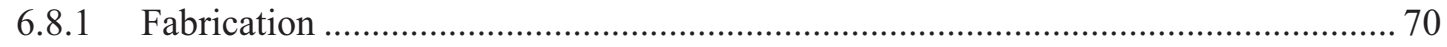

6.8.2 High Temperature Property Characterization for NFAs ....................................... 71

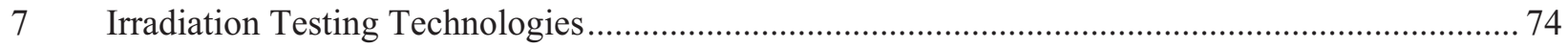

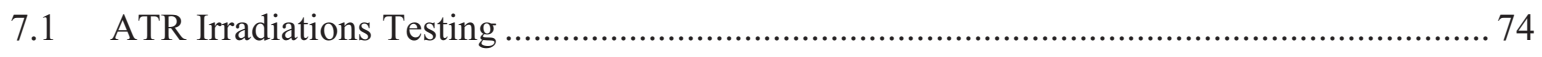

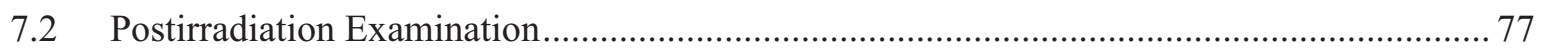

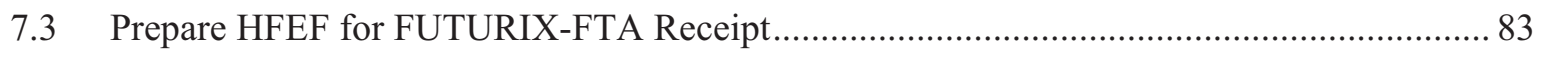

7.4 Post-Irradiation Examination Equipment Upgrade Project................................................... 84

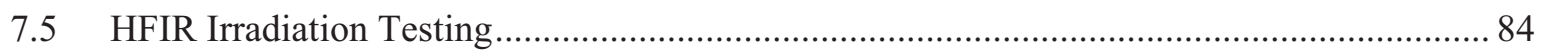

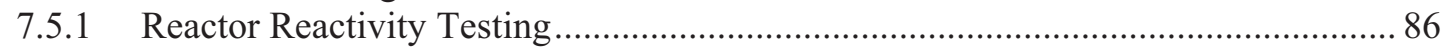

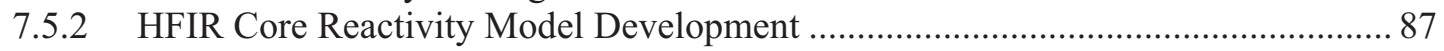

7.5.3 Design of Shielded Rabbits for Irradiating TEM Samples ..................................... 88 


\section{FIGURES}

Figure 1. Experimental sequence to reduce small amounts of $\mathrm{PuO} 2$ and $\mathrm{AmO} 2$ using La metal................7

Figure 2. Color 3-D drawing (left) and engineering line drawing (right) of DOR furnace (for

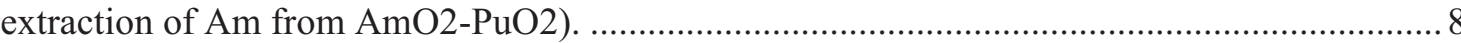

Figure 3. Left: View (3-D) of inside of small distillation furnace. Right: Design verified by evaporating and condensing $\mathrm{Mn}$ metal surrogate on $\mathrm{Cu}$ "cold finger"..................................... 8

Figure 4. First Np "nugget" formed by direct oxide reduction (DOR) of NpO2 in stirred molten salt bath

Figure 5. Lab scale continuous casting apparatus designed by Wagstaff Applied Technologies............... 10

Figure 6. Mn retention versus overpressure results. ........................................................................... 11

Figure 7. Induction heating power for (a) the mold coils and (b) the crucible coils ................................ 12

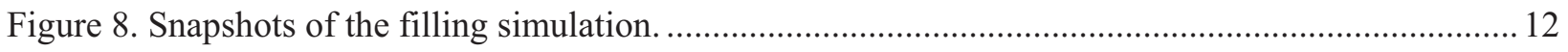

Figure 9. Deconvoluted DSC cooling curve for the B3 alloy (35U-20Pu-45Zr) .................................. 15

Figure 10. Partial and full transition enthalpies for some B alloys....................................................... 15

Figure 11. SEM images of fuel-clad interface reactions in (a) U-20Pu-30Zr at.\% and (b) U-20Pu30Mo at. $\%$

Figure 12. (a) Conceptual design of a laser ultrasound instrument for measuring mechanical properties of radiological samples. (b) Schematic showing the optical beam paths through the imaging module.

Figure 13. Images of (a) TEM lamellae extraction and (b) the TEM interface structure between layers in a surrogate TRISO fuel particle.

Figure 14. Sample holders. Left: inner dish with O-ring in front of outer dish. Right: inner dish and its O-ring inside outer dish and its O-ring.

Figure 15. Tool for positioning O-ring on inner dish. Bottom part is on left; piston with O-ring is on right; sleeve is around piston.

Figure 16. Radial profile of the thermal diffusivity of an unirradiated fresh fuel sample (blue-top) compared to the radial profile of a sample irradiated to about $6 \%$ burnup. Measurements were performed at room temperature.

Figure 17. Estimated burnups (at arrows) for beginning of FCMI for three as-fabricated smeared densities.

Figure 18. U-Pd-La-Ce-Pr-Nd-Zr alloys cast for characterization.

Figure 19. X-ray maps and back-scattered electron image (lower right) for alloy Pd-6 (U-15Zr3.9Pd-4.3Ln). Colors rendered are false. Highlighted regions for neodymium overlap the highlighted regions for palladium. However, the neodymium does not appear to be present in the fuel matrix, while some of the palladium is present there and appears to be associated with high zirconium regions.

Figure 20. Heats of formation of In-X alloys (left) and Tl-X alloys (right). .........................................26

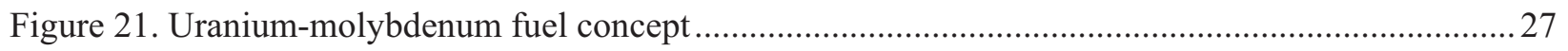

Figure 22. Unit Cell Burnup Calculations Showing Similar Burnup Capability for UO2 and U-Mo ........ 28 
Figure 23. Illustration of materials relationships between starting powder and subsequent fuel performance. 30

Figure 24. Neodymium-loaded AG-50W resin particles. .31

Figure 25. TG, DTG and DSC curves for Nd-loaded AG-50W resin in air 31

Figure 26. Mass spec results and sample points for sulfur determination via analytical chemistry...........32

Figure 27. Residual sulfur levels during decomposition under varied processing conditions. 32

Figure 28. Graph showing the effect of milling time on the particle size of uranium oxide powder.

Note that longer milling time does not decrease particle size as is usually observed.

Figure 29. Graph showing "green" density of a powder compact as a function of pressure for two different powders. The tremendous difference in density at the same pressure is a function of the properties of the powder such as particle size, size distribution and shape.

Figure 30 Electron Backscatter Diffraction images of the microstructure of two uranium oxide pellets processed identically except that the material in the left figure was sintered $300^{\circ} \mathrm{C}$ hotter resulting in larger grains. Grain size can have large effects on the properties of a material.

Figure 31. (a) Reduction of $\mathrm{U}_{0.8} \mathrm{Ce}_{0.2} \mathrm{O}_{2.21}$ using $\mathrm{CO} / \mathrm{CO}_{2}$ gases with dynamic control system, (b) $\mathrm{O} / \mathrm{M}$ as a function of temperature and $\mathrm{pO}_{2}{ }^{9}$...... 36

Figure $32 . \mathrm{H}_{2} / \mathrm{H}_{2} \mathrm{O}$ gas system $\mathrm{O} / \mathrm{M}$ control range using stock gases. .36

Figure 33. Comparison of recent LANL results for MOX and MA-MOX fuel forms with literature values for MOX fuel.

Figure 34. (a) SEM and EBSD images of a low density d-UO $\mathrm{UO}_{2}$ sample. (b) CSL GB distribution.

Figure 35. Simulation of GB diffusion for $D_{G B}^{2} / D_{G B}^{1}=10^{5}$ (a) mass flux and (b) normalized concentration.

Figure 36. In situ sintering data obtained for a pure urania pellet sintered at $2.5 \mathrm{C} / \mathrm{min}$ in a vacuum. The pellet was pressed to obtain slightly under $40 \%$ theoretical density. The blue triangles show data obtained during sintering and the diamonds are data recorded during cooling. The right-hand scale shows dilatometry shrinkage results for an identical material and heating rate.

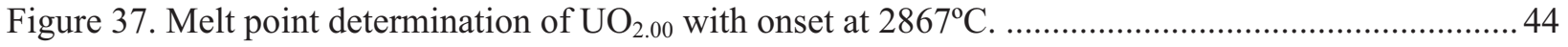

Figure 38. Plot of experimental and computed log of oxygen pressure versus O:Am. ............................46

Figure 39. Plot of experimental and computed log of oxygen pressure versus $\mathrm{O}: \mathrm{U}+\mathrm{Ce} \ldots \ldots \ldots \ldots \ldots \ldots \ldots \ldots . . . . . . . . . . . .46$

Figure 40. Transport and sequestering of fission product gases from the fuel pellet to a plenum region in the fuel rod....

Figure 41. STA, MS and accessories.

Figure 42. Thermochemical calculations of CO pressure determined to be substantially reduced by $\mathrm{SiC} / \mathrm{ZrC}$ getter mitigating kernel migration and overpressure.

Figure 43. Backscattered electron image of a polished cross section of a $\mathrm{Zr}-\mathrm{Y}$-SiC kernel.

Figure 44. Photograph of the Zr-Y gel spheres containing SiC particles in the gelation column and associated tubing.

Figure 45. Conceptual layout of ORNL Bldg. 3525 coating glove box laboratory. 


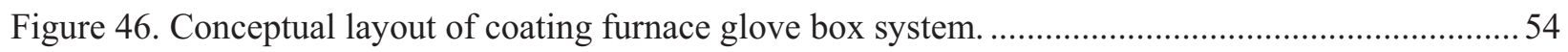

Figure 47. Fully ceramic AGR surrogate fuel..................................................................................... 57

Figure 48. High Temperature Strength Test Assembly ..................................................................... 58

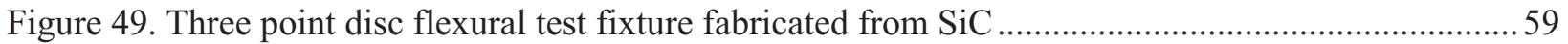

Figure 50. ZrC (0.95) Truncated Disc Test Specimens …................................................................... 59

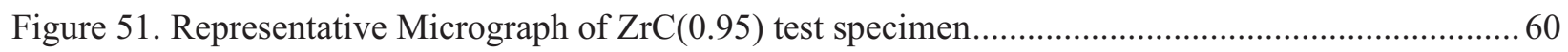

Figure 52. ZrC liquid-encapsulated with Zr-Ag solid solution: Optical macrograph (left), SEM image (right).

Figure 53. Infrared image of $\mathrm{ZrC}$ under irradiation at $1125^{\circ} \mathrm{C}$ using $2 \mathrm{MeV}$ protons (left), and TEM image of the irradiated $\mathrm{ZrC} 0.89$ with dose of $36 \mathrm{dpa}$ (right).

Figure 54. SEM images of micro-beams fabricated using FIB and the schematic of the machined notch (top), micro-cantilevers after being fractured (bottom left) and the fractography of the fractured micro-beam (bottom right).

Figure 55. Images of the interface between a) zirconium and b) vanadium and HT-9 following annealing at $704^{\circ} \mathrm{C}$ for 100 hours.

Figure 56. Graphs of yield stress and uniform elongation vs. irradiation temperature on tensile specimens tested at $25^{\circ} \mathrm{C}, 200^{\circ} \mathrm{C}$ and the irradiation temperature after being EDMmachined from the ACO-3 duct.

Figure 57. Charpy impact test data for ACO-3 duct material (HT-9) …................................................. 66

Figure 58. Fracture toughness of ACO-3 duct material (HT-9).....

Figure 59. Variation of microhardness after isochronal annealing at various temperatures for 1 hour..... 68

Figure 60. Variation of microhardness after isothermal annealing at 510 and $550{ }^{\circ} \mathrm{C}$ 68

Figure 61. (a) Machined tensile, ring pull, and TEM disk specimens, and (b) atom probe tomography (APT) specimens obtained from an MA-957 creep tube. .70

Figure 62. EPMA line composition profile (left) and BSE image (right) of 14YWT produced with

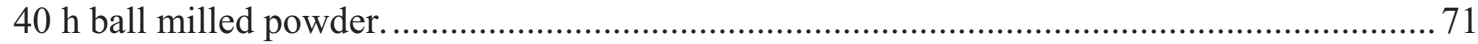

Figure 63. Atom probe tomographic image showing Y-Ti-O clusters in heat of 14YWT......................71

Figure 64. Temperature dependence of fracture toughness of 14YWT compared with the HT-9 steel.

Figure 65 . Fracture surface of $14 \mathrm{YWT}$ tested at $700{ }^{\circ} \mathrm{C}$ showing nanograins and debonding at grain boundaries

Figure 66. ATR reactor core cross section configuration (left) and enlargement of the East Flux Trap positions (right)..

Figure 67. GE2000 cask being inserted into the ATR canal to insert the AFC experiment capsules for shipment to the Materials and Fuels Complex (MFC) for PIE. .75

Figure 68. GE2000 cask loaded on the trailer for shipment to MFC. .76

Figure 69. FY 2011 planned irradiation schedule for continued irradiation of AFC-2 experiments.......... 77

Figure 70. Neutron radiography of fuel rodlets (left to right rodlets 1 through 6)................................... 80

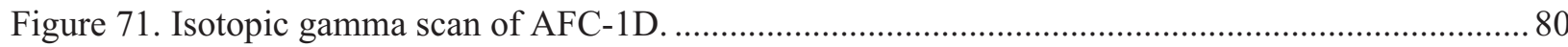




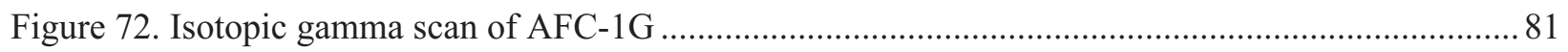

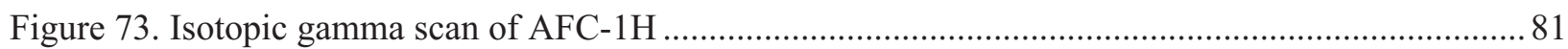

Figure 74. Neutron radiography of AFC-2A rodlets (left to right: rodlet 2, rodlet 1, rodlet 3, rodlet

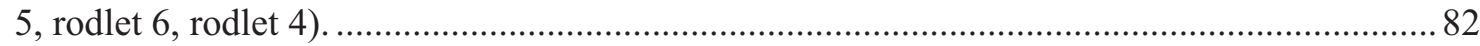

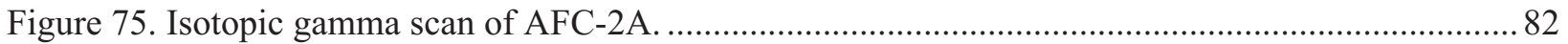

Figure 76. TN-106 shipping cask shown in HFEF cask cart with new cask cart adapter and shield ring.

Figure 77. Photograph of HFIR core showing central flux trap (left) and schematic showing the location of the various irradiation facilities within the flux trap region (right). The diameter of the flux trap is $12.7 \mathrm{~cm}$.

Figure 78. Sketch showing the location of the 9 rabbits in the standard rabbit train relative to the HFIR core. The fuel core height is $50.8 \mathrm{~cm}$.

Figure 79. Plots of the reactor power signal (normalized, red), the rate of rise of power signal (actually a RC-circuit conditioned power signal, not a true time rate of change of power signal, blue), and the derivative of the reactor power signal with respect to time (green) for the $\sim 8 \notin \mathrm{Cd}$ rabbit ejected from position 5 .

Figure 80. TEM rabbit design features the use of Gd spacers that also serve as the thermal neutron shield. Space is provided for a maximum of 12 TEM disks samples, however flux monitors will displace some of the TEM disks as needed. The number of Gd spacers can be reduced to adjust the reactivity of the rabbit.

\section{TABLES}

Table 1. Cast AFC-2B Alloys. (Compositions are listed in weight percent. Ln designates the lanthanide composition 53Nd-25Ce-16Pr-6La, which approximates fission product ratios.)

Table 2. Initial fracture toughness results from HT-9 recovered from FFTF/MOTA.

Table 3. Cycle 147A As-Run LHGR, Fission Heat Rates, and Burnup Distribution for AFC Fuel in the EFT at 50.2 EFPDs (Scaled to East Lobe Source Power of 21.7 MW)........................... 76

Table 4. Experiment AFC-1D composition and as-run irradiation data. ................................................. 78

Table 5. Experiment AFC-1G composition and as-run irradiation data. ............................................... 78

Table 6. Experiment AFC-1H composition and as-run irradiation data. ................................................ 78

Table 7. Experiments AFC-2A and 2B composition and as-run irradiation data. .................................. 79

Table 8. Experiment AFC-2C composition and as-run irradiation data. ................................................ 79

Table 9. Estimated maximum rabbit reactivity worth for hydraulic rabbit tube positions ........................ 88 


\section{ACRONYMS}

\begin{tabular}{|c|c|}
\hline$\mu-\mathrm{XRD}$ & Micro-focus X-ray Diffractometer \\
\hline ABTR & Advanced Burner Test Reactor \\
\hline $\mathrm{AFC}$ & Advanced Fuels Campaign \\
\hline AFCI & Advanced Fuel Cycle Initiative \\
\hline $\mathrm{AL}$ & Analytical Laboratory \\
\hline ANL & Argonne National Laboratory \\
\hline ASU & Arizona State University \\
\hline ATR & Advanced Test Reactor \\
\hline BFS & Bozzolo, Ferrante, and Smith Method \\
\hline BNL & Brookhaven National Laboratory \\
\hline BOC & beginning of cycle \\
\hline BSE & backscattered electron \\
\hline $\mathrm{CCD}$ & charge-coupled device \\
\hline $\mathrm{CEF}$ & compound energy formalism \\
\hline CETE & coupled-end-to-end \\
\hline $\mathrm{CP}$ & communication plate \\
\hline CSL & coincident site lattice \\
\hline DBTT & ductile brittle transition temperature \\
\hline DFT & density function theory \\
\hline DOE & Department of Energy \\
\hline DOR & direct oxide reduction \\
\hline dpa & displacements per atom \\
\hline DSC & differential scanning calorimetry \\
\hline DTG & differential thermogravimetry \\
\hline DU & depleted uranium \\
\hline EBR & Experimental Breeder Reactor \\
\hline EBSD & electron backscatter diffraction \\
\hline EDM & electron discharge machining \\
\hline EFPD & effective full-power day \\
\hline EFT & East Flux Trap \\
\hline EPMA & electron probe micro-analyzer \\
\hline FCCI & fuel-cladding-chemical interaction \\
\hline
\end{tabular}


FCMI fuel-clad-mechanical interaction

FCRD Fuel Cycle Research and Development

FE finite element

FFTF Fast Flux Test Facility

FIB focused ion beam

FMEF Fuels and Materials Examination Facility

FPG fission product gasses

FSR Fast-Spectrum Reactor

FY fiscal year

GB grain boundary

Gen-IV Generation IV

GFR gas-cooled fast reactor

HFEF Hot Fuel Examination Facility

HFIR High-Flux Isotope Reactor

HMTA hexamethylene tetramine

IFR Integral Fast Reactor

IMCL Irradiated Material Characterization Laboratory

INL Idaho National Laboratory

IRC INL Research Center

IRG Independent Review Group

JAEA Japan Atomic Energy Agency

LA lanthanide

LANL Los Alamos National Laboratory

LEAP local electrode atom probe

LEL lower explosive limits

LEU low enriched uranium

LHGR linear heat generation rate

LLNL Lawrence Livermore National Laboratory

LRUS laser resonance ultrasonic spectroscopy

LWR light water reactor

MA minor actinide

MAX $\quad M_{n+1} A X_{n}$ (Class of layered machinable ceramics)

MD molecular dynamics

MFC Materials and Fuels Complex 


\begin{tabular}{|c|c|}
\hline MOTA & Materials Open Test Assembly \\
\hline MOX & mixed oxide \\
\hline MS & mass spectrometer \\
\hline MXRD & Micro-focus X-ray Diffractometer \\
\hline $\mathrm{NE}$ & Office of Nuclear Energy \\
\hline NFA & nano-strengthened ferritic alloy \\
\hline NRC & Nuclear Regulatory Commission \\
\hline $\mathrm{O} / \mathrm{M}$ & oxygen-to-metal \\
\hline ODS & oxide dispersion strengthened \\
\hline OECD & Organization for Economic Co-operation and Development \\
\hline ORNL & Oak Ridge National Laboratory \\
\hline PIE & post-irradiation examination \\
\hline PNNL & Pacific Northwest National Laboratory \\
\hline $\mathrm{R} \& \mathrm{D}$ & research and development \\
\hline $\mathrm{RD} \& \mathrm{D}$ & research, development and demonstration \\
\hline $\mathrm{RE}$ & rare earth \\
\hline RED & radiation enhanced diffusion \\
\hline REDC & Radiochemical Engineering Development Center \\
\hline RPL & Radiochemical Processing Laboratory \\
\hline RT & room temperature \\
\hline SANS & small angle neutron scattering \\
\hline SD & smeared density \\
\hline SDSM\&T & South Dakota School of Mining and Technology \\
\hline SEM & scanning electron microscope \\
\hline SFR & Sodium Fast Reactor \\
\hline SRNL & Savannah River National Laboratory \\
\hline STA & simultaneous thermal analyzer \\
\hline STDM & scanning thermal diffusivity microscope \\
\hline TG & thermogravimetry \\
\hline TIMS & thermal ionization mass spectrometer \\
\hline TRISO & tristructural isotropic \\
\hline TRU & transuranic \\
\hline TSR & technical safety requirements \\
\hline IASCC & irradiation assisted stress corrosion cracking \\
\hline
\end{tabular}


UCB University of California-Berkeley

UCSB University of California Santa Barbara

UTK University of Tennessee Knoxville

WBS work breakdown structure

XRD $\quad \mathrm{X}$-ray diffraction

YSZ yttria-stabilized zirconia

\section{Periodic Elements}

\begin{tabular}{|c|c|}
\hline $\mathrm{Ag}$ & silver \\
\hline $\mathrm{Al}$ & aluminum \\
\hline Am & americium \\
\hline $\mathrm{C}$ & carbon \\
\hline $\mathrm{Ce}$ & cerium \\
\hline $\mathrm{Cr}$ & chromium \\
\hline $\mathrm{Fe}$ & iron \\
\hline $\mathrm{Ga}$ & gallium \\
\hline Gd & gadolinium \\
\hline In & indium \\
\hline $\mathrm{La}$ & lanthanum \\
\hline Ln & a $53 \mathrm{Nd}-25 \mathrm{Ce}-16 \mathrm{Pr}-6 \mathrm{La}$ compositional relationship \\
\hline $\mathrm{Mn}$ & manganese \\
\hline Mo & molybdenum \\
\hline $\mathrm{N}$ & nitrogen \\
\hline $\mathrm{Nb}$ & niobium \\
\hline $\mathrm{Nd}$ & neodymium \\
\hline $\mathrm{Np}$ & neptunium \\
\hline $\mathrm{Pd}$ & palladium \\
\hline $\operatorname{Pr}$ & praseodymium \\
\hline $\mathrm{Pu}$ & plutonium \\
\hline $\mathrm{Sm}$ & samarium \\
\hline $\mathrm{Tl}$ & thallium \\
\hline $\mathrm{U}$ & uranium \\
\hline $\mathrm{Zr}$ & zirconium \\
\hline
\end{tabular}




\section{Advanced Fuels Campaign FY 2010 Accomplishments Report}

\section{INTRODUGTION}

One of the major research and development (R\&D) areas under the Fuel Cycle Research and Development (FCRD) program is advanced fuels development. AFC has the responsibility to develop advanced fuel technologies for the Department of Energy (DOE) using a science-based approach focusing on developing a microstructural understanding of nuclear fuels and materials.

Accomplishments made during fiscal year (FY) 2010 are highlighted in this report, which focuses on completed work and results. The process details leading up to the results are not included; however, the technical contact is provided for each section. The order of the accomplishments in this report is consistent with the Advanced Fuels Campaign (AFC) work breakdown structure (WBS).

\section{GAMPAIGN MANAGEMENT AND INTEGRATION}

AFC National Technical Director (NTD), K.O. Pasamehmetoglu, kemal.pasamehmetoglu@inl.gov, INL

One of the most challenging aspects of the AFC is the management, integration, and coordination of the major R\&D activities across multiple national laboratories and universities working to achieve this goal. Several management activities were accomplished in FY 2010 that supports the overall goals of the FCRD program. AFC interfaces and collaborates with the FCRD campaigns, industry, various DOE programs and laboratories, federal agencies (e.g., Nuclear Regulatory Commission (NRC)), and International Organizations.

\subsection{Innovative Transmutation Fuel Concepts}

K.O. Pasamehmetoglu, kemal.pasamehmetoglu@inl.gov, INL

As part of the FCRD longer-term, science based focus, there is a desire to promote the generation of new ideas and foster exploration of transformational technology options. A call for proposals was issued during the first quarter of FY 2010 to generate a collection of innovative transmutation fuels concepts. The proposals were focused on a balanced science-based R\&D approach that included both performance enhancement and investigation of evolutionary concepts.

Nine national laboratory teams submitted twenty one whitepapers, which were evaluated by an independent technical review committee. The review process provided a comprehensive review of each whitepaper concept. Six criteria were used by the review committee to evaluate the technical content and potential impact of each proposal.

- Potential impact if successful and estimate of time to success

- Burnup and performance capability

- Efficient fabrication capability 
- Transmutation capability and fuel cycle impact

- Identification of needed R\&D

- $\quad$ R\&D team capability.

Review panel scores for each concept were sub-divided into three ranges:

High $(7,8,9)$ - a potential game changer that should be funded if at all possible

Medium $(4,5,6)$ - very innovative proposal that should be considered for funding

Low $(1,2,3)$ - should not be considered for funding at this time.

Each review committee member used a questionnaire to evaluate each concept. Then they prioritized the list to identify their top-ten. In addition, they recommended partial scope opportunities and possible combinations of multiple concepts. The first three proposals in the list below were funded for three years and the remaining seven were funded through the end of FY-10. All were required to conduct a feasibility R\&D plan as a year-end deliverable. Accomplishments for the three funded Innovative Fuels Concepts are included in their respective technical areas.

1. Advanced Metallic Fuel Concept for Reliable Performance to Ultra-high Burnup (ANL, INL) A.E. Wright, S.L. Hayes, ANL-FCRD-317, September 2010

2. Getter Fuel Pin Concept for Enhanced Burnup (BNL)

M. Todosow, BNL-FCRD-AFC-2010-001, November 17, 2010

3. Uranium Alloy Metal Fuel for Light Water Reactors (PNNL)

R.P. Omberg, FCRD-FUEL-2010-000186, PNNL-19814, August 2010

4. Advanced Dispersion Fuel R\&D Plan (INL)

E. Shaber, INL PLN-374, November 2010

5. Ultra-high Burnup Metallic Inert Matrix Nuclear Fuel Concept (LLNL)

P. Turchi, LLNL-PROP-45, October 2010.

6. Advanced High Integrity Gas Cooled Fast Reactor Fuel: MAX Phase Ceramic Materials (SRNL)

T. Adams, M3501020806 - FCRD-FUEL-2010-000190, September 2010

7. Multi-Layer Co-Extruded Fast Reactor Metallic Fuel: Co-Extrusion Technology

Development (SRNL)

T. Adams, M3501020809 - FCRD-FUEL-2010-000191, September 2010

8. Enhanced Thermal Conductivity and Grain Boundary Engineering for Oxide Fuels (ORNL)

9. High Burn-up Ceramic Composite Nuclear Fuels (LANL)

I. Usov, September 2010

10. Input to AFC on RD\&D Issues and Requirements for Thorium-Based Fuels (BNL)

M. Todosow, BNL-FCRD-AFC-2010-002, December 2010 


\title{
2.2 Advanced Fuels Separate Effects Tests R\&D Plan
}

\author{
J. Carmack, jon.carmack@inl.gov, INL
}

A Draft Advanced Fuels Separate Effects Tests (SET) R\&D Plan was developed to identify key, nearterm experiments, measurements, and characterization activities for advanced fuels modeling and simulation and to identify the data required to perform initial verification and validation of fuels performance and fabrication models.

Coordinating the experimental and the computational R\&D efforts across the DOE Office of Nuclear Energy (NE) is needed to support well designed experimental programs with computation simulations that accurately represent the data generated. Similarly, the computational models and simulations developed to represent nuclear fuel performance and behavior will be useless to nuclear fuel designers and fuel licensing authorities unless the models can be validated against fundamental phenomenological effects and integral generated data.

The Advanced Fuels SET R\&D Plan includes the general roles and responsibilities for the experimental nuclear fuel developers and the computation nuclear fuel modeling and simulation technical staff; a discussion of the SET R\&D plans for the general categories of nuclear fuel (e.g., metallic, ceramic) and cladding; and the irradiation testing experiments that cross the general metallic, ceramic, and cladding categories. These experiments will ultimately provide much of the data needed to validate coupled and integrated models and simulations.

\subsection{AFC Quarterly Meetings}

\section{L.A. Braase, lori.braase@inl.gov, INL}

Four AFC quarterly meetings were conducted during FY 2010. In general, the meetings consisted of DOE-NE guidance, industry partner's needs and insights, and technical presentations that provided the status of R\&D efforts. The meeting locations and dates are listed below.

- Las Vegas, Nevada, December 1-3, 2009. Two tours were provided on December 3. The first tour to the University of Nevada Las Vegas (UNLV) focused on their nuclear related facilities and capabilities. The second tour to Yucca Mountain started at the Information Center in Pahrump with lunch, presentations, and informal discussions.

- Santa Fe, New Mexico, March 2-3, 2010. Two new research areas added to the AFC were introduced and discussed: Light Water Reactor Fuels Technologies and Advanced Particle Fuels Technologies.

- Salt Lake City, Utah, June 2-3, 2010. The Innovative Fuels Concepts were presented and discussed.

- Gaithersburg, Maryland, September 15-17, 2010. Presentations were made by the new industry partners, AREVA, EnergySolutions, Shaw Group, and ENERCON.

\subsection{AFC Management Documents}

\author{
L.A. Braase, lori.braase@inl.gov, INL
}

Two high-level AFC documents were updated to reflect the Fuel Cycle R\&D (FCRD) change in program direction to a science-based approach. 
- The Draft Advanced Fuels Campaign Implementation Plan, FCRD-FUEL-2010-000041, was delivered to DOE-NE on March 31, 2010. It provides summary level detail describing how the AFC supports achievement of the overarching FCRD program mission and objectives.

- The Advanced Fuels Campaign Execution Plan, FCRD-FUEL-2010-000058, was delivered to DOE-NE on October 29, 2010. It provides the structure and management of research, development, and demonstration (RD\&D) activities within the FCRD program.

\subsection{International Collaborations}

J. Carmack, jon.carmack@inl.gov, INL

Internationally, researchers are very active with collaborations including Korea, France, Japan, China, and EURATOM. These interactions and collaborations are managed through a combination of participation in GENIV Global International Forum projects, INERI projects, and participation in bilateral and trilateral government to government agreements. In 2010, contacts with fuels and materials researchers in Russia were initiated.

\subsubsection{Gen-IV GACID Project}

J. Carmack, INL, K. McClellan, LANL

The Global Actinide Cycle International Demonstration (GACID) project seeks to demonstrate the irradiation and performance of MA-bearing MOX fuel in the Monju reactor in Japan. Critical to this effort is the supply of feedstock materials needed to fabricate characterization samples and fuels for the irradiation tests.

Cm Feedstock Supply - The U.S. is currently performing logistics related to shipment of 2 grams of $\mathrm{Cm}$ to Atalante, France to fulfill the U.S. commitment in this area to the GACID project. It is expected that approvals and shipping arrangements will be completed in the 2011 timeframe.

MOX and MA-MOX Material Property Characterization - To achieve licensing for MA-bearing MOX fuel in the Monju reactor, extensive material property measurements must be made. These measurements will be used to accurately predict the fuel performance and behavior while under irradiation in Monju. The U.S. performed thermal property measurements in support of GACID at the Los Alamos National Laboratory.

\subsubsection{Gen-IV Advanced Fuel Project}

\section{J. Carmack, INL}

The Gen-IV SFR Advanced Fuel project provides the means for collaboration on the development of advanced fuels for sodium fast reactors including metallic, ceramic, nitride, and carbide fuel systems. The U.S. coordinated and published the SFR Fuels Comparison report assembled from the contributions of all participants in the project. Each section of this report has been published in referred journal articles or is currently being prepared for publication. The U.S. representative to this project will become the project management board (PMB) chair for 2010. 


\title{
2.5.3 CEA-DOE Bilateral
}

\author{
K.O. Pasamehmetoglu, S. L. Hayes, INL
}

In the fuels area, the U.S. DOE and CEA are jointly pursuing the assessment of the $\mathrm{UO}_{2}-\mathrm{Am}_{\text {system }}$ as a transmutation system for Am. Researchers from DOE and CEA are currently studying the irradiation performance of an irradiation experiment testing this concept. The analyses of CEA and DOE will be shared and compared. This effort was initiated in FY2009 and continued through FY 2010.

\subsubsection{JAEA-DOE Bilateral}

J. Carmack, INL

This year the JAEA-DOE Bilateral activity centered on developing future collaborative fuel research and development activities. Key in this regard is the definition and planning of transient fuel experiments needed to understand fuel response to and behavior under off-normal and over-power conditions.

\subsubsection{EURATOM INERI Agreement}

\author{
J. R. Kennedy, INL
}

EURATOM-DOE collaborative fuel research and development have focused on specific technical staff exchanges on fabrication and characterization methods with the Joint Research Center-Institute of Transuranium Elements.

\subsubsection{China Bilateral}

K.O. Pasamehmetoglu, J. Carmack, INL

U.S. fuels representatives and Chinese CIAE representatives meet in Beijing, China to discuss collaborative topical areas under the US-China Civil Nuclear bilateral Collaboration in August 2010 and again in Albuquerque, NM in September 2010. U.S. fuels representatives toured the newly started CEFR fast test reactor located near Beijing. Discussion and collaboration will continue in FY 2011.

\subsubsection{Russia Bilateral}

J. Carmack, INL, S.A. Maloy, LANL

In May 2010, interactions with Russian counterparts were initiated by U.S. fuels representatives at the US-Russia Civil Nuclear Bilateral Collaboration meeting in Obnisk, Russia. Initial discussions were on collaborative irradiation testing of fuels and materials. Additional collaborations are still under discussion pending ratification of the 123 agreement.

\subsubsection{OECD/NEA Expert Group on Innovative Fuels}

K.O. Pasamehmetoglu, INL

Activities associated with the Innovative Fuels Expert Group continued. The group, chaired by a U.S. representative, is currently working on publishing a state-of-the-art report on innovative fuels. 


\section{METAL-BASED FUELS TECHNOLOGIES}

Technical Lead, J. R. Kennedy, rory.kennedy@inl.gov, INL

The FY 2010 accomplishments from Metal-Based Fuels Technologies have demonstrated significant advancement in all work areas. The technical area was charged with three Level 2 and fourteen Level 3 milestones (one Level 2 and fourteen Level 3 milestones pushed into 1st quarter FY 2011 by DOE request) and accomplished these on or before due dates. Accomplishment highlights include:

- The world's first radial profile of thermal diffusivity at $50 \mu \mathrm{m}$ spatial resolution (highest known spatial resolution capability) on irradiated ( $\sim 6$ at $\%$ burnup) and fresh metal fuel using the newly developed scanning thermal diffusivity microscope (STDM)

- The continuing development of the focused ion beam (FIB) and micro-focus x-ray diffractometer (MXRD) advancing to the use of radioactive materials (the development of these two instruments for use with highly radioactive materials are of great international interest)

- The advancement of the production of pure TRU elements for programmatic needs with the isolation of $\sim 5 \mathrm{~g} \mathrm{~Np}$ metal ( $\sim 97 \%$ purity) from reduction of $\mathrm{NpO}_{2}$, the fabrication and testing of an Am distillation apparatus, and the completed design of an $\mathrm{AmO}_{2}$ direct oxide reduction/isolation apparatus

- The surrogate demonstrated resolution of the americium retention (vapor pressure) "problem" during metal fuel casting process

- The completion of the feasibility study for continuous casting and microwave casting

- The completion of the conceptual design of a remote operated Laser Resonance Ultrasonic Spectroscopy (LRUS) apparatus for microstructure evolution tracking and fundamental mechanical constant determination

- The demonstration of fission product migration sequestering with preliminary considered agents

- The advancement of the determination of the fundamental behavior, properties, and fuelcladding-chemical interaction (FCCI) of U-Pu-Zr systems.

\subsection{Fuel Feedstock Preparation}

P. Lessing, paul.lessing@inl.gov, I. Glagolenko, L. Squires, INL

The Fuel Feedstock Preparation work area has two objectives: (1) maintain and update a database on the DOE complex TRU ( $\mathrm{Pu}, \mathrm{Am}, \mathrm{Np}$ ) supply and anticipated fuel feedstock requirements for future FCRD fuel fabrication needs and (2) obtain basic feedstock materials in the required amounts and convert them into the necessary chemical forms for successful fuel fabrication. For the latter, significant effort was directed towards developing techniques to reduce oxide feedstocks to obtain elemental metallic feedstocks of $\mathrm{Np}, \mathrm{Pu}$, and $\mathrm{Am}$.

To support development of an Am extraction method from a Savannah River Site feedstock (10\% $\mathrm{AmO}_{2}-\mathrm{PuO}_{2}$ ), small-scale experiments were conducted (Figure 1) to verify thermodynamic calculations that predict the reduction of $\mathrm{PuO}_{2}$ and $\mathrm{AmO}_{2}$ to their respective metals at elevated temperature by $\mathrm{La}$ metal. X-ray diffraction (XRD) analysis of the reaction products showed that La metal powder does reduce $\mathrm{PuO}_{2}$ to $\mathrm{Pu}$ metal and $\mathrm{PuO}$ (probably from re-oxidation of $\mathrm{Pu}$ ). The XRD analysis did not identify 
Am metal or residual $\mathrm{AmO}_{2}$ in the reduced pellets. It is suggested at this point that Am metal was indeed formed but evaporated out of the pellet. These studies are continuing.
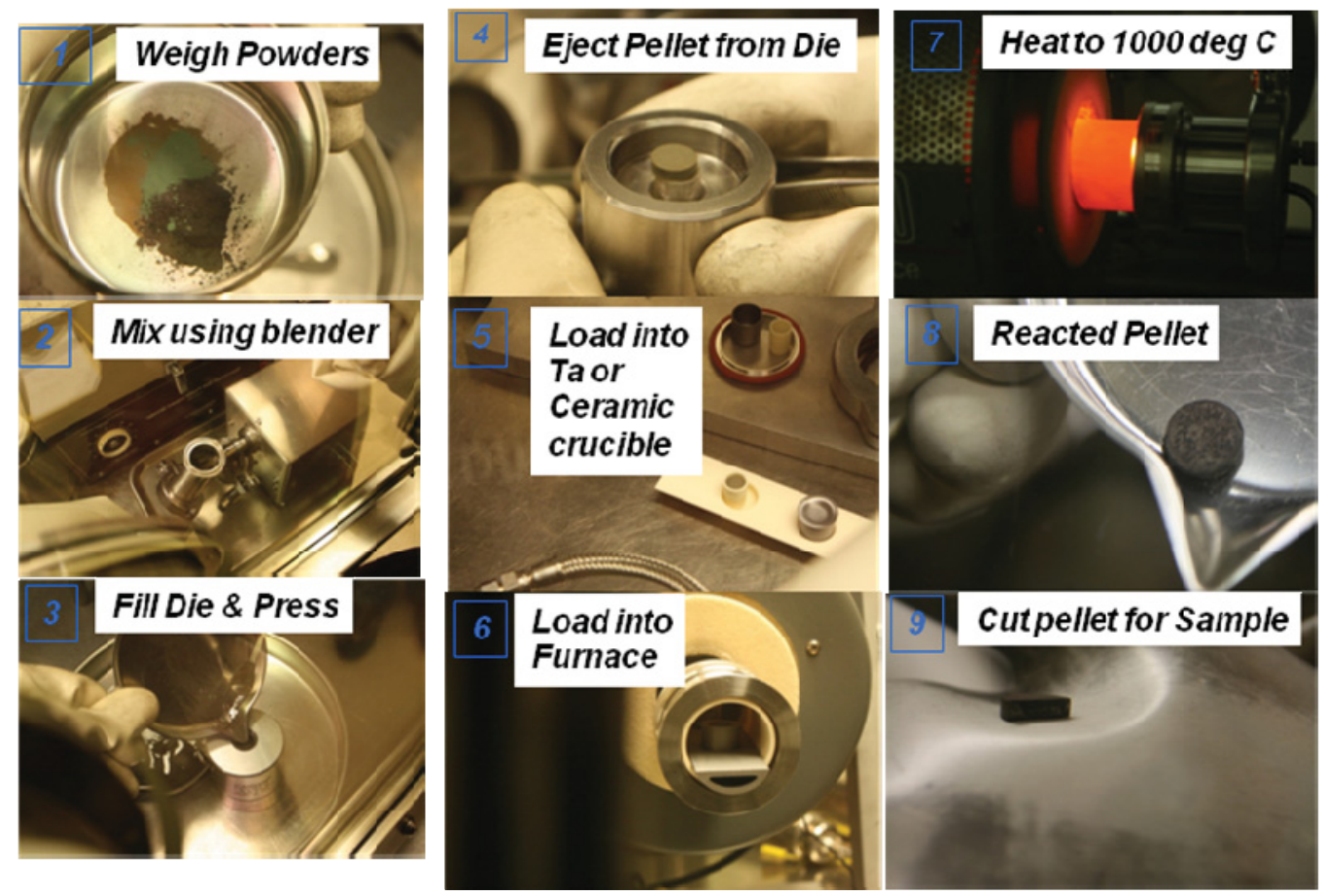

Figure 1. Experimental sequence to reduce small amounts of PuO2 and AmO2 using La metal.

Efforts continued in the development of a scaled apparatus to produce quantities of Am from $\mathrm{Am}-\mathrm{Pu}$ mixtures. Three-dimensional, color assembly drawings were used to create a series of engineering diagrams of a moderate-sized furnace that can be used to reduce by direct oxide reduction (DOR) and extract Am from small amounts of $10 \% \mathrm{AmO}_{2}-\mathrm{PuO}_{2}$. Example drawings are shown in Figure 2. This furnace apparatus is designed to produce approximately $20 \mathrm{~g}$ of Am per batch. 

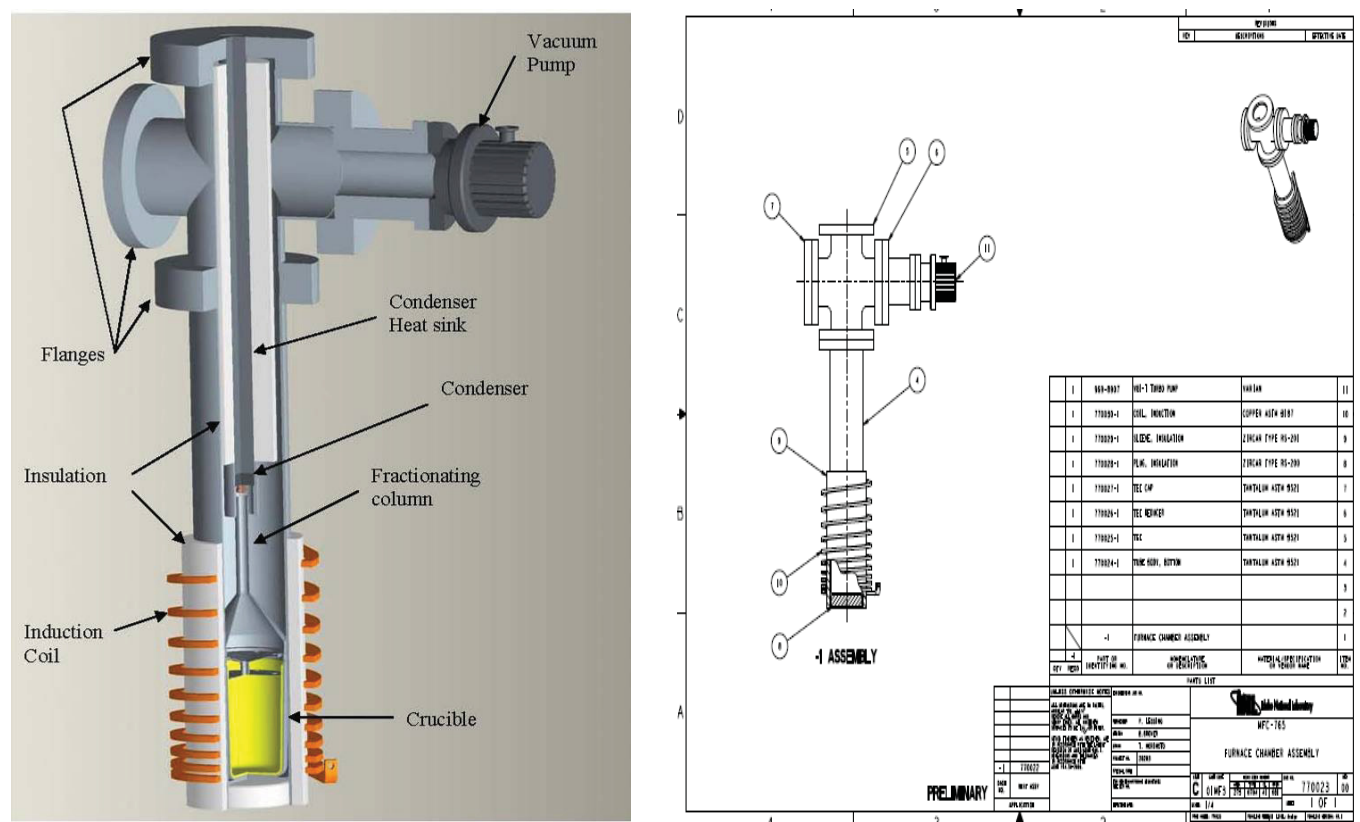

Figure 2. Color 3-D drawing (left) and engineering line drawing (right) of DOR furnace (for extraction of Am from AmO2-PuO2).

A small, high temperature distillation/condensation apparatus was successfully designed, fabricated, and tested (Figure 3, left). The primary purpose of this apparatus is to separate Am from feedstocks of available $20 \% \mathrm{Am}-\mathrm{Pu}$ alloy. The apparatus was successfully tested using manganese (Mn) as a surrogate metal (Figure 3, right).
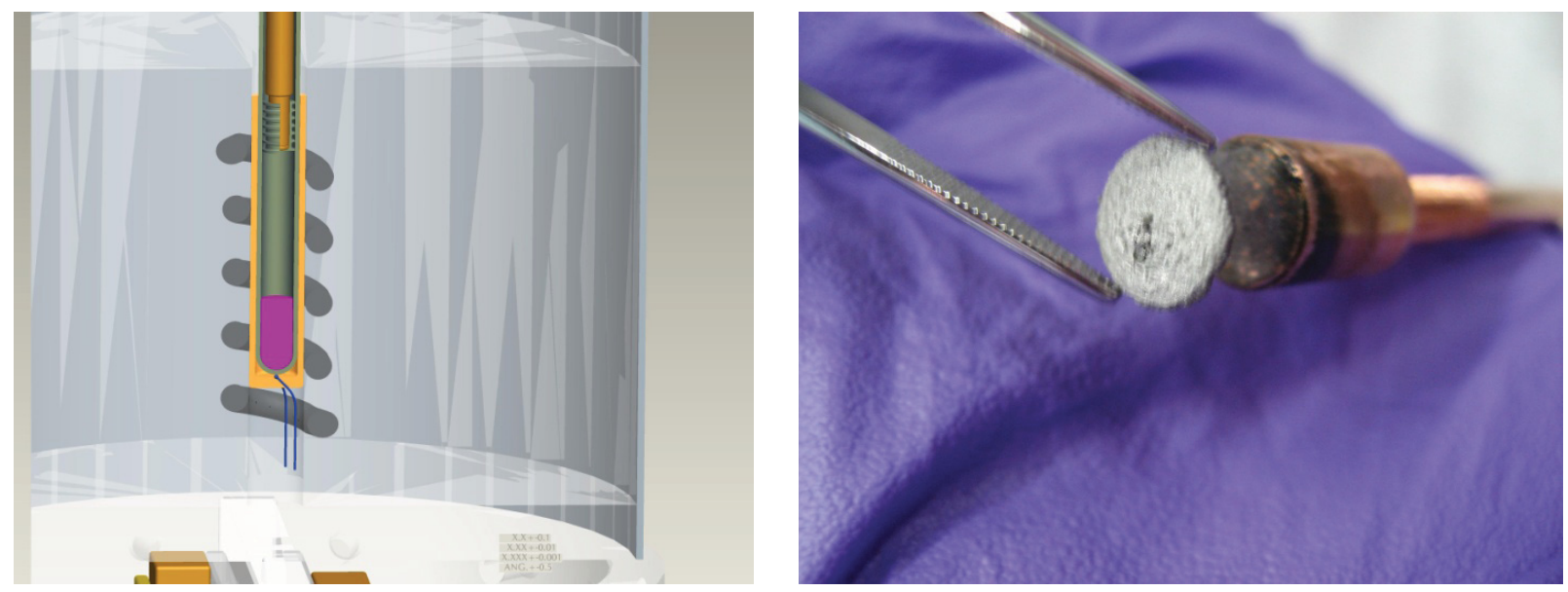

Figure 3. Left: View (3-D) of inside of small distillation furnace. Right: Design verified by evaporating and condensing Mn metal surrogate on Cu "cold finger".

Experimental procedures and conditions were developed that allowed the successful reduction (by DOR) of $\mathrm{NpO}_{2}$ to $\mathrm{Np}$ metal (Figure 4). This procedure utilized a molten salt medium to produce $\mathrm{Np}$ nuggets at approximately $97 \%$ purity. 


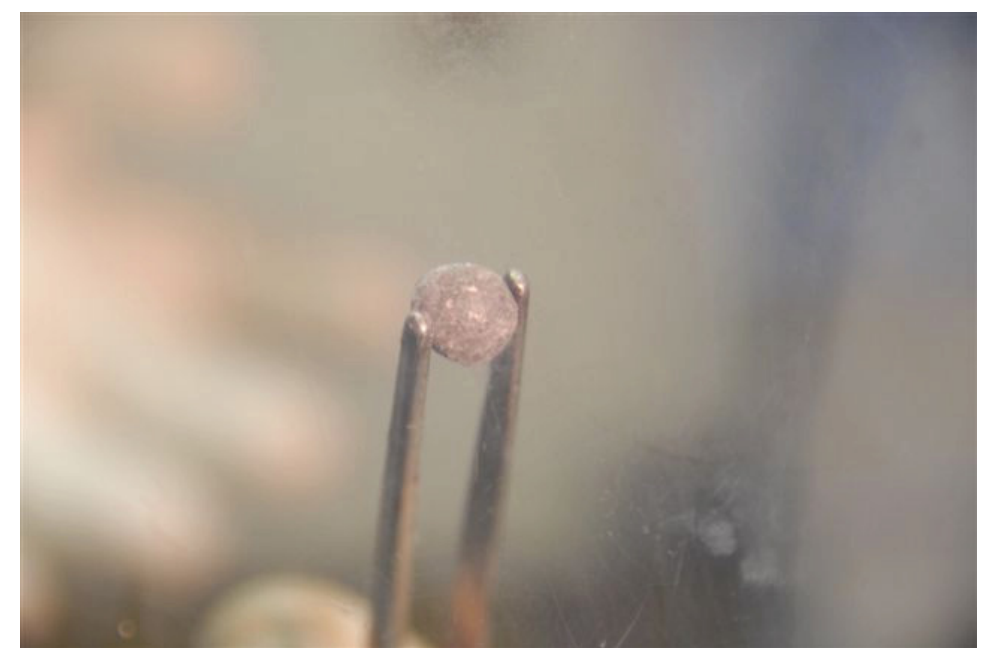

Figure 4. First Np "nugget" formed by direct oxide reduction (DOR) of NpO2 in stirred molten salt bath.

\subsection{Fuel Fabrication and Casting Process Development}

T. Hyde, timothy.hyde@inl.gov, R. Fielding, INL

The Fuel Fabrication and Casting Process Development work area has two objectives: (1) fabricate all required materials and samples to support the studies conducted within the metal fuels development technical area (including irradiation tests) and (2) develop a casting process that can eventually be operated under remote handling conditions (i.e., hot cell) for fabrication of reprocessed transmutation fuels.

Metal and metal alloy fabrication was performed in several facilities according to composition and need (13 castings in the Fuel Manufacturing Facility [FMF], 8 castings in the INL Analytical Laboratory [AL], and 5 non-actinide castings in the INL Research Center [IRC]). Primary support for these castings was for fuel characterization and FCCI studies. A major upgrade to the equipment gas control system of the AFCI glove-box in the FMF continued.

Exploratory studies for casting process development were completed wherein the feasibility of continuous and microwave casting was examined and a summary report issued. The exploratory work concluded that it is likely feasible to cast small diameter fuel slugs, on the order of $4.2 \mathrm{~mm}$, using continuous casting technology. A conceptual lab scale design was developed (Figure 5). Microwave casting showed less promise with little improvement over currently employed induction casting. A novel coating method was developed while working on the microwave casting, which may be beneficial in the development of reusable crucible and mold technologies. 


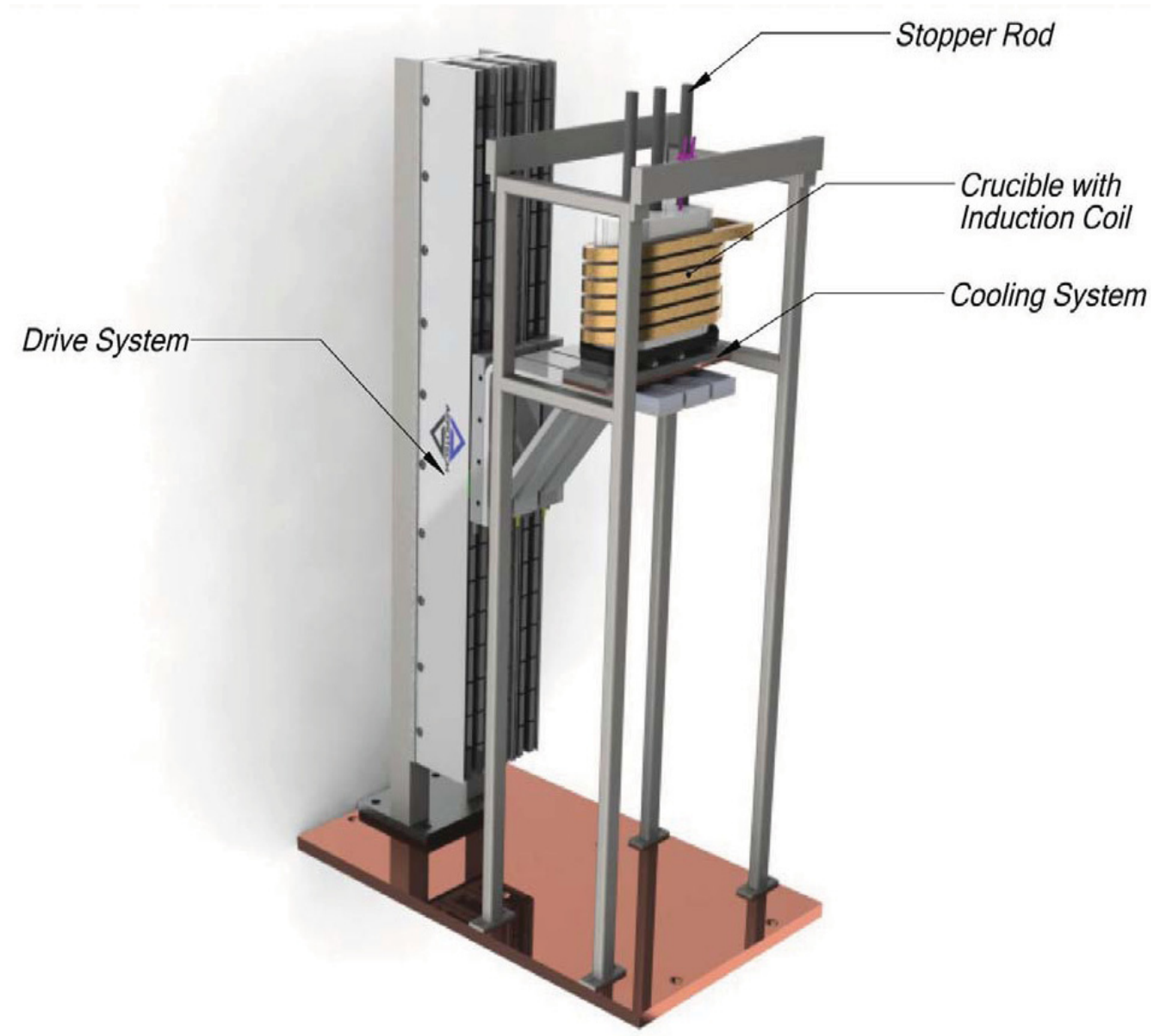

Figure 5. Lab scale continuous casting apparatus designed by Wagstaff Applied Technologies.

A draft implementation plan was developed to meet the grand challenge of $<0.1 \%$ fuel losses during metallic fuel fabrication process. As part of the draft implementation plan development, several experiments were conducted to show volatile species retention during prototypic casting activities. The experiments utilized both $\mathrm{Mn}$ and samarium $(\mathrm{Sm})$ as vapor pressure property surrogates for americium. Both species could be retained by using a modest positive overpressure during casting. Figure 6 shows a graph summarizing the Mn data as a plot of the ratio of initial input / final output of Mn against applied overpressure. If no Mn was lost during the experiment, the ratio would be 1. The Sm data was similar; however, because $\mathrm{Sm}$ was immiscible in the melt and appeared to react with the crucible, the data was somewhat more scattered and not as representative. 


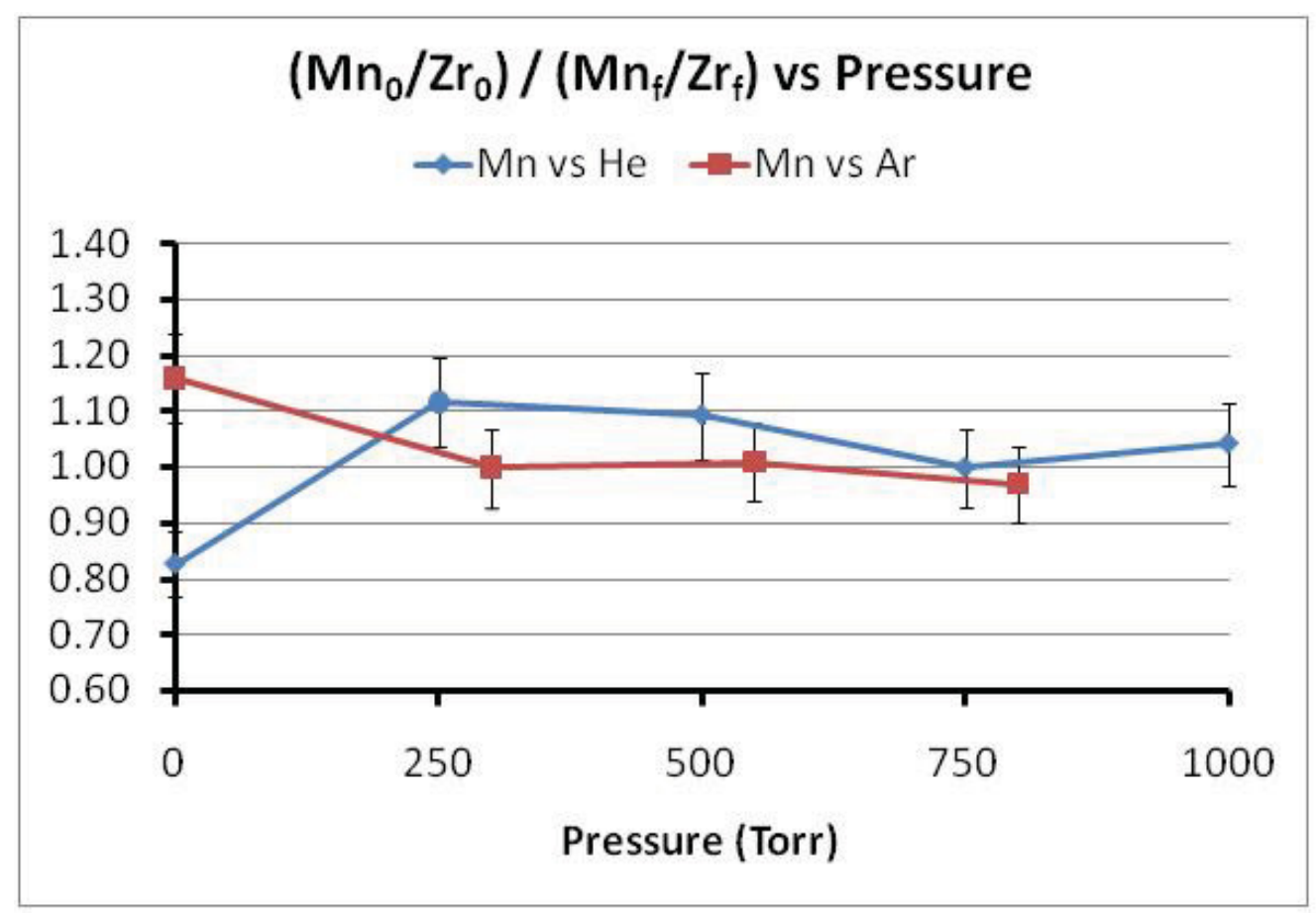

Figure 6. Mn retention versus overpressure results.

\subsection{Metal Fuel Casting Simulation}

D. Korzekwa,dak@lanl.gov, LANL

Further multi-physics simulations of the INL bench scale metal fuel casting furnace have been developed using the Truchas code at the Los Alamos National Laboratory (LANL). Results include an improved baseline model for induction heating of the mold, a study of the uncertainties in the simulation results due to boundary condition and material property parameters and a filling simulation that includes the argon atmosphere in the mold cavity. The induction heating simulations (see Figure 7) show the effects of the separate coils for the crucible and mold on the whole mold assembly. The crucible coils provide substantial heating of the top of the mold. The uncertainty study shows that the mold temperatures are relatively insensitive to boundary condition values, probably because the induction heating power is fairly high for all of the mold components. The largest sensitivities are to the thermal properties of the graphite. The filling simulation (see Figure 8) provides a testable prediction of the rate of filling when the argon gas must escape by bubbling up through the crucible of molten metal. The filling simulation is also a good demonstration of a high resolution highly parallel flow simulation. 


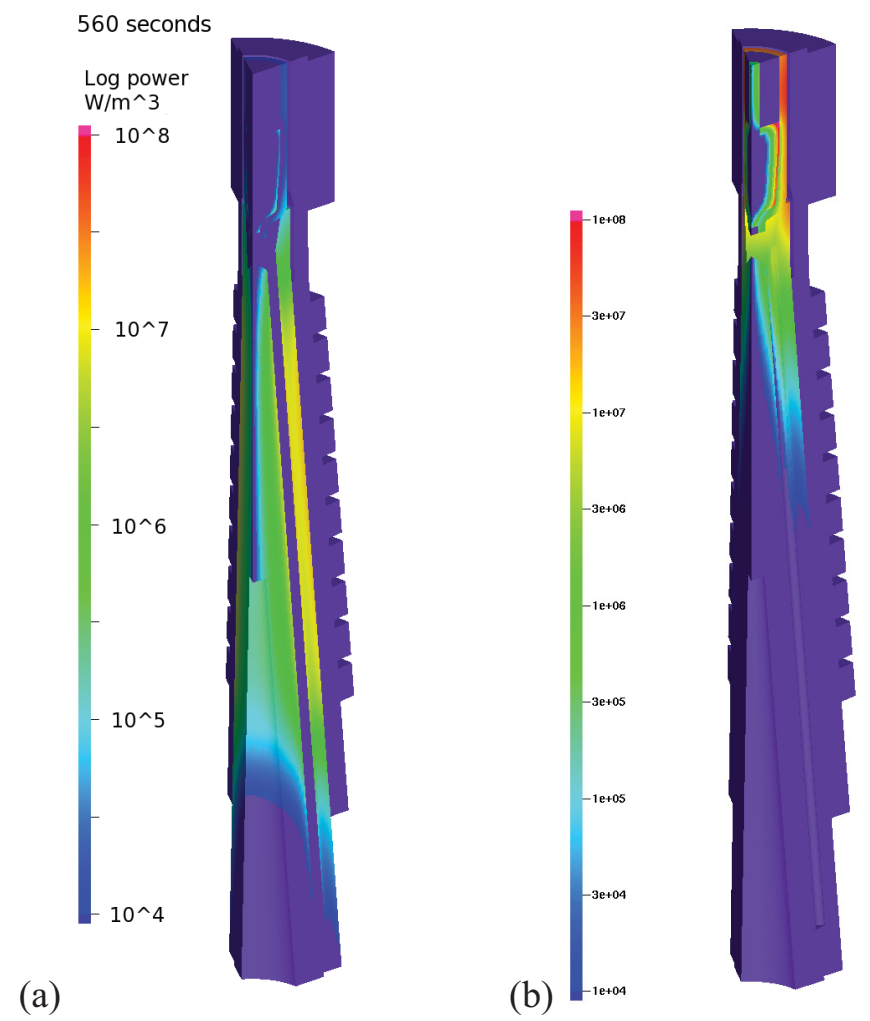

Figure 7. Induction heating power for (a) the mold coils and (b) the crucible coils
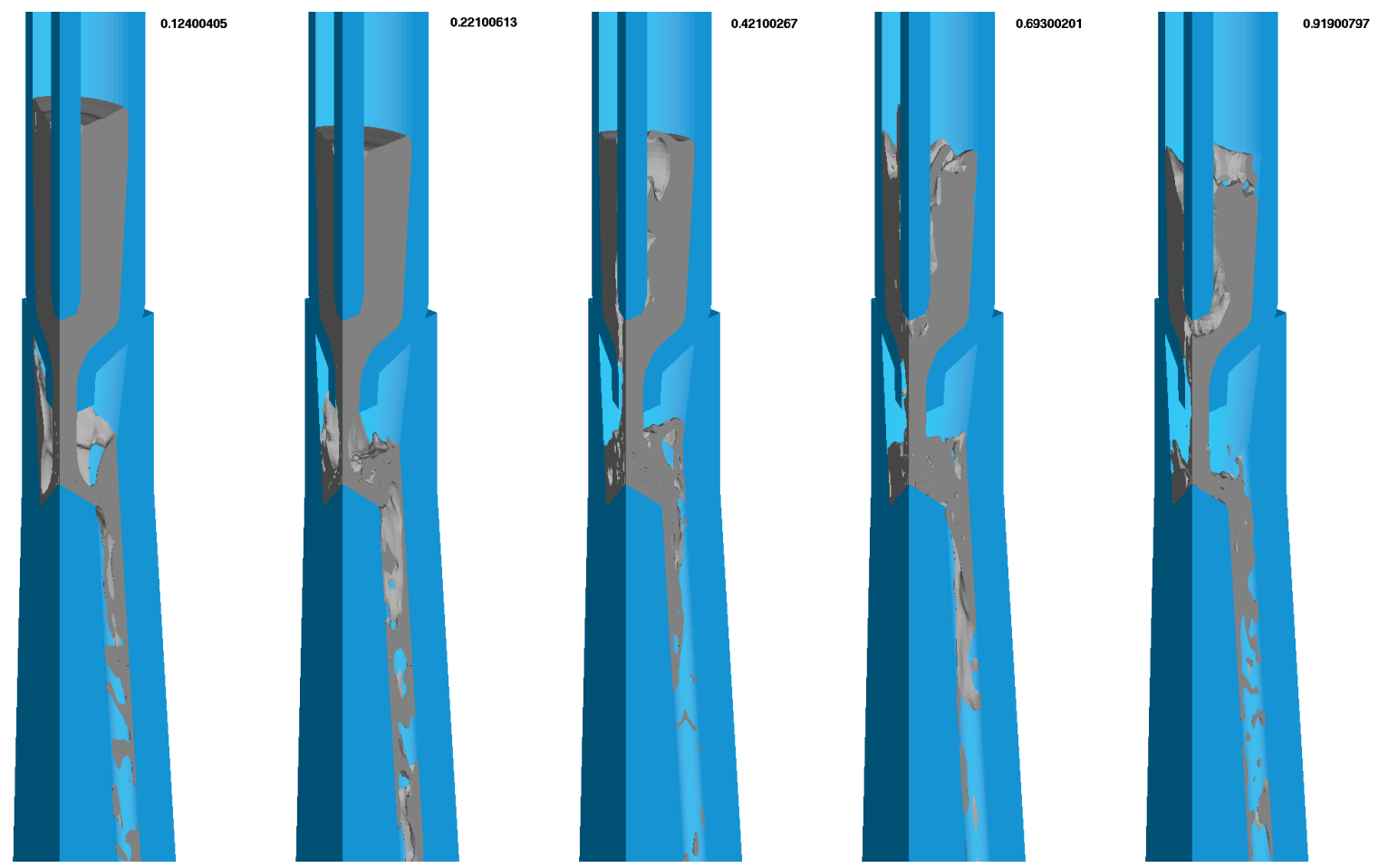

Figure 8. Snapshots of the filling simulation. 


\subsection{Characterization and Properties of Fuels}

T. O’Holleran, thomas.oholleran@inl.gov, R. Mariani, J. Cole, D. Janney, C. Papesch, L. Squires, INL

The Characterization and Properties of Fuels work area has two primary objectives: (1) to determine the phase, microstructure, and thermophysical properties of irradiation test fuels and related compositions and (2) determine the fuel cladding chemical interaction (FCCI) behavior of irradiation test fuels and related compositions with cladding material.

The general property characterization of eight alloys related to the AFC-2 irradiation test was performed and continues. These alloys are designated the B-alloys and their compositions are tabulated in Table 1. The compositions were chosen for a variety of reasons including the characterization of prospective low-fertile metallic fuels for a conversion ratio as low as 0.25 , higher TRU content alloys for conversion ratios close to unity, non-fertile fuel to accommodate actinide burning in either accelerators or reactors, and ternary fuel compositions that reflect reduced compositions of Am- and Np-bearing fuels (i.e., 5 element composition reduced to representation by a 3 element U-Pu-Zr composition) undergoing irradiation in the AFC-2A irradiation tests. Higher zirconium contents were of interest for possible fuel performance improvements.

Table 1. Cast AFC-2B Alloys. (Compositions are listed in weight percent. Ln designates the lanthanide composition $53 \mathrm{Nd}-25 \mathrm{Ce}-16 \mathrm{Pr}-6 \mathrm{La}$, which approximates fission product ratios.)

\begin{tabular}{|c|c|c|c|c|c|c|c|c|}
\hline Alloy & B1 & B2 & B3 & B4 & B5 & B6 & B7 & B8 \\
\hline $\mathrm{U}$ & 50 & 25 & 35 & 63.5 & - & - & 61 & 43.5 \\
\hline $\mathrm{Pu}$ & 30 & 55 & 20 & 20 & 90 & 70 & 24 & 36.5 \\
\hline $\mathrm{Zr}$ & 20 & 20 & 45 & 15 & 10 & 30 & 15 & 20 \\
\hline $\mathrm{Ln}$ & - & - & - & 1.5 & - & - & - & - \\
\hline
\end{tabular}

Approximately eighty percent of the initial thermal and phase characterization work is complete, which includes differential scanning calorimetry (DSC), laser flash diffusivity (LFD), x-ray diffraction (XRD) of as-cast and annealed cross-sections, and scanning electron microscopy of as-cast cross-sections. Some notable achievements this year include (1) the first determination of the enthalpy for the $\gamma-\delta$ transition in ternary alloy fuels and (2) a more detailed study of $\alpha-\mathrm{Zr}$ stabilization whose presence is believed to help reduce FCCI in metal alloy fuels. Both of these results are important for predictive empirical and first-principles modeling of metallic nuclear fuels.

\section{Publications}

- Munir, Z. A., et al. (2010), "Densification of Nano-CeO $\mathrm{Ce}_{2}$ Ceramics as Nuclear Oxide Surrogates by Spark Plasma Sintering”, J. Nucl. Mat., 404, p. 210-216.

- Janney, D. E. and J. R. Kennedy, “As-cast Microstructures in U-Pu-Zr Alloy Fuel Pins with 5$8 \mathrm{wt} \%$ Minor Actinides and 0-1.5wt\% rare-Earth Elements", Materials Characterization, in press.

- Cole, J. I., T. P. O'Holleran, D. D. Keiser Jr., and J. R. Kennedy," Out-of-pile Effects of Lanthanides on Fuel-Cladding Compatibility," submitted to Journal of Nuclear Materials.

- Xing, C., C. Jensen, H. Ban, R. Mariani, and J. R. Kennedy, (2010) "An Electromotive Force Measurement System for Alloy Fuels," full paper submitted for Proceedings of International Mechanical Engineering Congress and Exposition, IMECE2010-39457, ASME, Vancouver, British Columbia, November. 


\section{Enthalpy of $\gamma-\delta$ Transition in U-PU-Zr Fuels.}

The differential scanning calorimetry results were evaluated using a curve-fitting routine (Figure 9) and the enthalpies of individual phase transitions were determined. Individual transitions were assigned with reference to the published ternary phase diagrams, ${ }^{1}$ and a compositional analysis of the partial transformations of each alloy allowed the first determination of the transition enthalpy for the ternary fuel alloys (Figure 10).

For example, Figure 9 shows a peak resolved into two separate peaks on cooling. For this particular alloy composition (B3 in Table 1), the equilibrium room temperature phase is $\delta-\mathrm{UZr}_{2}$, and the high temperature phase is $\gamma-\mathrm{U}$ (the body-centered cubic phase). The published ternary phase diagrams for this alloy at different temperatures show that the transition does not occur in one step, rather the $\gamma$-U above $600 \mathrm{C}$ first transitions to $\gamma+\delta$ on cooling, and then the $\gamma+\delta$ alloy transitions to $100 \% \delta-\mathrm{UZr}_{2}$. As a consequence, only a portion of the sample transitions from $\gamma-\mathrm{U}$ to $\delta-\mathrm{UZr}_{2}$ in the first step (approx. $583 \mathrm{C}$, Figure 7) on cooling, and the remainder transitions to $\delta-\mathrm{UZr}_{2}$ on further cooling (approx. $574 \mathrm{C}$ ).

Each of these two resolved peaks has an enthalpy associated with it (area under the curve), corresponding to the two steps of the transition. The total peak (experimental curve) also has an enthalpy associated with it, corresponding to the $100 \%$ complete transition from $\gamma$ to $\delta$ over the entire temperature range $(590$ to $560 \mathrm{C}$ ). Since enthalpies are additive, and the ternary phase diagrams can be used to assess the mole percentages involved for the step-wise transitions, this single cooling curve provides three enthalpy values for the transition to $\delta-\mathrm{UZr}_{2}$, which are three of the points included in Figure 8. Note in Figure 8 that the data fit in red forces the line to go through zero (if no $\delta$ is formed, the enthalpy is identically zero). On the other hand, the black line is not forced through zero, which allows the measurement precision and error to be estimated. Also note fair agreement between the two lines is observed.

These results agree with prior reports for binary U-Zr alloys that found the enthalpy to be approximately $5 \mathrm{~kJ}$ per mole, ${ }^{2}$ but varying with the exact composition of the broad $\delta-\mathrm{UZr}_{2}$ phase range. The comparable results suggest that the heat of solution for the zirconium in the ternary $\gamma$-phase is similar to that for zirconium in the binary $\gamma$-phase, which might be expected; however it is possible that the activities of $\mathrm{Pu}$ and $\mathrm{Zr}$ in the $\gamma$ phase may be self-compensating. 


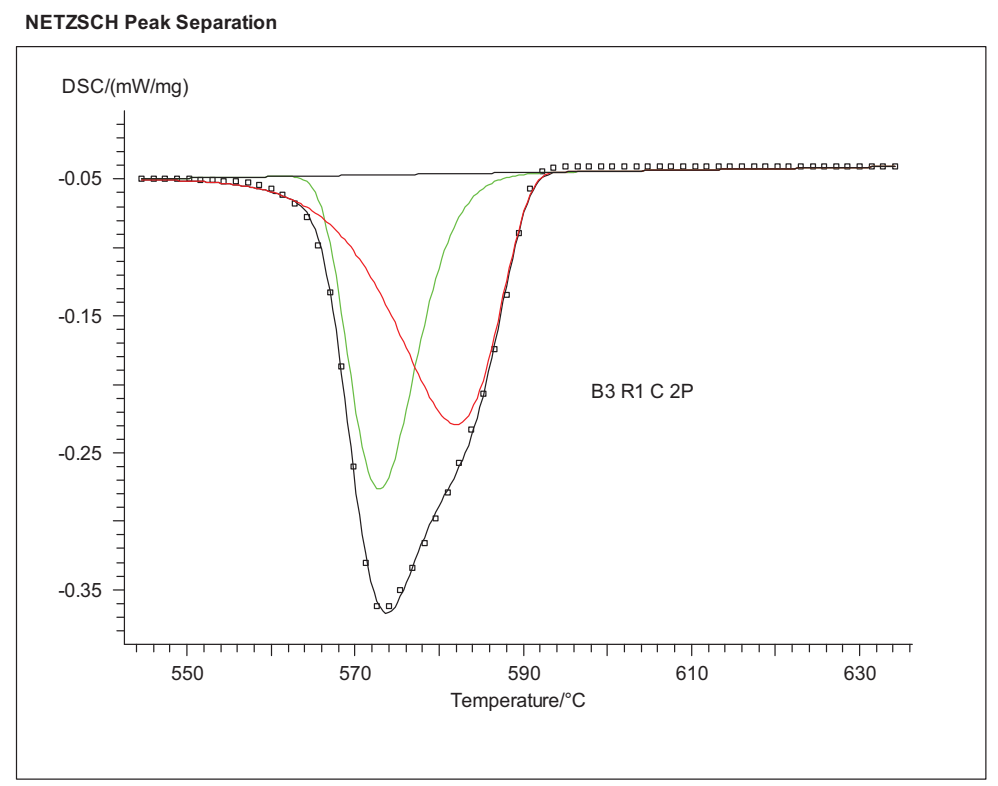

Figure 9. Deconvoluted DSC cooling curve for the B3 alloy (35U-20Pu-45Zr).

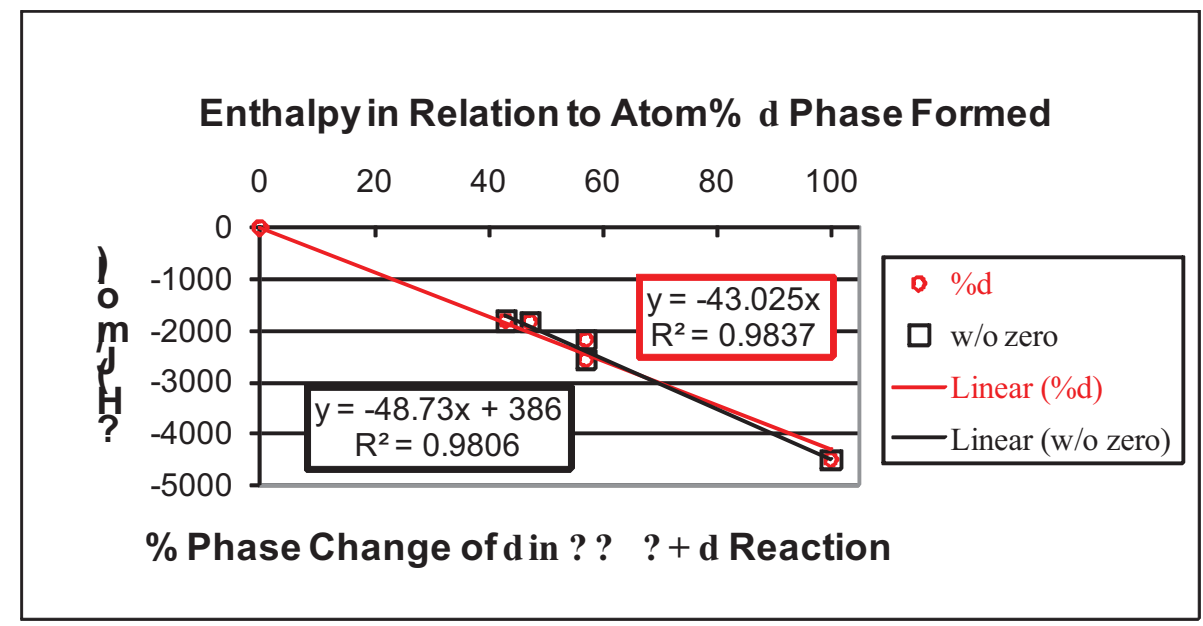

Figure 10. Partial and full transition enthalpies for some B alloys.

\section{a-Zirconium Stabilization in Metallic Fuel Alloys.}

Recent experimental results have provided insight into the interaction between the zirconium in U-Pu$\mathrm{Zr}$ alloys and dissolved oxygen. Other researchers have noted that $\alpha$-zirconium is stabilized by the presence of dissolved oxygen and its presence is believed to help reduce FCCI. ${ }^{1,3}$ It now appears that $\alpha$ zirconium can be stabilized on the fuel surface by simple vacuum-annealing of the ternary alloys with an ordinary passivation layer of oxygen on the alloy surface. While $\mathrm{x}$-ray diffraction patterns for as-cast alloys do not show the presence of $\alpha-Z r$, vacuum-annealed samples do exhibit significant levels of $\alpha-Z r$, even though the equilibrium phase diagram does not predict it for the composition ranges studied.

Additional samples were annealed by a different method that excluded a passivation layer of oxygen and these showed the absence of $\alpha-\mathrm{Zr}$. The results are particularly important for transmutation fuels that may be produced in an argon-filled, shielded hot-cell where ordinary passivation layers of oxide would not be expected to form on the alloy fuel. 
Out-of-pile FCCI studies are being used to investigate interaction phase development and bound temperatures at which fuel melting may be an issue due to eutectic phase formations. Diffusion couple studies between the ferritic-martensic alloy HT-9 and a matrix of minor actinide bearing U-Pu-Zr fuels containing fission product representative lanthanide or rare earth (RE) additions based on the AFC-2A irradiation test compositions were completed. The studies, conducted on two base fuel compositions, three different RE additive concentrations and at four different annealing temperatures revealed highly complex layered interaction phase development and the potential for formation of low melting point eutectic phase formations at temperatures as low as $650^{\circ} \mathrm{C}$.

In addition, six ternary alloys of $\mathrm{U}-20 \mathrm{Pu}$ - with 10,20 , or 30 at $\%$ zirconium or molybdenum were cast and diffusion couples with pure $\mathrm{Fe}$ or $\mathrm{Fe}-12 \mathrm{Cr}$ were constructed to isolate the effect of the major cladding alloy constituents on FCCI behavior and evaluate the use of Mo as a fuel alloying element, which may have certain advantages with respect to elemental redistribution. Initial results from diffusion couples annealed at $\sim 700^{\circ} \mathrm{C}$ for 25 hours reveal a profound difference in behavior between $\mathrm{Zr}$ and Mo containing fuels as indicated in Figure 11. The SEM images indicate that while the U-Pu-Zr fuel interaction into the cladding is on the order of a few hundred microns, the extent of U-Pu-Mo fuel interaction into the cladding is over $1 \mathrm{~mm}$.

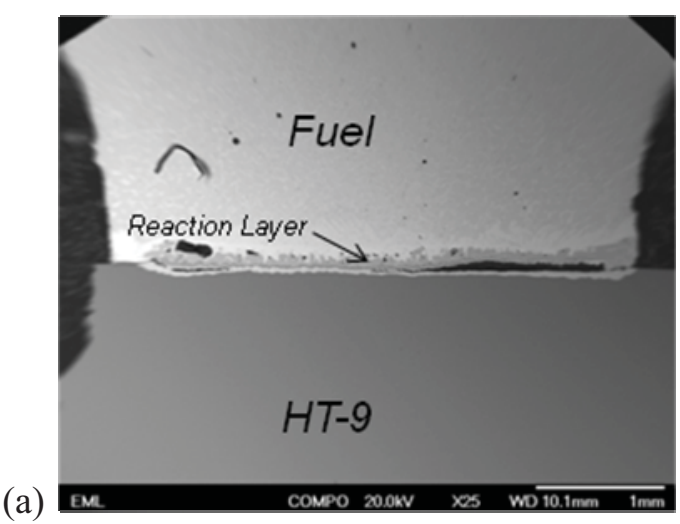

(b)

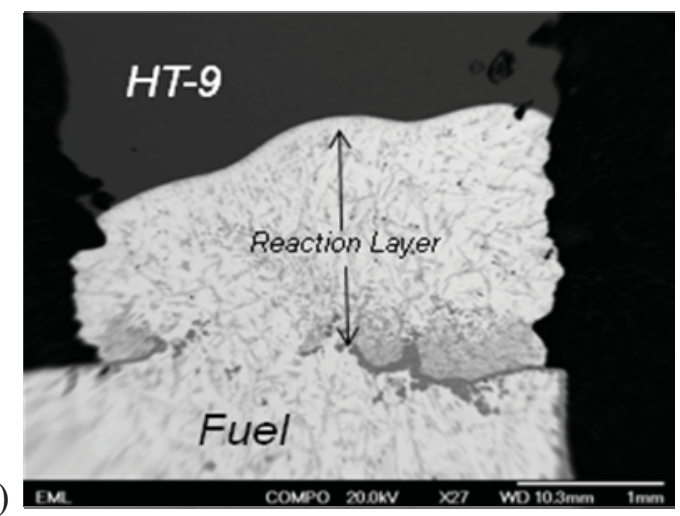

Figure 11. SEM images of fuel-clad interface reactions in (a) U-20Pu-30Zr at.\% and (b) U-20Pu-30Mo at. $\%$

\section{Publications}

- Mariani, R., (2010), "Nuclear Fuel Bodies Having Shell And Core Regions, Nuclear Reactors Including Such Nuclear Fuel Bodies, And Related Methods," U.S. Patent Filing 12/893,503, September 29, 2010.

\section{References}

1. O'Boyle, D. R., and A. E. Dwight (1970), "The Uranium-Plutonium-Zirconium Ternary Alloy System," Proc. 4th Int'l. Conf. on Plutonium and Other Actinides, ed. W.N. Miner, Nucl. Met. 1L, Part II, 720-733.

2. Akabori, M., T. Ogawa, A. Itoh, and Y. Morii (1995), "The Lattice Stability and Structure of $\delta$ $\mathrm{UZr}_{2}$ at Elevated Temperatures," J. Physics, Condens. Matter, 7 8249-8257.

3. Zegler, S. T., and C. M. Walter (October 1967), "Compatibility between Metallic U-Pu-Base Fuel and Potential Cladding Materials," AIME Nuclear Metallurgy Symposium on Plutonium Fuels Technology, AIME 13, 335-344. 


\subsection{Characterization Technique Development}

D. Hurley, david.hurley@inl.gov, S. Reese, R. Schley, J. Smith, M. Khafizov, INL

The Characterization Technique Development work area has the objective to develop laser-based techniques for the determination of mechanical and thermal properties of nuclear fuel. A key accomplishment in this work area was the preliminary design of a laser ultrasound instrument capable of measuring mechanical properties of radiological samples. The laser ultrasound instrument was designed around the Bossa Nova Tempo commercial interferometer. The design takes into account the eventual operation under remote operating conditions and consists of a frame that supports three removable modules. Module one is the Tempo interferometer, module two is the detection beam scanning module, and module three is the generation beam and imagining module. The conceptual design is shown in the right side of Figure 12.

(a)

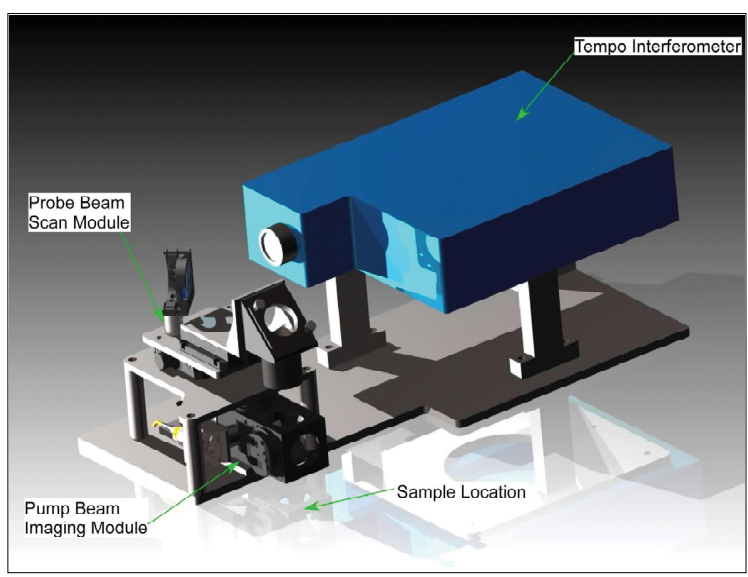

(b)

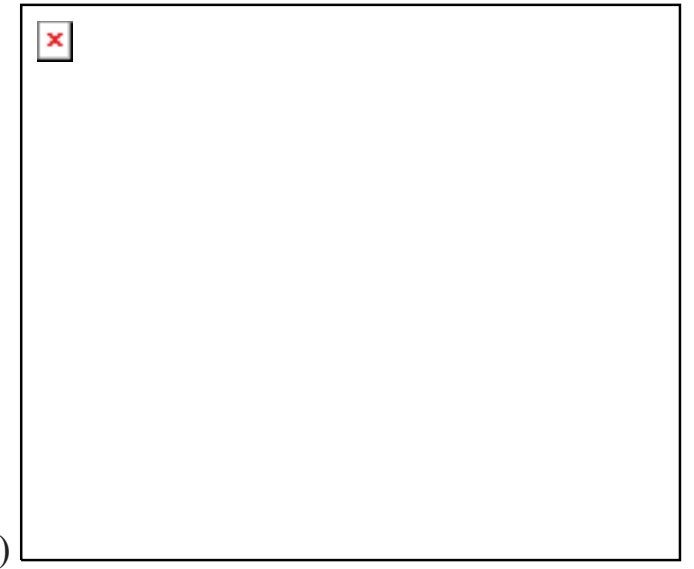

Figure 12. (a) Conceptual design of a laser ultrasound instrument for measuring mechanical properties of radiological samples. (b) Schematic showing the optical beam paths through the imaging module.

The framework, which aligns the modules, is mounted above the sample manipulation/heating stage (not shown in Figure 12). The scanning module accepts the detection beam from the interferometer and translates the beam in the $\mathrm{x}-\mathrm{y}$ plane via two motorized stages and reflects the beam down through a focusing lens onto the sample. The imaging module is located below the scanning module. The detection beam delivered from the scanning module enters the imaging module through an access port in the top of the module. Both the generation and detection beams exit through an access port in the bottom of the imaging module. The optical beam paths through the imaging module are shown in the left side of Figure 12.The generation laser pulse is delivered to the module via an optical fiber. A portion of the reflected generation beam is imaged by the lens onto a charge-coupled device (CCD) camera. This image is used to position the generation beam on the sample surface. This design, which uses a common framework for alignment of the modules, allows for replacement of modules using manipulators.

\section{Publications}

- Seung-Kyu Park, Sung-Hoon Baik, Hyung-Ki Cha, S. J. Reese, and D. H. Hurley (2010), "Characteristics of a Laser Resonant Ultrasonic Spectroscopy System for Measuring the Elastic Constants of Materials", Journal of the Korean Physical Society, 57, p. 375.

- Hurley, D. H., S. J. Reese, S. Park, Z. Utegulov, J. R. Kennedy, and K. Telschow (2010), “In situ laser-based resonant ultrasound measurements of microstructure mediated mechanical property evolution”, Journal of Applied Physics, 107, p. 063510. 


\subsection{Advanced Properties Technique Development}

M. Fig, matthew.fig@inl.gov, R. Kirchhofer, J. Cole, D. Janney, B. Sencer, INL

The Advanced Properties Technique Development work area has four objectives:

1. Support the development and adaptation of the FIB instrument for use with radioactive and highly radioactive materials

2. Support the development and adaptation of the $\mu$-XRD instrument for use with radioactive and highly radioactive materials

3. Support the initial implementation of the STDM for investigation on fresh and irradiated fuels

4. Initiate development of methods for the separate effects study of diffusion processes related to FCCI using ion beam techniques.

As part of development of the FIB/SEM towards use with irradiated fuels and materials, measures of success (MOS) were defined that relate to radiological challenges associated with samples of interest to the campaign. In defining the MOS for using a FIB/SEM to characterize irradiated nuclear fuels and materials as part of a post-irradiation examination (PIE) it must be recognized that little or no experience exists either nationally or internationally for using a FIB for irradiated fuels. Accordingly, a progression of more challenging samples is being introduced into the instrument and careful observation of radiological conditions and associated instrument performance are being made. To this end, a series of irradiated materials as well as surrogate and fresh fuels have been examined in the system. The activated materials examined include ceramic inert fuel matrix and structural metal samples that were irradiated in the Advanced Test Reactor (ATR). Fresh fuel samples included a depleted U-Mo fuel and a low-enriched uranium (LEU) TRISO particle fuel. An image of thinned lamellae taken from the interface between the $\mathrm{SiC}$ and the pyrolytic carbon layers of a surrogate TRISO particle along with an associated transmission electron microscope (TEM) image is shown in Figure 13.

(a)

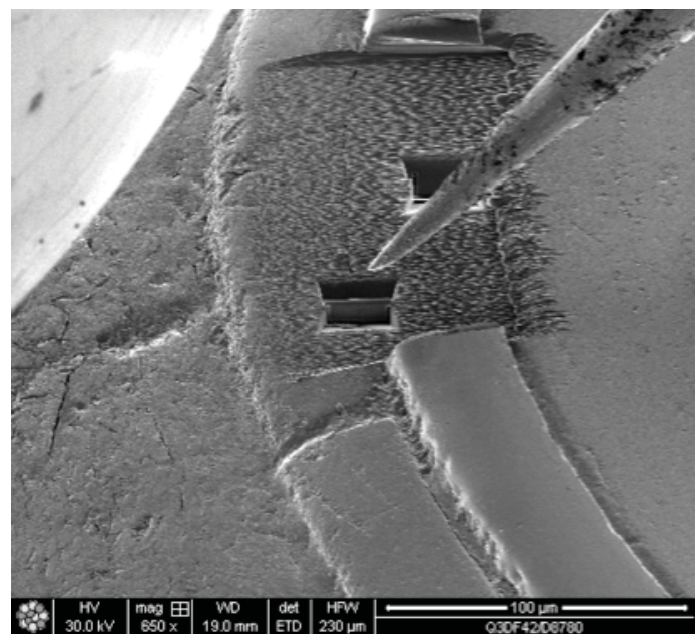

(b)

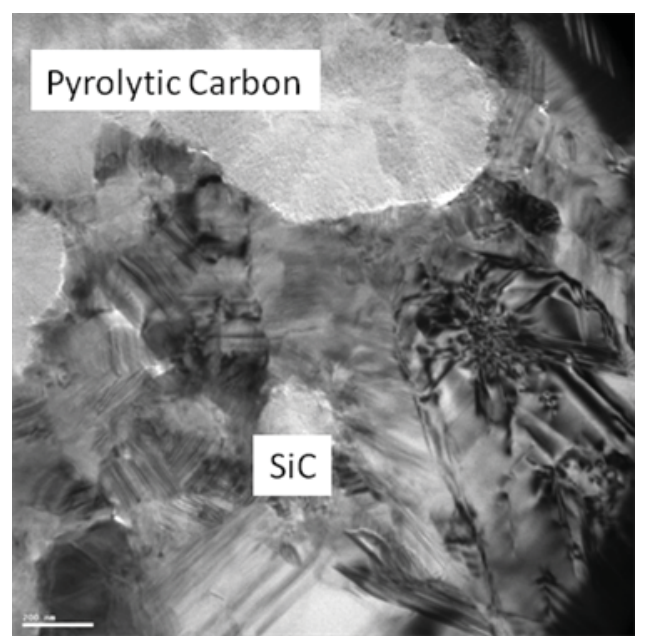

Figure 13. Images of (a) TEM lamellae extraction and (b) the TEM interface structure between layers in a surrogate TRISO fuel particle.

There is little national and international experience in the application of $\mu$-XRD techniques to the study off radioactive and highly radioactive materials. Accordingly, a progression of more challenging samples is being introduced into the instrument and careful observation of radiological conditions and 
associated instrument performance are being made. Initial examination of a series of closely spaced parallel scans stepping across layers in a non-radioactive sample to look for structural differences between the layers was performed to develop and test micro-diffraction techniques. Following this, first data from a sample of low count irradiated material was collected followed by collection of first data from a nonirradiated actinide-bearing sample (a diffusion couple with DU-10Zr against Fe).

In addition to the functional aspects of the instrument, the equally important aspects of the associated development of sample handling methods and sample holder designs were addressed. The design, fabrication, and testing of a two-part sample holder that can be used for metal foils (e.g., slices of fuel pins) and other non-powdered solid samples were completed. These holders consist of two nested dishes, each covered by a layer of Mylar, held in place by an O-ring (Figure 14). The inner dish can be loaded in a glovebox and then removed to a hood for decontamination. The inner dish can then be placed in an outer dish and covered by the second layer of Mylar. The outer dish, which is the same height as a standard met-mount, can be attached to an SEM stub and mounted in the diffractometer using an existing sample stage attachment. The dishes were tested by using them to contain any possible contamination while measuring radioactive samples.

Because handling Mylar and small objects in a glovebox can be difficult, a tool for putting the Mylar cover and O-ring on the inner dish was developed (Figure 15). The tool has three parts: (1) a bottom, which has a deep depression with a smaller recessed area inside to hold the dish, (2) a piston whose outer diameter is the same as that of the dish, and (3) a sleeve to guide the piston, and push the O-ring from the piston to the dish.

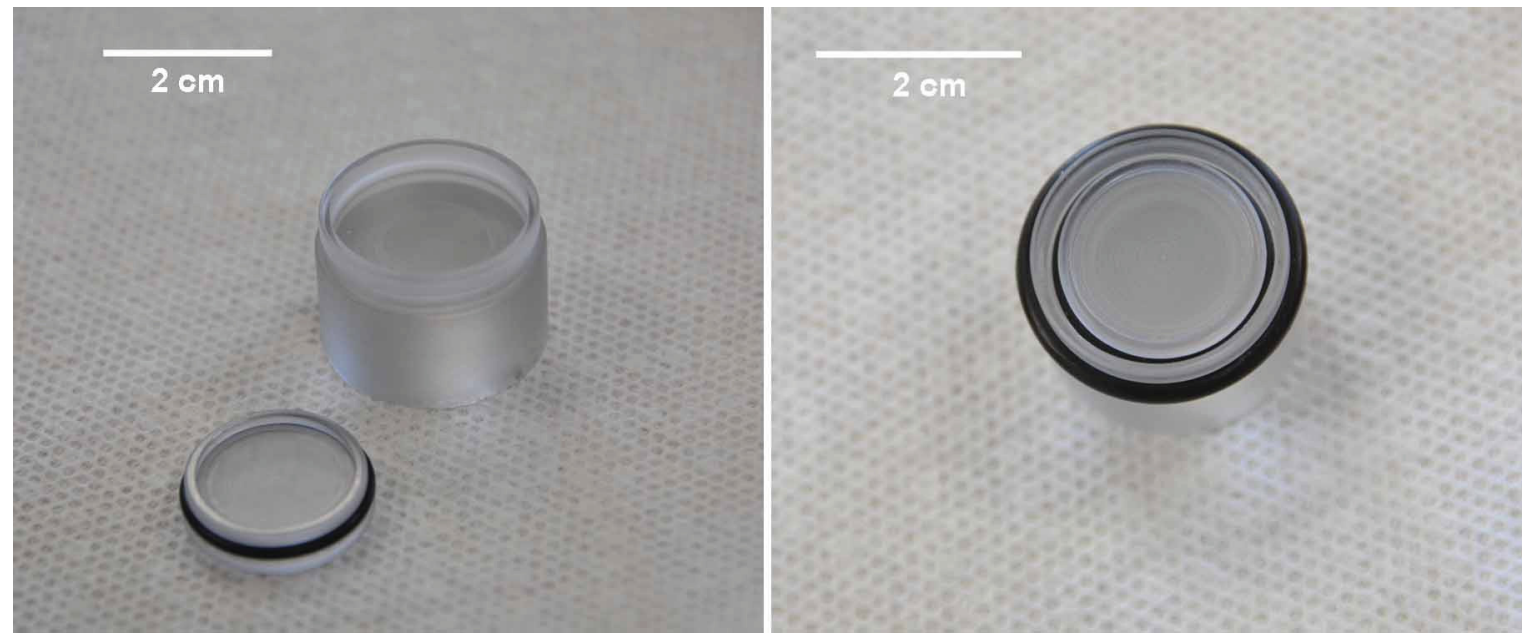

Figure 14. Sample holders. Left: inner dish with O-ring in front of outer dish. Right: inner dish and its Oring inside outer dish and its O-ring. 


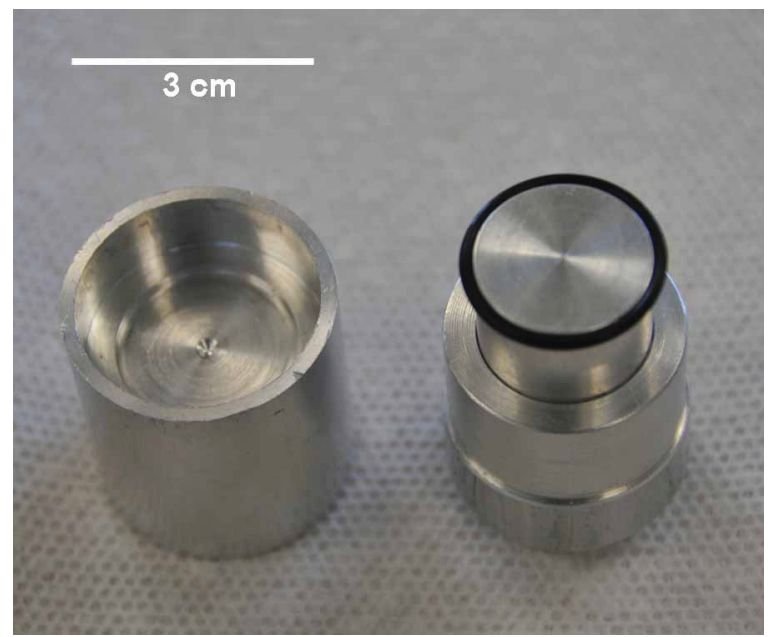

Figure 15. Tool for positioning O-ring on inner dish. Bottom part is on left; piston with O-ring is on right; sleeve is around piston.

The scanning thermal diffusivity microscope has allowed the first in world determination of thermal diffusivity values on irradiated metallic nuclear fuels at 50 micron spatial resolution. Implementation of this instrument will afford the highest spatial resolution in establishing the radial profile in the nuclear fuel of the highly important property of thermal diffusivity. Following the successful development and installation of the instrument in a hot cell, the thermal diffusivity profiling of both an unirradiated and an irradiated fuel sample were completed. Results taken from this profiling are shown in Figure 16. These initial results show a decrease in the thermal diffusivity resulting from the microstructural changes in the metallic fuel produced during reactor irradiation but do not appear to be as great as observed in oxide fuels.

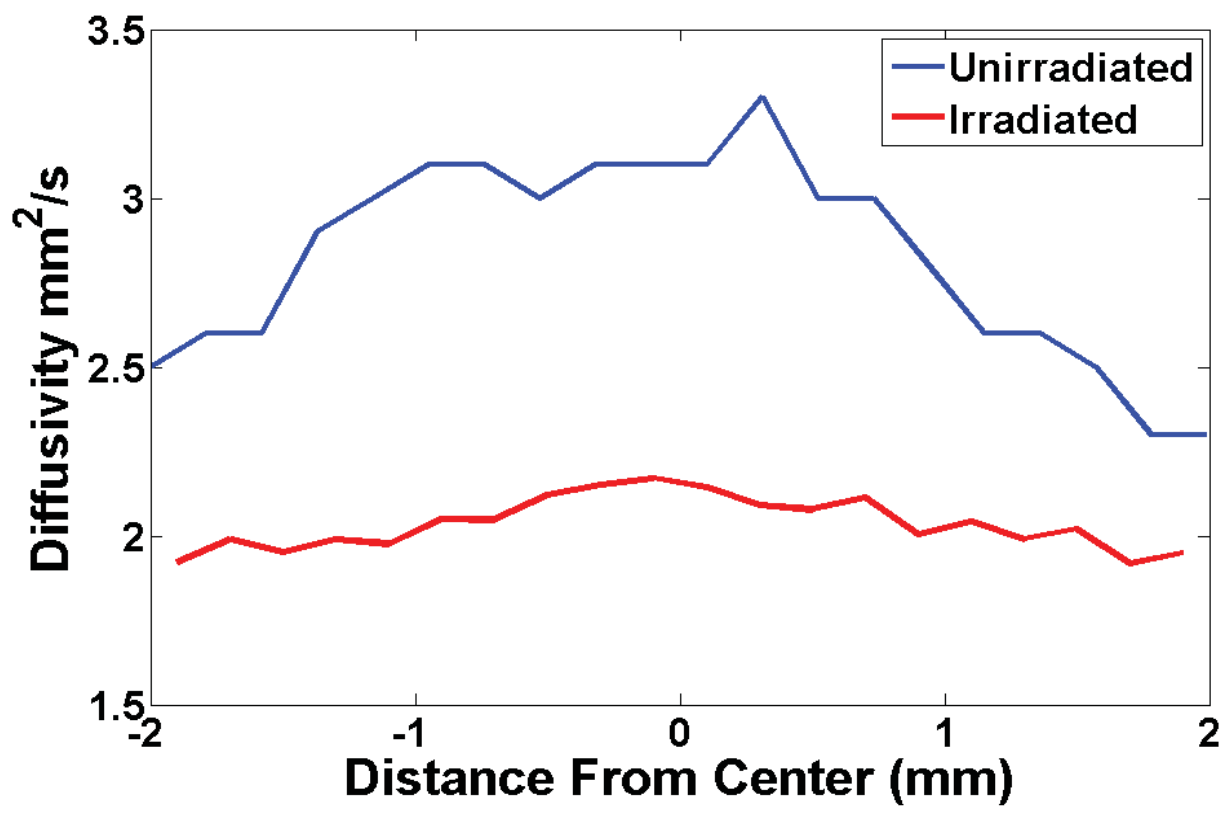

Figure 16. Radial profile of the thermal diffusivity of an unirradiated fresh fuel sample (blue-top) compared to the radial profile of a sample irradiated to about $6 \%$ burnup. Measurements were performed at room temperature. 
Further development efforts were directed towards methods for heating a sample during measurement. A fused glass heating capsule was designed and is currently under consideration and testing. Design work towards the use of fiber optics was performed. This could lead to a dramatic simplification of a future STDM and allow vital equipment to be placed outside of the hostile hot cell environment.

To the initiation of the development of methods for the separate effects study of diffusion processes related to FCCI using ion beam techniques, materials were cast or acquired including pure $\mathrm{Fe}, \mathrm{Mo}, \mathrm{Zr}, \mathrm{Ce}$, $\mathrm{Nd}$, alloys of Ce-50Nd, Fe-15Cr, and Fe-15Cr-15Ni. Diffusion couples (pre-bonded) of Fe versus $\mathrm{Zr}$ and Mo versus $\mathrm{Zr}$ were prepared and irradiated with protons to $5 \mathrm{dpa}$. PIE of the samples was initiated.

\section{Publications}

- Michael Myers, Bulent H. Sencer, Lin Shao, "A multi-scale model of localized heating caused by ion bombardment", Nuclear Instruments and Methods, in press.

\subsection{Modeling of Interdiffusion between U-based Fuels and Fe-based Claddings}

A. M. Yacout, yacout@anl.gov, A. E. Wright, ANL

An approach was developed that utilizes semi-empirical, molecular modeling to analyze interdiffusion effects at the interface between uranium-based fuels and Fe-based cladding materials under the high temperatures associated with reactor off-normal and accident conditions. The approach (the BFS Bozzolo, Ferrante, and Smith - method for alloys) can also take account of effects of lanthanide fission products, e.g., lanthanide transport to the fuel-cladding interface, in metallic fuel. Preliminary investigation of the approach started by looking at available information for the formation of lanthaniderich precipitates in $\mathrm{U}-\mathrm{Zr}$ fuel and the segregation patterns of all constituents to the surface. Parameters necessary for the calculations, such as estimates of surface energies for elements, were investigated. Advanced simulation of $(\gamma \mathrm{U}, ß \mathrm{Zr})$ solid solution behavior, including the behavior of the lattice parameter and coefficient of thermal expansion as a function of $\mathrm{Zr}$ concentration and temperature, has been performed. Output from these calculations is used to study the surface structure of $\mathrm{U}-\mathrm{Zr}$ for different crystallographic orientations, determining the respective concentration profiles, surface energy, and segregation behavior. The calculations are important for determining interaction behavior of this fuel type with cladding materials (e.g., $\mathrm{Fe}, \mathrm{Ni}$, and $\mathrm{Cr}$ ), especially at high temperatures. The analysis is completed with simulations of the deposition of $\mathrm{Fe}, \mathrm{Ni}$ and $\mathrm{Cr}$ on $\mathrm{U}-\mathrm{Zr}$ substrates with varying $\mathrm{Zr}$ concentration. The work is summarized in a paper titled "Atomistic Modeling of Fuel-Cladding Interaction," by G. Bozzolo, H. O. Mosca, A. M. Yacout, and G. L. Hofman, which was accepted for presentation to the Nuclear Materials 2010 meeting in Karlsruhe, Germany, October 2010. In the paper, all results are discussed and interpreted by means of the concepts of strain and chemical energy underlying the BFS method, thus obtaining a simple explanation for the observed $\mathrm{Zr}$ segregation and its influence in allowing for diffusion of cladding elements into the U-Zr fuel. In FY 2011, interactions involving lanthanide fission products will be assessed, and empirical information for validating the analysis from existing databases and/or potential future experiments will be considered. 


\title{
3.8 Innovative Fuel Concept: Advanced Metallic Fuel Concept for Reliable Performance to Ultra-high Burnup
}

\author{
A. E. Wright, aewright@anl.gov, ANL, S. L. Hayes, steven.hayes@inl.gov, INL
}

As an outcome of the AFC call for innovative fuels concepts, Argonne National Laboratory (ANL) and Idaho National Laboratory (INL) received funding to begin developing an innovative design concept for ultra-high burnup sodium-cooled fast-reactor metallic fuel.

The concept takes as its starting point the historic advantages inherent in metallic fuel used in a fast reactor but includes the following innovative features, which together have the potential to lead to a fuel design that could perform reliably to ultra-high burnup (nominally 40 at.-\%):

- Decreased fuel smeared density (perhaps in the form of annular fuel) to accommodate swelling

- Coating/liner on cladding inner surface to mitigate fuel-cladding chemical interaction

- Vented fuel pin design to reduce the stress on cladding at high burnup

- Mo-based fuel alloy to eliminate constituent redistribution

- Minor alloy additions to immobilize lanthanide fission products

- An advanced fabrication method to minimize waste generation in a remote, hot cell environment

An additional key feature of the concept is that it would retain compatibility with an electrochemical recycle scheme.

A status report and three-year plan for combined ANL/INL activities in developing the advanced, ultra-high burnup metallic fuel concept was jointly issued by the two laboratories. The report describes the concept; its technical basis; the general approach to the development of the concept; principal fuel design and fabrication issues; impacts on core neutronics and design; fuel irradiation performance areas needing investigation; safety considerations; and plans for issue resolution, including projected costs and schedule.

During FY 2010, ANL focused on addressing fuel burnup-limiting factors, the U-Mo fuel option, specific fuel additives to control lanthanide migration, core-design and neutronics effects with Mo-based fuels compared to Zr-based fuels, neutronics effects due to reduced fuel smeared density, effects of ultrahigh burnup on fuel operating temperature, power reactor operations and maintenance issues and safety implications associated with vented fuel pins, and experiments needed for issue resolution.

\subsubsection{General Limits on Achieving Ultra-high Burnup}

Y. S. Kim, yskim@anl.gov, G. L. Hofman, and A. M. Yacout, ANL

Preliminary estimates were made of burnup limits in metallic fuel due to solid fission-product buildup for different fuel smeared densities (SD) ranging between 50 and $75 \%$. Effects of the close-off of open porosity by the solid fission-product buildup, and subsequent increased fuel-cladding mechanical interaction (FCMI) due to fission-gas accumulation in closed-off porosity, were evaluated. As shown in Figure 17 , the initial estimates indicate that achieving burnups of $\sim 40 \%$ will require as-fabricated SDs of roughly $55 \%$. 


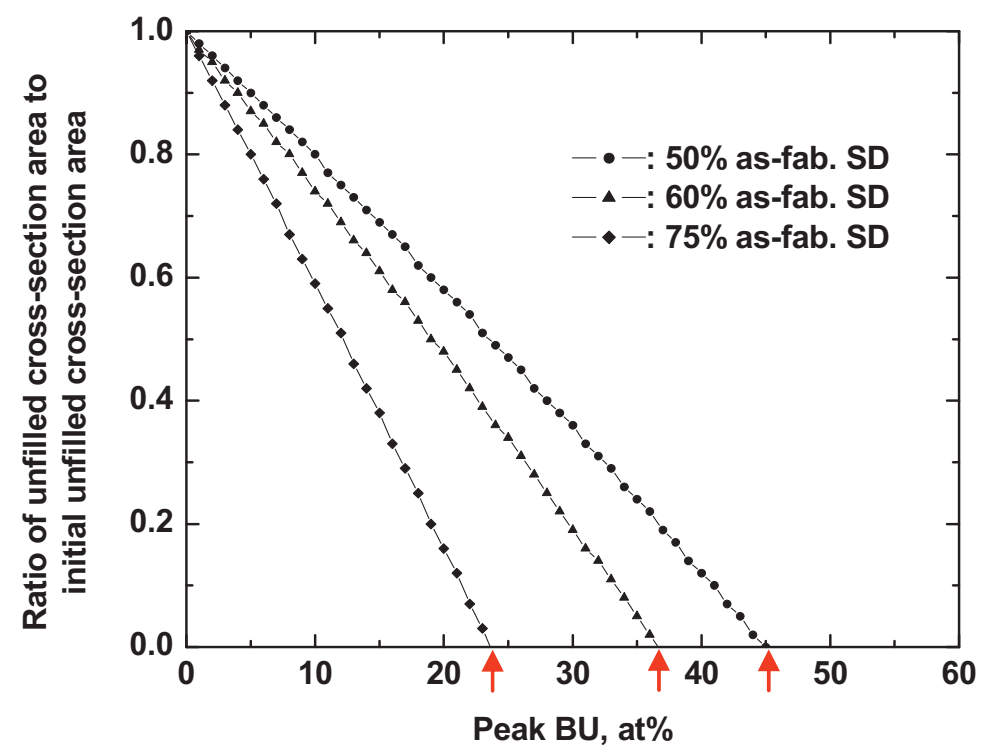

Figure 17. Estimated burnups (at arrows) for beginning of FCMI for three as-fabricated smeared densities.

Existing HT9 cladding creep correlations, which were developed for applications limited to less than five years of fuel in-reactor residence time, have been evaluated for their applicability to possible current goals of up to 20 years residence time for the ultra-high burnup fuels. Extrapolation of the correlations to such longer periods of time led to unrealistic cladding strain values. This confirmed the need to develop new creep correlations applicable to extended cladding exposure times. New correlations are currently under investigation, and the development of a generalized thermal creep correlation for HT-9 will be pursued in FY 2011.

\subsubsection{Core Neutronics and Design for Ultra-high Burnup Metal Fuels}

T. K. Kim, tkkim@anl.gov, ANL

The impact on core performance characteristics of replacing the reference U-TRU-Zr with U-TRUMo fuel was evaluated. The results show that, for the case of the reference ABR-1000 core concept ${ }^{1}$, the performance characteristics are comparable for the two fuels, except for minimal changes in TRU requirement and discharge burnup. The effect of smeared density (SD) change on core performance was assessed using a $3000 \mathrm{MWth}$ sodium-cooled fast reactor model with U-TRU-10Mo fuel. The fuel design parameters were chosen such that the fuel volume fraction became $38 \%$ with a SD of $75 \%$. Sensitivity calculations were performed by decreasing the SD to $60 \%$ and $50 \%$ without changing other design parameter values. The fuel volumes for SDs of $60 \%$ and $50 \%$ were found to decrease as much as the SD decreased. As a result, for the same ratio of TRU mass to heavy metal mass, the core multiplication factor decreases as the SD decreases. Thus, the low SD fuel needs more fissile material (i.e., TRU in this case) for maintaining criticality. During FY 2011, a reference ultra-high burnup core concept will be developed that utilizes the fuel pin design features of the innovative metallic fuel concept.

A multi-batch, high power density core concept was developed using U-TRU-Mo fuel with SD of $60 \%$. The core performance characteristics were evaluated using the REBUS-3 code. To increase the burnup of U-TRU-Mo fuel, a sensitivity study was performed, which showed that more than $40 \%$ burnup could be achieved by either increasing the number of batches or the cycle lengths and that a many-batch and short-cycle-length scheme is favorable to minimize excess reactivity and peak fast fluence compared to a small-batch and long-cycle-length scheme. 


\section{References}

1. T. K. Kim, et.al., "Core Design Studies for a 1000 MWth Advanced Burner Reactor," Annals of Nuclear Energy 36, (2009) 331-336

\subsubsection{Alloy Additions to Control Fuel Constituent Migration}

Y.S.Kim, yskim@anl.gov, G. L. Hofman, and A. M. Yacout, ANL

S. L. Hayes, steven.hayes@inl.gov, R. D. Mariani, E. L. Shaber, R. S. Fielding, and P. G. Medvedev, INL

INL initiated experiments to assess minor alloy additions that were considered candidates to immobilize lanthanide fission products in metallic fuel, with an initial focus on palladium.

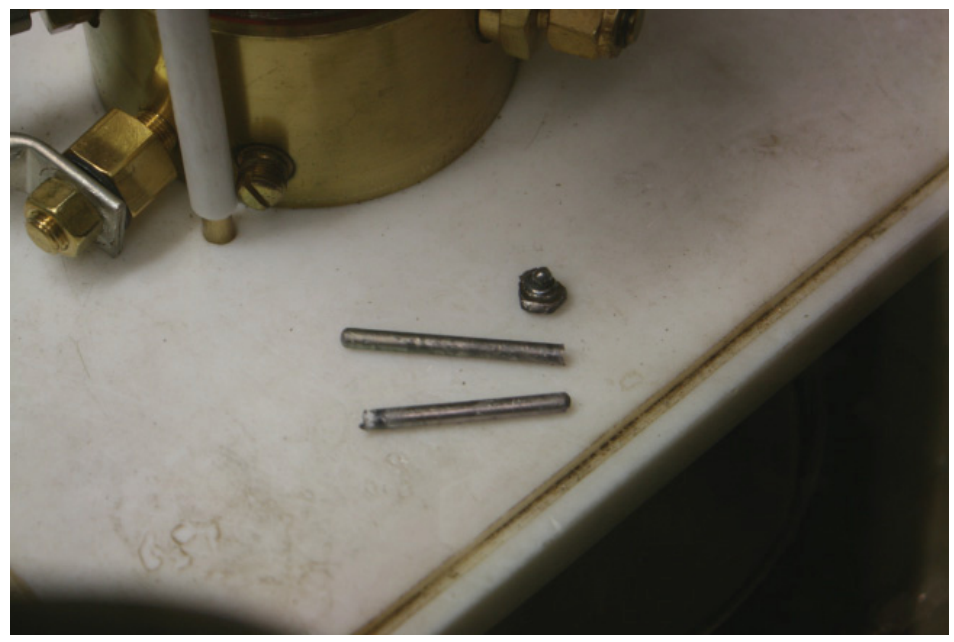

Figure 18. U-Pd-La-Ce-Pr-Nd-Zr alloys cast for characterization.

Several alloys have been cast with an interest to examine dopants (minor amounts of metal additives) for their ability to sequester lanthanide fission products within the fuel matrix, or at least stabilize them against interaction with the cladding. Lanthanides migrate to the fuel periphery where they participate in and possibly accelerate FCCI in U-Zr fuel alloys. Candidate dopants were chosen based on detailed analysis of binary and ternary alloy systems and on a set of criteria stemming from that analysis. To date, six alloys have been cast with U-Zr-Pd-Ln constituents, six with U-Zr-Ti-Ln constituents, and six with UMo-Pd-Ln constituents (Ln designates a 53Nd-25Ce-16Pr-6La compositional relationship that approximates the LA fission product ratios). The total LA content ranged from zero to $4.3 \mathrm{wt} \%$, which corresponds to approximately $16 \%$ burnup. Preliminary scanning electron microscope (SEM) results (see Figure 19) for the U-Zr-Pd-Ln system indicate that lanthanides indeed phase segregate with palladium in the unirradiated as-cast microstructures. 

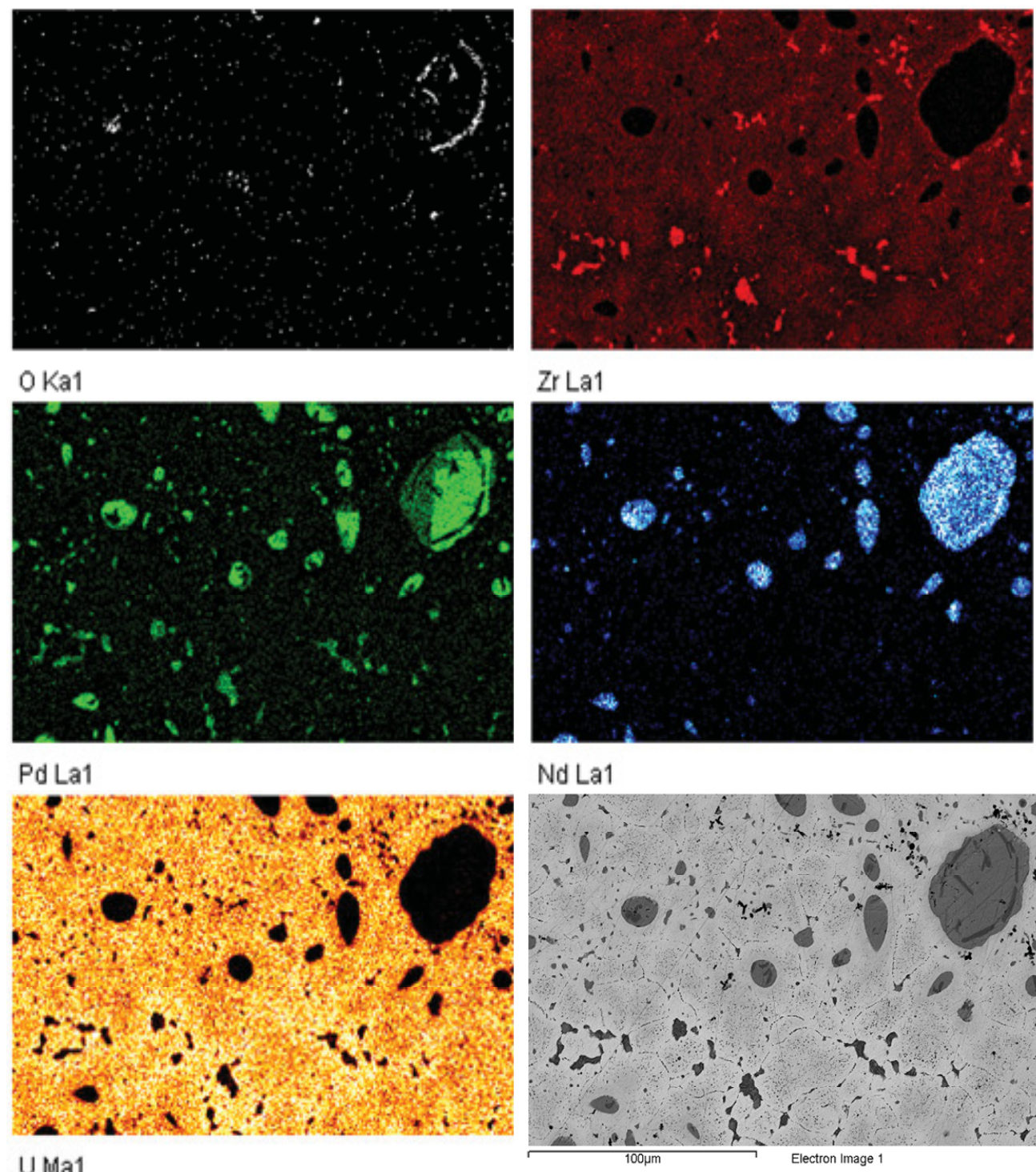

Nd La1

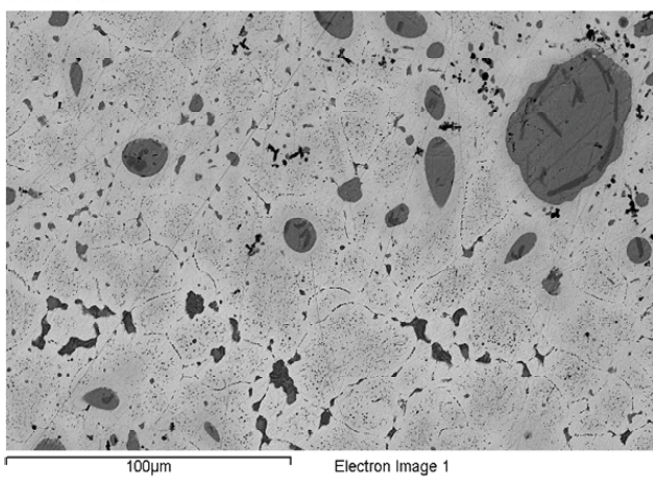

Figure 19. X-ray maps and back-scattered electron image (lower right) for alloy Pd-6 (U-15Zr-3.9Pd4.3Ln). Colors rendered are false. Highlighted regions for neodymium overlap the highlighted regions for palladium. However, the neodymium does not appear to be present in the fuel matrix, while some of the palladium is present there and appears to be associated with high zirconium regions.

At ANL, preliminary investigation of the effects of indium (In), thallium (Tl), and gallium (Ga) on immobilization of lanthanide fission products (LA) was performed using an advanced approach for modeling multi-component alloys. The results show the immobilization dependence on surface energy of the individual element and the possible immobilization enhancement by using a combination of all three elements. Figure 20 compares the compound formation enthalpies of In and $\mathrm{Tl}$ with fuel and cladding constituents. The low (i.e., negative) enthalpies of formation of In with all LA relative to fuel constituents imply that In will preferentially form compounds with the LA. LA may thereby be immobilized in the fuel matrix. The positive enthalpies of formation of In with iron (Fe) and cerium $(\mathrm{Ce})$ predict that In will not react with cladding. Tl shows a behavior similar to In. It has positive enthalpies of formation with cladding constituents, slight negative enthalpies of formation with fuel constituents, and large negative enthalpies of formation with LA. Since Ga is known to stabilize plutonium $(\mathrm{Pu})$ and is positioned in the 
same group as In, it may also be a good candidate for this purpose. However, Ga will form stronger compounds with zirconium $(\mathrm{Zr})$ than with LA. In addition, Ga reacts with all cladding constituents. Thus, Ga seems to be less attractive than In and $\mathrm{Tl}$.
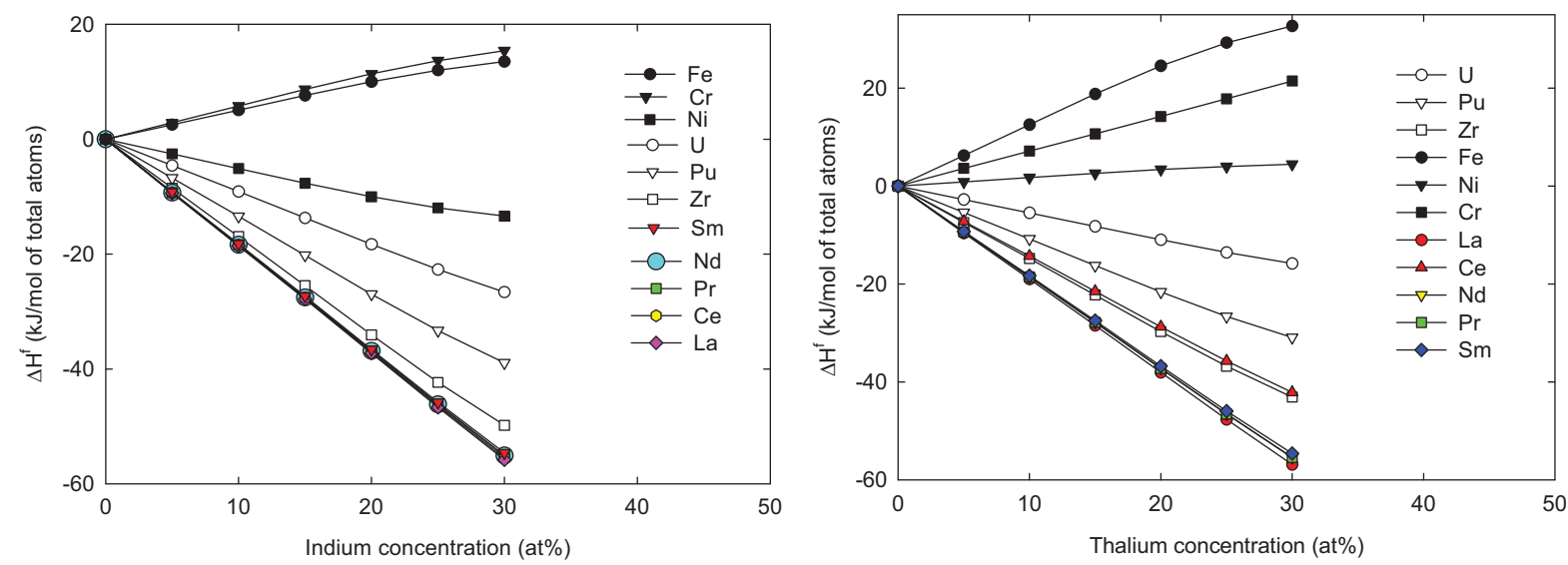

Figure 20. Heats of formation of In-X alloys (left) and TI-X alloys (right).

Incorporation of fuel additives will require more fuel development time, but will avoid the disadvantages associated with cladding liners (increased effective cladding thickness and potential liner degradation with burnup). To investigate the effectiveness of uranium U-Mo with respect to fuel constituent redistribution and in dealing with LA migration, out-of-pile tests are being planned for FY 2011. Test samples would be composed of depleted uranium with additions of 10 weight $\%$ Mo and 10 weight $\% \mathrm{Ce}$. Based on its high fission yield and migration behavior similar to other LA, Ce is selected as the representative element, at a concentration that will simulate the situation in fuel at high burnup. A central hole $(\sim 1 \mathrm{~mm}$ in diameter) along the axial centerline of the sample disc may be included to investigate whether LAs migrate by a direct transport mechanism, such as vapor transport through interconnected open pores in real fuel. The heating test is designed to provide a thermal gradient that exists radially in a typical fuel pin during irradiation and will run for approximately three months. Work in FY 2011 will also include (a) further analysis of LA migration and effects of fuel additives on LA control, (b) modeling to identify potential elements and their amounts in support of both in-pile and outof-pile experiments, and (c) evaluation of the effects on fuel pin thermal performance associated with decreased smeared density, sodium logging, annular fuel slug, etc.

\section{Publications}

- Mariani, R., (2010), "Dopants for High Burnup in Metallic Nuclear Fuels," U.S. Patent Filing No. 12/702,077, February 8, 2010.

\subsubsection{Burnup Effect on Fuel Operating Temperature}

T. H. Bauer, thbauer@anl.gov ANL

The thermal conductivity of several fast reactor fuel concepts and designs capable of burnups up to 50 at.\% is being evaluated. Specific options are being considered where fuel smeared density (as low as $50 \%$ ) allows for extensive buildup of solid fission products before the latter begin to cause mechanical loading of the cladding. Evaluations of fuel thermal conductivity and fuel pin centerline temperature over a full burnup range are underway for multiple fuel design options, including: (a) fresh fuel material in either powder or slug form and (b) the presence or absence of bond sodium. A Fortran program, which was developed and validated near the end of the Integral Fast Reactor (IFR) Program, is being used to 
estimate the thermal conductivity of irradiated advanced U-Pu-Zr metallic fuel covering a wide range of alloys and morphologies of potential interest for advanced fuels capable of very high burnup.

Computations are based on work reported in the IFR Metal Fuels Handbook and include porosity dependence of thermal conductivity as well as fuel solidus and liquidus values calculated by the MELTS software program based on Gibbs free energies.

\title{
3.8.5 Vented-fuel Impacts on Reactor Maintenance, Operations, and Safety
}

\section{W. D. Pointer, dpointer@anl.gov, and T. H. Bauer, ANL}

Previously-existing information pertaining to operation with vented fuel and its implications regarding plant design and operations, including cover-gas cleanup systems and sodium purification systems, was collected and reviewed. Compared to the fission gas plenum concept, the economic benefits of the vented fuel are due to reduced vessel height, thinner cladding, longer fuel residence time, lower pumping power associated with a lower power drop, etc. In addition, the continuous removal of the fission gases would reduce the most mobile radioactive species from the core inventory and thus substantially reduce the potential radioactive source terms. However, as a trade-off, there are penalties such as extra fission gas storage space, extra purification system capacity, extra biological shielding, etc. Work in FY 2011 will focus on evaluating vent performance analytically, designing an experiment concept to evaluate vent performance empirically, and evaluating impacts of fuel pin venting on sodiumcooled fast reactor facility design, operation, and safety.

\subsection{Innovative Fuel Concept: Uranium Alloy Metal Fuel for Light Water Reactors}

\author{
R. Omberg, ron.omberg@pnl.gov, PNNL
}

This project is developing a new, high density, uranium alloy metal fuel for LWRs. This fuel has the potential for increasing the linear heat rate and power density in a reactor while possibly providing more favorable reactivity temperature coefficients. More favorable reactivity temperature coefficients have the potential to improve transient maneuvering between power levels. In addition, it has the ability to establish better performance under accident conditions. The fundamental features of the concept are shown in Figure 21.

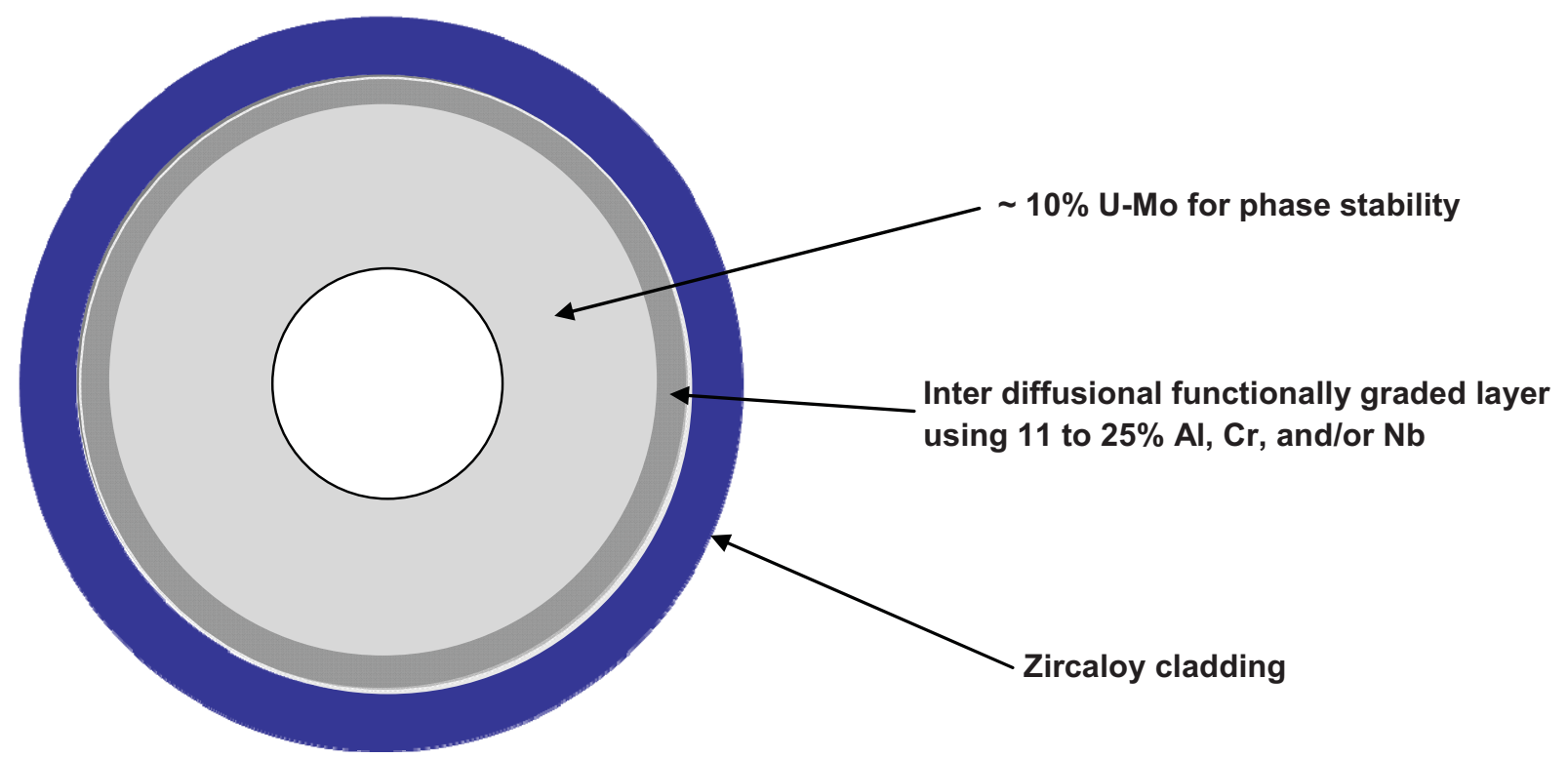

Figure 21. Uranium-molybdenum fuel concept 
As the figure indicates, this concept consists of U-Mo alloy with an inter-diffused functionally graded layer for improved surface corrosion resistance. Materials being considered for improved corrosion resistance include small quantities of niobium $(\mathrm{Nb})$, aluminum $(\mathrm{Al})$, and/or $\mathrm{Cr}$. On the outer radius of the metal fuel slug, a higher concentration of an alloy of $\mathrm{Nb}, \mathrm{Al}$, and/or $\mathrm{Cr}$ is solution heat treated and diffused into the outer surface for a coating providing superior corrosion resistance in the event of a cladding breach.

In-reactor tests to demonstrate the irradiation swelling and fission gas release characteristics of this fuel are scheduled for insertion into ATR in August 2012. Reactor physics calculations have been performed and indicate that if enrichments in U-Mo fuel are similar to those in existing LWRs, then the burnup capability will be similar. Unit cell burnup calculations for $\mathrm{UO}_{2}$ and $\mathrm{U}-\mathrm{Mo}$ fuel demonstrating this are shown in Figure 22.

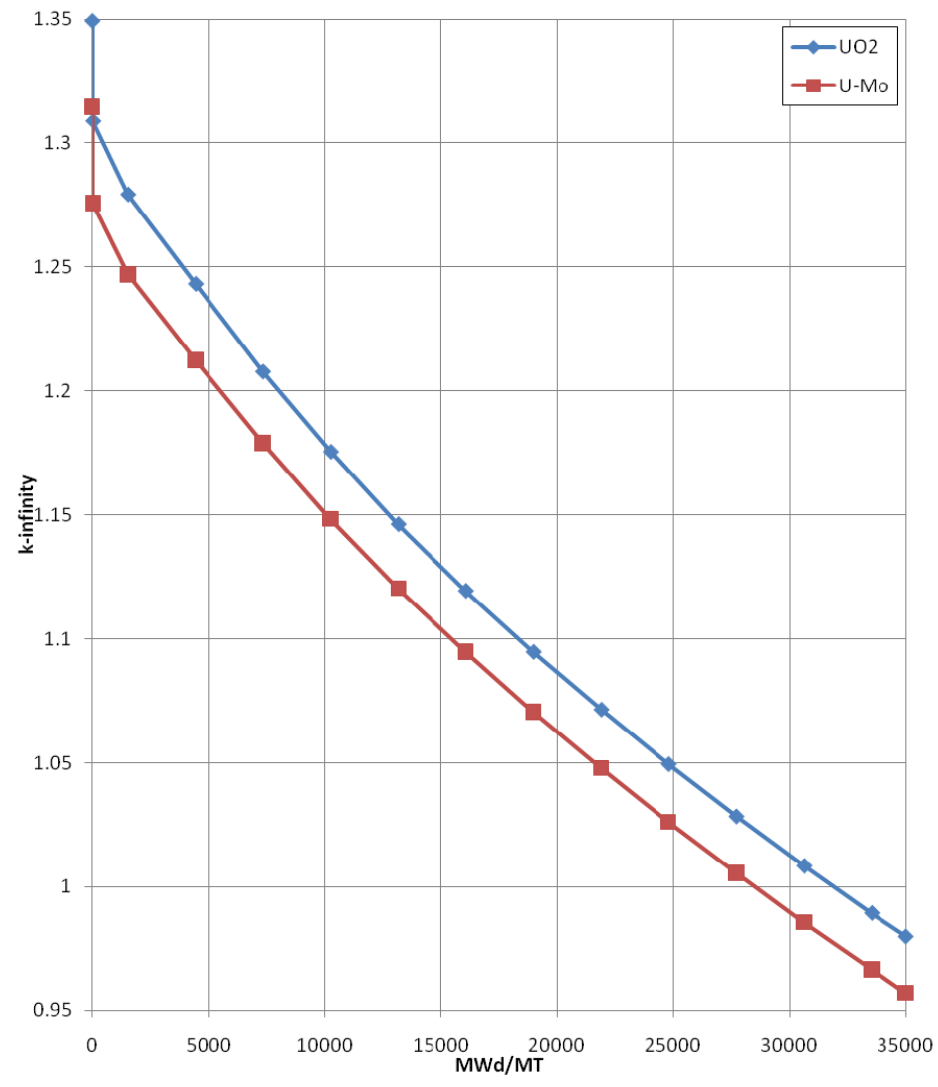

Figure 22. Unit Cell Burnup Calculations Showing Similar Burnup Capability for UO2 and U-Mo 


\section{GERAMIC-BASED FUELS TECHNOLOGIES}

Technical Lead, K. McClellan, kmcclellan@lanl.gov, LANL

Key challenges for AFC are the development of reliable low-loss fuel fabrication methods and fuel technology development to enable major increases in fuel burn up and performance beyond current technologies. Fuels fabrication activities support fuels testing and irradiation activities in the program. Ceramic fuel fabrication and characterization accomplishments for FY 2010 are discussed in this section. FY 2010 highlights include:

- Emphasis was increased on feedstocks to support separate and integral effects testing with the first reference feedstock for fundamental studies synthesized at ORNL and shipped to LANL.

- Processing studies of urania-based fuels incorporated a new commercial feedstock to provide the reference system for comparison in advanced fabrication process development and coordination of modeling and experiment for both processing and performance studies.

- A technique was developed to dynamically measure the change of thermal conductivity with microstructural evolution during fuel sintering.

- Substantial progress was made in the development of new, modern fuel property determination capabilities that support fundamental science including dynamic oxygen-to-uranium control during testing and a bench top melt point measurement system.

- Interrupted sintering tests were performed on mixed oxide fuel compositions under different atmospheres as part of a systematic study to establish the relations between processing conditions and resulting microstructure and chemistry for 80/20 and 70/30 MOX and two minor actinidebearing analogues.

- The state of thermo-chemical models were advanced for AmO2-x and the model (U,Ce)O2 $\pm x$ which support both process and performance modeling and corresponding improved fundamental understanding of fuel chemistry.

- A series of ceramic-based innovative fuel concepts were identified through a competitive process and a three year research and development plan was defined for each concept.

\subsection{FY 2010 Geramic Fuel Approach}

Ceramic fuel development for FY 2010 focused on oxide fuel and was a balance of effort seeking transformational R\&D while incrementally advancing fuel technology. This balance was established via fuel material processing and performance studies that advance fundamental understanding of the relationships for given fuel forms between fuel composition, pellet fabrication processing, corresponding material properties and subsequent fuel performance.

The ceramic fuel fabrication and characterization R\&D supports open, modified-open and closed fuel cycle options. The balance of FY 2010 effort included fuel fabrication and performance studies which initiate separate effects-type testing but still support integral effect-type testing. Separate effects test studies are designed to establish and articulate the underlying physical processes at the lower length scales while supporting definition of phenomenology at the meso-scale and subsequent understanding of behavior at the engineering (continuum) scale. In addition to the resulting improvement of theoretical understanding of fuel fabrication and performance, the separate effects testing aspect of the program is 
intended to directly inform and support the development of predictive fabrication and performance models.

FY 2010 work was structured around the fact that the key issues for establishing low loss processing and improved fuel performance are materials issues. Therefore, a fundamental approach was taken to understanding the relationships between composition, processing, properties, and performance (see Figure 23) and then establishing enhanced ability to control processing and fuel performance. Highlights from the FY 2010 ceramic fuel development R\&D are categorized in this section using that materials relationship structure. Highlights for several innovative concepts are also included.

\subsection{Decomposition of Rare Earth Loaded Resin Particles}

\section{S. L. Voit, voitsl@ornl.gov, ORNL}

Researchers from the United States, Europe, and Japan are investigating methods of fabricating high-specific activity spherical particles for fuel and target applications. ${ }^{1,2}$ The capital, operating, and maintenance costs can be significant for a facility that processes material with such a high source term. Thus fuel synthesis and fabrication methods that minimize waste and process losses, and require less footprint are desired.

One method for producing MA-bearing spherical particles is loading the actinide metal onto a cation exchange resin. Picart et al. demonstrated the viability of using a resin loading process for the fabrication of uranium-actinide mixed oxide microspheres for transmutation of minor actinides in a fast reactor. ${ }^{3}$ For effective transmutation of actinides, it will be desirable to extend the in-reactor burnup and minimize the number of recycles of used actinide materials. Longer burn times increase the chance of FCCI or fuelclad-mechanical interaction (FCMI). Sulfur is suspected of contributing to Irradiation Assisted Stress Corrosion Cracking (IASCC) ${ }^{4}$ so it is necessary to maximize the removal of sulfur during decomposition of the resin.

\section{References}

1. Pillon, S., et al. (2003), J. of Nucl. Mater., 320, p. 36-43.

2. Buiron, et al. (2007), "Minor actinides transmutation in SFR depleted uranium radial blanket, neutronic and thermal hydraulic evaluation", Global 2007, Boise, Idaho, September 9-13.

3. Picart, S., et al. (2009), Proceedings of Global 2009, Paris, France, Paper 9400, September 6-11.

4. Chung, H., and W. Shack (2006), ANL Report ID ANL-04/10, OSTI ID: 915725, January 31. 


\title{
4.3 Decomposition and Sulfur Removal from Nd-Loaded Resin
}

\author{
S. L. Voit, voitsl@ornl.gov, ORNL
}

The present effort extends previous work ${ }^{1}$ by quantifying the removal of sulfur during the decomposition process. Neodymium was selected as a surrogate for tri-valent actinide metal cations. The Nd-resin prior to decomposition is shown in Figure 24. Samples were analyzed using a simultaneous thermal analyzer, XRD, and analytical chemistry.

A baseline thermal treatment was carried out in air following a previously established procedure and the sulfur content at various stages of decomposition was determined. The effect of using a hydrogen-bearing process gas on sulfur removal was studied under varied conditions. An example of the thermogravimetric and

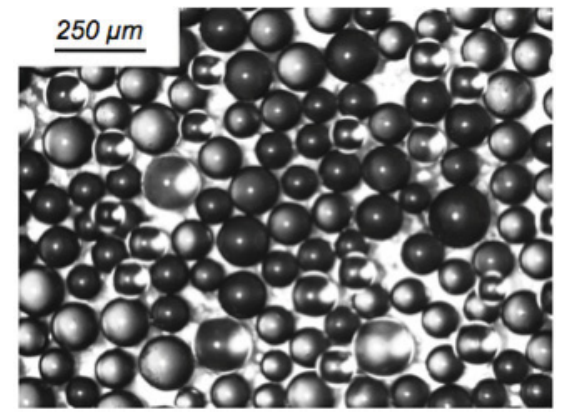

Figure 24. Neodymium-loaded AG$50 W$ resin particles. differential scanning calorimetric analysis is presented in Figure 25. The four major reactions highlighted on the differential scanning calorimetry (DSC) curve are accompanied by sulfur loss, as determined by off-gas analysis and shown in Figure 26. Samples for analytical chemistry were taken at different stages of the decomposition process. The residual sulfur results for various processing conditions are plotted in Figure 27.

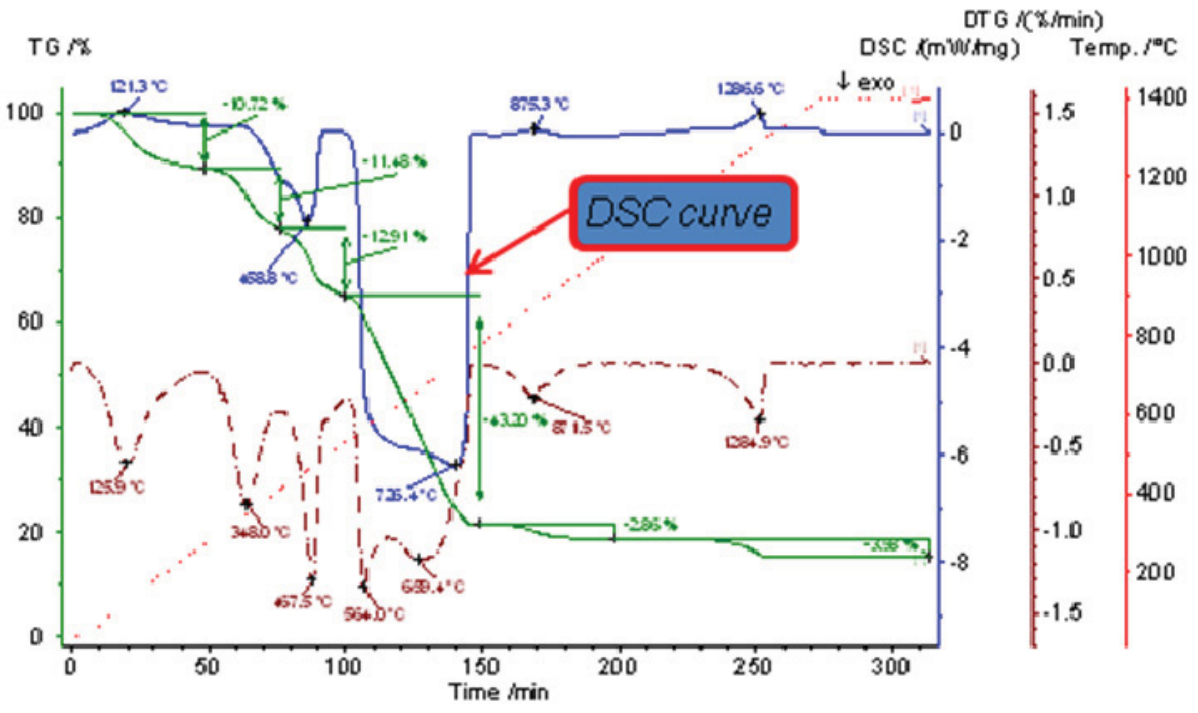

Figure 25. TG, DTG and DSC curves for Nd-loaded AG-50W resin in air 


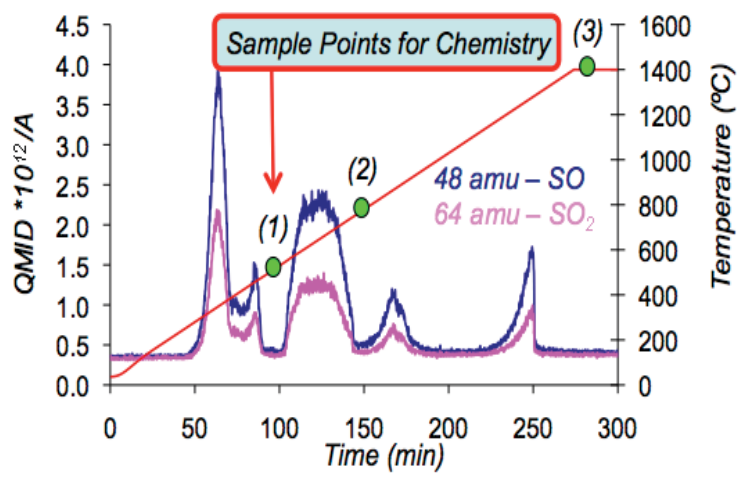

Figure 26. Mass spec results and sample points for sulfur determination via analytical chemistry.

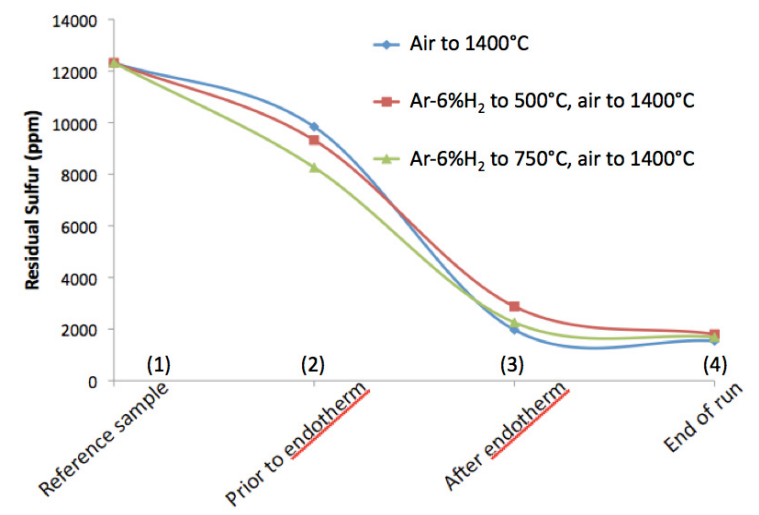

Figure 27. Residual sulfur levels during decomposition under varied processing conditions.

Results indicate that a hybrid approach using both hydrogen- and oxygen-assisted sulfur removal may yield improved results over decomposition in air alone. Even at present sulfur levels, resin technology may be used for producing a near-dustless feed material for a fuel/target where the minor actinide (MA) concentrations are not more than $10 \%$ loading in the matrix.

\title{
References
}

1. Hale, W. (1971), J. Inorg. Nucl. Chem., 33, 1227-1232

\subsection{Uranium Oxide Based Processing Studies}

\author{
E. Luther, eluther@lanl.gov, LANL
}

The FCRD program desires to improve fuel pellet properties and the methods used to produce them. Fuel pellets with engineered microstructures may be more stable in pile by reducing fuel cladding interactions and allowing higher power and/or deeper burn. Improving processing methods will reduce the number of steps required to fabricate pellets leading to reduced process losses, remote handling, and more uniformity among pellets which require less post processing (e.g., grinding) and behave more predictably in pile. To achieve these objectives, a fundamental, scientific understanding of powder processing science is necessary. Progress in understanding several key processing principles has been achieved this year and is discussed below.

The behavior of an object depends on the properties of the material it is fabricated from. The properties of a material are largely determined by the composition of the material but can vary significantly depending on how the material was fabricated. For nuclear fuel pellets, in pile performance will depend on the properties and therefore, upon the processing methods used to make the pellet. The research performed is aimed at understanding the relationship between processing and performance. By understanding this relationship, we seek to gain control over the ceramic microstructure that is produced during processing to allow us to tailor the properties of the fuel pellet. As examples, controlled porosity might be engineered into a microstructure to allow fission gas release, a second phase with high thermal conductivity might be designed into a microstructure to reduce centerline temperature without impacting performance, or grain boundaries may be pinned to prevent fuel restructuring, thereby allowing for higher burn up.

Ceramic components such as uranium oxide fuel pellets are most often fabricated from ceramic powders. The particle size and size distribution of the powder is extremely important to how the powder 
behaves during processing. Milling to reduce particle size will change the behavior of the powder during subsequent steps viz. compaction and sintering. In Figure 28, the particle size of a powder is determined before and after milling for 15 minutes and 2 hours. As can be seen, the particle size initially decreases but then increases with milling time. Understanding and controlling this behavior is critical since powder with a finer particle size will not compact as well as a larger powder; however, finer powders are more active and will sinter more readily. Studies such as this allow us to optimize milling time.

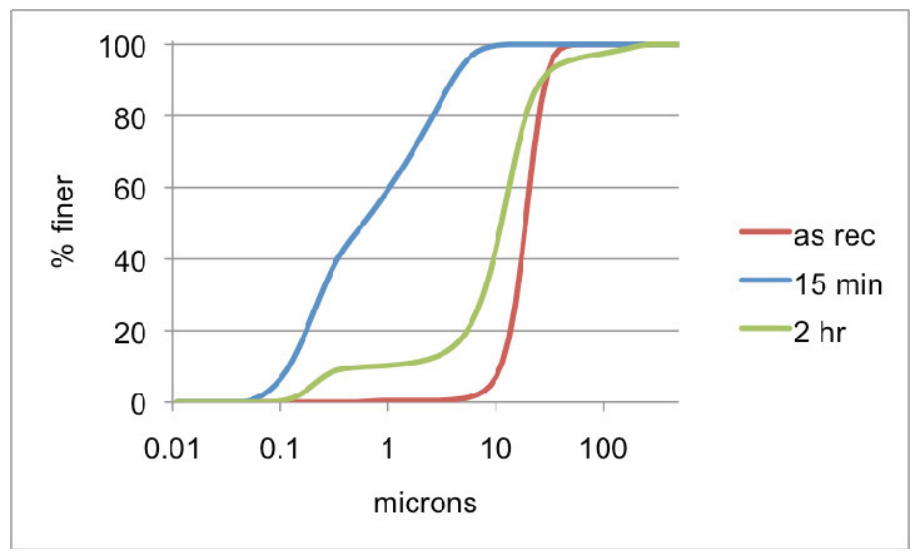

Figure 28. Graph showing the effect of milling time on the particle size of uranium oxide powder. Note that longer milling time does not decrease particle size as is usually observed.

After a ceramic powder is milled, it is compacted or pressed into a desired shape. The extent to which the powder flows into the shape is dependent on the powder size, size distribution and shape. Good flow behavior allows compaction to a higher density. The more pressure used to compact the powder, the higher the density achieved. However, since powder does not flow perfectly, pressure gradients occur in the compact creating regions of high and low density. Non-uniform density is undesirable since differential shrinkage will occur during sintering creating sintering stresses that lead to microstructural defects. Figure 29 shows compaction behavior of two different powders highlighting the very different behavior that powder size and shape can have on material with the same chemical composition. These studies allow us to determine the appropriate consolidation pressure to achieve uniform pellets. Work on characterizing the flow behavior of powders as a function of conditioning processes will continue in the next fiscal year.

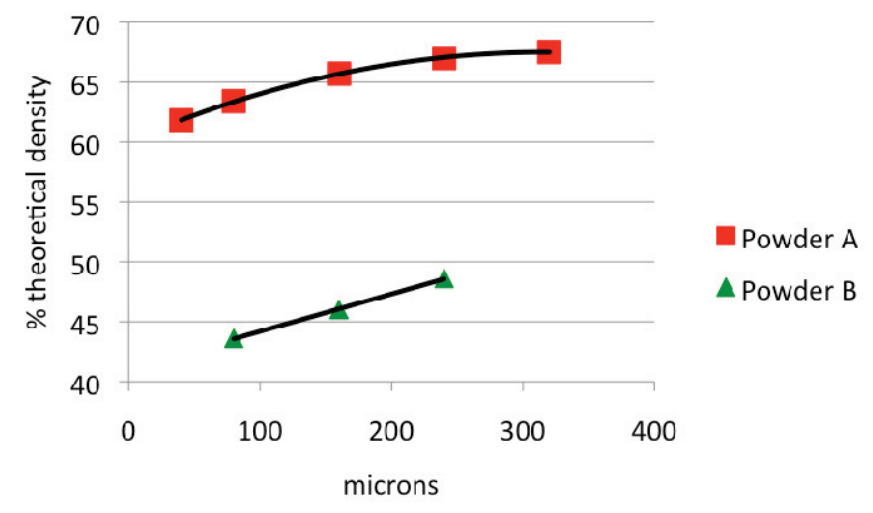

Figure 29. Graph showing "green" density of a powder compact as a function of pressure for two different powders. The tremendous difference in density at the same pressure is a function of the properties of the powder such as particle size, size distribution and shape. 
Once powder has been formed into a desired shape, the material is densified by heat treatment or sintering. Sintering is a complicated process that depends on both the chemical and physical properties of a material. The rate and extent to which a material densifies can be affected by the processing parameters chosen in the preceding steps; therefore, the material is considered to be "path dependent". Characterization of the microstructure of the sintered part is important to understand the influences of changing various process parameters. Figure 30 shows electron backscatter diffraction (EBSD) images showing the microstructure of two uranium oxide fuel pellets processed exactly the same way except for the sintering temperature. As can be seen, the grains of the material sintered at higher temperature are almost twice as large as those in other material. The different colors of the grains indicate crystallographic orientation and provide additional structural information. Grain size can have important effects on the properties of a material such as strength and creep resistance. Work to engineer desired grain sizes in a pellet will continue in the next fiscal year.

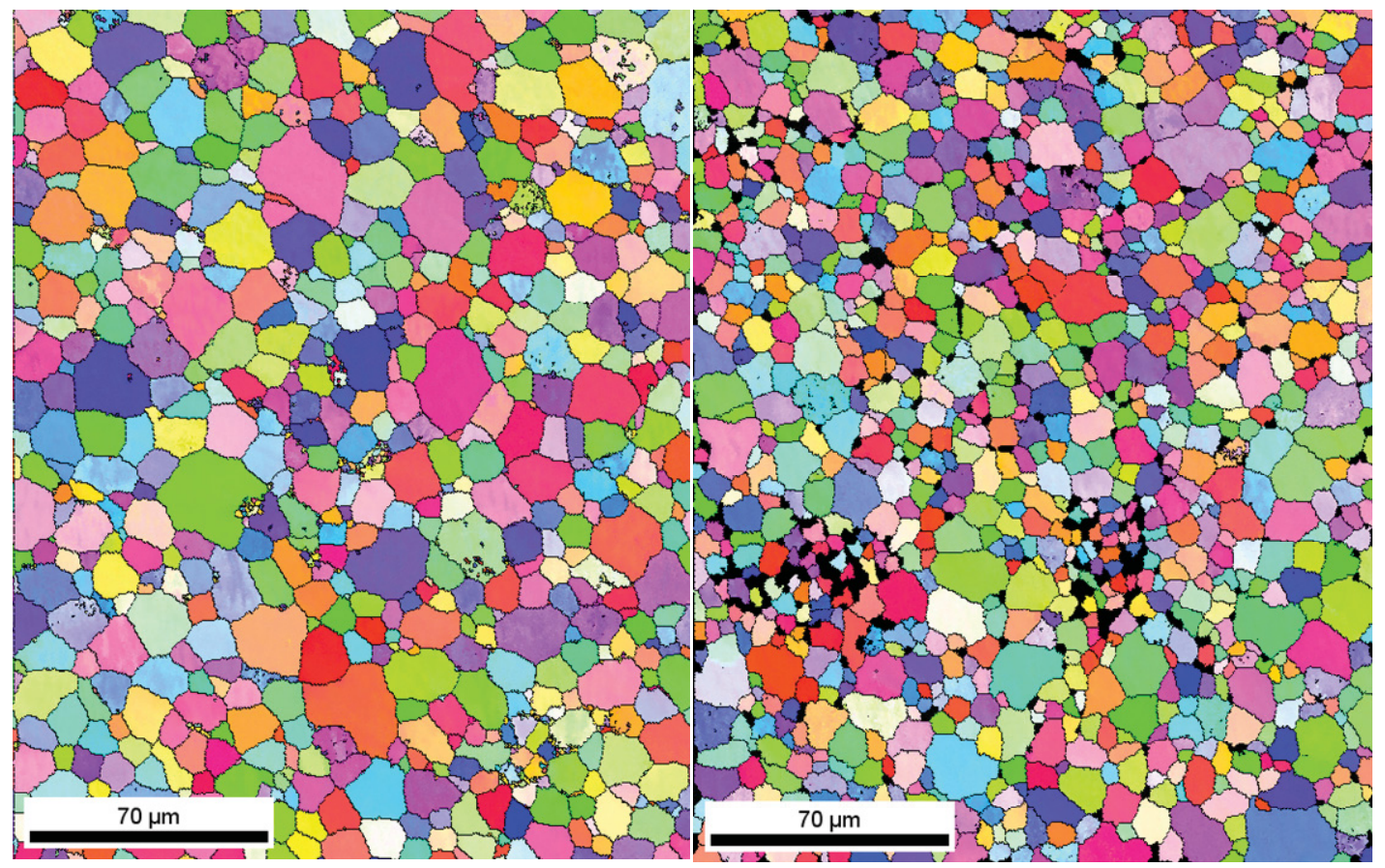

Figure 30 Electron Backscatter Diffraction images of the microstructure of two uranium oxide pellets processed identically except that the material in the left figure was sintered $300^{\circ} \mathrm{C}$ hotter resulting in larger grains. Grain size can have large effects on the properties of a material.

In pursuit of programmatic goals, draft reports on "Advanced Ceramic Fabrication Techniques," "Ceramic Feedstock Acquisition and Conditioning for Separate Effects Testing," and "State of the Art Sintering Models for Ceramic Fuels" have been submitted. A presentation was made at the Materials Challenges in Alternative \& Renewable Energy 2010 conference sponsored by the American Ceramic Society.

\subsection{Dynamic 0/M Gontrol}

D. Byler, dbyler@lanl.gov, LANL

The oxygen-to-metal $(\mathrm{O} / \mathrm{M})$ ratio of oxide nuclear fuel materials plays a significant role in all aspects of processing, properties and performance of the fuel. Because of the effects that it can have on key fuel properties including thermal conductivity and melting point, substantial effort has been placed on $\mathrm{O} / \mathrm{M}$ 
control. Processing and fabrication of fuels are also greatly dependent on $\mathrm{O} / \mathrm{M}$ due to the effects that it has on the sintering kinetics and the ability to achieve the desired $\mathrm{O} / \mathrm{M}$ value during the fabrication process to meet design requirements. Additionally, the performance of the fuel is affected because $\mathrm{O} / \mathrm{M}$ can have adverse effects during irradiation that can result in FCCI and potential fuel pin breaches. To control and set the $\mathrm{O} / \mathrm{M}$ of a material, knowledge of the temperature, oxygen activity and composition space must be known. With this information, for a given composition and desired final stoichiometry, an oxygen activity above a sample may be set. ${ }^{1-8}$ During this process, dynamic control must be maintained to control the oxygen activity over an increasing or decreasing temperature range, thereby effectively changing oxygen partial pressure above the sample with temperature. A large body of research has been conducted on Urania and urania solid solutions to understand and model these effects, but gaps in the research and the non-availability of certain data make model validations difficult.

The focus of the research during FY 2010 was to implement a dynamic O/M control system that could be used to improve thermophysical property measurements, provide data sets for modeling oxygen activity as a function of $\mathrm{O} / \mathrm{M}$ and further control capabilities for processing. This "dynamic" control of $\mathrm{O} / \mathrm{M}$ comes from the ability of a gas control system to dynamically change mixing ratios of gases with time or temperature as determined from experiments, literature and models.

The dynamic $\mathrm{O} / \mathrm{M}$ control system is based upon the gas mixing system that was developed in previous years to allow static $\mathrm{O} / \mathrm{M}$ control by setting a gas-mixing ratio of either $\mathrm{CO} / \mathrm{CO}_{2}$ or $\mathrm{H}_{2} / \mathrm{H}_{2} \mathrm{O}$. The refined system utilizes a new and "dynamic" LabView program to set desired partial pressures of oxygen according to a predetermined schedule to effectively set the oxygen activity above a sample with changing temperature to achieve the desired stoichiometry of the sample. Evaluation of this system was done using a thermogravimetric analyzer (TGA), by which mass changes were recorded and evaluated based on the initial sample mass to generate $\mathrm{O} / \mathrm{M}$ values of the samples, knowing the starting stoichiometry. Tests with $\mathrm{CO} / \mathrm{CO}_{2}$ were very good to set $\mathrm{O} / \mathrm{M}$ values up to 2.05 , although difficulties were encountered because at the $\mathrm{CO} / \mathrm{CO}_{2}$ ratios that were used, carbon was deposited on the sample support in the TGA, obscuring the "true" mass changes. These results were presented at the Materials Challenges and Renewable Energy (MCARE) conference in Cocoa Beach in February 2010. The final $\mathrm{O} / \mathrm{M}$ of the samples was determined by post-experiment weights and corrections were made accordingly. Comparisons of this data with models generated by ORNL showed very close matches of measured with predicted values (see Figure 31a). Due to the issues with carbon deposition on the sample support in the TGA, a parallel path was chosen for the $\mathrm{H}_{2} / \mathrm{H}_{2} \mathrm{O}$ system that uses argon with $6 \%$ hydrogen in place of pure hydrogen due to safety concerns and possible mixing ratios available. Using this gas system, oxygen partial pressures required to control at low $\mathrm{O} / \mathrm{M}$ were easily possible and because of the use of the water, better control could be attained by using the water bath temperature as an effective "knob" to turn. To attain higher $\mathrm{O} / \mathrm{M}$ values, premixing of the argon- $6 \%$ hydrogen was required to provide partial pressures of oxygen to allow control up to an $\mathrm{O} / \mathrm{M}$ of approximately 2.15 at higher temperatures. Figure $31 \mathrm{~b}$ illustrates the partial pressure of oxygen required to achieve various $\mathrm{O} / \mathrm{M}$ values for $\mathrm{UO}_{2+\mathrm{x}}$, with the partial pressure of oxygen in atmospheres pressure. Figure 32 illustrates the $\mathrm{pO}_{2}$ control range with stock gases using argon- $6 \%$ hydrogen and water as a function of water bath temperature and type of argon used to dilute the argon- $6 \%$ hydrogen. 


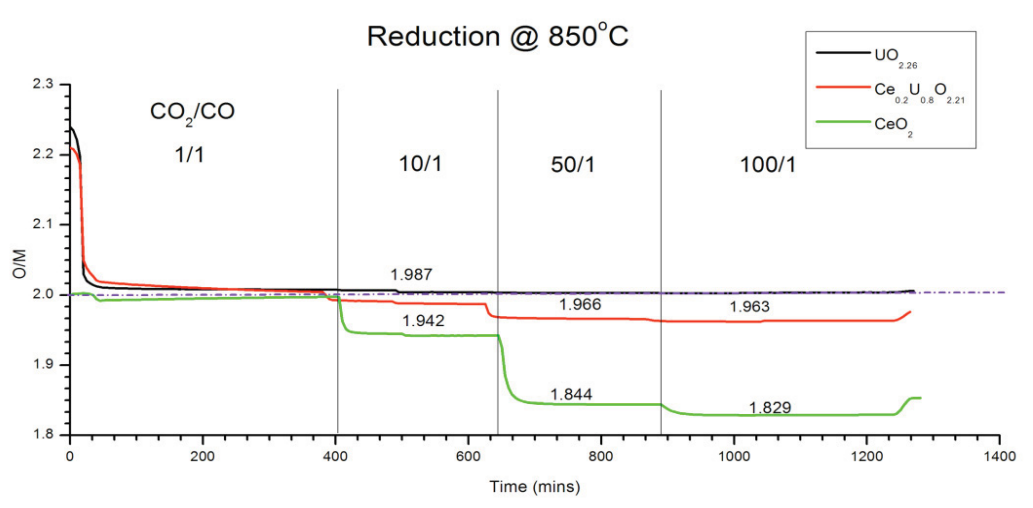

(a)

(b)

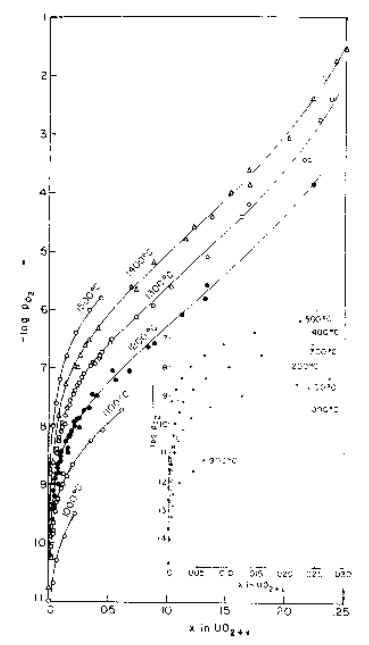

Figure 31. (a) Reduction of $\mathrm{U}_{0.8} \mathrm{Ce}_{0.2} \mathrm{O}_{2.21}$ using $\mathrm{CO} / \mathrm{CO}_{2}$ gases with dynamic control system, (b) O/M as a function of temperature and $\mathrm{pO}_{2}{ }^{9}$.

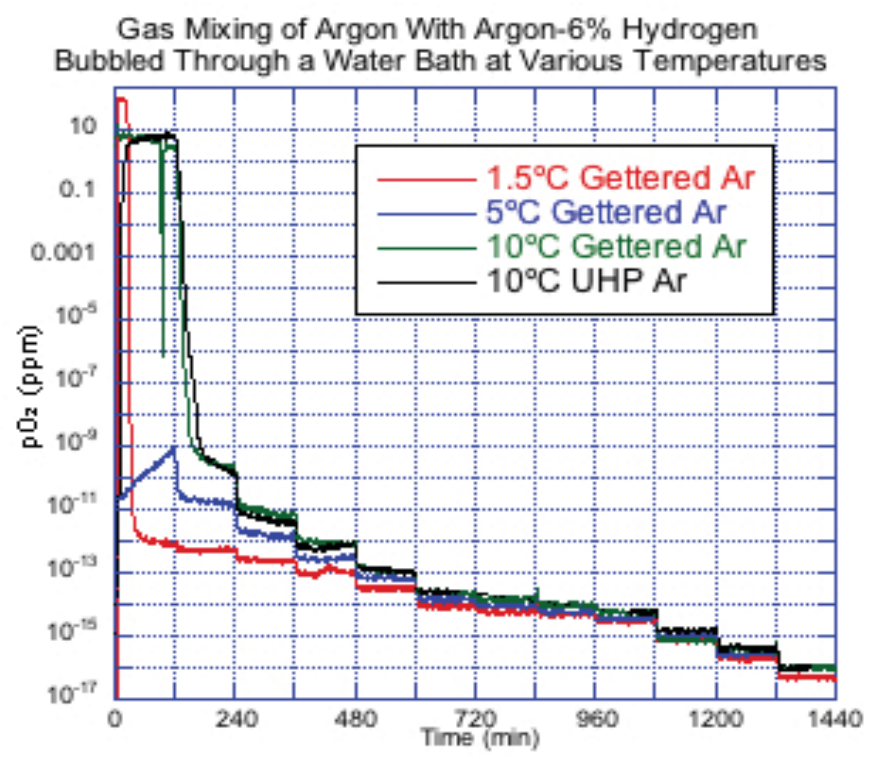

Figure 32. $\mathrm{H}_{2} / \mathrm{H}_{2} \mathrm{O}$ gas system $\mathrm{O} / \mathrm{M}$ control range using stock gases.

In summary, the dynamic $\mathrm{O} / \mathrm{M}$ control using $\mathrm{CO} / \mathrm{CO}_{2}$ was very good up to an $\mathrm{O} / \mathrm{M} \sim 2.05$ and correlated well to the ORNL predictions for stoichiometry at various gas ratios. Additionally, using the argon- $6 \%$ hydrogen/water system, a large range can be attained up to at least 2.15 for urania using premixed gases. Small refinements will be made and implemented to the dynamic system for improved thermophysical testing as a function of $\mathrm{O} / \mathrm{M}$ and insitu control of stoichiometry for sintering operations.

\section{References}

1. Konno, K. and T. Hirosawa, Melting temperature of mixed oxide fuels for fast reactors. Journal of Nuclear Science and Technology, 2002. 39(7): p. 771-7.

2. Kato, M., et al., The effect of $\mathrm{O} / \mathrm{M}$ ratio on the melting of plutonium and uranium mixed oxides. Transactions of the American Nuclear Society, 2007. 96: p. 193-4. 
3. Kato, M., et al., Solidus and liquidus of plutonium and uranium mixed oxide. Journal of Alloys and Compounds, 2008. 452(1): p. 48-53.

4. Kato, M., et al., Solidus and liquidus temperatures in the UO2-PuO2 system. Journal of Nuclear Materials, 2008. 373(1-3): p. 237-245.

5. Morimoto, K., et al., Thermal conductivities of hypostoichiometric (U, Pu, Am)O2-x oxide. Journal of Nuclear Materials, 2008. 374(3): p. 378-385.

6. Morimoto, K., et al., Thermal conductivities of (U, Pu, Am)O2 solid solutions. Journal of Alloys and Compounds, 2008. 452(1): p. 54-60.

7. Morimoto, K., et al., Preparation and characterization of (Pu, U, Np, Am, simulated FP) O2-X. Journal of the Physics and Chemistry of Solids, 2005. 66(2/4): p. 634-8.

8. Picard, E., et al., First in-pile experimental results of high-plutonium-content oxide fuel for plutonium burning in fast reactors. Nuclear Technology, 2000. 129(1): p. 1-12.

9. Hagemark, K., Broli, M. Equilibrium oxygen partial pressures over the nonstoicheiometric uranium oxides $\mathrm{UO} 2+\mathrm{x}$ and $\mathrm{U} 3 \mathrm{O} 8 \mathrm{-z}$ at higher temperatures, Journal of Inorganic Nuclear Chemistry. 1966, 28: pp 2837-2850.

\title{
4.6 MOK and MA-MOK Fabrication and Process Development
}

\author{
S. Willson, willson@lanl.gov, LANL
}

Efforts in the LANL plutonium facility concentrated on process improvements and understanding related to Pu-U mixed oxide (MOX) and MA-bearing MOX (MA-MOX) fuel development. Rather than production of test articles for irradiation, refocusing the efforts on method improvement for a time will facilitate more efficient future test article production with a superior quality assurance pedigree. More complete documentation of extant reactor test articles was also compiled during this time, and samples of fuel pellet material were shipped from LANL to INL for thermal analysis to better predict reactor performance of these novel nuclear fuel forms.

Documentation and quality control are integral to any research project. FY 2010 efforts extend both to the improvement of the paper trail, and the physical improvement of the process methods.

- Submission of the AFC2-C\&D as-built report captured key documentation and research experience.

- Use of outside resources to purchase a new automatic press will serve the dual purpose of decreasing worker dose and dramatically improving control over pellet compaction parameters.

- Development of resonant ultrasound is being pursued as a non-destructive examination of pellet quality.

Fundamental property research of novel fuel compositions will assist in design of new fuel compositions and improve safety basis calculations for reactor tests. Using new information to decrease the uncertainty margins for reactor tests will allow more efficient use of expensive reactor resources. This data will also tie in with modeling and simulation efforts, both for fuel fabrication and fuel performance. 
- Measurement of elastic constants by resonant ultrasound is under development.

- Sintering curves are being collected for process improvement and determination of activation energies.

- Thermal conductivity is desirable for calculations of fuel performance and the reactor safety case. Thermal conductivity is the product of heat capacity, density, and thermal diffusivity.

- Initial heat capacity determinations have been made of MOX and MA-MOX materials using differential scanning calorimetry.

- Density measurements at temperature will be derived from dilatometry.

- Thermal diffusivity samples from LANL have been shipped to INL, and will be measured by laser flash in FY 2011.

Sintering kinetics of fuel materials under argon and argon/hydrogen cover gases are being studied in PF-4 using interrupted sintering. This is a non-standard technique that has been employed because it allows use of the same furnace in which reactor test articles are fabricated. The technique involves raising the temperature of a fuel pellet at a specified rate to a specified temperature, then quenching the furnace and measuring the pellet. This is repeated at various temperatures to construct a sintering curve.

The furnace is an atmosphere controlled all-metal furnace. The material of the furnace, and the selection of cover gases and temperature, controls the oxygen potential within the furnace during sintering. The oxygen potential in turn sets the stoichiometry of fuel pellets and may dramatically impact the sintering kinetics. In addition to the benefit of using the metal sintering furnace to provide a direct correspondence between these studies and actual reactor test articles, pulling sintered pellets from the furnace at various temperatures allows measurement of the oxygen stoichiometry and mapping of that information to sintering temperature and atmosphere. It can be seen in Figure 33 that LANL data are consistent with those obtained for MOX systems. Completion of this study is expected to yield activation energies for sintering of four different fuel forms under two atmospheres each. 
Kutty et. al.

- Ramp Rate $=6^{\circ} \mathrm{C} / \mathrm{min}$

- Gas Flow $=18 \mathrm{~L} /$ hour

- 50/50 MOX

\section{LANL}

- Ramp rate $=5^{\circ} \mathrm{C} /$ minute

- Gas Flow $=48 \mathrm{~L} /$ Hour

- $80 / 20$ and 70/30 MOX and MAMOX

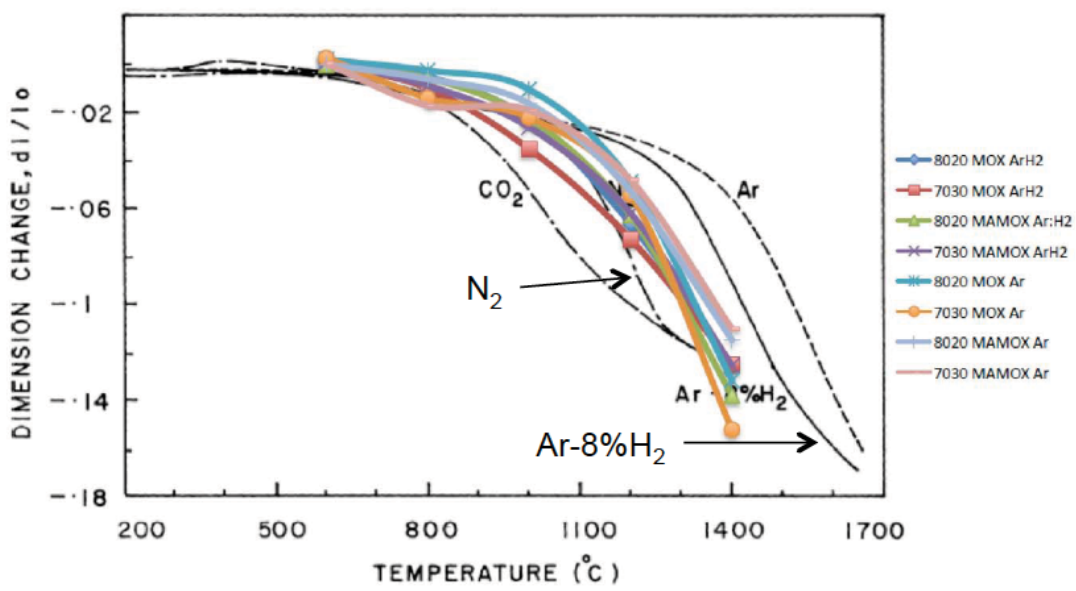

- Original Figure from T.R.G. Kutty et. Al., Journal of Nuclear Materials 264 (1999) 10-19.

Figure 33. Comparison of recent LANL results for MOX and MA-MOX fuel forms with literature values for MOX fuel.

Because it is far less labor intensive to generate traditional sintering curves using a dilatometer, and because the flexibility of possible experiments is broader by dilatometry than by interrupted sintering, standard dilatometer measurements will be made in FY 2011 and compared with the results of interrupted sintering. It is expected that the correlation can be made strong enough to justify additional dilatometry, which can then be linked back to actual test article fabrication by reference to the interrupted sintering curves obtained in the metal furnaces.

These particular systems are not easily studied. Results will be published by LANL upon completion of this work. Derivation of activation energies from the completed suite of experiments will elucidate the active diffusion mechanisms important to the sintering processes of these materials. This improved understanding of the sintering process is expected to assist in design of more effective sintering and fuel sample production parameters.

Interim presentations of this work in FY 2010 include poster presentations at the American Ceramic Society, the American Nuclear Society, and Plutonium Futures conferences.

\title{
4.7 Microstructural Characteristics of Sintered Urania
}

\author{
P.Peralta, pperalta@asu.edu, ASU
}

Mass transport properties in oxide nuclear fuels can be strongly influenced by microstructure, in general, and grain boundary (GB) structure, in particular. In this regard, the study of the distribution and proportion of special GBs that match the Coincident Site Lattice (CSL) criterion can be extremely helpful to understand their effects on fission product mobility, since mass transport of fission products along boundaries has a strong dependence on GB crystallography. This, in turn, suggests that the development of a tailored microstructure with a higher fraction of chosen GBs could help reduce the fission product mobility across fuel pellets. 
Experimental data are scarce on GB crystallography of oxide fuels or their surrogates. The aim of this study is to characterize the microstructure of fuel surrogates and use the results to inform atomistic and mesoscale models of fission product transport.

Electron microscopy techniques were used to quantify the microstructure of depleted uranium oxide $\left(\mathrm{d}-\mathrm{UO}_{2}\right)$ as a surrogate. In particular we used SEM and electron backscattered diffraction (EBSD) to determine grain size and porosity distributions, as well as GB misorientation distributions. The collected data were used to obtain statistics of overall GB misorientations and of CSL GBs that meet Brandon criteria.

The microstructures of two d-UO $\mathrm{U}_{2}$ pellets with different densities $(91 \%$ and $95 \%)$ were characterized. The low density pellet presented equiaxial grains with an average grain size of $6 \pm 2 \mu \mathrm{m}$ and large pores at the GBs. Results indicate that the length fraction of special GBs was about 16\%, which compares well with results reported for YSZ. ${ }^{1}$ Close to half of all the CSL boundaries present were $\sum 3, \sum 9$, and $\sum 5$, which is consistent with results presented by Randle. ${ }^{2}$ The largest fraction of CSL GBs was $\sum 9$ and the general CSL distribution differed from the reported for $\mathrm{YSZ}^{1}$ (see Figure 34). Results for the denser d$\mathrm{UO}_{2}$ sample showed a GB distribution that is closer to that reported for YSZ. ${ }^{1}$

(a)

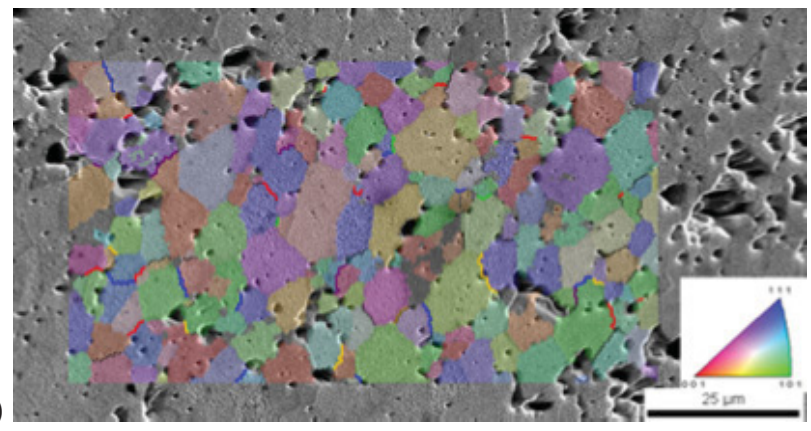

(b)

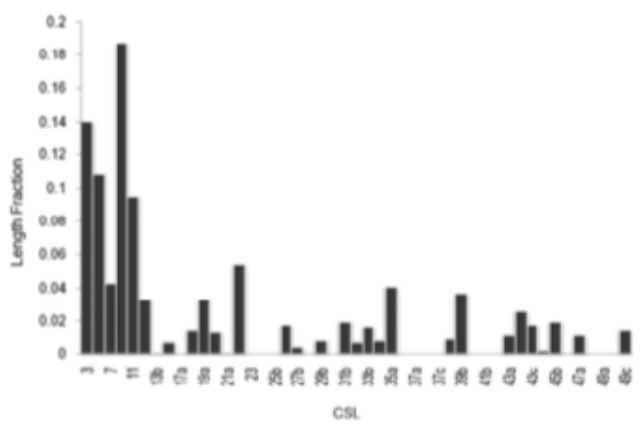

Figure 34. (a) SEM and EBSD images of a low density $d-U_{2} \mathrm{O}_{2}$ sample. (b) CSL GB distribution.

The results shown above were then used to study the effect of GB misorientation distribution on the diffusion of fission products using finite element (FE) techniques. The actual microstructure was modeled using 2-D elements with at least one element through the thickness of the GB. Diffusivities were assigned to the GBs $\left(D_{G B}\right)$ as well as the grain bulks $\left(D_{B}\right)$ and their ratio, $D_{G B} / D_{B}$, was varied to understand the effect of GB diffusion. All simulations were performed under steady state conditions with a normalized concentration gradient along the vertical direction while keeping the sides insulated. Results from initial simulations, where all the GBs were given the same diffusivity, show that localization of flux on the GBs occurs when the ratio $\mathrm{D}_{\mathrm{GB}} / \mathrm{D}_{\mathrm{B}}$ is higher than $10^{4}$ and a percolation path becomes visible for $\mathrm{D}_{\mathrm{GB}} / \mathrm{D}_{\mathrm{B}} \geq 10^{6}$. This is in agreement with the analytical results from simple 1-D models. ${ }^{3}$

A procedure was then developed to determine the lower and upper bounds of the effective diffusivity of the microstructure using FE, while providing more detail about the microstructure. The GBs were assigned diffusivities depending on their misorientation angles. The GB network was sub-divided into two categories - high $\left(D_{G B}^{2}\right)$ and low $\left(D_{G B}^{1}\right)$ diffusivity. The CSL GBs were included in the low diffusivity group. The FE results showed a clear percolation path for the microstructure when the ratio $D_{G B}^{2} / D_{G B}^{1}>10^{4}$. The results were compared with work published in the open literature, where random networks were used rather than actual microstructures. ${ }^{4}$ That work pointed out that percolation occurs when the fraction of high diffusivity GBs is greater than a threshold value of 0.653 . The fraction of high 
diffusivity GBs in the microstructure examined was found to be 0.684 , which agrees with the presence of clear percolation paths. The results for the simulation with $D_{G B}^{2} / D_{G B}^{1}=10^{5}$ are shown in Figure 35 .
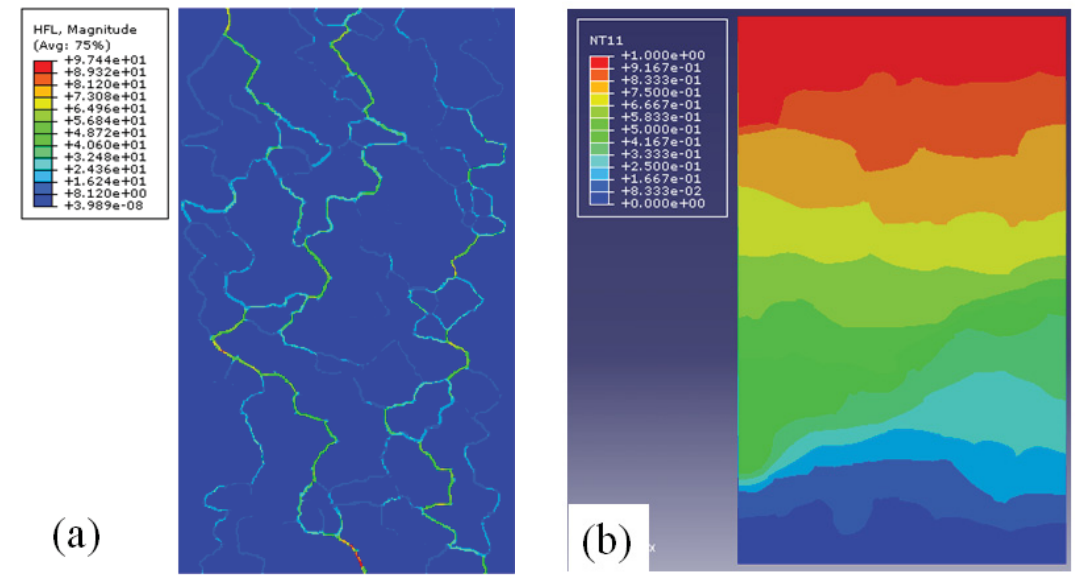

Figure 35. Simulation of $G B$ diffusion for $D_{G B}^{2} / D_{G B}^{1}=10^{5}$ (a) mass flux and (b) normalized concentration.

\section{Publications}

- Rudman, K., P. Peralta, C. Stanek, K. Wheeler, M. Parra, D. Byler, and K. McClellan (2010), "Quantification of Microstructure Variability in Surrogates for Oxide Nuclear Fuels," TMS Annual Meeting, Seattle, WA.

- Nerikar, P. V., K. Rudman, T. G. Desai, D. Byler, C. Unal, K. J. McClellan, S. R. Phillpot, S. B. Sinnott, P. Peralta, B. P. Uberuaga, and C. R. Stanek (2010), "Grain Boundaries in $\mathrm{UO}_{2}$ : Scanning Electron Microscopy Experiments and Atomistic Simulations," Paper accepted for publication in the Journal of the American Ceramic Society.

\section{References}

1. Vonlanthen, P., and B. Grobety (2008), Ceramics International, 34: p. 1459-1472.

2. Randle, V. (2002), Interface Science, 10(4): p. 271-277.

3. Shewmon, P. (1989), Diffusion in Solids, Warrandale, PA: TMS.

4. Chen, Y. and C. A. Schuh (2006), Acta Materialia, 54: p. 4709-4720.

\subsection{Thermal Transport}

A. Nelson, atnelson@lanl.gov, LANL

Progress at LANL in the area of thermophysical property measurement during FY 2010 was principally made in the area of capability development. Procurement and installation of a Netzsch LFA 427 equipment suite for measurement of thermal diffusivity from room temperature to $2000^{\circ} \mathrm{C}$ was completed. In conjunction, authorization for handling and analysis of DU-containing powders and pellets using this technique allowed for initial measurements of the thermal conductivity of baseline uranium. While the resultant data sets do not represent significance to the community themselves, availability of this capability is a critical and previously unavailable component of the ceramic fuels program. This 
capacity will allow for measurement of thermal conductivity of fuel forms and materials of interest as a function of process and fabrication variables as well as more chemistry or structure parameters.

In addition to the first thermal diffusivity measurements performed on standard dense urania pellets, a novel study was initiated to understand the role of fabrication variables on the early stages of urania sintering. Careful control of instrument and furnace parameters allowed for development of in situ techniques for measurement of the thermal diffusivity during pellet sintering. This approach allows for exploration of the effects that variables such as powder structure, chemistry, atmosphere oxygen partial pressure, or heating ramp rates will have on early stages of sintering. Figure 36 shows an example of data obtained through this technique. A green urania pellet is pressed without pressing aids and placed on a sample holder that can accommodate the anticipated shrinkage. During sintering, flash diffusivity measurements are taken at $50^{\circ} \mathrm{C}$ intervals through a final temperature of $1600^{\circ} \mathrm{C}$. The same measurement can then be performed upon return to room temperature to record the behavior of the sintered material.

The result of this technique is a plot illustrating the densification of the pellet through thermal transport rather than the more familiar dimensional shrinkage. As early stage sintering begins, surface diffusion and evaporation/condensation redistributes material to lower energy positions such that particle necking initiates. Capturing and understanding this critical point in the early stages of sintering is vital to development of sintering kinetics models. Furthermore, this phenomena precedes bulk densification and associated dimensional contraction as is measured by conventional dilatometry.

This technique was presented at the Nuclear Materials 2010 conference in Karlsruhe, Germany to an international community of fuels researchers. Having demonstrated the requisite conditions and current limitations, the next step will be adapting in situ sintering diffusivity measurement techniques to study materials and variables of specific interest. Initially this will consist of pure urania sintered in a variety of controlled atmospheres to evaluate the impact of $\mathrm{O} / \mathrm{M}$ on sintering rate. It is well understood that hyperstoichiometry has a positive impact on sintering. However, in situ diffusivity measurement of pellets sintered in different atmospheres of varying oxygen activity (and therefore different $\mathrm{O} / \mathrm{M}$ ) will provide a clear understanding of the early stages of sintering necessary for further development of advanced models.

Along with these advanced studies, standard evaluation of thermophysical properties of fuels and fuel surrogates will continue. The installation and availability of the high temperature LFA will facilitate study of the thermal conductivity of both urania and (U,Ce ) $\mathrm{O}_{2}$ acting as a MOX surrogate. Surrogate MOX studies to $2000^{\circ} \mathrm{C}$ represent meaningful baseline data required for reactor design needs. The second and complimentary portion of urania studies will focus on evaluation of separate parameters necessary for qualification of ongoing modeling efforts. For example, the role of grain size can be varied to develop a comprehensive map of its impact on thermal transport. $\mathrm{O} / \mathrm{M}$ can be varied in a comparable manner. 


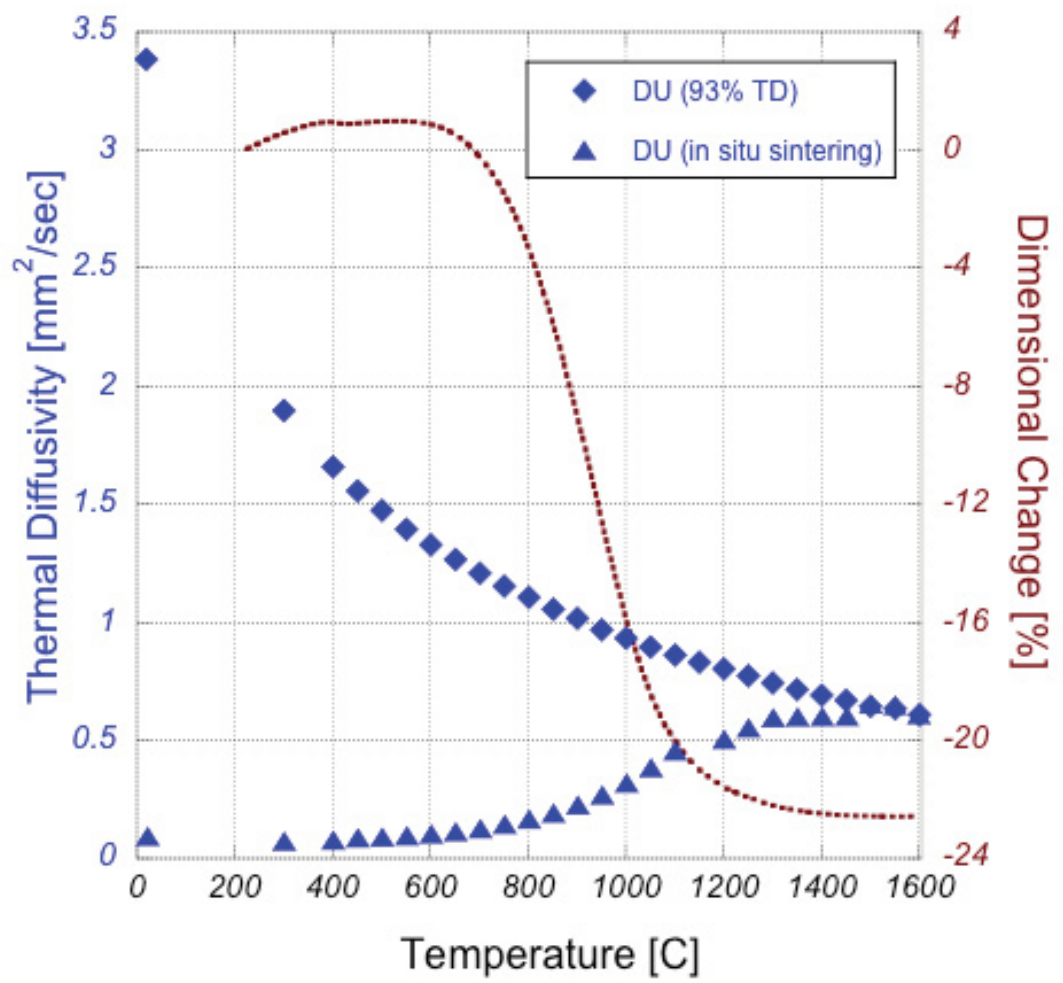

Figure 36. In situ sintering data obtained for a pure urania pellet sintered at $2.5 \mathrm{C} / \mathrm{min}$ in a vacuum. The pellet was pressed to obtain slightly under $40 \%$ theoretical density. The blue triangles show data obtained during sintering and the diamonds are data recorded during cooling. The right-hand scale shows dilatometry shrinkage results for an identical material and heating rate.

\subsection{Melt Point Determination System Development}

D. Byler, dbyler@lanl.gov, LANL

Ceramic nuclear fuels are complex high melting oxides that may incorporate one or more fissile materials to meet design requirements for proper performance. Design of these nuclear fuels requires models and data that are precise enough to do safety calculations and adequately design for the duration of use and operating temperatures. The materials used in these fuels are very complex with variable oxidative states and constituents that have been shown to affect the processing, properties and performance of the fuels, in particular the melting point of the materials. In pure $\mathrm{UO}_{2+x}$, the melt point has been shown to vary by as much as $750^{\circ} \mathrm{C}$ from materials that are stoichiometric to materials with an oxygen-to-metal $(\mathrm{O} / \mathrm{M})$ ratio of $2.20: 1{ }^{1}$ With these large melt point variations from relatively small changes, data sets accounting for $\mathrm{O} / \mathrm{M}$ variations, materials constituents, and irradiation effects are critical to inform modelers and designers.

For FY 2010, the goal of the research was to select, build and test a design for a desktop melt point determination system that could then be used as a prototype for the development of a system that could be placed in a glovebox or hot cell environment to test fresh or irradiated fuels, respectively. From the development and testing of the prototype, a path forward was proposed to design changes and a possible timeline for implementation for fuel materials. To validate the design, a series of tests was done to calibrate and verify that values recorded coincided with published literature values. 
Evaluation of designs from the early 1960s until present was made to determine what had been effective in determining the melt point of materials with the least error. Surprisingly, designs had not changed substantially from the early work by General Electric in the early 1960s. Several methods have been employed over the years, but bulk melting is generally accepted as being the best because it captures the interaction of the entire material. Most of the bulk measurement techniques utilized an RF heated susceptor to melt the fuel materials. The melt point was determined by the thermal lag in the temperature signal from a high temperature pyrometer. This technique is referred to as the thermal arrest method. Interestingly, values for "simple" $\mathrm{UO}_{2.00}$ varied between $2400^{\circ} \mathrm{C}$ and $2900^{\circ} \mathrm{C}$ with varying levels of error reported. ${ }^{1-10}$ Presumably much of this error was due to $\mathrm{O} / \mathrm{M}$ variations leading to very different melting points.

A design currently employed by the JAEA was chosen as a good candidate for modification to meet design concerns over water in the flux concentrator coil in close proximity to nuclear materials at temperatures near $3000^{\circ} \mathrm{C}{ }^{3}$ To mitigate these concerns, the concentrator coil was removed and replaced by ceramic insulation to control radiant heat from the susceptor. This change in design proved to be a difficult challenge due to heat management issues associated with the extremely high temperatures at which the materials melt. The system was tested using oxide standards up to $\sim 2400^{\circ} \mathrm{C}$ to calibrate the pyrometer to the variations of sapphire windows and turning mirror that was used. The values were consistently $\sim 30^{\circ} \mathrm{C}$ low for the melting point. This provided an offset correction for the system. Due to heat management issues, the insulation package was modified to improve heating efficiency and reduce radiant losses. This modification reduced the power requirements from near $12 \mathrm{~kW}$ to $5.8 \mathrm{~kW}$ to achieve $3000^{\circ} \mathrm{C}$ with an empty crucible.

From these preliminary calibrations, a plan was proposed for the transition of the melt point system to a glovebox and hotcell environment. Further measurements were carried out with the modified design to measure the melt point of $\mathrm{UO}_{2}$ and $\mathrm{U}-\mathrm{Ce}-\mathrm{O}$ pseudo binaries. Figure 37 illustrates the melt point determination for $\mathrm{UO}_{2.00}$ with a melt onset temperature of $2867^{\circ} \mathrm{C}$, which is slightly higher than the accepted value of $2845^{\circ} \mathrm{C}$, although they state an error of $\pm 25^{\circ} \mathrm{C}$ for their measurements, corresponding quite well with the measured value.

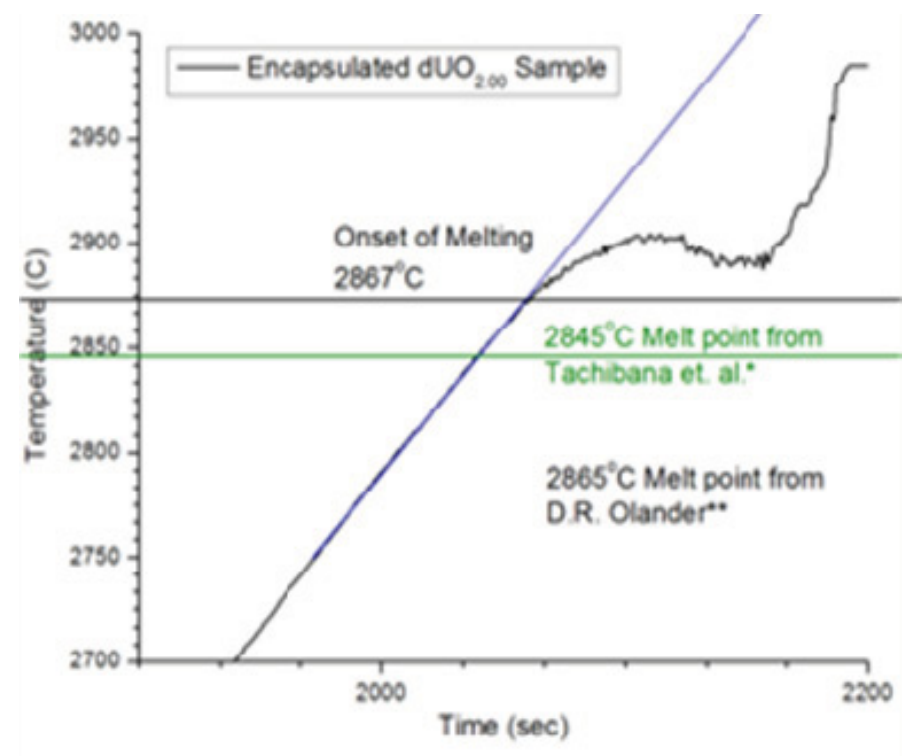

Figure 37. Melt point determination of $\mathrm{UO}_{2.00}$ with onset at $2867^{\circ} \mathrm{C}$. 
To summarize the achievements, a melt point determination system was built, calibrated and tested using $\mathrm{UO}_{2.00}$ and successfully measured the melting point onset. A plan was proposed for transitioning the design to a glovebox and hotcell environment with the caveats regarding excess heat management from the modified design. Refinements to the system remain to be made to improve reproducibility and ease of use.

\section{References}

1. Bates, J. L. (1970), J. Nucl. Mater. 36, 195-210.

2. Latta, R. E., and R. E. Fryxell (1970), J. Nucl. Mater. 35, 195-210.

3. Komatsu, J., T. Tachibana, and K. Konashi (1988), J. Nucl. Mater. 154, 38-44.

4. Christensen, J. A. (1962), United States Report, HW-69234.

5. Christensen, J. A. (1964), Tans. Amer. Nucl. Soc. 7, 390.

6. Kono, K., and T. Hirosana, J. Nucl. Sci. Tech. 36, No.7, 596-604.

7. Riley, B. (1964), J. Sci. Instrum. 41, 504-507.

8. Reed, T. B., R. E. Foley, and A. J. Strauss (1972), J. Cryst Growth 15, Iss.3, 174-178.

9. Kato, M., K. Morimoto, and H. Sugata (2008), J. of Alloys and Comp. 452, Iss. 1, 48-53.

10. Kato, M., K. Morimoto, H. Sugata, K. Konashi, and M. Kashimura (2008), J. Nucl. Mater. 373 , Iss. 1-3, 237-245.

\subsection{Oxide Thermochemical Modeling}

T. Besmann, besmanntm@ornl.gov ORNL

The thermochemical behavior of oxide nuclear fuel and targets under irradiation is dependent on the $\mathrm{O} / \mathrm{M}$ ratio. When fuel is irradiated, fission fragments and free oxygen are created resulting in an average increase in $\mathrm{O} / \mathrm{M}$ with fuel burnup. Some of the fission products form species that will migrate to and react with the cladding surface in a phenomenon known as FCCI. ${ }^{1,2}$ Cladding corrosion is life-limiting, so it is desirable to understand influencing factors, such as oxide thermochemistry, which can be used to guide the design and fabrication of higher burn up fuel.

A phased oxide fuel thermochemical model development effort is underway within the AFC. First, models of binary oxide systems, such as $\mathrm{U}-\mathrm{O}, \mathrm{Pu}-\mathrm{O}, \mathrm{Am}-\mathrm{O}$, etc., are developed. Next, the binary systems will be combined to form pseudobinary systems such as U-Pu-O. The model development effort requires the use of data to allow optimization based on known thermochemical parameters as a function of composition and temperature. Available data are mined from the literature and supplemented by experimental work as needed. 


\section{Thermochemical Modeling of $\mathrm{AmO}_{2-x}$}

An effort to model the $\mathrm{AmO}_{2-\mathrm{x}}$ phase was undertaken to provide basic information for use in the thermochemical and phase equilibrium modeling of transuranic fuels and targets. A thermochemical representation of the fluorite structure $\mathrm{AmO}_{2-\mathrm{x}}$ phase was developed using the compound energy formalism (CEF) approach. ${ }^{3}$ The Gibbs free energies for the constituents and a set of interaction parameters were determined using reported oxygen potential-temperature-composition data. A good fit to the experimental information was obtained which well-reproduces the behavior as shown in Figure 38. Details of this work are published in the Journal of Nuclear Materials. ${ }^{4}$

\section{Thermochemical Modeling of U-Ce-U,}

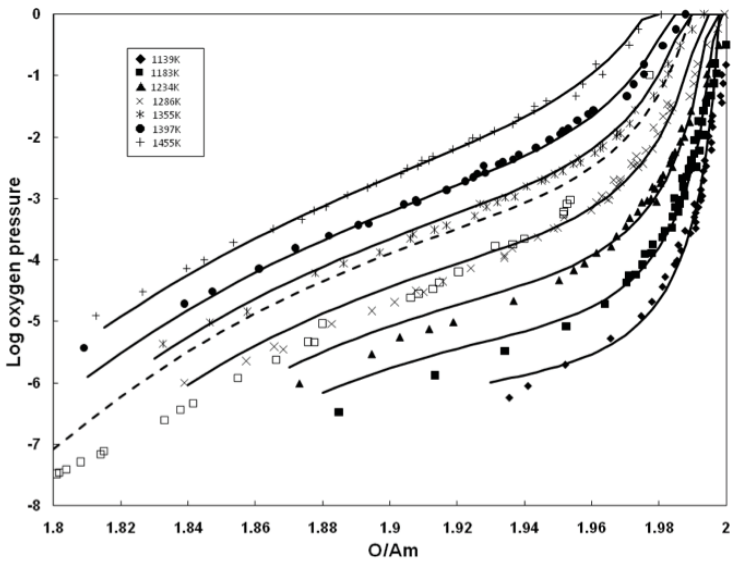

Figure 38. Plot of experimental and computed log of oxygen pressure versus O:Am.

Due to the difficulty of performing fuel fabrication development with actinide materials, fundamental studies with uranium are performed using surrogate materials as stand-ins for transuranic elements. In most cases, cerium can be used as a suitable substitute for plutonium when performing $\mathrm{O} / \mathrm{M}$ and sintering kinetics studies because of identical valence states. Cerium is also a major fission product element, and thus understanding its behavior in fuel is an important issue as well.

The successful representation of the U-O and $\mathrm{Ce}-\mathrm{O}$ systems, by Gueneau, et al. ${ }^{5}$ and Zinkevich, et al., ${ }^{6}$ respectively, has been extended using the CEF approach to modeling the thermochemical behavior of $\mathrm{UCeO}_{2-\mathrm{x}}$. The initial attempts to establish the coefficients and site fractions that lead to minimization of the Gibbs free energy were unsuccessful when considering the complete set of available data. As a result, an assessment was performed which would allow the grouping of data that was self-consistent. ${ }^{7,8,9}$ These data were used to perform an initial optimization of the CEF model, which reproduced the behavior with reasonable accuracy, as seen in Figure 39, however the paucity of experimental data prevented a more precise fit to

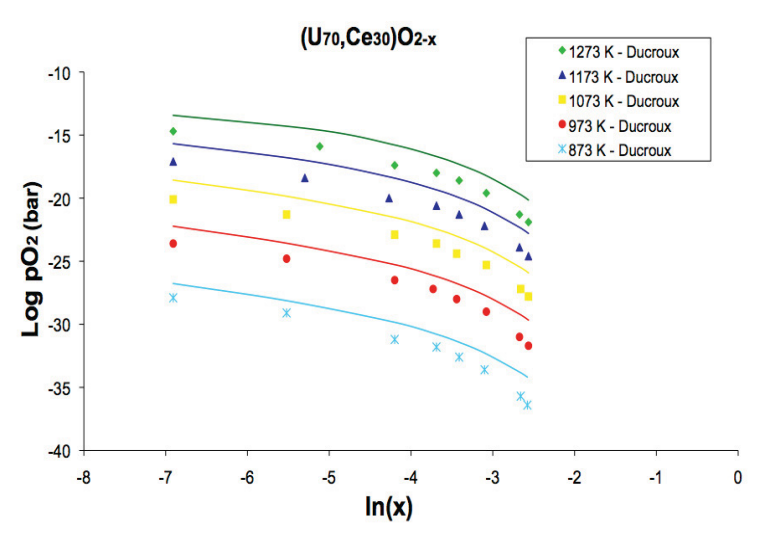

Figure 39. Plot of experimental and computed log of oxygen pressure versus $\mathrm{O}: \mathrm{U}+\mathrm{Ce}$ the data. Future work should include a more critical assessment of the literature data along with a new effort to generate experimental data to support model development and to provide a better description of the evolution of the miscibility gap as a function of composition and temperature.

\section{References}

1. Kleykamp, H. (1985), J. Nucl. Mater. 131, p. 221

2. Adamson, M. G., et al. (1985), J. Nuc. Mater. 130, p. 375-392

3. Hillert, M. (2001), J. Alloys Compd. 320, p. 161-176 
4. Besmann, T. (2010), J. Nucl. Mater. 402, p. 25

5. Gueneau, C., et al. (2002), J. Nucl. Mater. 304, p. 161

6. Zinkevich, M., et al. (2006), Solid State Ionics 177, p. 989-1001

7. Markin, T. L., and E. Crouch (1970), J. Inorg. Nucl. Chem. 32, p. 77-82

8. Norris, D., and P. Kay (1983), J. Nucl. Mater. 116, p. 184-194

9. Ducroux, R., and P. Baptiste (1981), J. Nucl. Mater. 97, p. 333-336

\subsection{Innovative Fuel Concept: BNL Fuel Design \& Analysis - The Vented Fuel Pellet/Getter Concept for High Burnup Fuel}

M. Todosow, todosowm@bnl.gov, J. Valente, BNL

Brookhaven National Laboratory (BNL) submitted three white papers in response to the call by the AFC for Innovative Transmutation Fuels Concepts. One concept, The Vented Fuel Pellet/Getter Concept for High Burnup Fuel, was selected for "full funding" following review by a panel from the AFC, DOE-NE, and independent experts. The concept is to extend the burnup of nuclear fuel by enhancing the release, transport and sequestering of fission product gases from the fuel pellet to a plenum region in the fuel rod (see Figure 40). The initial direction provided by the AFC National Technical Director and the review committee was to focus on the getter aspect of the proposal. Therefore the project is currently focused on developing:

- A getter material that preferentially captures and retains fission product gasses (FPG) under operating, transient and accident conditions to lower the gas internal pressure on the clad barrier and remove some highly absorbing FPG from the active core region to improve the burnup reactivity swing. If this objective can be achieved, the internal gas pressure in the fuel rod will also be reduced thereby enhancing clad integrity.

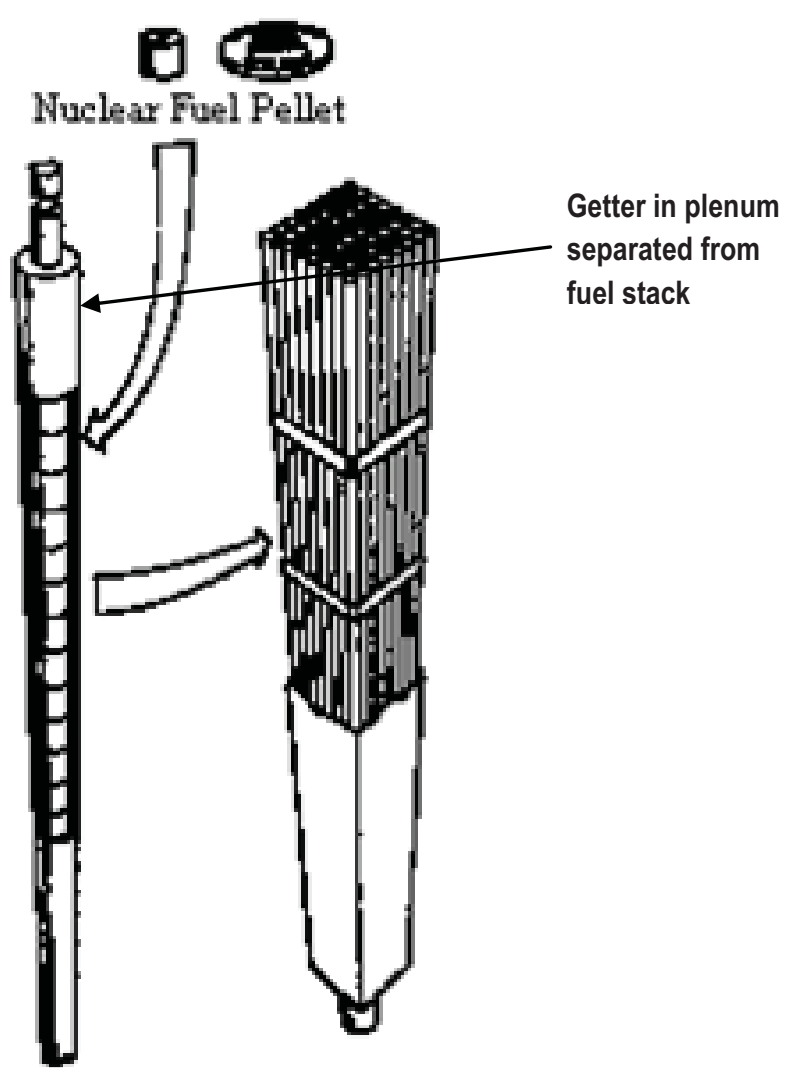

Figure 40. Transport and sequestering of fission product gases from the fuel pellet to a plenum region in the fuel rod

- A "communication plate (CP)" between the fuel and plenum region that effectively acts as a one-way diode which: 1) preferentially enhances the diffusion of FPG released from the fuel into the plenum while limiting the diffusion of helium (which is in the pellet-clad gap to enhance thermal conductivity) out of the gap; and 2) prevents the FPG from diffusing back into the active fuel region. 
- Compatible mechanical design and materials for both the getter and CP to interface with light-water reactor (LWR) and fast-spectrum reactor (FSR) fuel rod designs for oxide fuels. Utilization with liquid metal-bonded metallic fuels will be more challenging.

In addition, work was initiated on a White Paper to provide input to the AFC on research, development, and demonstration (RD\&D) issues and requirements addressing thorium-based fuel options. 


\title{
5 COATED PARTIGLE FUELS TECHNOLOGIES
}

Technical Lead, L. L. Snead, sneadll@ornl.gov, ORNL

The Coated Particle Fuels Technologies program has made significant recent progress in the three key areas of research: fundamental modeling coupled to experimental validation, TRU fuel fabrication facility development with parallel fabrication of surrogate fuels, and development of the new fully ceramic microencapsulated fuels. As briefly summarized in this section the program is on schedule (and budget) to install TRU kernel and TRU coating capabilities allowing fabrication and irradiation of TRU bearing fuels in 2012. Also in this program modeling and kernel development has been applied to the fabrication of a specifically engineered "deep burn" kernel which includes SiC getters to extend fuel life. Recently, research carried out under the coated particle fuels program has led to the patent submission for a new fully ceramic microencapsulated fuel designed to be the first microencapsulated fuel capable of irradiation in light water reactors. Highlights of this fuel form are included in this section along with supporting modeling and experimental efforts to address such high burn-up (Deep Burn) issues as mitigation of silver migration, palladium attack, and a fundamental understanding of the evolving kernel thermochemistry.

\subsection{Deep Burn Simultaneous Thermal Analyzer Update}

\author{
S. L. Voit, voitsl@ornl.gov, ORNL
}

A Netzsch simultaneous thermal analyzer (STA) and mass spectrometer (MS) procured to support the Deep Burn Program was received at ORNL on September 24, 2010. A schematic of the STA, MS and associated equipment is shown in Figure 41.

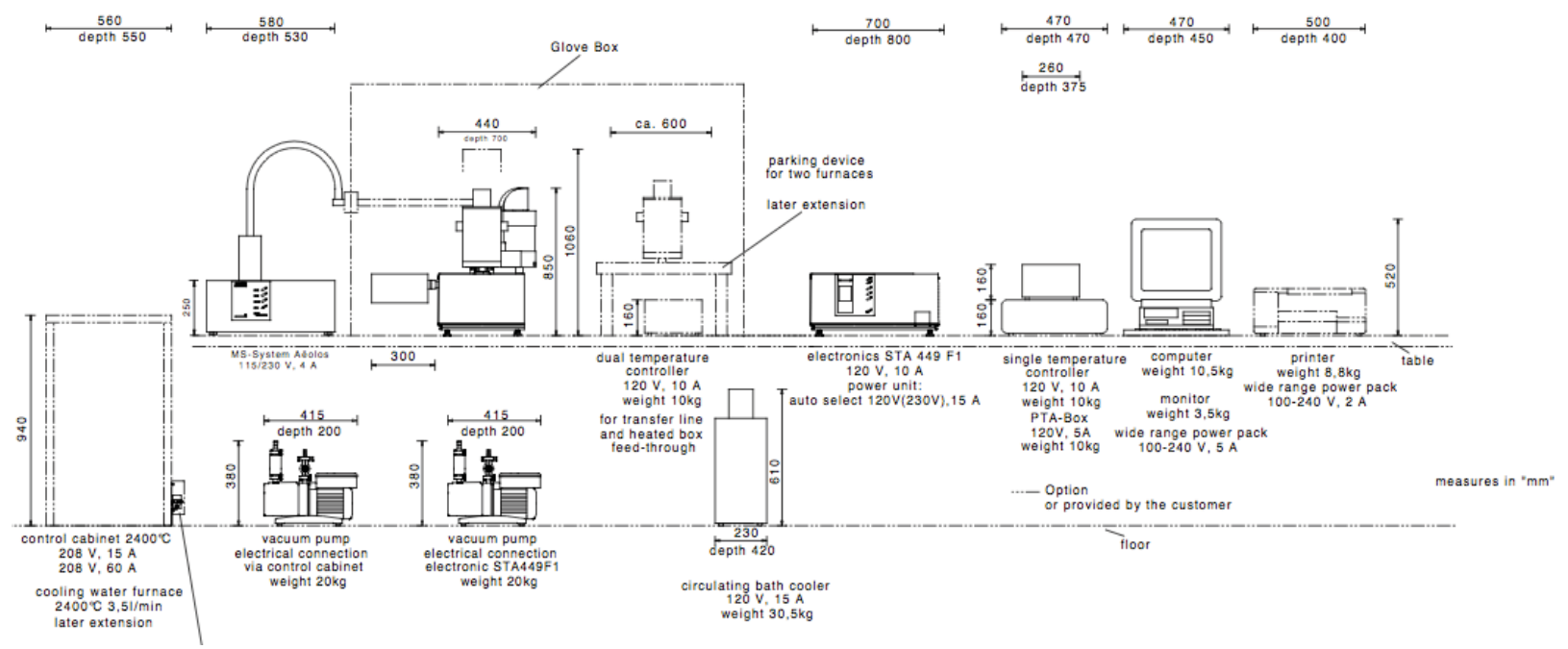

Figure 41. STA, MS and accessories.

After receipt of the STA, a kick-off meeting was held with a team from the ORNL facilities engineering services to discuss technical requirements for installation of the STA in a glovebox in building 3525. The STA glovebox will be a controlled atmosphere system designed for processing actinide-bearing samples. A conceptual glovebox design has been generated and design requirements have been identified. During the period in which the glovebox system is being designed and built, the STA will be setup and tested in building 4515 , after which measurements will begin with uranium- 
bearing compounds. In early FY 2011, electrical and water cooling systems will set up in the building 4515 lab space and Netzsch personnel will be brought in to guide installation.

\subsection{Deep Burn Datahase Development}

T. M. Besmann, besmanntm@ornl.gov, ORNL

An improved thermochemical database was developed and exercised to generate phase compositions and oxygen potentials as a function of burn-up for model Deep Burn fuel. The results were compared to experimental information in the literature, providing evidence for additional oxidation processes that may be occurring. The database was used to generate pressures in fuel particles to demonstrate the effect of gettering on both overpressure and CO pressure that drives kernel migration (see Figure 42). Density functional theory (DFT) calculations of the diffusion of $\mathrm{Pd}$ in $\mathrm{PuO}_{2}$, focusing on $\mathrm{Pd}$ 's movement on the oxygen sublattice using a large supercell, predicted an energy barrier of around $180 \mathrm{meV}$ for diffusion associated with two oxygen vacancies providing a mechanistic framework for determining transport. Work has been completed on studying the interaction of Pd with the surface of SiC. The highlights include finding reaction mechanisms with low energy barriers for the removal of $\mathrm{C}(0.04 \mathrm{eV})$ and $\mathrm{Si}$ $(1.52 \mathrm{eV})$ from $\mathrm{SiC}$. The energy barrier for Si removal is the rate limiting step. 3-D KMC (TETTRIS) modeling of Cs transport through tristructural isotropic (TRISO) particle layers was performed and the results compared with a German experimental database. Qualitative agreement is very good and diffusion coefficients related to transport along cracks and grain boundaries were benchmarked.

$\mathrm{Ab}$ initio studies of $\mathrm{Cs}$ and $\mathrm{Ag}$ diffusion in $\mathrm{ZrC}$ are largely completed with calculation of barriers to potential cooperative hopping mechanisms for $\mathrm{Ag}_{\mathrm{Zr}}-1 \mathrm{Va}_{\mathrm{Zr}}$ and $\mathrm{Ag}_{\mathrm{C}}-1 \mathrm{Va}_{\mathrm{C}}$ defect clusters. The influence of both individual vacancies and small voids on the thermal conductivity of $\mathrm{SiC}$ was calculated using the Green-Kubo molecular dynamics (MD) method. The MD results were compared with those obtained from the standard Klemens continuum model and experimental data. MD predictions for the thermal conductivity of $\mathrm{SiC}$ containing voids with a radius of $2.86 \AA$ are in good agreement with experimental data. The aggregate of this understanding are means for mitigating/validation kernel migration and particle overpressure, determination of pathways and rates of fission product transport, potential for controlling palladium $(\mathrm{Pd})$ attack of $\mathrm{SiC}$, and understanding the complex relationships that govern thermal transport in a radiation environment, all of which will allow for understanding and thus improvements in fuel performance. 


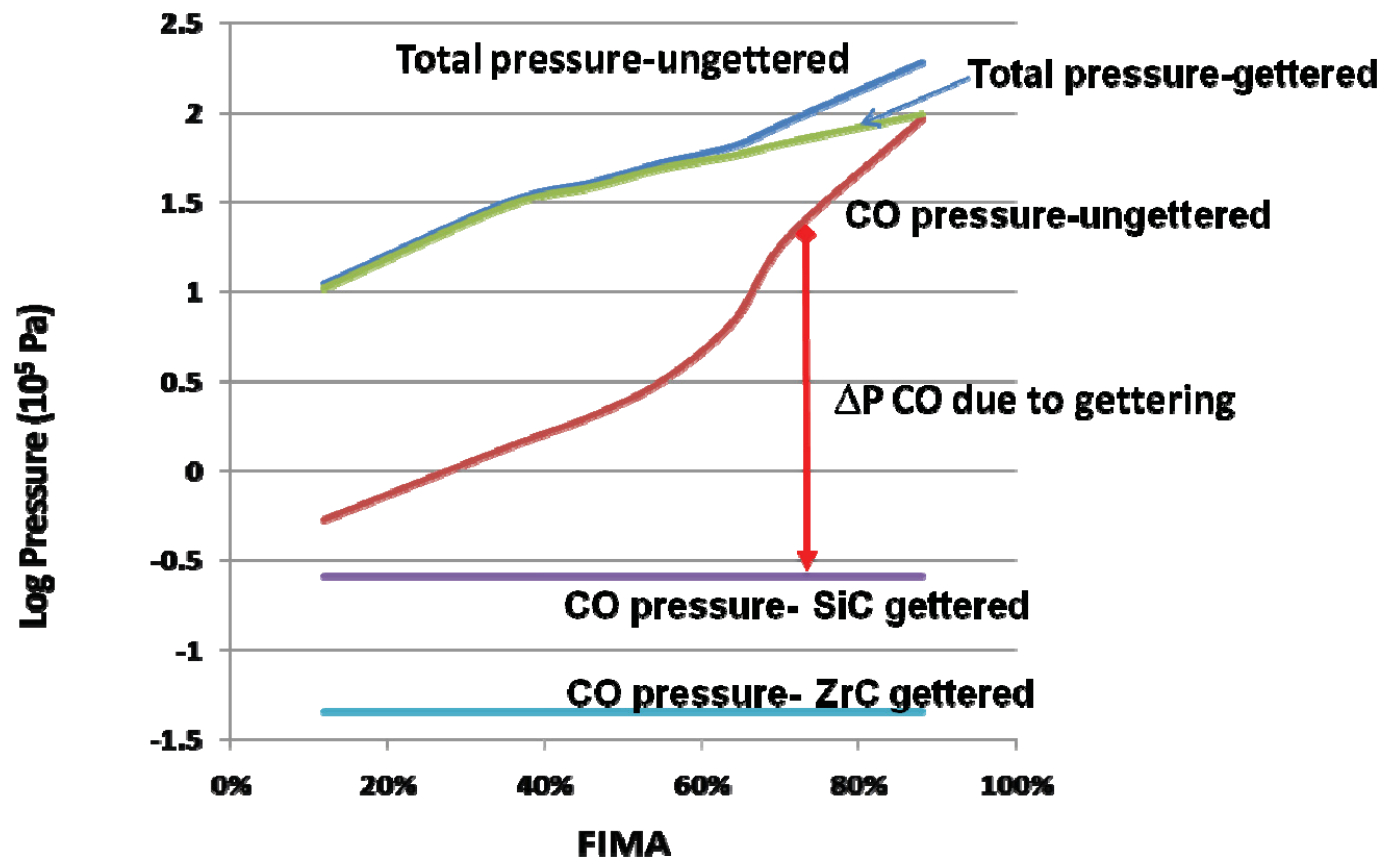

Figure 42. Thermochemical calculations of CO pressure determined to be substantially reduced by $\mathrm{SiC/ZrC} \mathrm{getter} \mathrm{mitigating} \mathrm{kernel} \mathrm{migration} \mathrm{and} \mathrm{overpressure.}$

\subsection{TRU Kernel Development}

R. Hunt, huntrd@ornl.gov, ORNL

The coated particle fuel effort of the AFC has been developing the internal gelation process to make TRISO-coated TRU fuel particles. This TRU fuel would then be used in a high-temperature gas-cooled reactor until a high burnup is achieved. Under this scenario, the internal pressure for each particle could easily exceed $5.07 \times 10^{7} \mathrm{~Pa}$ at $1400 \mathrm{~K}$. Therefore, it has been proposed to use $\mathrm{SiC}$ as an oxygen getter and a potential sequestering agent for palladium, rhodium, and ruthenium. Based on thermodynamic modeling, the maximum $\mathrm{SiC}$ requirement for gettering (initial plutonium reduction and reactions during fission) and sequestering is $0.57 \mathrm{~mol}$ of $\mathrm{SiC}$ per mole of initial plutonium. When $\mathrm{Zr}-\mathrm{Y}$ is used as a surrogate for the TRUs, this level of $\mathrm{SiC}$ powder has been successfully added to gel spheres that were prepared using the internal gelation process. If the $\mathrm{SiC}$ powder is added to the HMTA/urea solution and adequately dispersed using an ultrasonic probe, then strong $\mathrm{Zr}-\mathrm{Y}$ kernels loaded with $\mathrm{SiC}$ as shown in Figure 43 can be prepared without the use of a dispersing agent.

Since $\mathrm{SiC}$ powder could be adequately dispersed in $\mathrm{Zr}-\mathrm{Y}$ kernels, preparations are underway to incorporate $\mathrm{SiC}$ powder into $\mathrm{Pu}$ microspheres and $90 \% \mathrm{Pu} / 10 \% \mathrm{~Np}$ microspheres. If these TRU kernels with $\mathrm{SiC}$ can be fabricated successfully, then small fractions of Am and $\mathrm{Cm}(<10 \%)$ may also be added to $\mathrm{Pu}$ microspheres. 


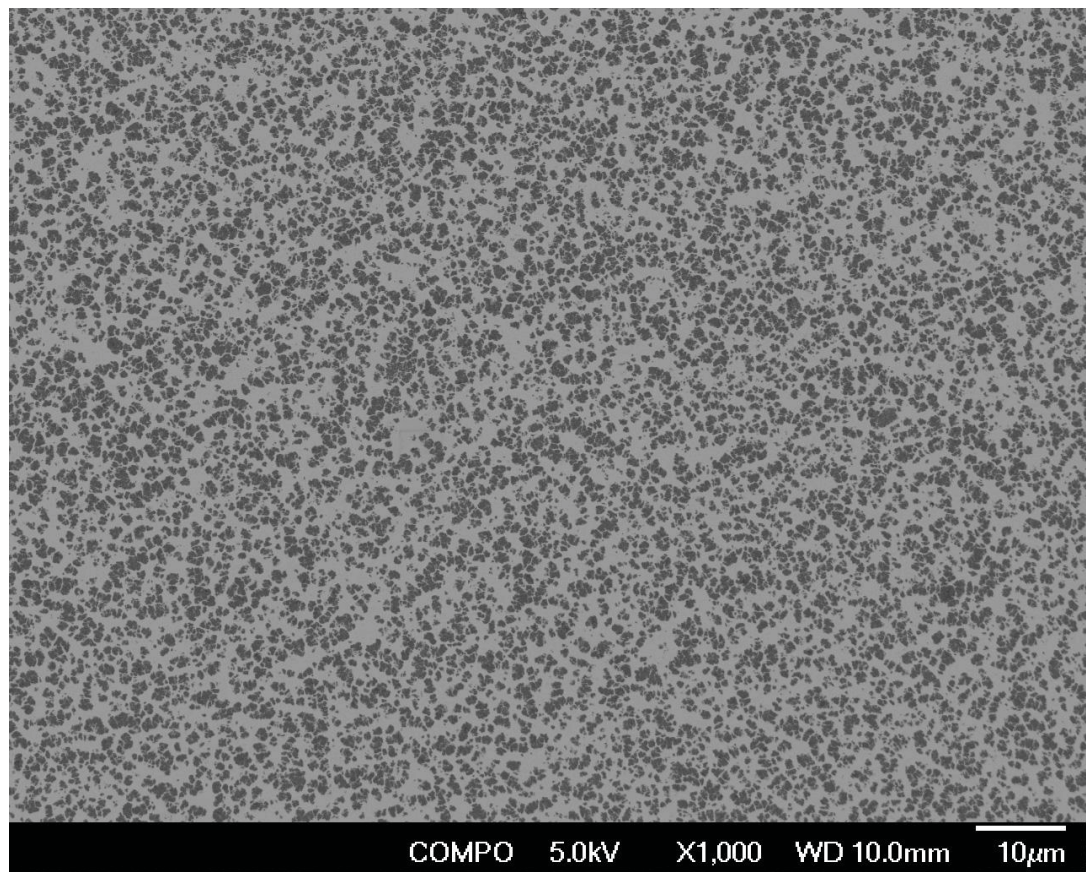

Figure 43. Backscattered electron image of a polished cross section of a Zr-Y-SiC kernel.

\section{Publications}

- Hunt, R. D., F. C. Montgomery, and J. L. Collins. "Treatment Techniques to Prevent Cracking of Amorphous Microspheres Made by the Internal Gelation Process." Journal of Nuclear Materials, 405: 160-164.

- de Almeida, V. F., R. D. Hunt, and J. L. Collins. "Pneumatic Drop-on-Demand for Production of Metal Oxide Microspheres by Internal Gelation." Journal of Nuclear Materials, 404: 44-49.

- Hunt, R. D., J. D. Hunn, J. F. Birdwell, T. B. Lindemer, and J. L. Collins. "The Addition of Silicon Carbide to Surrogate Nuclear Fuel Kernels Made by the Internal Gelation Process." Journal of Nuclear Materials, 401: 55-59.

\subsubsection{TRU Kernel Production Facility}

R. Hunt, huntrd@ornl.gov, ORNL

The AFC is developing the internal gelation process to fabricate TRU fuel kernels that will subsequently be coated with carbon and $\mathrm{SiC}$ to produce TRISO fuel particles. The internal gelation process converts an acidic TRU solution into gel spheres, which are aged, washed, and sintered into fuel kernels. In FY 2010, installation of an internal gelation system in a new glovebox in Lab 109 of Bldg. 7920 at the Radiochemical Engineering Development Center (REDC) was completed. Support equipment was installed in the adjoining glovebox. Each of the unit operations up to sintering was tested and demonstration runs were completed successfully with and without including $\mathrm{SiC}$ particles in the asproduced kernels. Figure 44 is a photograph of the $\mathrm{Zr}-\mathrm{Y}$ gel spheres (containing SiC particles) flowing in the gelation column during the last demonstration run in September. In addition to this work, considerable effort was applied to revising the REDC Bldg. 7920 Safety Basis Documentation needed to secure operational approval to fabricate TRU kernels using the glovebox kernel fabrication system; fabrication of $(\mathrm{Pu}, \mathrm{Np})$ oxide kernels is planned to begin in 2QFY 2011. The Safety Basis Supplement for "Actinide- 
Bearing Ceramics R\&D at Building 7920" and the associated Technical Safety Requirements (TSR) revisions were submitted to the DOE-Oak Ridge Operations Office in May and approval was received in September. Preparation of other required safety documentation such as research safety summaries and procedures is underway to support implementation of the revised TSR scheduled to begin in 1QFY 2011. Completion of the readiness review and authorization for operation with actinides is expected in early 2QFY 2011.

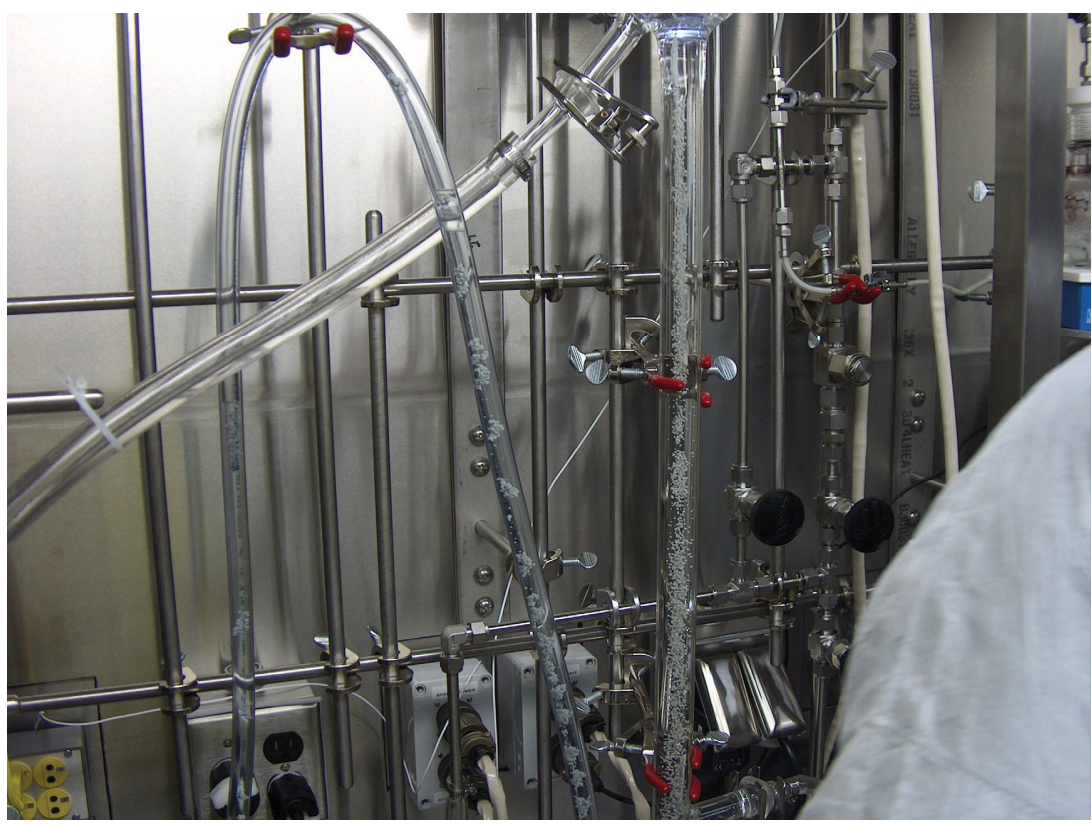

Figure 44. Photograph of the Zr-Y gel spheres containing SiC particles in the gelation column and associated tubing.

\subsection{Deep Burn TRU Particle Coating Laboratory}

J. Miller, millerjh2@ornl.gov, ORNL

Work in FY 2010 related to Deep Burn particle coating was focused on design, planning, and procurement for the TRU particle coating laboratory to be housed on the second floor of the Irradiated Fuels Examination Laboratory (Bldg. 3525) at ORNL. A schematic layout of the coating laboratory is provided in Figure 45. The Deep Burn TRU Particle Coating Laboratory will contain a dedicated custom glove box, which houses the coating furnace, and two standard glove boxes for sample preparation and particle classification. A fume hood is also planned for component cleaning and chemical handling. In addition, the design allows room to expand the capabilities of the lab in the future to include particle compacting.

A schematic of the custom coating glove box is shown in Figure 46. The coating glove box will provide access to the coating furnace from two sides with glove ports at three levels to give adequate access to the furnace for operation and minor maintenance. The ends of the glove box are removable to allow hands-on access for major repair and maintenance when the TRU kernels are not present. The glove box also has strategically placed bag ports to allow practical access to the top and bottom of the furnace. The coating furnace itself will be identical to the existing uranium particle coater used to fabricate the AGR-1 TRISO recently shown to have demonstrated excellent in-pile performance. 


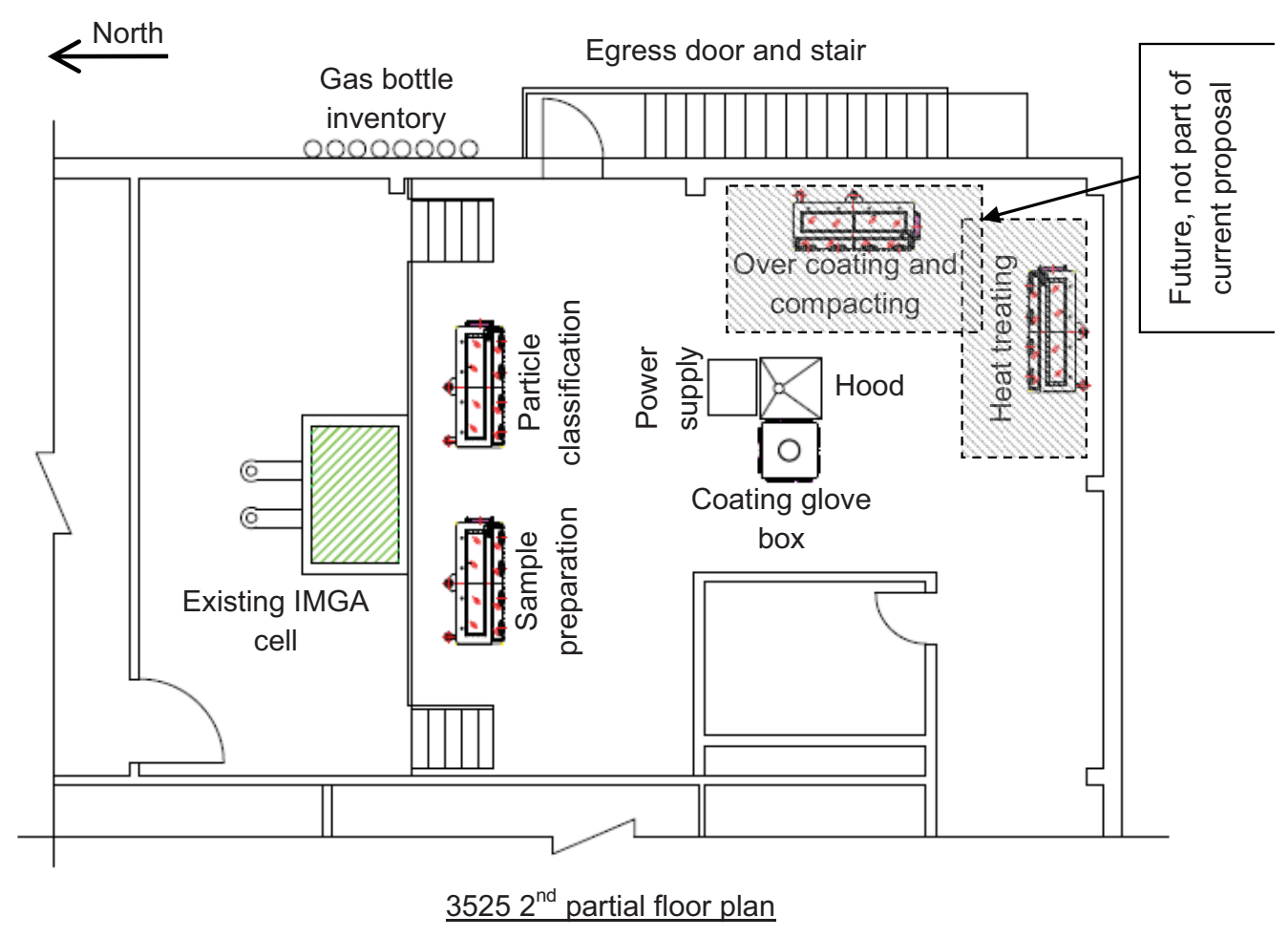

Figure 45. Conceptual layout of ORNL BIdg. 3525 coating glove box laboratory.

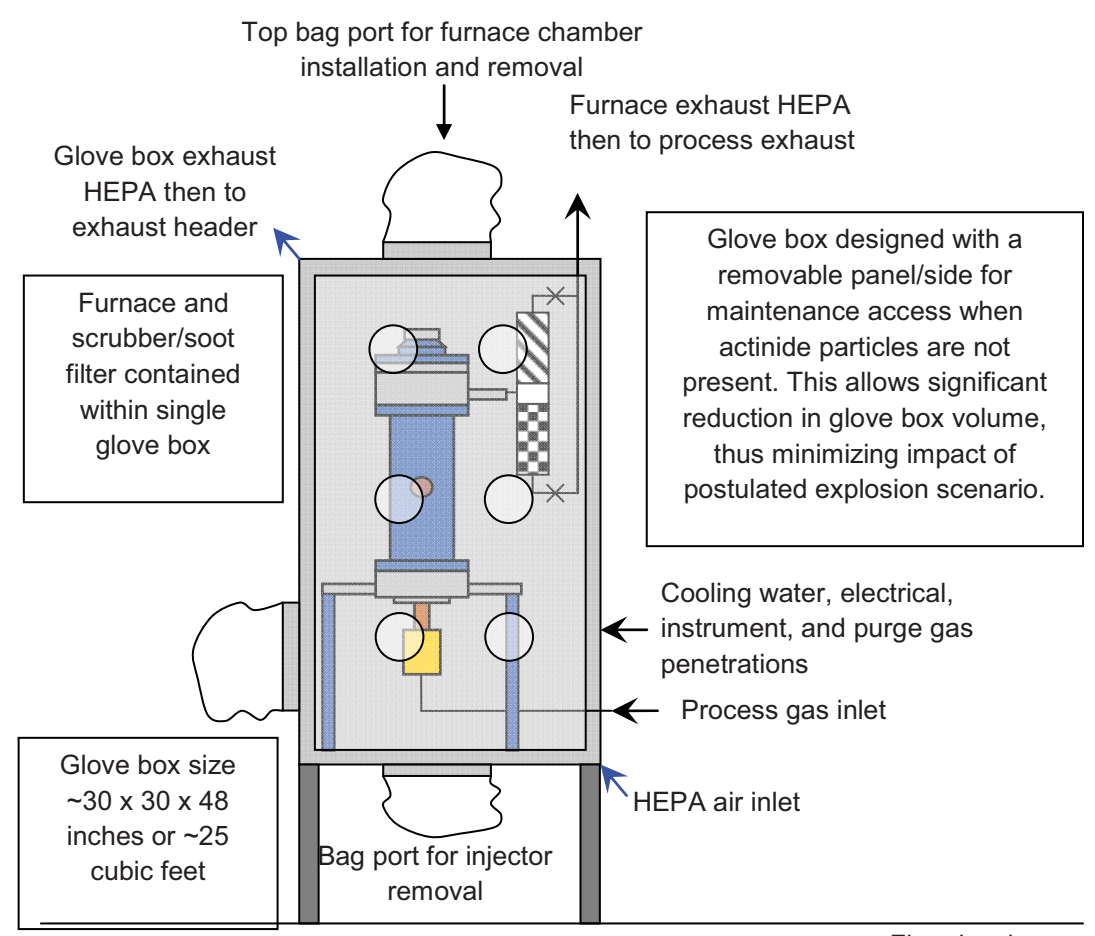

Floor level

Figure 46. Conceptual layout of coating furnace glove box system. 
The majority of the effort in FY 2010 was centered on developing a safe and defendable ventilation plan for the coating furnace/glove box system. The safe containment and ventilation of the flammable species used in the deposition of the TRISO coating layers presents a complex engineering challenge. Many concepts for handling the flammable gases in the safety rated ventilation system of a non-reactor nuclear facility were evaluated. These concepts included a fully inert glove box system, reacting (burning or flaring) the flammable gases in a controlled manner as they exit the furnace, and dilution of the flammable gases below the lower explosive limit with either airflow or inert gas injection. After much evaluation, the ventilation concept selected was dilution of the flammable species below their respective lower explosive limits (LEL) using airflow through the glove box. The concept calls for the air to be drawn through the glove box from bottom to top to provide a sweep of diluent air to remove any flammable gases (primarily hydrogen) thus preventing any accumulation of flammable species in the glove box. The flow rate of the air will be sufficient to dilute the maximum possible flow rate of flammable gases below $25 \%$ of the LEL considering the worst case gas system malfunction. The maximum flow rate of the flammable gases is controlled by engineered flow restricting orifices that limit the maximum flow of each gas before it enters the building.

Following is an outline summary of the features of the Deep Burn TRU Coating Laboratory. The characteristics of each glove box (and hood) are presented in list format.

\section{Coating glove box}

- High air flow for dilution of flammable gases below the lower explosive limit

- Non standard shape, but sized to fit within existing glove box specification

- Houses coating furnace

- $10 \mathrm{~g}$ of Pu bearing kernels

- $\quad 480 \mathrm{~V} 3$ phase for power supply (outside box)

- $220 \mathrm{~V}$ single phase for recirculation/chiller for furnace jacket cooling (outside box)

- Two 120v electrical circuits inside box

\section{$\underline{\text { Hood }}$}

- $\quad$ 4 foot standard sash hood

- General area exhaust system

- Rad materials capable hood

- Houses metheltrichlorosilane precursor

- Houses chlorine gas precursor

- Houses flow meters for all coating gases

- Provide some space for furnace component cleaning prior to coating runs (no Pu kernel materials, only limited contamination from prior coating runs)

- Two 120V electrical circuits 


\section{Sample preparation glove box}

- Standard size and shape, $6 \mathrm{ft}$ long

- Standard low flow negative pressure glove box

- Two $120 \mathrm{~V}$ electrical circuits

- Houses metallographic sample mounting equipment

- Houses metallographic sample grinding and polishing equipment

- Will have limited quantity chemicals acids, bases, solvents, for metallographic etching and cleaning

- The only glove box expected to see much contamination

- Limited quantity of radioactive materials ( $<1$ gram samples)

\section{Particle classification glove box}

- Standard size and shape, $6 \mathrm{ft}$ long

- Standard low flow negative pressure glove box

- Two 120V electrical circuits

- Houses particle sorting equipment - roller micrometer, sieves, balance, particle sampler (these are $120 \mathrm{~V}$ powered devices to sort particles by size and shape)

- $10 \mathrm{~g}$ coating batches of Pu kernels

- Limited quantities of solvent/cleaning chemicals for cleaning equipment (alcohol, Formula 409 , etc.)

\section{Gas inventory outside building}

- Quantities of gases minimized to that needed for one coating run

- Hydrogen, argon, nitrogen, acetylene, propylene, methane

- $\quad$ Space for $\sim 10$ gas bottles

- Gases piped into building

- $120 \mathrm{~V}$ electrical service for heat tracing (if needed)

- Flow limiting orifice in lines

- Back flow preventers

- Interlock valves tied to flammable gas detectors

At the end of FY 2010, the bulk of the work was in the area of detailed design and procurement of TRISO particle coating equipment and facility infrastructure. Detailed facility design issues and specifications being actively worked include booster fan size, model, and capacity, electrical circuit identification and specification, lighting plan, filter and duct sizing and structural support, flange connections, pipe size and routing, instrumentation panel layout and specifications, alarm strategies, 
specification and procurement package preparation for the various components, and engineering controls methodology. Procurement of laboratory infrastructure components is expected to begin shortly as the specification packages are completed and FY 2011 funding permits.

The following bullets summarize the status of the coating furnace and glovebox:

- The coating furnace drawings are complete/approved and out for fabrication with delivery of the first components expected in October 2010

- A purchase order for the standard glove boxes was awarded to Flanders Filters Incorporated with delivery scheduled for February 2011

- The design of the coating furnace glove box is nearing completion. The procurement package preparation is ongoing with submission of the purchase request (request for vender bids) expected in early 2011.

\subsection{Fully Ceramic Fuel for Waste Destruction}

L.L.Snead, sneadll@ornl.gov, ORNL

As part of the Coated Particle Fuel effort of the FCRD AFC a new concept transuranic fuel form was developed and has been submitted for patent by ORNL (see Figure 47). In comparison with commonly compacted high temperature gas cooled reactor fuel, this new fully ceramic fuel compacts the TRISO within a fully dense $\mathrm{SiC}$ matrix. This form of $\mathrm{SiC}$, which was originally developed for the fusion program and has been demonstrated to be thermally and radiation stable, will have the advantage of not shrinking under irradiation (as does graphite). This enables the use of microencapsulated fuels for multiple reactor platforms including light water reactors. Preliminary analysis of commercial LWR's utilizing such fuel suggest that a $20 \%$ core loading can reduce the resulting transuranic waste by more than $60 \%$.

Additionally, being a repository friendly material, the $\mathrm{SiC}$ based fuel would require a minimum of postirradiation processing for permanent disposal or long-term disposition.

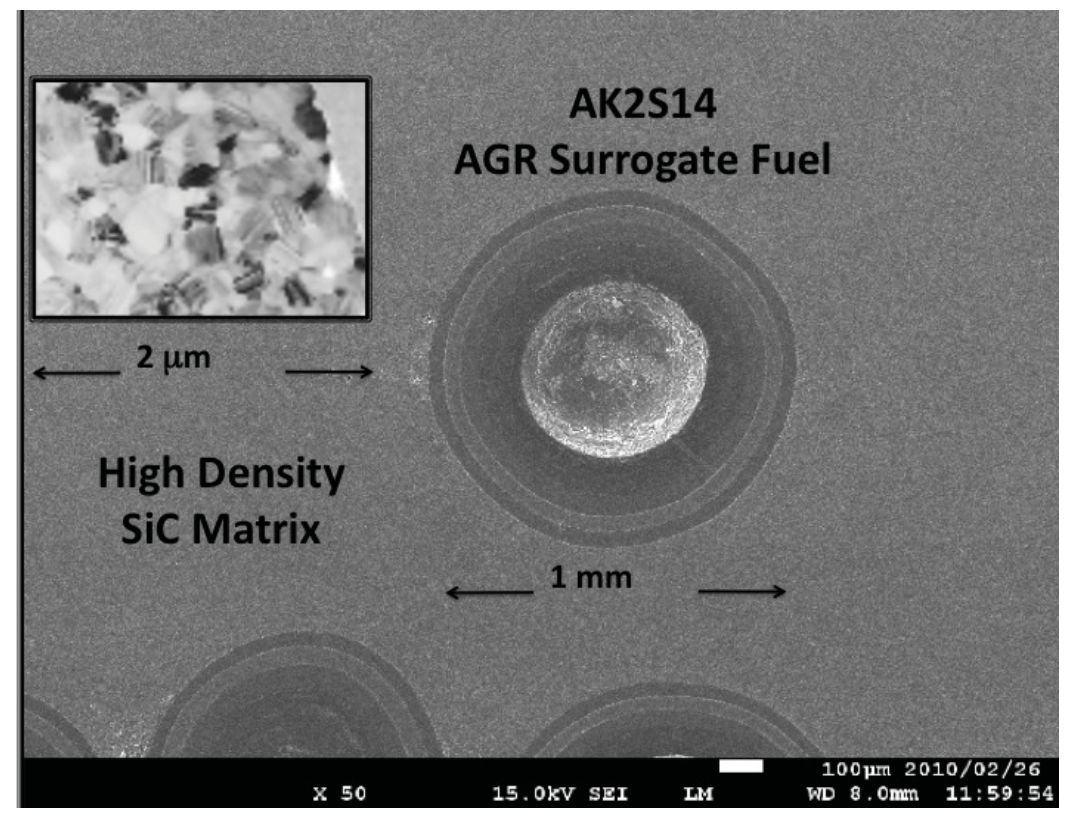

Figure 47. Fully ceramic AGR surrogate fuel. 


\title{
5.6 ZrC Properties Measurement \& Handhook
}

\author{
Y. Katoh, katohy@ornl.gov, ORNL
}

$\mathrm{ZrC}$ is being considered as a potential replacement for the currently employed $\mathrm{SiC}$ as the primary fission product barrier coating in TRISO fuels to take advantage of its properties including high melting point, comparable fission product retention capability and resistance to corrosion by fission product palladium. However little is known about the mechanical properties of $\mathrm{ZrC}$ with varying stoichiometries (compositions) especially at elevated temperatures. The Deep Burn program proposed studying $\mathrm{ZrC}$ as a coating material for TRISO fuel which includes measurement of high temperature mechanical properties of stoichiometric variants of $\mathrm{ZrC}$ culminating with the compilation of historic and newly generated data into a properties handbook to assist in fuel modeling.

In this regard the benchmarking experiments to evaluate the high temperature strength of $\mathrm{ZrC}$ stoichiometric variants have commenced. The setup uses an ultra high vacuum $\left(10^{-6}-10^{-7}\right.$ Torr $)$, high temperature (up to 2073K) furnace coupled to an MTS test frame as shown in Figure 48. A three point bend fixture fabricated from $\mathrm{SiC}$ (see Figure 49) is being used for the experiments to obtain the high temperature mechanical strength data. The test sample is comprised of zone refined $\mathrm{ZrC}$ with five different compositions (C/Zr: $0.84,0.89, .95,1.05$ and 1.2) in the form of $3.00 \mathrm{~mm}$ diameter, $0.25 \mathrm{~mm}$ thick, truncated discs (see Figure 50). The sample microstructure of a test specimen with a C/Zr ratio of 0.95 is shown in Figure 51.

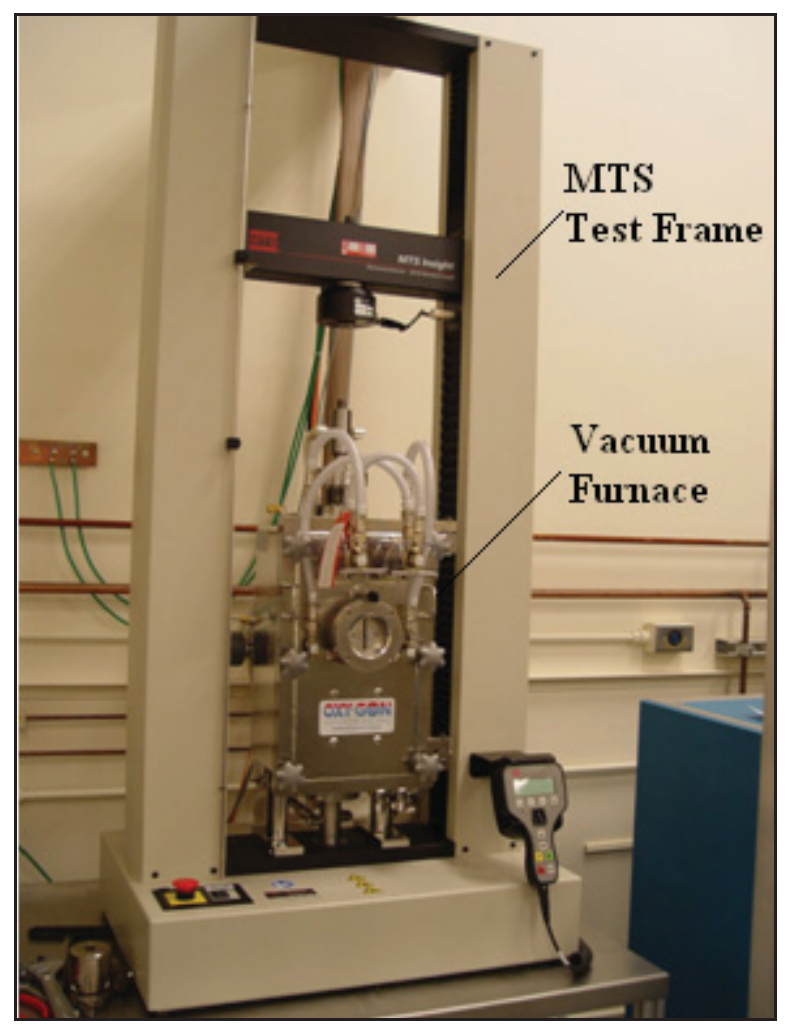

Figure 48. High Temperature Strength Test Assembly 


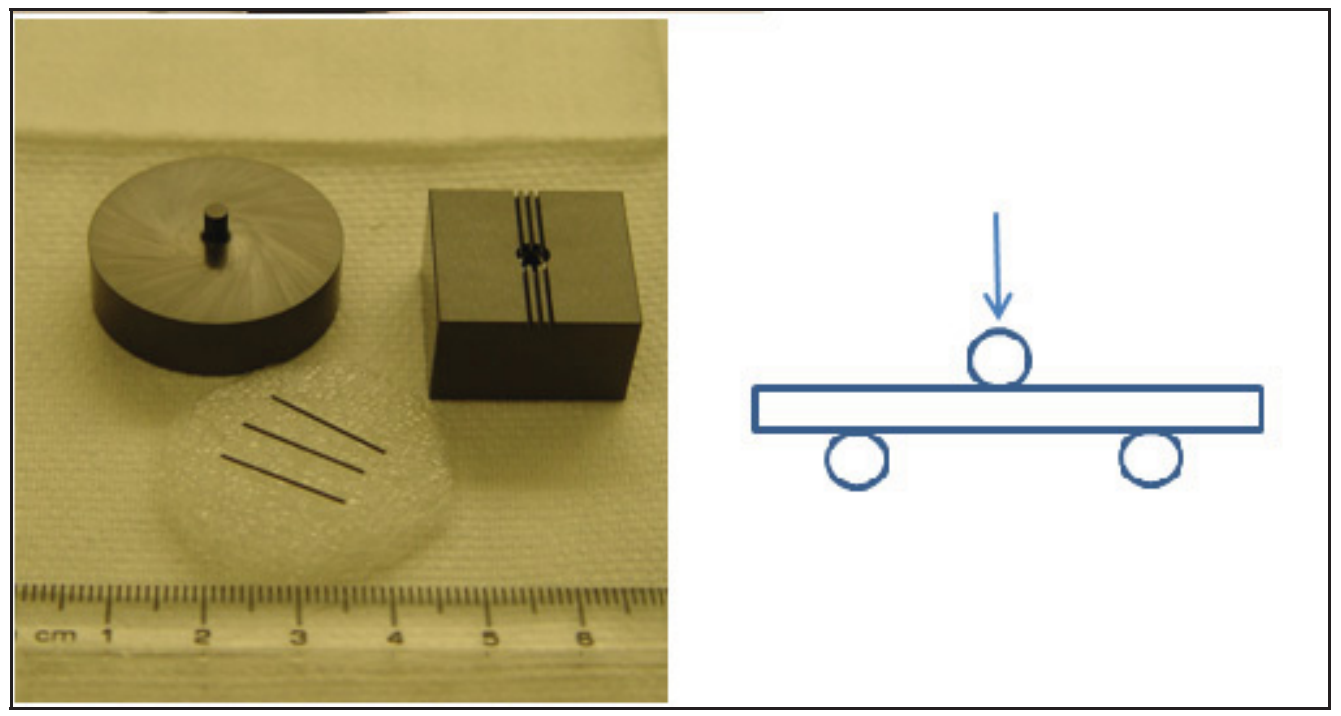

Figure 49. Three point disc flexural test fixture fabricated from SiC

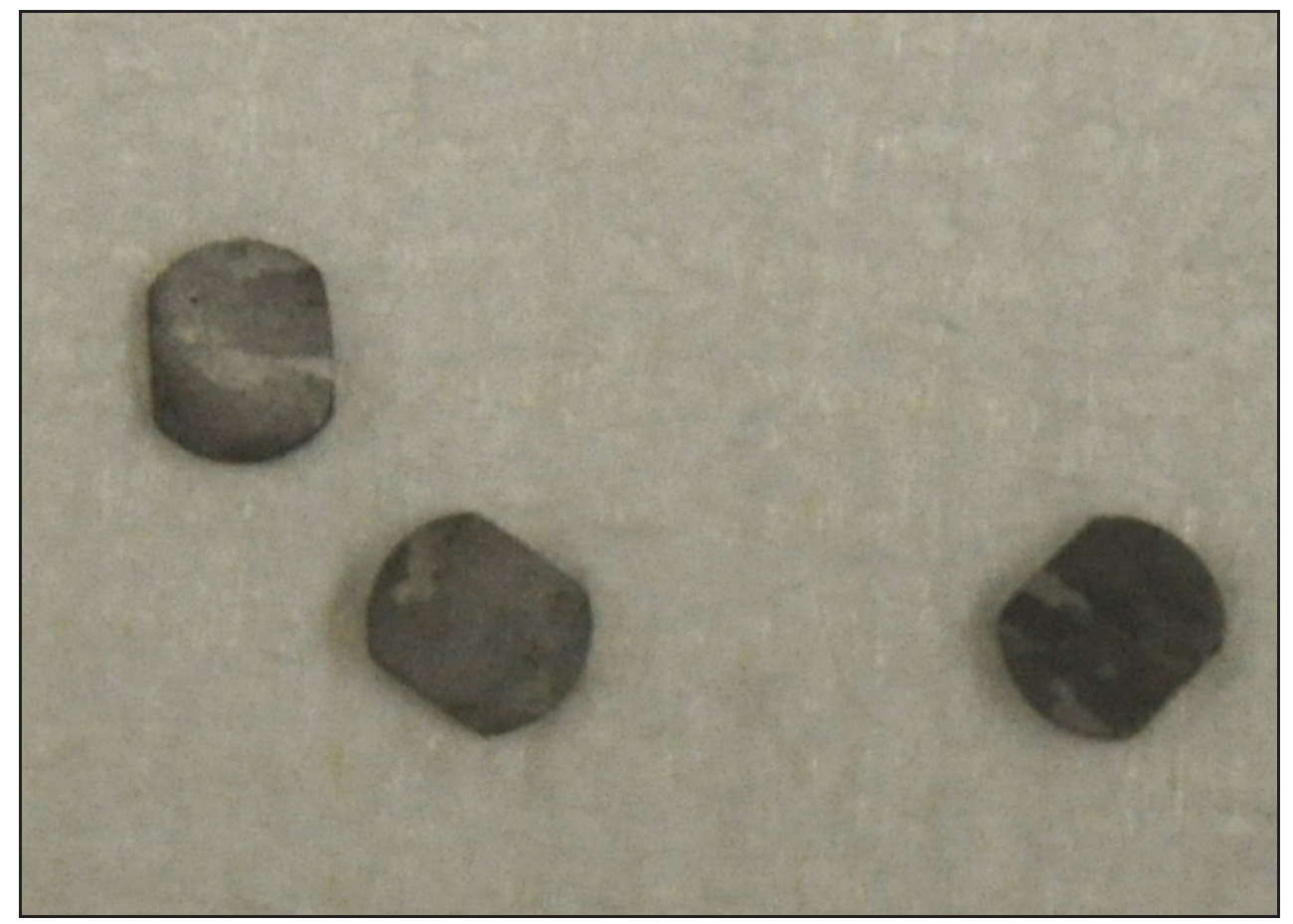

Figure 50. ZrC (0.95) Truncated Disc Test Specimens 


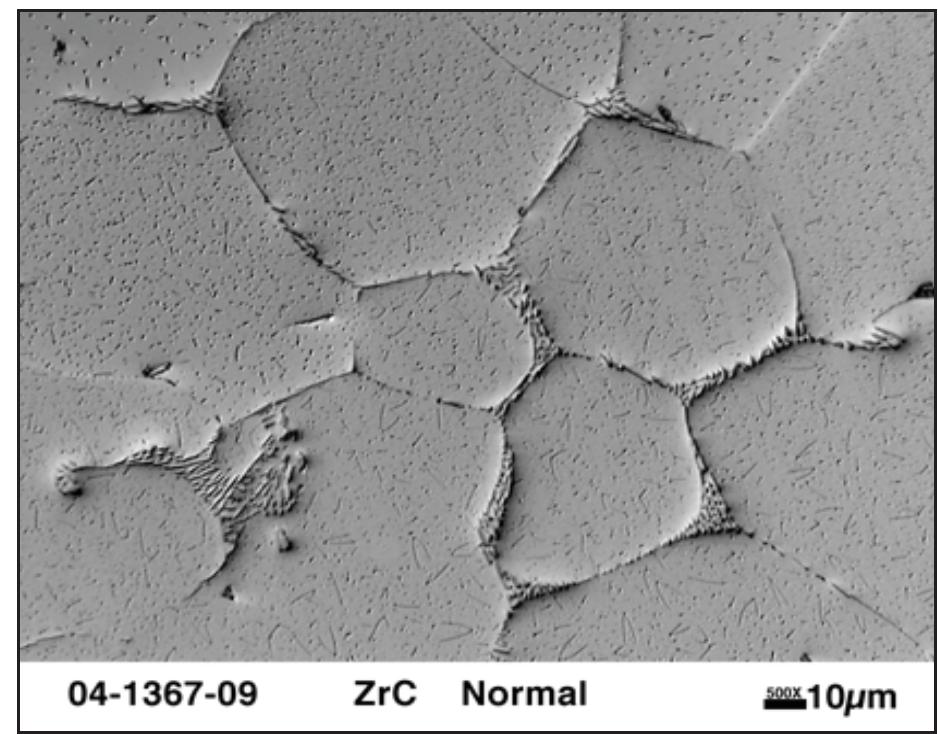

Figure 51. Representative Micrograph of $\mathrm{ZrC}(0.95)$ test specimen

Currently, experiments with a fixed strain rate of $0.002 / \mathrm{sec}$ are complete on all the five stoichiometric variants at 300,1073 , and $1273 \mathrm{~K}$. A decrease in the strength was observed with increasing carbon ratio and increasing temperature. The tests at 1473, 1673 and $1873 \mathrm{~K}$ are underway. Significant changes in strength are expected beyond $1473 \mathrm{~K}$, where a brittle to ductile transition is expected to occur, especially with smaller strain rates. The experiments include at least five strain rates to obtain details on the high temperature deformation and associated mechanisms of all the five stoichiometric variants. A final benchmark report detailing the analysis of results and the fractured surface microstructure will follow after the completion of the tests. The results of these tests will also be included in the final version of the $\mathrm{ZrC}$ properties handbook to complete the requirement of the Deep Burn program.

\subsubsection{Pd/ZrC Interaction}

C. Heske, heske@unlv.nevada.edu, UNLV

In FY 2010, the University of Nevada Las Vegas focused on investigating the interaction between Pd (one of the primary metallic fission products of interest) and $\mathrm{ZrC}$ to better understand fission product diffusion. After successful preparation of reproducible and relevant $\mathrm{ZrC}$ surfaces, the UNLV group has begun to study $\mathrm{Pd} / \mathrm{ZrC}$ interfaces, both in view of the Pd growth mode (morphology) as well as chemical interactions (corrosion). Interfaces have been annealed in $100^{\circ} \mathrm{C}$ steps up to $600^{\circ} \mathrm{C}$. No significant diffusion or $\mathrm{Pd} / \mathrm{ZrC}$ chemical interaction was found, in contrast to earlier $\mathrm{Pd} / \mathrm{SiC}$ studies at $800^{\circ} \mathrm{C}$. Additional anneals of the $\mathrm{Pd} / \mathrm{ZrC}$ samples are needed at higher temperatures to support comparison of the two studies. To enable that planned effort the system's sample heater was upgraded to allow measurements up to $1200^{\circ} \mathrm{C}$. The technical details of the $\mathrm{Pd} / \mathrm{ZrC}$ study can be found in the milestone M3GOR08VH050142 deliverable report entitled "Interaction of Metallic Fission Products with $\mathrm{ZrC}-$ Characterization of $\mathrm{ZrC}$ Surfaces and $\mathrm{Pd} / \mathrm{ZrC}$ Interfaces."

In addition, examination of the first ORNL $\mathrm{ZrC}$ coated particle samples was initiated. Two batches of $\mathrm{ZrC}$ coated particles ( $\mathrm{ZrC} 17$ and $\mathrm{ZrC} 21)$ were received and samples were annealed to $1050^{\circ} \mathrm{C}$. Initial XPS results indicate the $\mathrm{ZrC} 21$ sample showed a clear $\mathrm{ZrC}$ signature while the $\mathrm{ZrC} 17$ did not. In addition, $\mathrm{Ar}+$ ion sputtering $(2.5 \mathrm{keV})$ was successfully employed to reduce oxide species as required for future fission produce deposition and annealing experiments. 
For the remainder of the project, the UNLV group will strive to anneal $\mathrm{Pd} / \mathrm{ZrC}$ samples up to $1200^{\circ} \mathrm{C}$, as well as initiate the study of $\mathrm{Pd} / \mathrm{ZrC}$ interactions using $\mathrm{ZrC}$-coated particles from the ORNL coater.

\subsubsection{Ag/ZrC Interaction}

T. R. Allen, allen@engr.wisc.edu, U. Wisconsin, Madison

During FY 2010, investigation of the interaction of the important fission product Ag with $\mathrm{ZrC}$ continued at the University of Wisconsin - Madison. The work is being performed to develop a better understanding of the interaction between $\mathrm{Ag}$ and $\mathrm{ZrC}$ in terms of diffusion and solubility. By having an encapsulated $\mathrm{ZrC}$ disk react with a surrounding $\mathrm{Zr}-\mathrm{Ag}$ alloy and a subsequent outer graphite container under vacuum, $\mathrm{Ag}$ solubilities in $\mathrm{ZrC}_{0.76}$ and $\mathrm{ZrC}_{0.78}$, and $\mathrm{ZrC}_{0.84}$ were experimentally determined to all be around $0.05 \mathrm{wt} \%$, which are the first reported values of $\mathrm{Ag}$ solubilities at $1500^{\circ} \mathrm{C}$.

A more important breakthrough achieved this year was the development of a new liquid encapsulation method and the successful measurement of a diffusion coefficient of $\mathrm{Ag}$ in $\mathrm{ZrC}_{0.84}$. This was performed using an arc melter to construct a constant source diffusion couple between $\mathrm{ZrC}$ and $\mathrm{Zr}$ $\mathrm{Ag}$ solid solution. Figure 52 shows images of a cross section of a sample used for the diffusion experiment, where the sample was annealed at $1500^{\circ} \mathrm{C}$ for $50 \mathrm{hr}$ in an argon atmosphere. This method overcame difficulties encountered using standard techniques and allowed the diffusion coefficient of $\mathrm{Ag}$ in $\mathrm{ZrC}_{0.84}$ at $1500^{\circ} \mathrm{C}$ to be experimentally determined to be $\sim 5.0 \times 10^{-17} \mathrm{~m}^{2} / \mathrm{s}$, the first known value of this diffusion coefficient. An additional ( $\mathrm{ZrC} / \mathrm{Ag}$ gas) constant source diffusion couple between a $\mathrm{ZrC}_{0.95}$ disk and encapsulating Zr-Ag solid solution was constructed and diffusion annealed. Ag concentration on this sample, and thus Ag diffusivity, will be measured using SIMS in early FY 2011. This new method can also be used to determine the temperature dependence of $\mathrm{Ag}$ diffusivity in $\mathrm{ZrC}$.
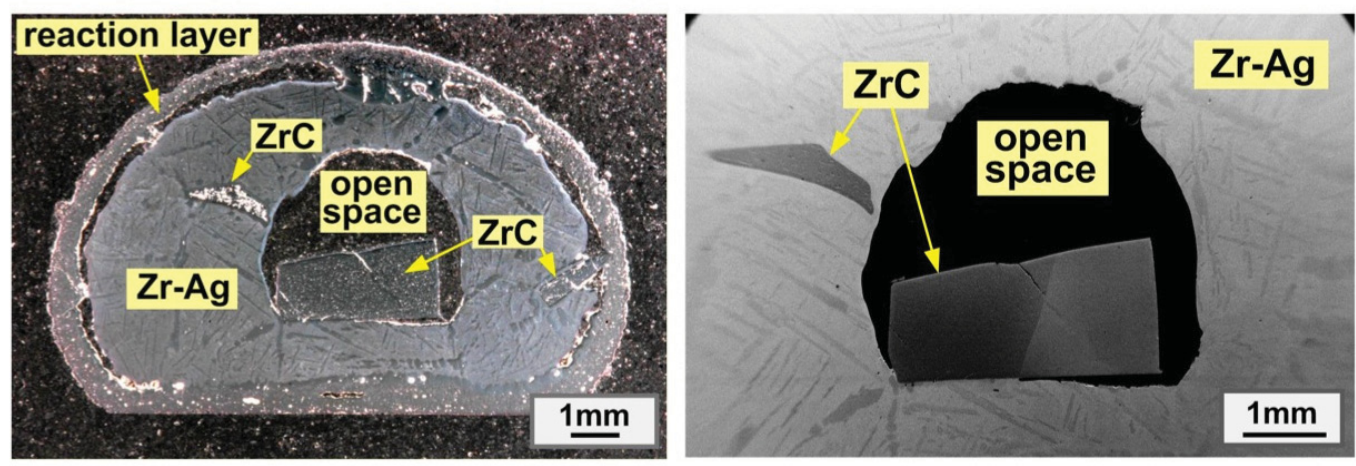

Figure 52. ZrC liquid-encapsulated with Zr-Ag solid solution: Optical macrograph (left), SEM image (right).

\subsubsection{Irradiation Effects in Zre}

T. R. Allen, allen@engr.wisc.edu, U. Wisconsin, Madison

The irradiation behavior of $\mathrm{ZrC}$ depends on the stoichiometry $(\mathrm{C} / \mathrm{Zr}$ ratio $)$ of the material. It is speculated that the sub-stoichiometric compositions $(\mathrm{C} / \mathrm{Zr}<1)$ experience relatively less damage compared to the nearly-stoichiometric compositions since the reduction of the annihilation rate of the irradiation-induced defects with the structural carbon vacancies is less pronounced in the nearlystoichiometric $\mathrm{ZrC}$ with higher carbon contents. It is important to study the radiation response over a range of stoichiometry because the in-pile performance can be strongly influenced by the processing route and conditions of the $\mathrm{ZrC}$-TRISO fuel coating process. Proton irradiation of a series of high purity zone refined $\mathrm{ZrCx}$ samples $(\mathrm{C} / \mathrm{Zr}=0.84,0.89 .0 .95,1.05$, and 1.17$)$ were conducted at $1125^{\circ} \mathrm{C}$ to a fluence of 
$2.0 \times 10^{19}$ protons $/ \mathrm{cm}^{2}$, which corresponds to 2 displacements per atom (dpa) for the stoichiometric $\mathrm{ZrC}$ with dose rate of approximate $1.83 \times 10^{-5} \mathrm{dpa} / \mathrm{s}$. The samples were subsequently examined for changes to the microstructure (dislocation loops, voids, graphite precipitates) and fracture toughness was measured using a cantilever micro-beam technique. Figure 53 shows an infrared image of the $\mathrm{ZrC}$ disks under 2 $\mathrm{MeV}$ proton irradiation at $1125^{\circ} \mathrm{C}$ along with a TEM image of the irradiated $\mathrm{ZrC} 0.89$ with a dose of 36 dpa. The irradiated microstructures all featured prismatic dislocation loops, and no irradiation-induced voids were observed even with a dose up to $36 \mathrm{dpa}$ for $\mathrm{ZrC}_{0.89}$.
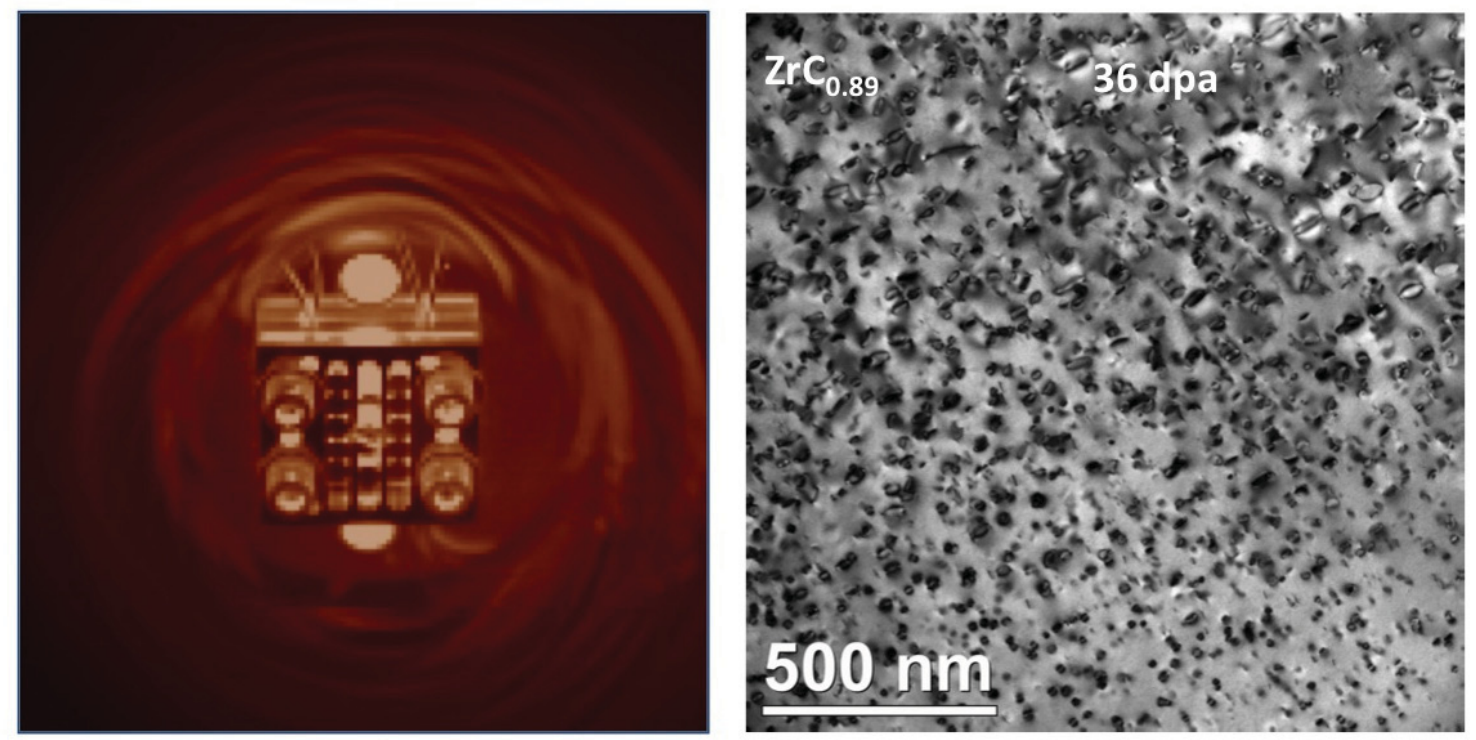

Figure 53. Infrared image of ZrC under irradiation at $1125^{\circ} \mathrm{C}$ using $2 \mathrm{MeV}$ protons (left), and TEM image of the irradiated $\mathrm{ZrC0.89}$ with dose of $36 \mathrm{dpa}$ (right).

It was determined that the fracture load on average increased to $2622 \mu \mathrm{N}$ for the irradiated cantilevers from $2030 \mu \mathrm{N}$ for the unirradiated cantilevers indicating a 30\% increase in the fracture toughness due to proton irradiation. Figure 54 shows SEM images of the micro-beams fabricated using a focused ion beam and of the irradiated micro-cantilevers after being fractured. 


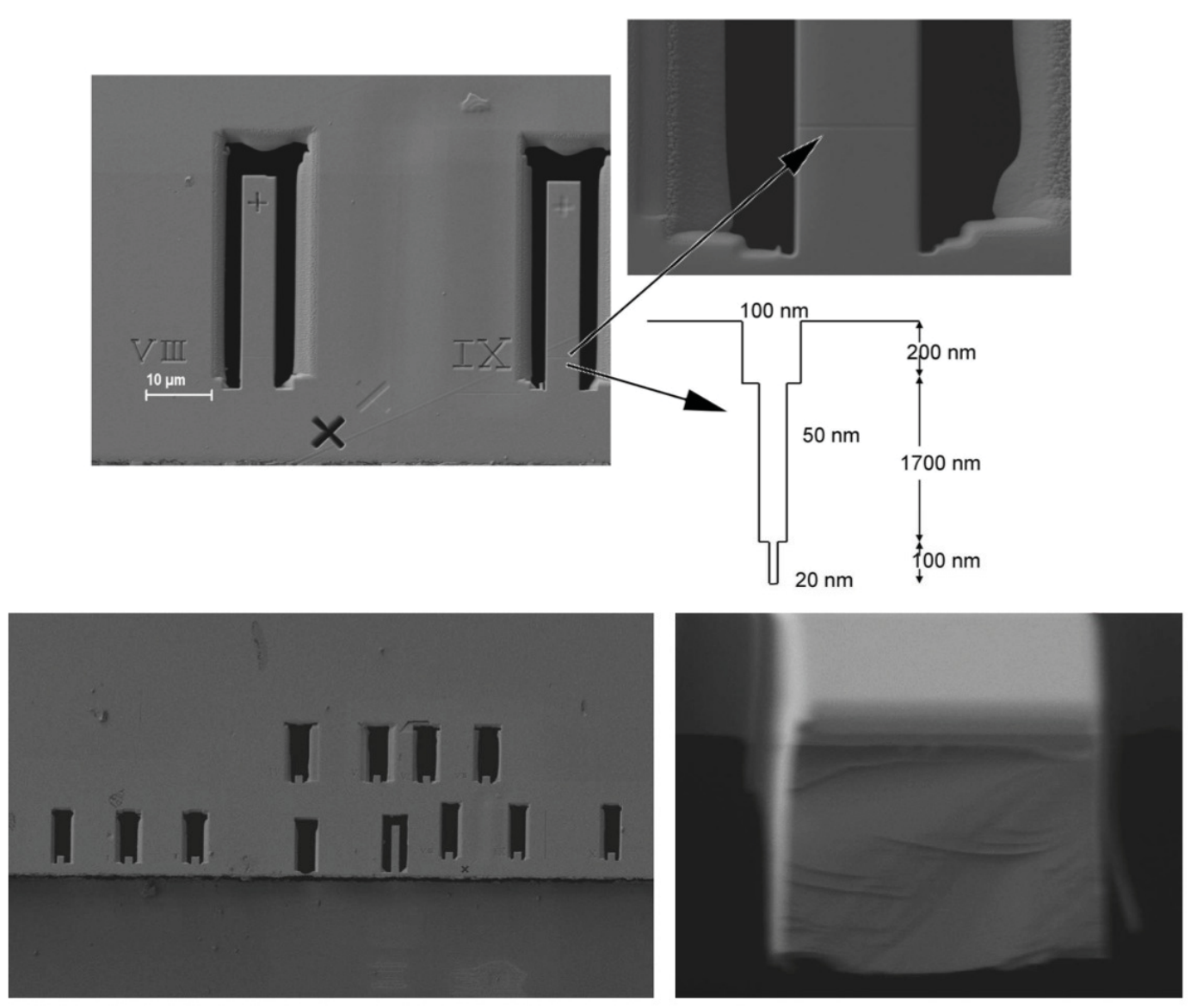

Figure 54. SEM images of micro-beams fabricated using FIB and the schematic of the machined notch (top), micro-cantilevers after being fractured (bottom left) and the fractography of the fractured microbeam (bottom right).

Samples were prepared for proton irradiation at $1400^{\circ} \mathrm{C}$. The thermocouple feed-through of the irradiation sample stage has been modified to the C-type to accommodate the higher irradiation temperature. Unfortunately, proton beam equipment failures have delayed the work and the $1400^{\circ} \mathrm{C}$ irradiation experiment has been pushed into early FY 2011. Following the completion of the irradiation, PIE of the specimens will be conducted and reported. 


\section{GORE MATERIALS TECHNOLOGIES}

Technical Lead, Stuart Maloy, maloy@1anl.gov, LANL

Significant accomplishments have been achieved from the Core Materials Technology Development Technical Area during FY 2010. Some of the highlight accomplishments for FY 2010 include: Completing mechanical testing (fracture toughness, Charpy and tensile testing) coupled with initial microstructural analysis of the most highly irradiated fast reactor core component (ACO-3 duct made of HT-9 steel) after irradiation in FFTF to a maximum dose of 155 dpa. initiation of a Zr liner fabrication effort to produce lined cladding tube samples for an ATR irradiation test, a large scale ( $>50$ pound) heat of 14YWT (a leading radiation resistant nanostrengthened ferritic alloy [NFA]) has been produced for future testing and development, a three year technology research development plan was developed for investigating the use of $\mathrm{M}_{\mathrm{n}+1} \mathrm{AX}_{\mathrm{n}}(\mathrm{MAX})$ phase ceramics for core materials applications. The technical lead for Core Materials Technologies is Stuart Maloy at LANL.

\subsection{Advanced Materials Development: FCCI Resistant Cladding \\ J. I. Cole, james.cole@inl.gov \\ J. Gan, and R. Fielding, INL \\ I. Kim and H. Wang, Texas A\&M University \\ K. Sridharan, T. R. Allen, M. Mohammadian, University of Wisconsin}

The advanced fuel cladding development effort at the INL has focused on fabrication development, characterization and testing of barrier coatings and liners to mitigate or eliminate chemical interactions between nuclear fuel and cladding alloys. Fabrication of coatings or liners along the interior length of a long narrow cladding tube has multiple challenges that are being addressed to enable substantially increased fuel burn-up levels. Activities during FY 2010 included completion of a series of studies characterizing vanadium liner interaction with HT-9 cladding during fabrication processing, fabrication of over 50 coating coupons on HT-9 and MA-957 substrates for neutron and heavy-ion irradiation experiments, initiation of $\mathrm{Zr}$ liner fabrication effort to produce lined cladding tube samples for an ATR irradiation test and development of a draft irradiation test plan for a planned FY 2011 insertion date.

For coating development, effort focused on preparing samples for irradiation testing, both neutron and heavy-ion. Over 50 samples with varying fabrication conditions and coating materials (TiN, TiN/TaN multilayers, $\mathrm{SiC}$ and $\mathrm{ZrN}$ ) were prepared. A subset of the TiN and multilayer samples was irradiated at Michigan Ion Beam Laboratory to total doses of 10, 50 and 200 dpa with Fe heavy-ions. The heavy-ion experiments are being used as an initial screening tool for optimizing deposition parameters for irradiation tolerance. These initial irradiation tests will provide insight into coating stability and the nature of fuelcoating-cladding intermixing/interdiffusion under irradiation.

The liner studies being conducted are in collaboration with Century Tubing Inc. of San Diego California. In the prior year, vanadium lined HT-9 cladding tubes were fabricated using six different thermomechanical processing strategies. Vanadium was chosen as a lining material because it exhibits an extremely low rate of interaction with metallic nuclear fuels. An initial investigation of the microstructure and hardness of the fabricated lined cladding tubes revealed that the microstructure adjacent to the vanadium liner was not the expected tempered martensite in several of the tubes. SEM characterization of the processed tubes and subsequent diffusion couple studies revealed that the $\mathrm{V}$ liner decarburizes the cladding tubes when held in contact with the tubes at elevated temperature. In contrast, a diffusion couple test conducted with $\mathrm{Zr}$ showed no such decarburization (see Figure 55). As a result, a new series of fabrication studies using $\mathrm{Zr}$ as the liner material was initiated. Examination of the Zr-lined tubes will be carried out in FY 2011, and sections from these tubes will be used in ATR irradiation experiment. 

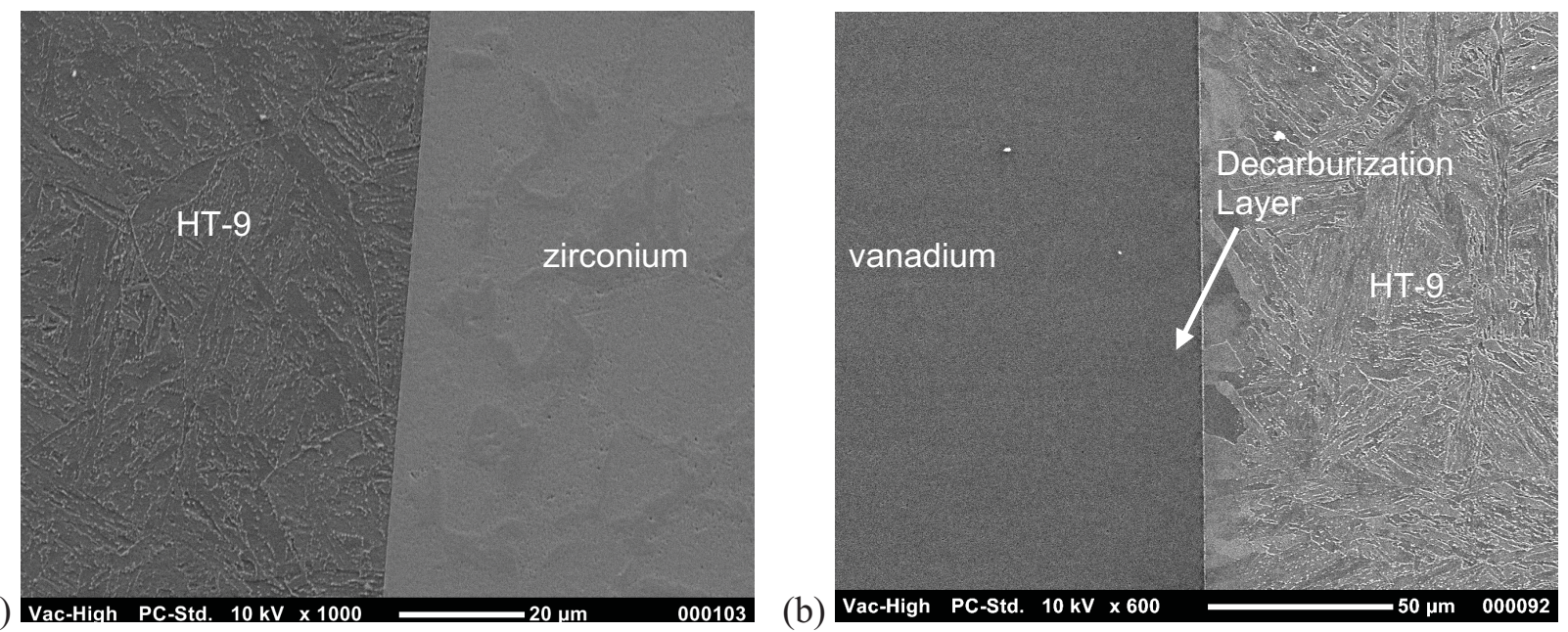

Figure 55. Images of the interface between a) zirconium and b) vanadium and HT-9 following annealing at $704^{\circ} \mathrm{C}$ for 100 hours.

\section{Publication}

Mohammadian, M. A., T. R. Allen, K. Sridharan, J. I. Cole, R. F. Fielding, and C. Young, "Characterization of Vanadium-lined Fuel Cladding Fabricated with Various Process Parameters", submitted to the Journal of Nuclear Materials.

\subsection{HT-9 Knowledge Based Testing}

T. Saleh, tsaleh@lanl.gov, and S. Maloy, LANL

Seven plates cut from the ACO-3 duct were electron discharge machining (EDM) machined into tensile, compact tension and Charpy specimens at the LANL Sigma complex. Total specimens machined were 144 Charpy, 57 compact tension, 126 tensile specimens and 500 TEM. Specimens have doses up to 155 dpa from being irradiated in the FFTF at irradiation temperatures from 370 to $505^{\circ} \mathrm{C}$. The Charpy and fracture toughness testing were completed at ORNL and the tensile testing was completed at LANL.

The tensile results performed on specimens EDM machined from the ACO-3 duct are summarized in Figure 56. Complete data with stress/strain curves was reported in "Summary of Tensile Testing Results for Irradiated HT-9 Steels from the ACO-3 Duct", M3501050202, 9/30/10. Figure 56 shows that the largest increase in yield stress is for the specimens irradiated below $430^{\circ} \mathrm{C}$. Even though these specimens were irradiated to a lower total dose, $\sim 20 \mathrm{dpa}$, much higher hardening was observed. With the measured increase in yield stress, there was also a reduction in uniform elongation. All specimens show necking and a plastic failure but for specimens irradiated below $430^{\circ} \mathrm{C}$, uniform elongation is reduced while still greater than $1 \%$. 

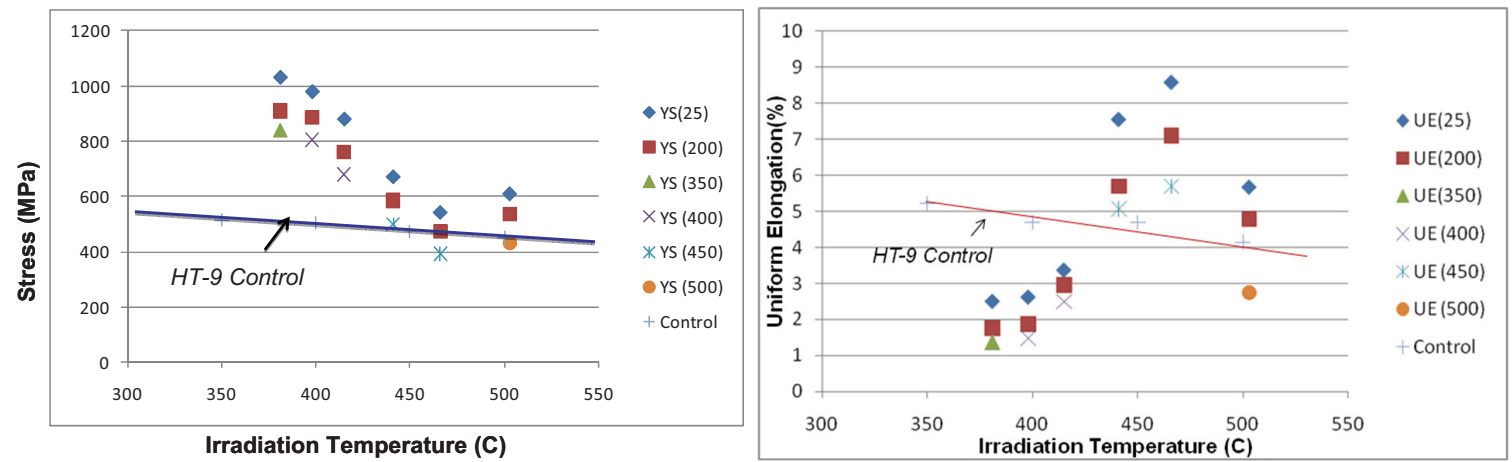

Figure 56. Graphs of yield stress and uniform elongation vs. irradiation temperature on tensile specimens tested at $25^{\circ} \mathrm{C}, 200^{\circ} \mathrm{C}$ and the irradiation temperature after being EDM-machined from the ACO-3 duct.

\subsection{Fracture Toughness and Charpy Impact Measurements}

T. S. Byun, byunts@ornl.gov, ORNL

Fracture toughness and Charpy impact tests have also been completed on specimens EDM- machined from the ACO-3 duct and the results were reported in April, 2010 as the milestone report: M3501050305 "Fracture Toughness and Charpy Impact Test Results for ACO-3 Duct Material" (ORNL/TM -2010/88). The highlights of test results reported are as follows:

1. The effect of irradiation temperature was dominant in both Charpy impact property and fracture toughness(see Figure 57 and Figure 58)

2. Greater shift of transition temperature in Charpy impact energy occurred after irradiation at relatively low temperatures

3. Upper shelf energies were $5.5-6.5 \mathrm{~J}$ before irradiation and $2-5 \mathrm{~J}$ after irradiation, depending on irradiation temperature, dose, and specimen orientation

4. The DBTT in fracture toughness was below RT when irradiation temperature $>430{ }^{\circ} \mathrm{C}$, while it was higher than RT when irradiation temperature $<430^{\circ} \mathrm{C}$.
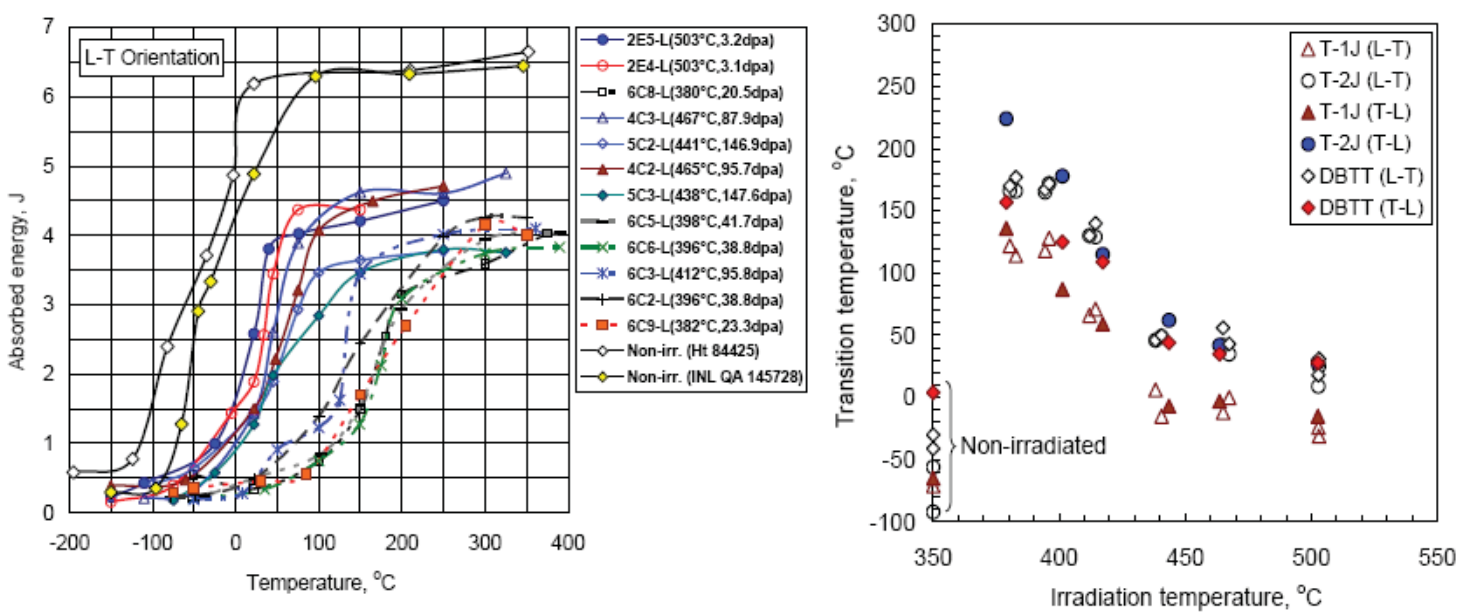

Figure 57. Charpy impact test data for ACO-3 duct material (HT-9) 


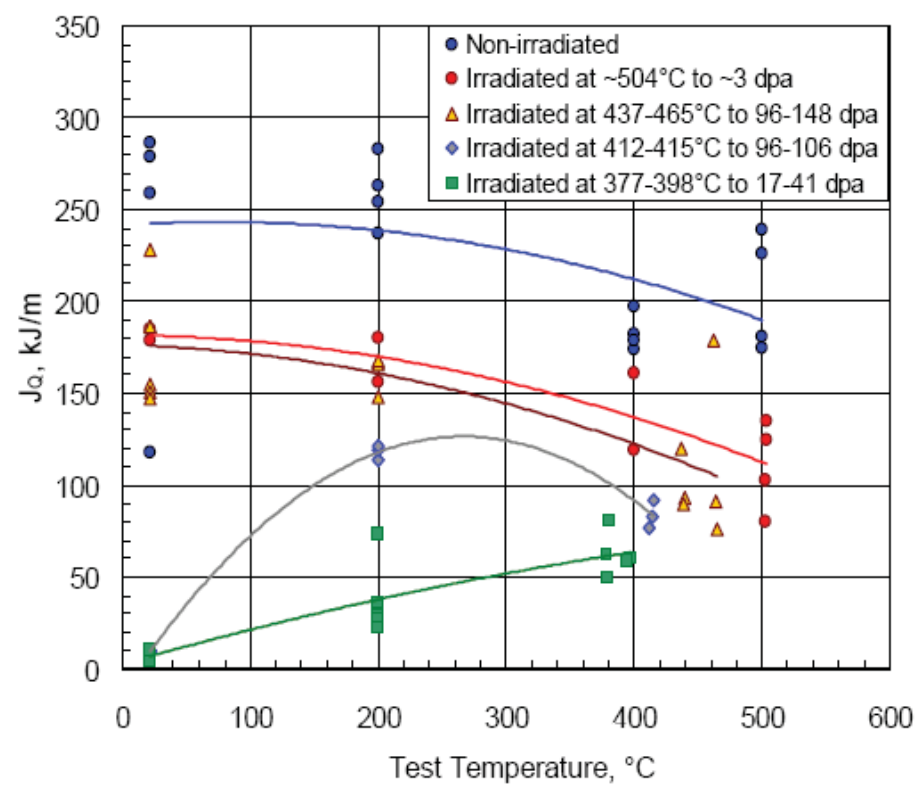

Figure 58. Fracture toughness of ACO-3 duct material (HT-9)

\subsection{Thermal Annealing and Damage Recovery Study}

T. S. Byun, byunts@ornl.gov, ORNL

Preliminary (hardness) tests in a thermal annealing effect study on specimens from the ACO-3 duct have been completed. This annealing recovery experiment aimed at providing a knowledge base for the life extension of core materials by reactor operational means. The goal of the FY 2010 task was to determine the thermal annealing conditions. These selected conditions will be applied to the fracture toughness tests, which will be carried out in FY 2011 by reusing the undeformed portion of the tested Charpy specimens. In FY 2010 microhardness measurements were made after (a) isochronal annealing at temperatures ranging from 300 to $650^{\circ} \mathrm{C}$ for 1 hour, (b) isothermal annealing at $510^{\circ} \mathrm{C}$ up to 20 hours, or (c) isothermal annealing at $550^{\circ} \mathrm{C}$ up to 5 hours.

In the isochronal annealing study it was found that the specimens after irradiation at relatively low temperatures showed higher as-irradiated hardening and consequently larger annealing recovery (see Figure 59). The hardness values decreased below the average value for nonirradiated specimens after annealing at $575^{\circ} \mathrm{C}$ or higher, which indicates a full recovery from radiation damage in HT-9 steel. As seen in Figure 60, a full recovery of hardening damage was also observed after isothermal annealing at $510^{\circ} \mathrm{C}$ for 20 hours or at $550^{\circ} \mathrm{C}$ for 2 hours. The thermal annealing at $550{ }^{\circ} \mathrm{C}$ for 2 hours was selected as a primary treatment condition for the fracture toughness tests in FY 2011. The same sets of specimens used for hardness testing will be selected for the fracture toughness testing.

It is notable that in both isochronal and isothermal annealing cases the irradiation plus annealing treatment can soften the HT-9 steel below its original strength. A detailed study for the microstructural evolution will be followed after FY 2011. 


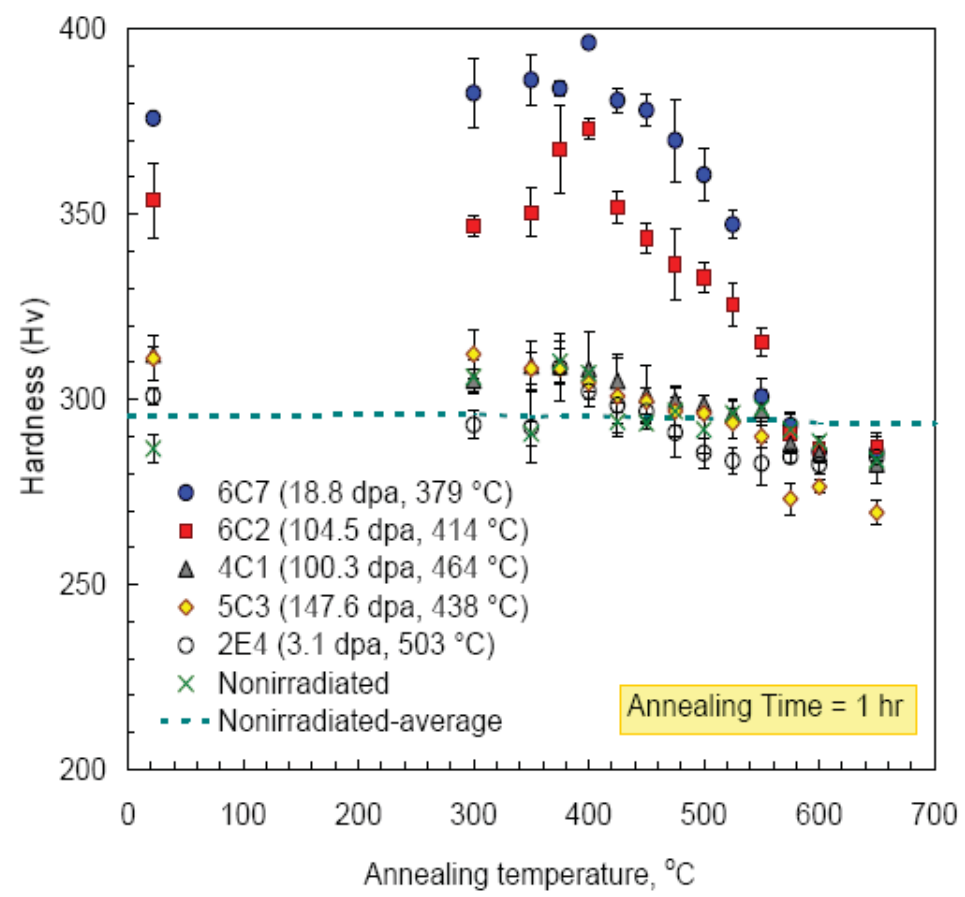

Figure 59. Variation of microhardness after isochronal annealing at various temperatures for 1 hour
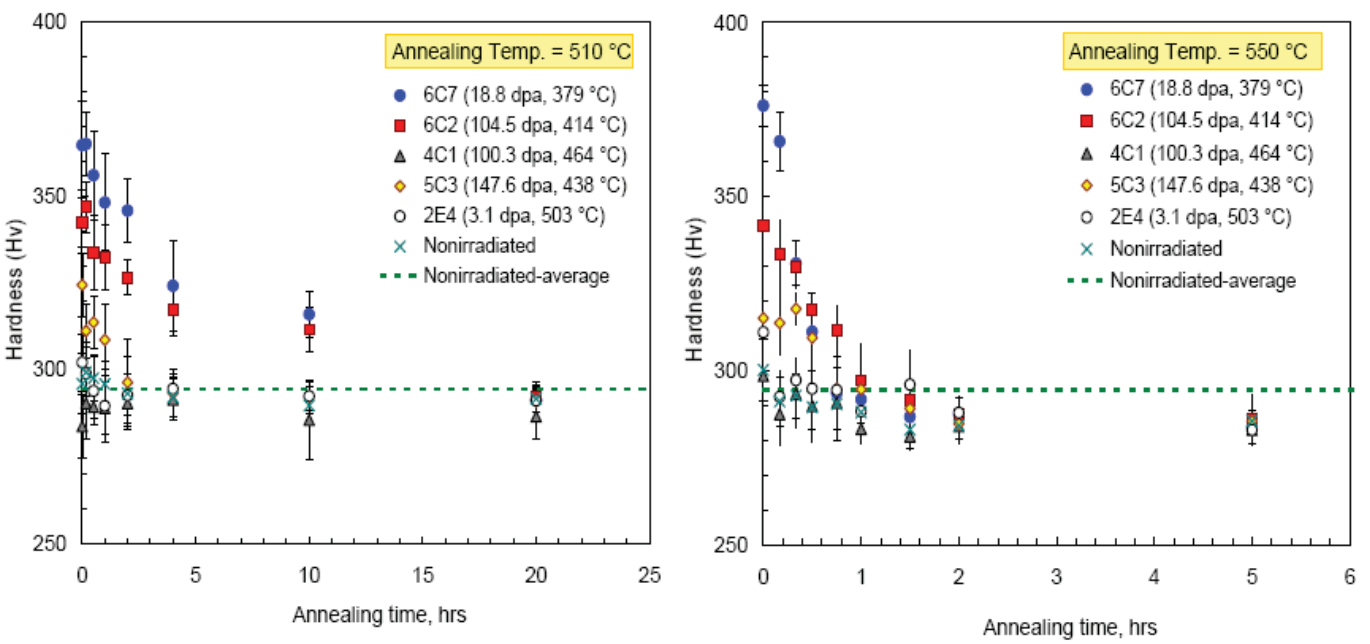

Figure 60. Variation of microhardness after isothermal annealing at 510 and $550{ }^{\circ} \mathrm{C}$

\subsection{Microstructural Analysis of ACO-3 Duct}

B. H. Sencer, bulent.sencer@inl.gov, INL

J. Vanden Bosch, O. Anderoglu, LANL

To aid in the development of atomistic models and to gain a fundamental understanding of radiation effects after high dose fast reactor exposures, detailed microstructural examinations are underway at INL and LANL. INL is investigating the microstructures using transmission electron microscopy. LANL is investigating microstructures using TEM, small angle neutron scattering (SANS) and Mossbauer spectroscopy. Specimens were investigated after five different exposures: Tirr $=380^{\circ} \mathrm{C}$, dose $=20 \mathrm{dpa}$, 
Tirr $=410^{\circ} \mathrm{C}$, dose $=100 \mathrm{dpa}$, Tirr $=440^{\circ} \mathrm{C}$, dose $=155 \mathrm{dpa}$, Tirr $=465^{\circ} \mathrm{C}$, dose $=92 \mathrm{dpa}$ and $\operatorname{Tirr}=505^{\circ} \mathrm{C}$, dose $=2$ dpa. Results show an increase in scattering intensity (from SANS measurements) with decreasing temperature. TEM results identify these scattering centers as second phase precipitates which are predominantly G-phase (predominantly a Ni-Mn-Si phase ). Other phases identified are alpha prime and carbides. This data is very helpful in developing new alloys with improved radiation tolerance. The details of this microstructural analysis will be documented in a detailed report in FY 2011.

\title{
6.6 FFTF/MOTA Specimen Retrieval and Testing
}

M. B. Toloczko, mychailo.toloczko@pnl.gov, PNNL

The goal for the year was to obtain fracture toughness data primarily from HT-9 disk compact tension specimens recovered from FFTF/Materials Open Test Assembly (MOTA). Testing on T-91 was to be performed if adequate specimens and time were available. Prior to performing the fracture toughness testing, it was necessary to finish setting up and shakedown testing a new state-of-the-art fracture toughness testing system. Considerable time was devoted to this part of the work to ensure that the best fracture toughness data would be obtained on these high value specimens. Shakedown testing was completed late in the year leaving only about two months of part-time work to perform fracture toughness testing. Initial fracture toughness testing was performed at room temperature on several unirradiated HT-9 specimens and two irradiated specimens, one of which was irradiated to $7.2 \mathrm{dpa}$ at $375^{\circ} \mathrm{C}$ and the other of which was irradiated to $37 \mathrm{dpa}$ at $412^{\circ} \mathrm{C}$. As shown in Table 2, a strong difference in toughness response was observed between the two irradiation temperatures with the $375^{\circ} \mathrm{C}$ specimen displaying brittle fracture and having a $\mathrm{J}_{\mathrm{Q}}$ value of only $30 \mathrm{~kJ} / \mathrm{m}^{2}$ while the specimen irradiated at $412^{\circ} \mathrm{C}$ displayed essentially the same toughness response as the unirradiated material. These results are consistent with tests performed on the HT-9 ACO-3 duct and indicate a strong change in toughness response over a relatively narrow temperature range. Further, in-depth testing will continue in FY 2011 to better define and understand the cause of the shift in response.

Table 2. Initial fracture toughness results from HT-9 recovered from FFTF/MOTA.

\begin{tabular}{|c|c|c|c|c|c|c|c|}
\hline Material & Heat & \multicolumn{1}{|c|}{$\begin{array}{c}\text { Thermomechanical } \\
\text { Treatment }\end{array}$} & $\begin{array}{c}\text { Irrad. } \\
\text { Temp. } \\
\left({ }^{\circ} \mathbf{C}\right)\end{array}$ & $\begin{array}{c}\text { Dose } \\
(\mathbf{d p a})\end{array}$ & $\begin{array}{c}\text { Test } \\
\text { Temp. } \\
\left({ }^{\circ} \mathbf{C}\right)\end{array}$ & $\begin{array}{c}\mathrm{J}_{\mathbf{Q}} \\
\left(\mathbf{k J} / \mathbf{m}^{2}\right)\end{array}$ & $\begin{array}{c}\mathrm{K}_{\mathbf{Q}} \\
(\mathbf{M P a V m})\end{array}$ \\
\hline HT-9 & 20818 & $\begin{array}{l}1038 \mathrm{C} / 5 \mathrm{~min} / \mathrm{AC}+ \\
760 \mathrm{C} / 30 \mathrm{~min} / \mathrm{AC}\end{array}$ & unirr. & --- & 25 & 260 & $\mathrm{NA}$ \\
\hline HT-9 & 91354 & $\begin{array}{l}1038 \mathrm{C} / 5 \mathrm{~min} / \mathrm{AC}+ \\
760 \mathrm{C} / 30 \mathrm{~min} / \mathrm{AC}\end{array}$ & 375 & 7.2 & 25 & 30 & 82 \\
\hline HT-9 & 91354 & $\begin{array}{l}1038 \mathrm{C} / 5 \mathrm{~min} / \mathrm{AC}+ \\
760 \mathrm{C} / 30 \mathrm{~min} / \mathrm{AC}\end{array}$ & 412 & 37 & 25 & 265 & $\mathrm{NA}$ \\
\hline
\end{tabular}

\subsection{Tensile Testing and Microstructure of High Dose MA-957 0nS Steel}

\author{
M. B. Toloczko, mychailo.toloczko@pnl.gov, PNNL; T. Saleh- LANL
}

A large number of MA-957 creep tube specimens with a dose of $\sim 110$ dpa and irradiation temperature ranging from $410^{\circ} \mathrm{C}$ to as high as $750^{\circ} \mathrm{C}$ were recovered from FFTF/MOTA. These specimens have the highest irradiation dose ever achieved on an oxide dispersion strengthened (ODS) steel, and thus represent an excellent opportunity to study the effects of irradiation on the microstructure and properties of this class of advanced alloy that is under consideration for clad and duct. A plan was devised to obtain 
tensile properties and microstructure of these specimens by cutting tensile specimens and microscopy specimens from the tubes. Arrangements were made to cut the specimens at LANL, and the cutting was successfully completed near the end of the fiscal year. An example of a set of specimens cut from a creep tube is shown in Figure 61. Specimens will be shipped back to PNNL in early FY 2011 with testing and examination to begin immediately.

(a)

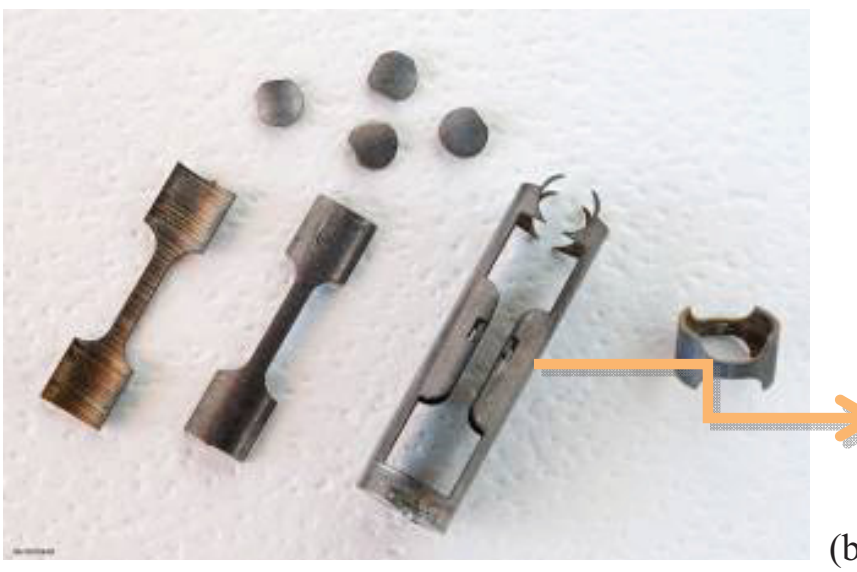

(b)

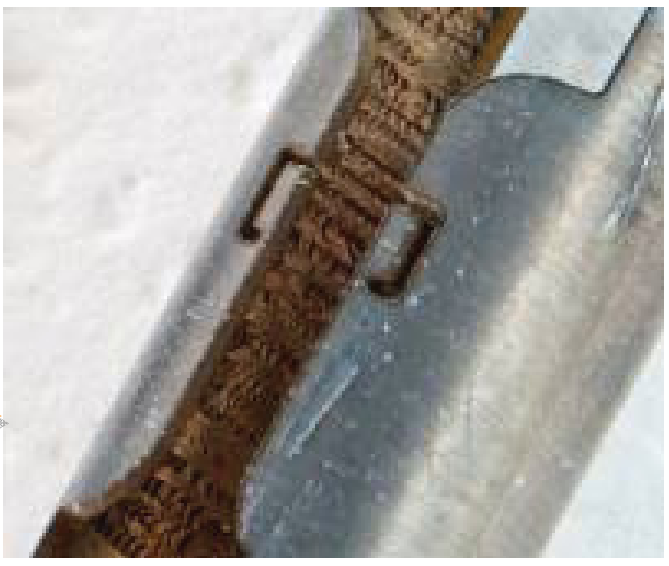

Figure 61. (a) Machined tensile, ring pull, and TEM disk specimens, and (b) atom probe tomography (APT) specimens obtained from an MA-957 creep tube.

\title{
6.8 Advanced Clad Material Development
}

\author{
D. Hoelzer, hoelzerd@ornl.gov, ORNL; \\ S. Maloy and D. Hammon, LANL; P. Hosemann, UCB \\ G.R. Odette, UCSB; B.D. Wirth, UTK; M. West, SDSM\&T
}

To burn fuels to up to $40 \%$ burnup without changing the cladding requires development of materials to withstand doses greater than $400 \mathrm{dpa}$. Advanced materials that are more radiation resistant than ferritic/martensitic steels (e.g., HT-9) must be developed and tested under irradiation. During this fiscal year, progress has been made in understanding radiation effects in advanced materials and development of new materials.

\subsubsection{Fabrication}

S.A. Maloy, Maloy@lanl.gov, LANL

A project to produce large scale ( $>50$ pound) heats of 14YWT (a leading radiation resistant nanostrengthened ferritic alloy [NFA]) has made excellent progress this fiscal year. It is being led by LANL in collaboration with ORNL, University of California Santa Barbara (UCSB), University of CaliforniaBerkeley (UCB), University of Tennessee Knoxville (UTK), South Dakota School of Mining and Technology (SDSM\&T) and ATI Powder Metals Inc. (formerly Crucible Research Inc.) The initial task of this project focused on characterizing three small powder heats that were ball milled and extruded. Five heats of 14YWT were extruded at ORNL using ball milled powders from two of the powder heats at UCB. Detailed microstructural analysis of the powders and extruded alloys has been conducted at UCSB and ORNL. Electron probe microanalysis (EPMA) and back scattered electron (BSE) analysis shows that uniform distributions of $\mathrm{Y}$ and $\mathrm{Ti}$ and nano-size grain structures are produced in alloy heats made with $>20 \mathrm{~h}$ ball milled powders (see Figure 62.) Characterization of the initial heats using the local electrode atom probe (LEAP) shows that a fine distribution of oxide particles has been obtained uniformly 
throughout the material (see Figure 63). Hardness measurements have shown that very high strengths up to $2.4 \mathrm{GPa}$ are obtained in the optimum alloy heats.

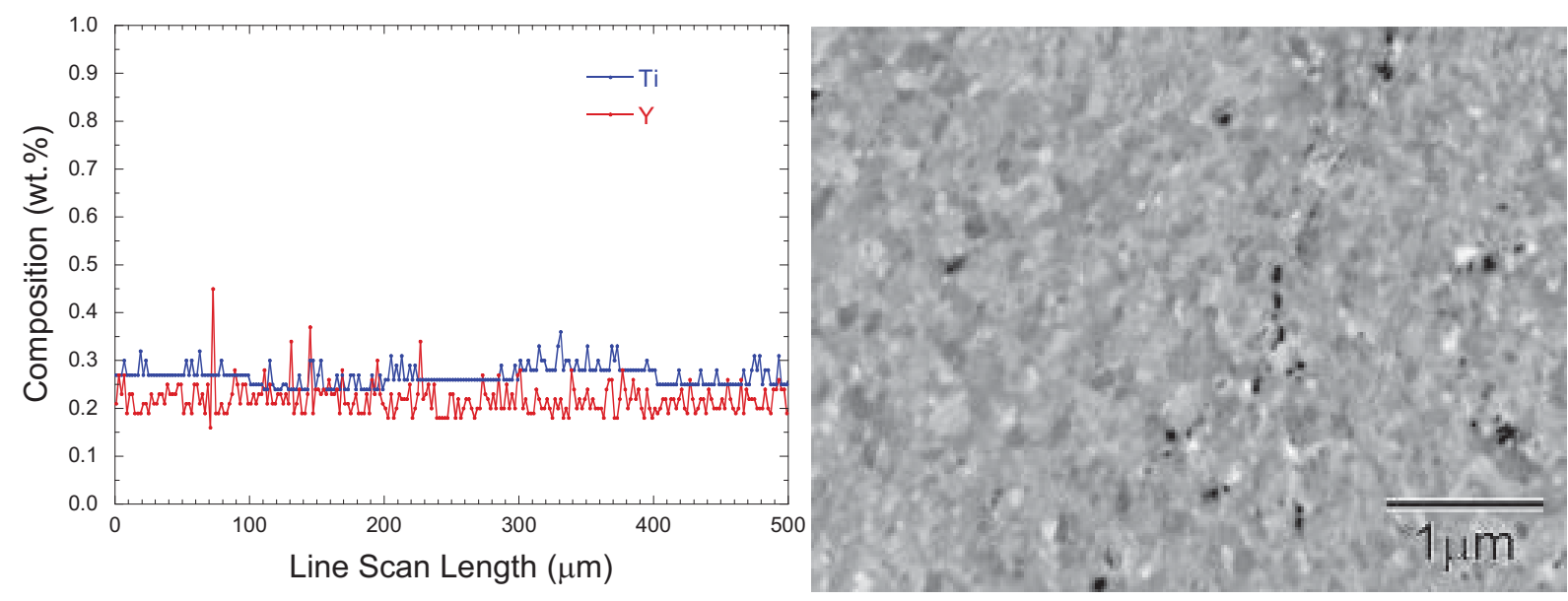

Figure 62. EPMA line composition profile (left) and BSE image (right) of 14YWT produced with $40 \mathrm{~h}$ ball milled powder.

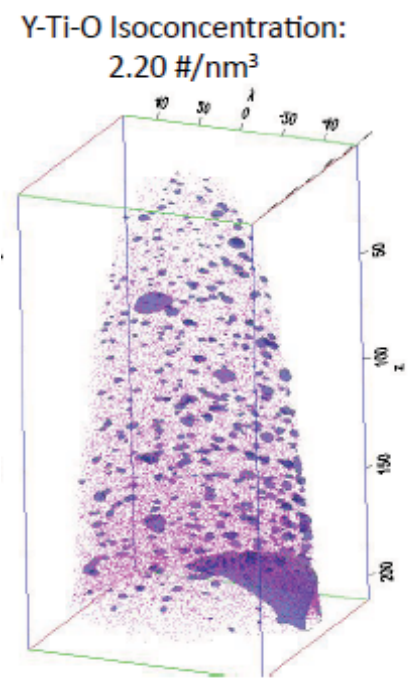

Figure 63. Atom probe tomographic image showing Y-Ti-O clusters in heat of 14YWT.

Based on results obtained in the initial task, a large powder heat ( 132 pounds) has been gas atomized by ATI Powder Metals and is now being characterized and consolidated. The future task is to have the large powder heat ball milled at the Zoz pilot plant in Germany and then consolidated to form a large 14YWT heat. In separate studies underway, two 14YWT heats of 1.6 and $2.4 \mathrm{~kg}$ have been produced using the newly acquired CM08 attritor mill at ORNL and these materials will be used in studies to demonstrate forging and rolling to thin sheet form and determine friction stir weld parameters for joining.

\subsubsection{High Temperature Property Characterization for NFAs}

T. S. Byun, byunts@ornl.gov, ORNL

Nanostrengthened ferritic alloys (NFAs) have been developed to improve high temperature strength and radiation resistance by refining grains and including nanoclusters as noted above. Among the key 
properties of NFAs needed to be assessed for advanced reactor applications; the cracking resistance at high temperatures has not been well known. In FY 2010, the high temperature fracture behavior has been investigated for the latest NFA, 14YWT (SM10). The fracture toughness of the alloy was above 140 $\mathrm{MPa} \sqrt{\mathrm{m}}$ at low temperatures, room temperature $(\mathrm{RT})$ and $200^{\circ} \mathrm{C}$, but decreased to a low fracture toughness range of $52-82 \mathrm{MPa} \sqrt{\mathrm{m}}$ at higher temperatures up to $700^{\circ} \mathrm{C}$ (see Figure 64). This behavior was explained by the fractography results indicating that the unique nanostructure of 14YWT alloy produced shallow plasticity layers at high temperatures and a low-ductility grain boundary debonding occurred at $700^{\circ} \mathrm{C}$, as seen in Figure 65 . It is suggested that the fracture toughness of the 14YWT alloy be improved by introducing a coarser microstructural feature that can deflect cracks and absorb more energy, reducing gas-trapped pores, and/or strengthening boundaries through changes in the mechanical alloying and thermo-mechanical treatment conditions.

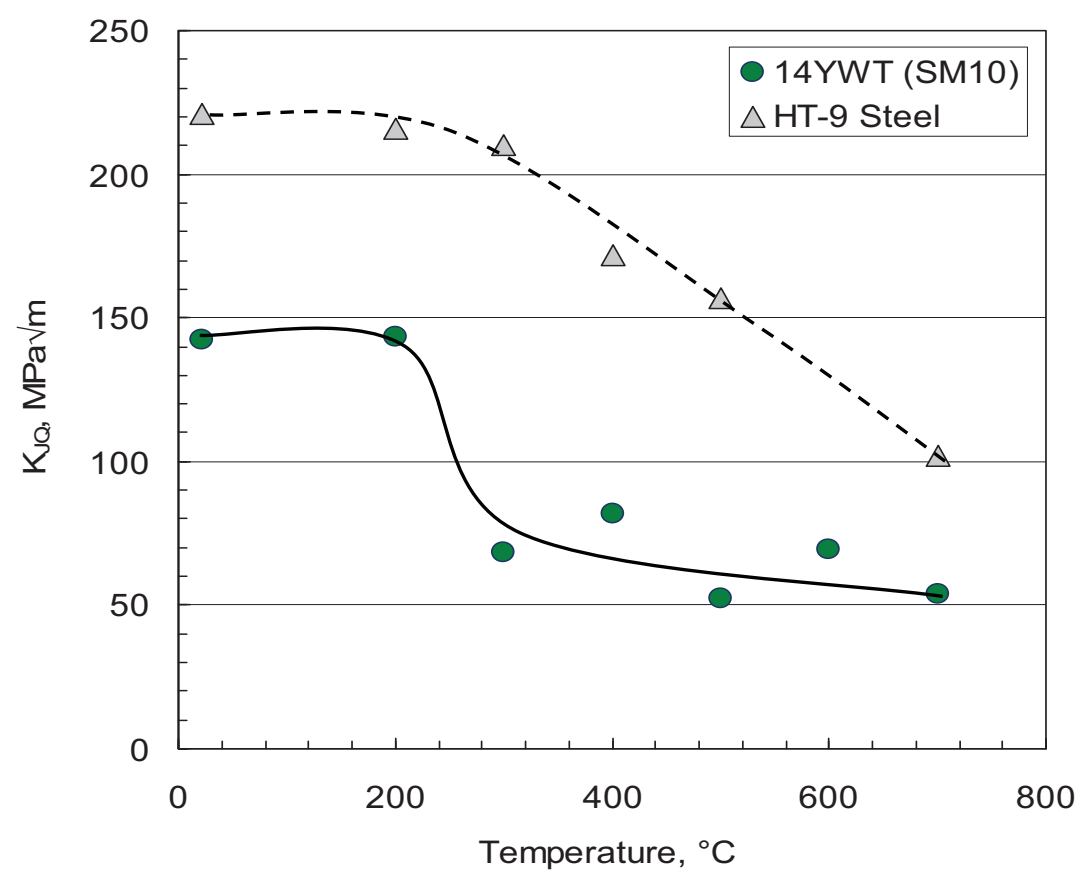

Figure 64. Temperature dependence of fracture toughness of 14YWT compared with the HT-9 steel 


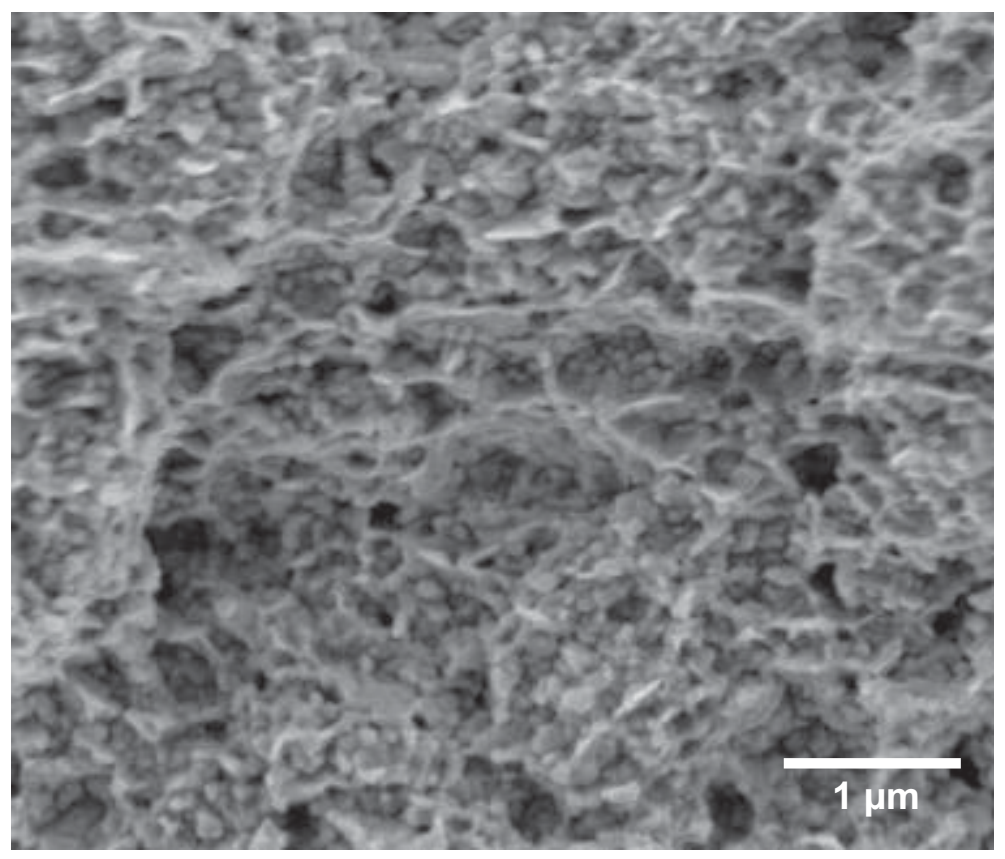

Figure 65. Fracture surface of $14 \mathrm{YWT}$ tested at $700{ }^{\circ} \mathrm{C}$ showing nanograins and debonding at grain boundaries 


\section{IRRADIATION TESTING TECHNOLOGIES}

Technical Lead, S. L. Hayes, steven.hayes@inl.gov, INL

The focus of the Irradiation Testing Technologies technical area underwent a significant shift during FY 2010 in order to better align with the science-based, goal-oriented objectives of the FCRD program. The primary objectives of the tasks to be pursued in the Irradiation Testing Technologies technical area during the upcoming five years were realigned to support three areas of specific emphasis.

The first area of emphasis is the feasibility testing of emergent, innovative fuel concepts that have the potential to make substantial progress toward achieving the Advanced Fuels Grand Challenges. Tasks in this area will largely consist of small-scale, integral experiments performed in the ATR coupled with conventional postirradiation examinations. Planning for the first two such tests were initiated this year and are expected to begin in FY 2011.

The second area of emphasis is the development of a capability to perform separate effects testing (SET), both in-pile and out-of-pile, to broadly advance the theoretical understanding of nuclear fuel behavior under irradiation and to inform/validate the complementary advanced modeling and simulation effort. Tasks in this area will consist of designing and deploying new irradiation testing capabilities, including low-dose hydraulic rabbit tests in HFIR and an irradiation test vehicle capable of controlling temperature as well as making in situ measurements of fuel performance parameters in the ATR.

Substantial work in preparing for the HFIR rabbit tests was completed this year, and tests are expected to begin in FY 2011; conceptual design of the new ATR irradiation vehicle was initiated and will continue in earnest next year. Coupled with the new irradiation testing capabilities will be the implementation of advanced postirradiation examination capabilities to characterize irradiated fuels at the micro- and/or nano-scales. Accomplishments reported relative to the PIE Upgrade Project at INL is a critical investment in this area.

The third area of emphasis is to gain an understanding the differences and/or limitations between testing advanced fast reactor fuels in neutron-shrouded positions in thermal test reactors in contrast to their performance in a prototypic fast-spectrum environment. Tasks in this area will consist of both analytical assessments as well as comparisons between equivalent fuels irradiated in both thermal and fast-spectrum reactors. These results will be important input to guiding the irradiation testing direction of current and future fuel development programs. Preparations at HFEF for the return of the FUTURIXFTA experiment for postirradiation examinations are a key element in this area.

\subsection{ATR Irradiations Testing}

K. Barrett, kristine.barrett@inl.gov, D. Utterbeck, R. Roesener, INL

During FY 2010, AFC experiment assemblies were inserted into the ATR east flux trap (EFT) drop-in positions E1, E2, and E3 (see Figure 66) for irradiation during the following ATR operating cycles: 145B (startup November 2009), 146A (startup January 2010), 146B (startup April 2010), 147A (startup June 2010), and 148A (startup August 2010). AFC-2C located in position E-3 was discharged from ATR after completion of cycle 145B (January 2010). the gas-cooled fast reactor (GFR) non-fuel material experiment was reinserted into the $\mathrm{E} 3$ position during cycle 146A. AFC-2D and AFC-2E remained in positions E1 and $\mathrm{E} 2$ for continued irradiation throughout FY 2010. The AFC-2B (discharged from ATR in April 2009) and AFC-2C experiments were shipped to the INL Material and Fuels Complex (MFC) for PIE analysis in July 2010 (see Figure 67 and Figure 68). This shipment resulted in achievement of an established Level 2 milestone. INL personnel who directly contributed to this milestone achievement include: Kristine 
Barrett (AFC experiment manager), Debra Utterbeck (Irradiation Testing department manager), and Robert Roesener (ATR shipping engineer).
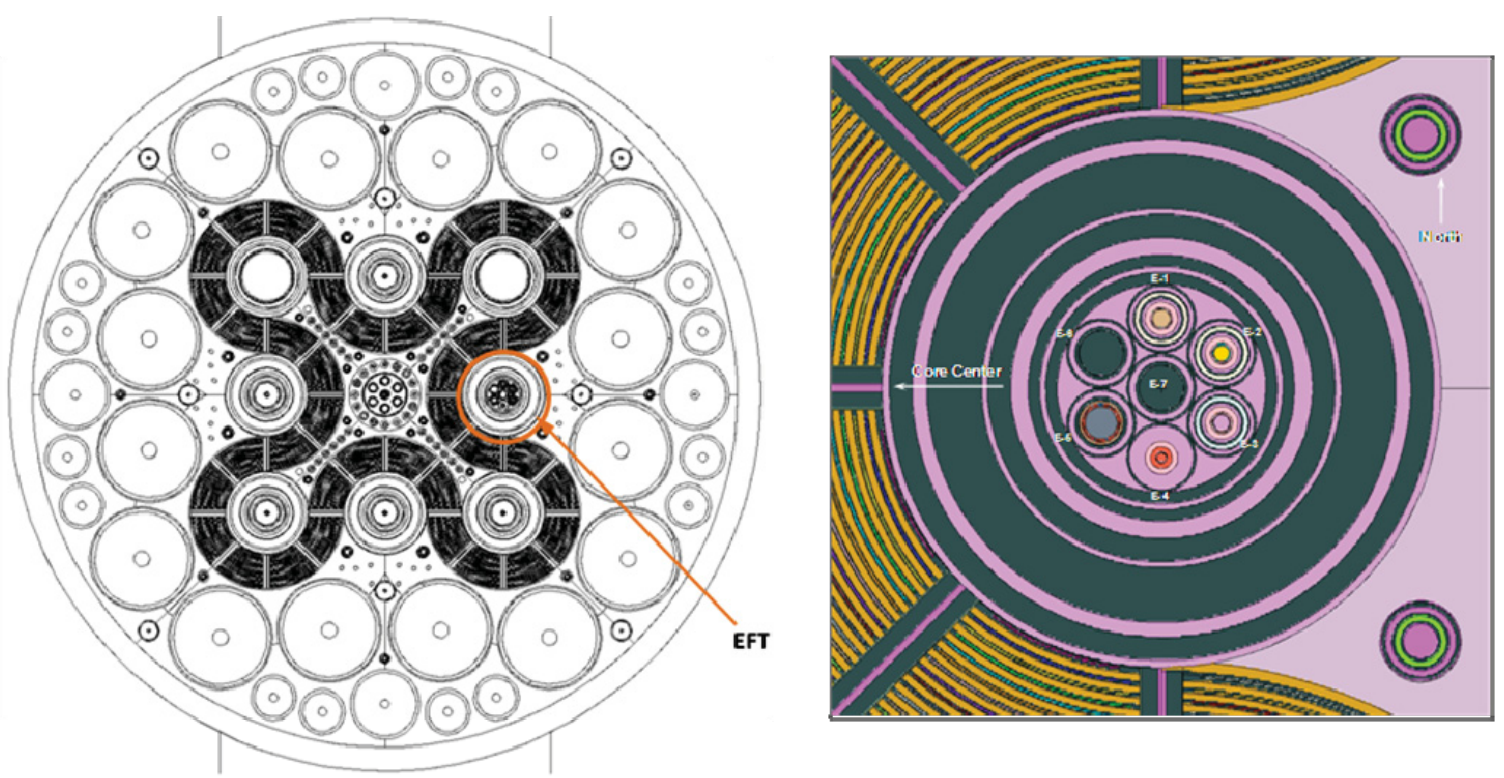

Figure 66. ATR reactor core cross section configuration (left) and enlargement of the East Flux Trap positions (right).

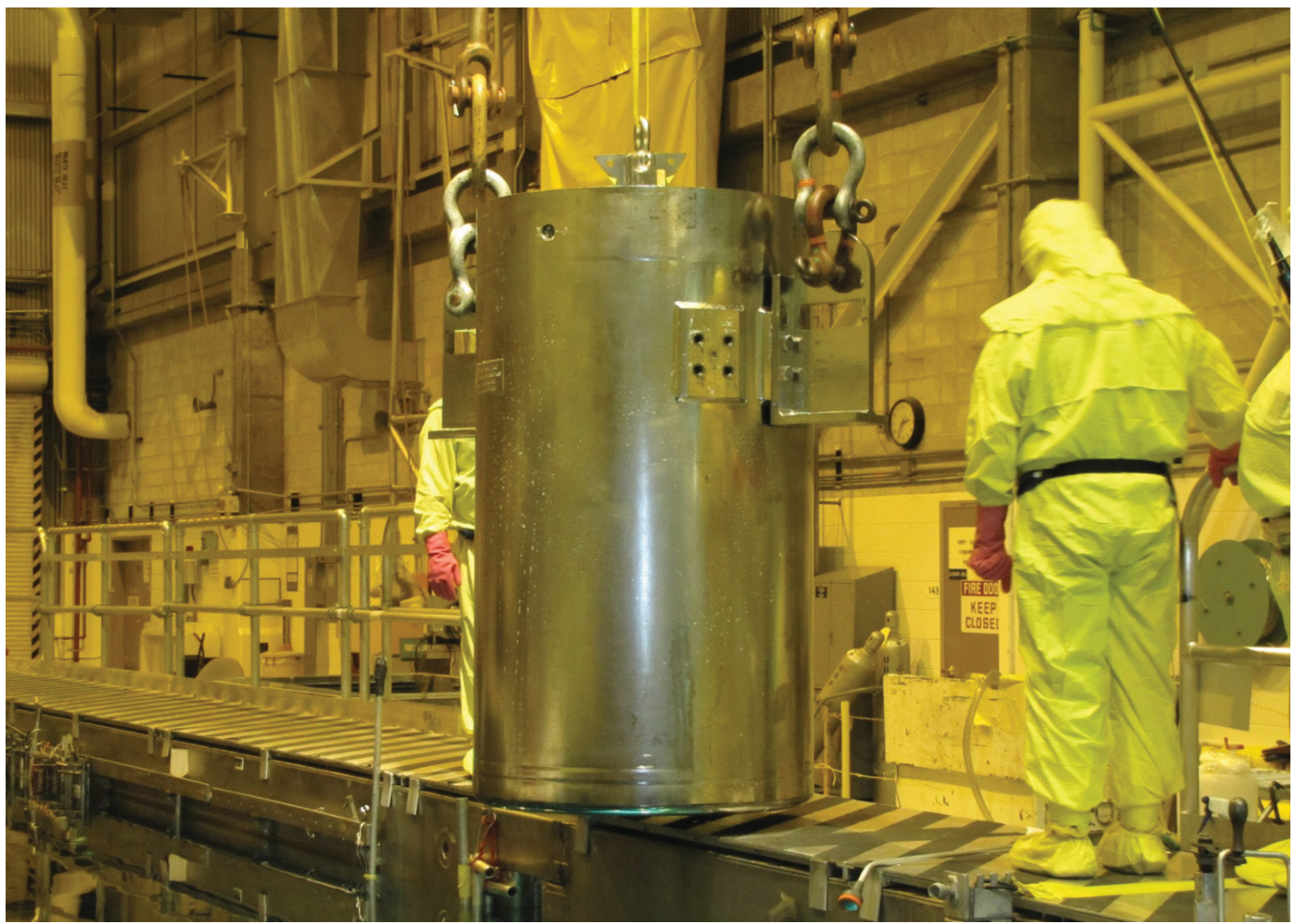

Figure 67. GE2000 cask being inserted into the ATR canal to insert the AFC experiment capsules for shipment to the Materials and Fuels Complex (MFC) for PIE. 


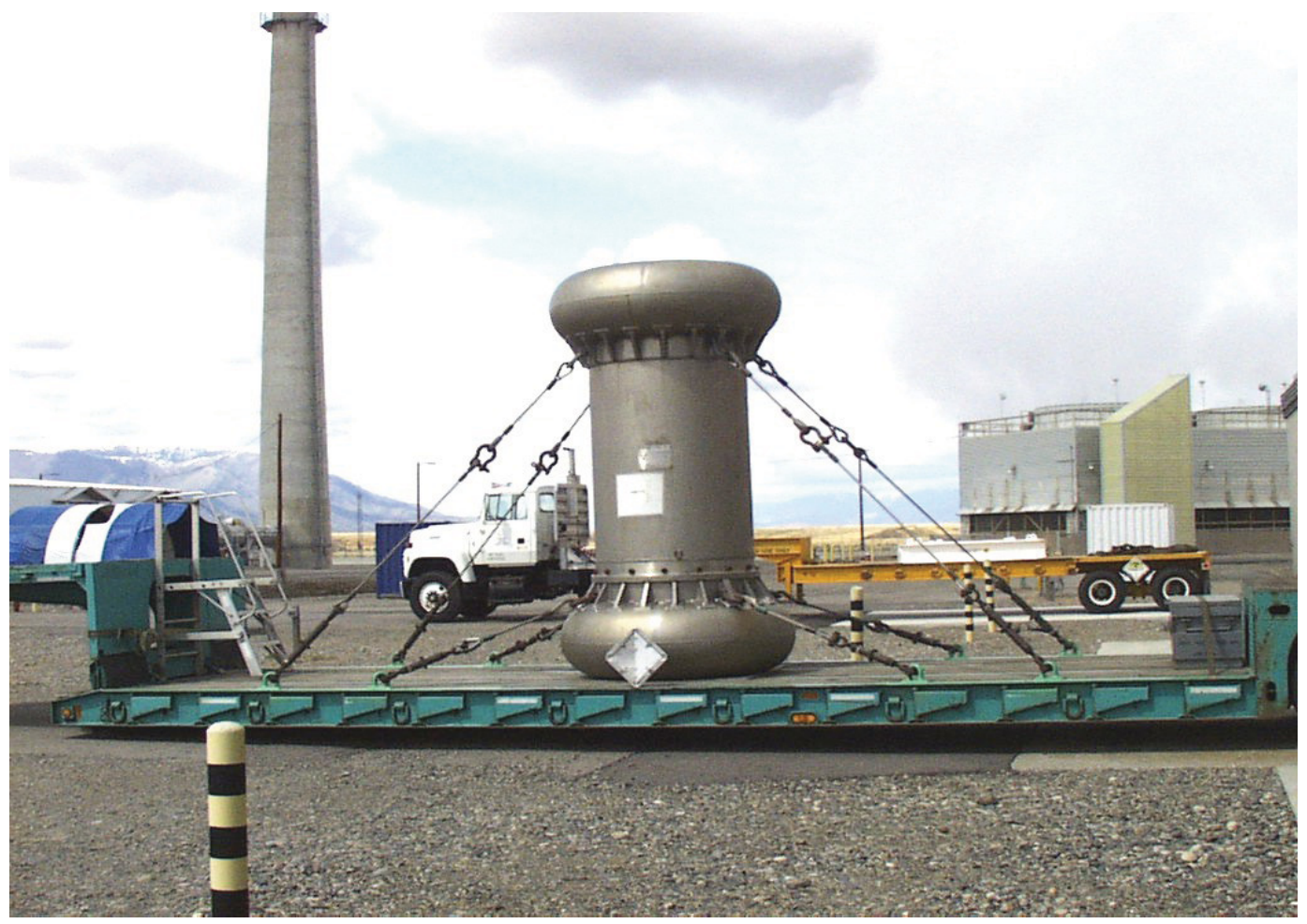

Figure 68. GE2000 cask loaded on the trailer for shipment to MFC.

Table 3 shows the as-run linear heat generation rate (LHGR) and burnup distribution calculations for each rodlet in the AFC-2D and AFC-2E experiments for Cycle 147A, which was the last full cycle completed in FY 2010. The peak rodlet in capsule AFC-2C reached 15.38 atom $\%$ burnup at completion of ATR cycle 145B. The peak rodlet in capsule AFC-2D reached 23.38 atom $\%$ burnup and the peak rodlet in capsule AFC-2E reached 13.02 atom\% burnup at the completion of ATR cycle 147A. Both AFC-2D and AFC-2E capsules were reinserted in ATR for continued irradiation during ATR cycle 148A. The AFC-2D capsule will require five additional ATR irradiation cycles (approximately 262 effective full-power days [EFPDs]) to reach $\geq 40$ atom $\%$ burnup. The AFC-2E capsule will require five additional ATR irradiation cycles (approximately 262 EFPDs) to reach the desired burnup of $\geq 20$ atom $\%$ burnup (see Figure 69). Discharge of the AFC-2D and AFC-2E experiments is anticipated in the first quarter of FY 2012.

Table 3. Cycle 147A As-Run LHGR, Fission Heat Rates, and Burnup Distribution for AFC Fuel in the EFT at 50.2 EFPDs (Scaled to East Lobe Source Power of 21.7 MW)

\begin{tabular}{|c|c|c|c|c|c|c|c|c|c|c|}
\hline \multicolumn{2}{|c|}{$\begin{array}{l}\text { Test Position } \\
\text { and ID }\end{array}$} & $\begin{array}{l}\text { Linear Heat } \\
\text { Rate } \\
(W / \mathrm{cm})\end{array}$ & $\begin{array}{c}\text { Fission } \\
\text { Heat Rate } \\
\text { (W/g) }\end{array}$ & $\begin{array}{l}\text { Fission } \\
\text { Density } \\
\text { (f/cc) }\end{array}$ & $\begin{array}{c}{ }^{239} \mathrm{Pu} \\
\text { Depletion } \\
\text { (atom\%) }\end{array}$ & $\begin{array}{l}\text { Heavy Metal } \\
\text { Depletion } \\
\text { (atom\%) }\end{array}$ & $\begin{array}{l}{ }^{241} \text { Am } \\
\text { Depletion } \\
\text { (atom\%) }\end{array}$ & $\begin{array}{l}{ }^{235} \mathrm{U} \\
\text { Depletion } \\
\text { (atom\%) }\end{array}$ & $\begin{array}{c}{ }^{237} \mathrm{~Np} \\
\text { Depletion } \\
\text { (atom\%) }\end{array}$ & $\begin{array}{c}{ }^{239} \mathrm{Pu}+{ }^{235} \mathrm{U} \\
\text { Depletion } \\
\text { (atom\%) }\end{array}$ \\
\hline \multirow{6}{*}{$\begin{array}{c}\text { E-1 } \\
\text { FC-2D }\end{array}$} & Rodlet 1 & 228.46 & 134.91 & $1.46 \mathrm{E}+21$ & $15.82 \%$ & $9.07 \%$ & $42.28 \%$ & $16.84 \%$ & $21.15 \%$ & $16.48 \%$ \\
\hline & Rodlet 2 & 290.37 & 171.53 & $1.97 \mathrm{E}+21$ & $21.04 \%$ & $11.10 \%$ & $35.75 \%$ & $21.67 \%$ & -- & $21.45 \%$ \\
\hline & Rodlet 3 & 305.65 & 185.12 & $2.11 \mathrm{E}+21$ & $23.02 \%$ & $12.86 \%$ & $55.55 \%$ & $23.56 \%$ & $26.81 \%$ & $23.38 \%$ \\
\hline & Rodlet 4* & -- & -- & -- & -- & -- & -- & -- & -- & -- \\
\hline & Rodlet 5 & 287.73 & 172.48 & $1.98 \mathrm{E}+21$ & $21.56 \%$ & $12.06 \%$ & $53.18 \%$ & $22.15 \%$ & $26.43 \%$ & $21.95 \%$ \\
\hline & Rodlet 6 & 250.24 & 148.92 & $1.00 \mathrm{E}+21$ & $17.75 \%$ & $9.97 \%$ & $45.79 \%$ & $18.36 \%$ & $23.22 \%$ & $18.15 \%$ \\
\hline \multirow{2}{*}{$\begin{array}{c}\text { E-2 } \\
\text { AFC-2E }\end{array}$} & Rodlet 1 & 327.79 & 150.67 & $1.66 \mathrm{E}+21$ & $8.87 \%$ & $6.22 \%$ & -- & $8.60 \%$ & -- & $8.67 \%$ \\
\hline & Rodlet 2 & 336.08 & 156.39 & $1.79 \mathrm{E}+21$ & $11.23 \%$ & $6.41 \%$ & -- & $11.79 \%$ & -- & $11.62 \%$ \\
\hline
\end{tabular}




\begin{tabular}{|c|c|c|c|c|c|c|c|c|c|}
\hline $\begin{array}{l}\text { Test Position } \\
\text { and ID }\end{array}$ & $\begin{array}{l}\text { Linear Heat } \\
\text { Rate } \\
(\mathrm{W} / \mathrm{cm})\end{array}$ & $\begin{array}{l}\text { Fission } \\
\text { Heat Rate } \\
\text { (W/g) }\end{array}$ & $\begin{array}{l}\text { Fission } \\
\text { Density } \\
\text { (f/cc) }\end{array}$ & $\begin{array}{c}{ }^{239} \mathrm{Pu} \\
\text { Depletion } \\
\text { (atom\%) }\end{array}$ & $\begin{array}{l}\text { Heavy Metal } \\
\text { Depletion } \\
\text { (atom\%) }\end{array}$ & $\begin{array}{l}{ }^{241} \mathrm{Am} \\
\text { Depletion } \\
\text { (atom\%) }\end{array}$ & $\begin{array}{c}{ }^{235} \mathrm{U} \\
\text { Depletion } \\
\text { (atom\%) }\end{array}$ & $\begin{array}{c}{ }^{237} \mathrm{~Np} \\
\text { Depletion } \\
\text { (atom\%) }\end{array}$ & $\begin{array}{c}{ }^{239} \mathrm{Pu}+{ }^{235} \mathrm{U} \\
\text { Depletion } \\
\text { (atom\%) }\end{array}$ \\
\hline Rodlet 3 & 324.26 & 154.64 & $1.78 \mathrm{E}+21$ & $11.70 \%$ & $6.91 \%$ & $30.25 \%$ & $12.79 \%$ & $19.07 \%$ & $12.40 \%$ \\
\hline Rodlet 4 & 360.12 & 163.57 & $1.89 \mathrm{E}+21$ & $12.24 \%$ & $6.54 \%$ & -- & $13.50 \%$ & -- & $13.02 \%$ \\
\hline Rodlet 5 & 335.41 & 155.92 & $1.73 E+21$ & $10.96 \%$ & $6.80 \%$ & $28.16 \%$ & $11.77 \%$ & $17.01 \%$ & $11.50 \%$ \\
\hline Rodlet 6 & 295.29 & 134.97 & $1.49 \mathrm{E}+21$ & $9.29 \%$ & $5.33 \%$ & -- & $9.81 \%$ & -- & $9.64 \%$ \\
\hline
\end{tabular}

* Dummy Rodlet

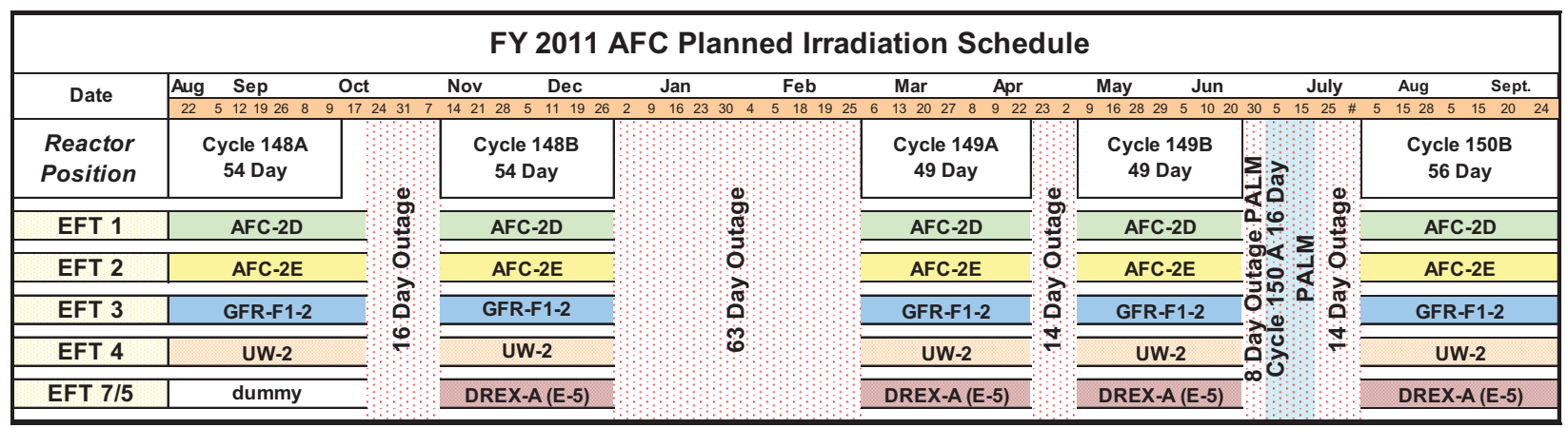

Figure 69. FY 2011 planned irradiation schedule for continued irradiation of AFC-2 experiments.

AFC-3 series of experiments are scheduled to begin in ATR cycle 150B (July 2011) in the outboard A positions A11 and A12. Physics, thermal, and structural analyses for the AFC-3 experiment design were performed and completed in FY 2010 (ECAR-1145, ECAR-1201, and ECAR-1155, respectively). Completion of the analyses resulted in achievement of an established Level 3 milestone. INL personnel who contributed to this milestone achievement include: Kristine Barrett (AFC experiment manager), Marci Smolinski (neutronics analyst), Misti Lillo (neutronics analyst), Glenn Roth (thermal analyst), Tom Clark (structural analyst), Spencer Snow (structural analyst), Michael Teague (design engineer), Debra Utterbeck (Irradiations Testing department manager), and Ron Harwell (Structural Analysis department manager). The structural analysis results indicated that the current design needs to be re-evaluated to reduce the thermal load or reduce the LHGR limit. AFC-3 redesign effort will continue in FY 2011 and final design analyses will be performed to support ATR safety document preparation.

\subsection{Postirradiation Examination}

H. J. M. Chichester, heather.chichester@inl.gov, B. A. Hilton, D. L. Porter, INL

Postirradiation examination (PIE) is conducted on FCRD fuel experiments to characterize the feasibility and relative performance of advanced fuel forms for actinide transmutation advanced fuel cycles and to provide scientific characterization data to support modeling and simulation development. In FY 2010, non-destructive examinations were completed on rodlets from experiments AFC-1D, 1G, 1H, and $2 \mathrm{~A}$, including neutron radiography and gamma scanning. Experiments $\mathrm{AFC}-2 \mathrm{~B}$ and $2 \mathrm{C}$ were shipped from ATR to HFEF in July 2010 and non-destructive PIE was initiated with visual exam, neutron radiography, and gamma scanning of the capsules in FY 2010.

The composition and a summary of the irradiation conditions for each fuel experiment are listed in Table 4 through Table 8. 
Table 4. Experiment AFC-1D composition and as-run irradiation data.

\begin{tabular}{|l|l|l|l|}
\multicolumn{1}{c|}{$\begin{array}{c}\text { AFC-1D } \\
\text { Composition }\end{array}$} & \multicolumn{1}{c|}{$\begin{array}{c}\text { Burnup } \\
\text { (at.\%) }\end{array}$} & \multicolumn{1}{|c|}{$\begin{array}{c}\text { Fission Density } \\
\text { (fission/cm3) }\end{array}$} & \multicolumn{1}{c|}{$\begin{array}{c}\text { Peak LHGR } \\
\text { (W/cm) }\end{array}$} \\
\hline $\mathrm{Pu}-12 \mathrm{Am}-40 \mathrm{Zr}$ & 24.13 & $1.96 \mathrm{E} 21$ & 147.83 \\
\hline $\mathrm{Pu}-10 \mathrm{Am}-10 \mathrm{NP}-40 \mathrm{Zr}$ & 30.79 & $2.24 \mathrm{E} 21$ & 167.80 \\
\hline $\mathrm{Pu}-40 \mathrm{Zr}$ & 33.34 & $3.30 \mathrm{E} 21$ & 253.85 \\
\hline $\mathrm{Pu}-12 \mathrm{Am}-40 \mathrm{Zr}$ & 34.08 & $2.84 \mathrm{E} 21$ & 216.59 \\
\hline $\mathrm{Pu}-60 \mathrm{Zr}$ & 39.55 & $2.25 \mathrm{E} 21$ & 170.14 \\
\hline $\mathrm{DUMMY}$ & - & - & - \\
\hline
\end{tabular}

Table 5. Experiment AFC-1G composition and as-run irradiation data.

\begin{tabular}{|l|l|l|l|}
\multicolumn{1}{c|}{$\begin{array}{c}\text { AFC-1G } \\
\text { Composition }\end{array}$} & \multicolumn{1}{|c|}{$\begin{array}{c}\text { Burnup } \\
\text { (at.\%) }\end{array}$} & \multicolumn{1}{|c|}{$\begin{array}{c}\text { Fission Density } \\
\text { (fission/cm3) }\end{array}$} & \multicolumn{1}{c|}{$\begin{array}{c}\text { Peak LHGR } \\
\text { (W/cm) }\end{array}$} \\
\hline Pu-10Np-40Zr & 24.49 & $2.04 \mathrm{E} 21$ & 149.85 \\
\hline DUMMY & - & - & - \\
\hline (U0.5,Pu0.25,Am0.15,Np0.10)N & 28.03 & $3.48 \mathrm{E} 21$ & 269.27 \\
\hline Pu-10Np-40Zr & 33.18 & $2.98 \mathrm{E} 21$ & 208.93 \\
\hline DUMMY & - & - & - \\
\hline DUMMY & - & - & - \\
\hline
\end{tabular}

Table 6. Experiment AFC-1H composition and as-run irradiation data.

\begin{tabular}{|l|l|l|l|}
\multicolumn{1}{c}{$\begin{array}{c}\text { AFC-1H } \\
\text { Composition }\end{array}$} & \multicolumn{1}{c|}{$\begin{array}{c}\text { Burnup } \\
\text { (at.\%) }\end{array}$} & $\begin{array}{c}\text { Fission Density } \\
\text { (fission/cm3) }\end{array}$ & \multicolumn{1}{|c|}{$\begin{array}{c}\text { Peak LHGR } \\
\text { (W/cm) }\end{array}$} \\
\hline U-29Pu-4Am-2Np-30Zr & 24.91 & $2.79 \mathrm{E} 21$ & 197.42 \\
\hline U-34Pu-4Am-2Np-20Zr & 28.32 & $3.48 \mathrm{E} 21$ & 259.46 \\
\hline U-25Pu-3Am-2Np-40Zr & 37.83 & $3.54 \mathrm{E} 21$ & 251.12 \\
\hline U-29Pu-4Am-2Np-30Zr & 36.00 & $3.91 \mathrm{E} 21$ & 266.25 \\
\hline U-28Pu-7Am-30Zr & 33.24 & $3.96 \mathrm{E} 21$ & 268.97 \\
\hline U-25Pu-3Am-2Np-40Zr & 29.40 & $2.77 \mathrm{E} 21$ & 192.73 \\
\hline
\end{tabular}


Table 7. Experiments $A F C-2 A$ and $2 B$ composition and as-run irradiation data.

\begin{tabular}{|l|l|l|l|l|l|l|}
\hline \multicolumn{1}{|c|}{ Composition } & \multicolumn{3}{|c|}{ AFC-2A } & \multicolumn{3}{c|}{ AFC-2B } \\
\hline & $\begin{array}{c}\text { Burnup } \\
\text { (at.\%) }\end{array}$ & $\begin{array}{c}\text { Fission } \\
\text { Density } \\
\text { (fission/cm3) }\end{array}$ & $\begin{array}{c}\text { Peak } \\
\text { LHGR } \\
\text { (W/cm) }\end{array}$ & $\begin{array}{c}\text { Burnup } \\
\text { (at.\%) }\end{array}$ & $\begin{array}{c}\text { Fission } \\
\text { Density } \\
\text { (fission/cm3) }\end{array}$ & $\begin{array}{c}\text { Peak } \\
\text { LHGR } \\
\text { (W/cm) }\end{array}$ \\
\hline U-20Pu-3Am-2Np-15Zr & 6.73 & $1.33 \mathrm{E} 21$ & 354.08 & 11.47 & $2.30 \mathrm{E} 21$ & 358.14 \\
\hline U-20Pu-3Am-2Np-1RE-15Zr & 9.42 & $1.43 \mathrm{E} 21$ & 355.66 & 15.64 & $2.43 \mathrm{E} 21$ & 359.54 \\
\hline $\begin{array}{l}\text { U-20Pu-3Am-2Np-1.5RE- } \\
\text { 15Zr }\end{array}$ & 10.52 & $1.28 \mathrm{E} 21$ & 326.46 & 17.32 & $2.22 \mathrm{E} 21$ & 340.89 \\
\hline $\begin{array}{l}\text { U-30Pu-5Am-3Np-1.5RE- } \\
\text { 20Zr }\end{array}$ & 10.78 & $1.37 \mathrm{E} 21$ & 342.89 & 17.55 & $2.49 \mathrm{E} 21$ & 368.43 \\
\hline U-30Pu-5Am-3Np-1RE-20Zr & 9.77 & $1.29 \mathrm{E} 21$ & 331.46 & 16.47 & $2.21 \mathrm{E} 21$ & 328.68 \\
\hline 42U-30Pu-5Am-3Np-20Zr & 7.99 & $1.19 \mathrm{E} 21$ & 319.82 & 13.35 & $2.07 \mathrm{E} 21$ & 326.22 \\
\hline
\end{tabular}

LHGR $=$ Linear Heat Generation Rate

$\mathrm{RE}=6 \% \mathrm{La}, 16 \% \mathrm{Pr}, 25 \% \mathrm{Ce}, 53 \% \mathrm{Nd}$

Table 8. Experiment AFC-2C composition and as-run irradiation data.

\begin{tabular}{|l|l|l|l|}
\multicolumn{1}{c|}{$\begin{array}{c}\text { AFC-2C } \\
\text { Composition }\end{array}$} & \multicolumn{1}{c|}{$\begin{array}{c}\text { Burnup } \\
\text { (at.\%) }\end{array}$} & \multicolumn{1}{|c|}{$\begin{array}{c}\text { Fission Density } \\
\text { (fission/cm3) }\end{array}$} & \multicolumn{1}{|c|}{$\begin{array}{c}\text { Peak LHGR } \\
\text { (W/cm) }\end{array}$} \\
\hline$\left(\mathrm{U}_{0.75}, \mathrm{Pu}_{0.20}, \mathrm{Am}_{0.03}, \mathrm{~Np}_{0.02}\right) \mathrm{O}_{1.95}$ & 10.37 & $9.19 \mathrm{E} 20$ & 226.67 \\
\hline$\left(\mathrm{U}_{0.80}, \mathrm{Pu}_{0.20}\right) \mathrm{O}_{1.98}$ & 13.78 & $1.25 \mathrm{E} 21$ & 308.48 \\
\hline$\left(\mathrm{U}_{0.75}, \mathrm{Pu}_{0.20}, \mathrm{Am}_{0.03}, \mathrm{~Np}_{0.02}\right) \mathrm{O}_{1.98}$ & 15.03 & $1.35 \mathrm{E} 21$ & 321.15 \\
\hline$\left(\mathrm{U}_{0.80}, \mathrm{Pu}_{0.20}\right) \mathrm{O}_{1.98}$ & 15.38 & $1.41 \mathrm{E} 21$ & 342.16 \\
\hline$\left(\mathrm{U}_{0.75}, \mathrm{Pu}_{0.20}, \mathrm{Am}_{0.03}, \mathrm{~Np}_{0.02}\right) \mathrm{O}_{1.95}$ & 14.06 & $1.25 \mathrm{E} 21$ & 307.43 \\
\hline$\left(\mathrm{U}_{0.75}, \mathrm{Pu}_{0.20}, \mathrm{Am}_{0.03}, \mathrm{~Np}_{0.02}\right) \mathrm{O}_{1.98}$ & 11.51 & $1.02 \mathrm{E} 21$ & 260.23 \\
\hline
\end{tabular}

Non-destructive PIE of experiments AFC-1D, $1 \mathrm{G}$, and $1 \mathrm{H}$ indicate that the fuel rodlets are intact and that fuel behavior is similar to that expected based on previous metallic fuel experiments. Figure 70 shows neutron radiography of the AFC-1D, $1 \mathrm{G}$, and $1 \mathrm{H}$ rodlets. 


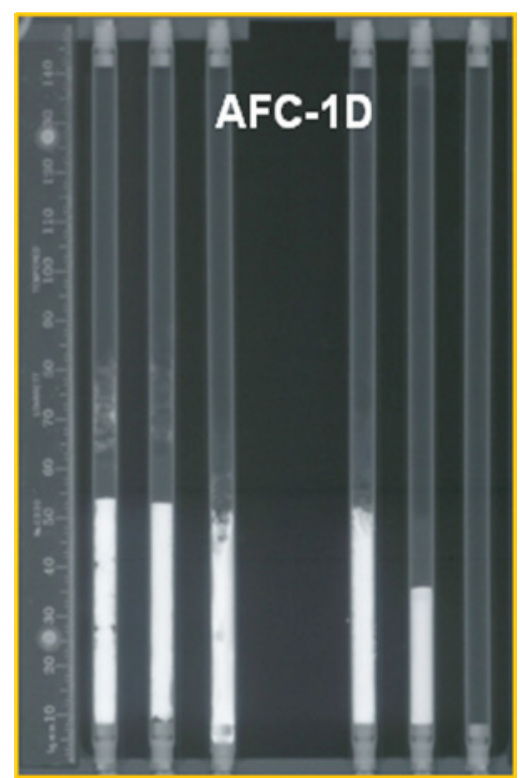

(a) AFC-1D

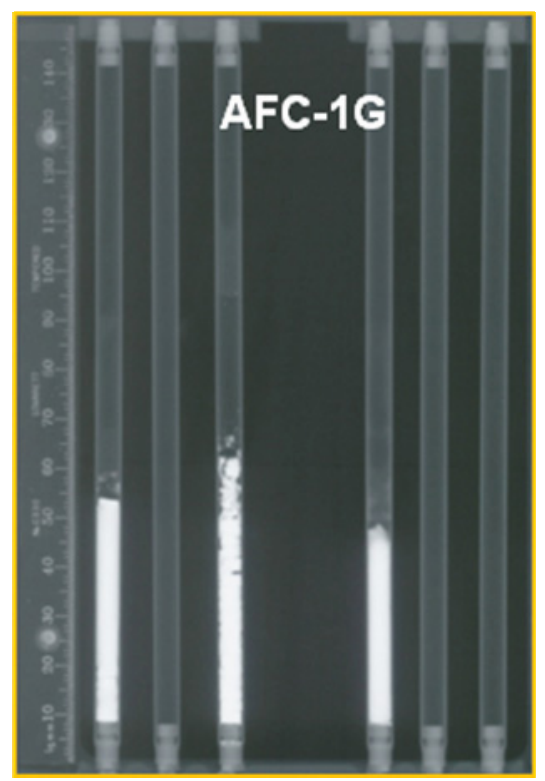

(b) AFC-1G

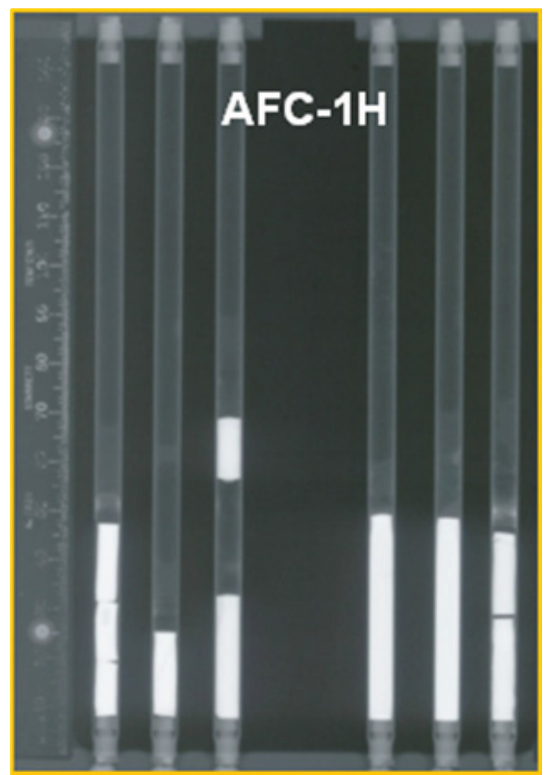

(c) $\mathrm{AFC}-1 \mathrm{H}$

Figure 70. Neutron radiography of fuel rodlets (left to right rodlets 1 through 6).

Gamma scanning collects axial profiles of specific isotopes, indicating the presence and location of the rodlet hardware, fuel, and sodium. Noble metal ruthenium and rare earth praseodymium do not redistribute axially and indicate fuel location. Cesium dissolved in the sodium collects at the ends of fuel slugs and fuel columns. Figure 71 through Figure 73 show the isotopic gamma scans for AFC-1D, 1G, and $1 \mathrm{H}$, respectively.

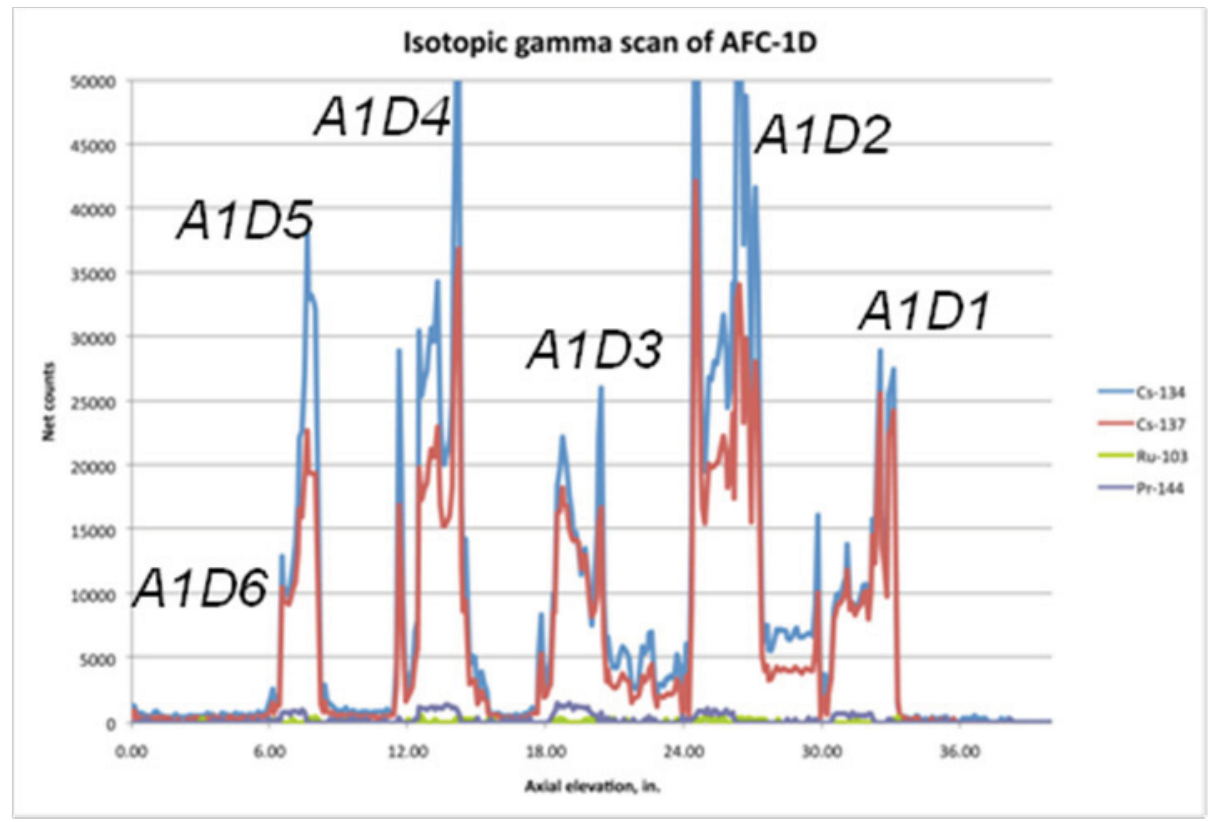

Figure 71. Isotopic gamma scan of AFC-1D. 


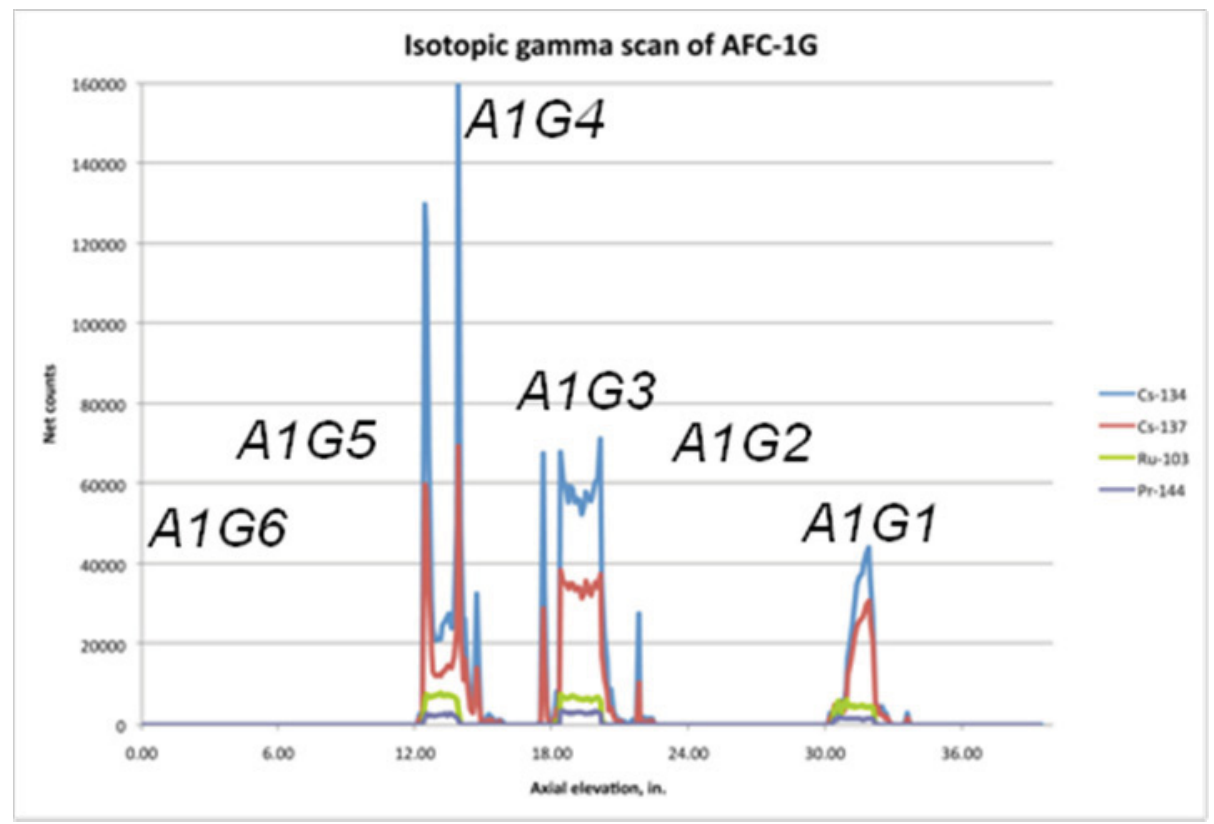

Figure 72. Isotopic gamma scan of AFC-1G

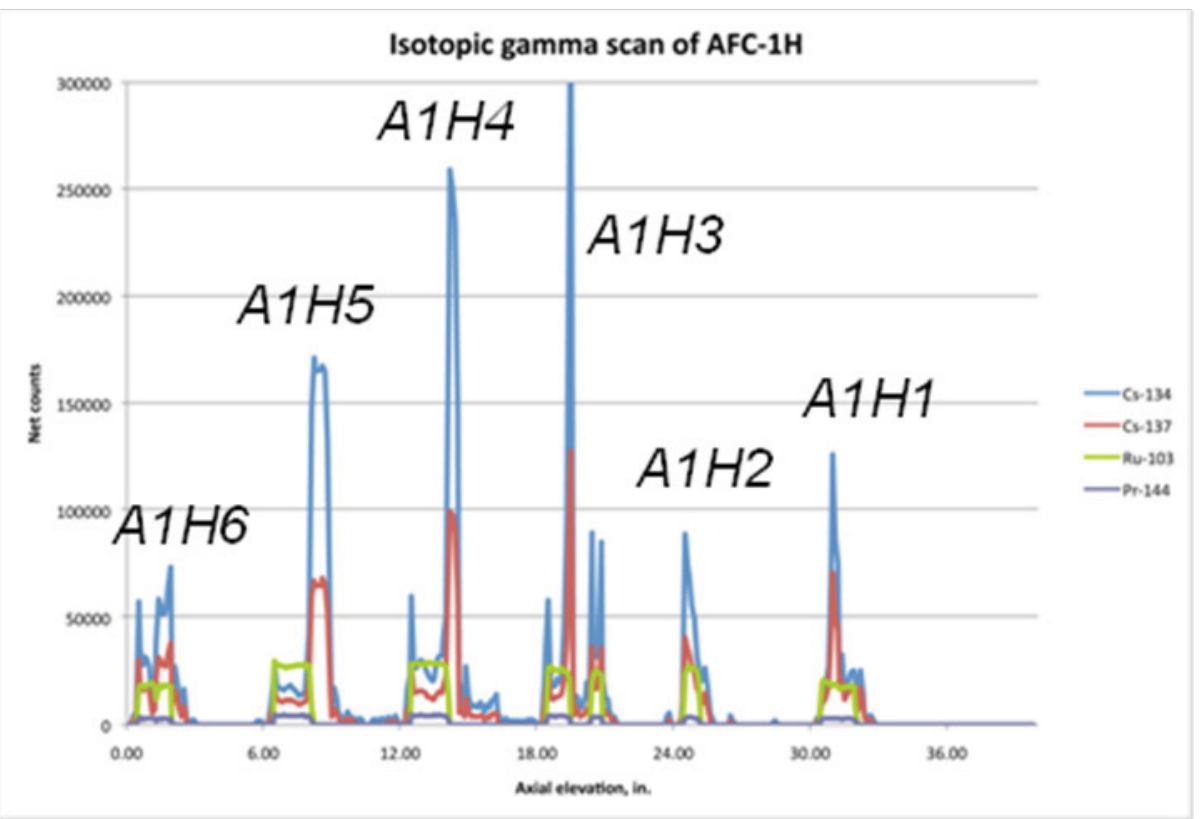

Figure 73. Isotopic gamma scan of $\mathrm{AFC}-1 \mathrm{H}$

Non-destructive PIE of fuel experiment AFC-2A indicates that fuel melting occurred and that two rodlets likely breached during irradiation. Examining the fuel and sodium appearance in neutron radiography, shown in Figure 74, with the axial location of the isotopes from gamma scanning, shown in Figure 75, it appears that there is no sodium plug in AFC-2A rodlet 2 and rodlet 6 . This suggests that AFC-2A rodlets 2 and 6 breached during irradiation. The irradiation test train design includes 6 fuel rodlets inside a single sealed capsule. One consequence of this design is that the breach of any one rodlet causes fission gases to be released to the common capsule plenum which reduced the thermal 
conductivity in the gap between the rodlets and the capsule, increasing the temperature in all of the rodlets. Therefore, a single rodlet failure may cause cascading failures of other rodlets.

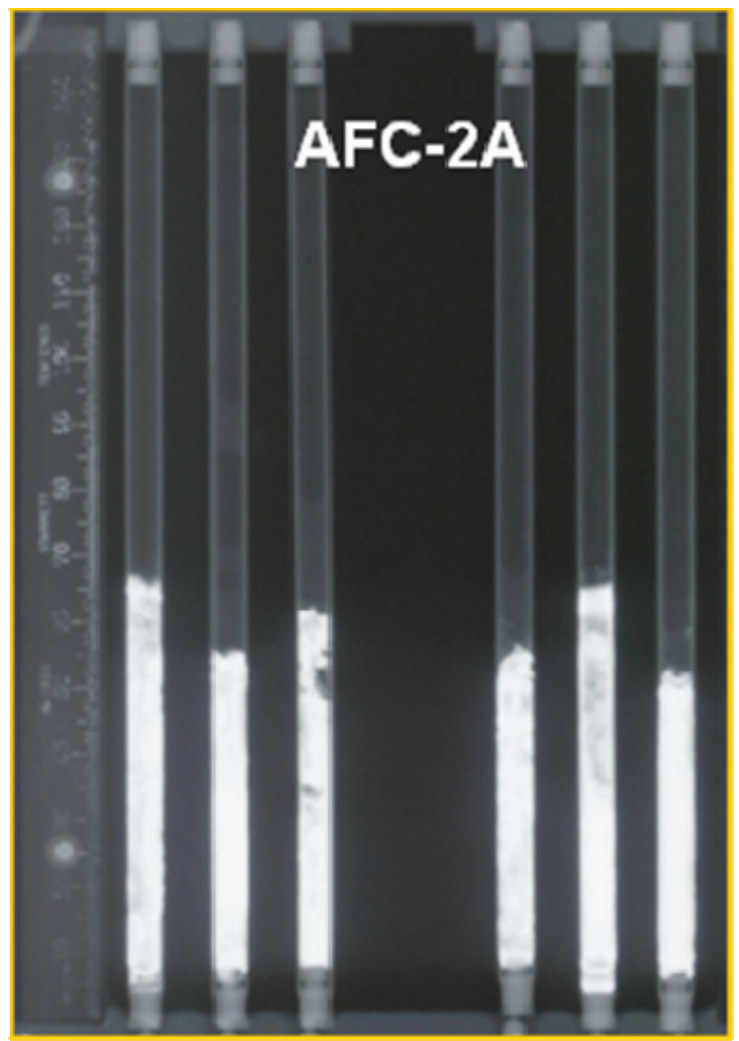

Figure 74. Neutron radiography of AFC-2A rodlets (left to right: rodlet 2, rodlet 1 , rodlet 3 , rodlet 5 , rodlet 6 , rodlet 4).

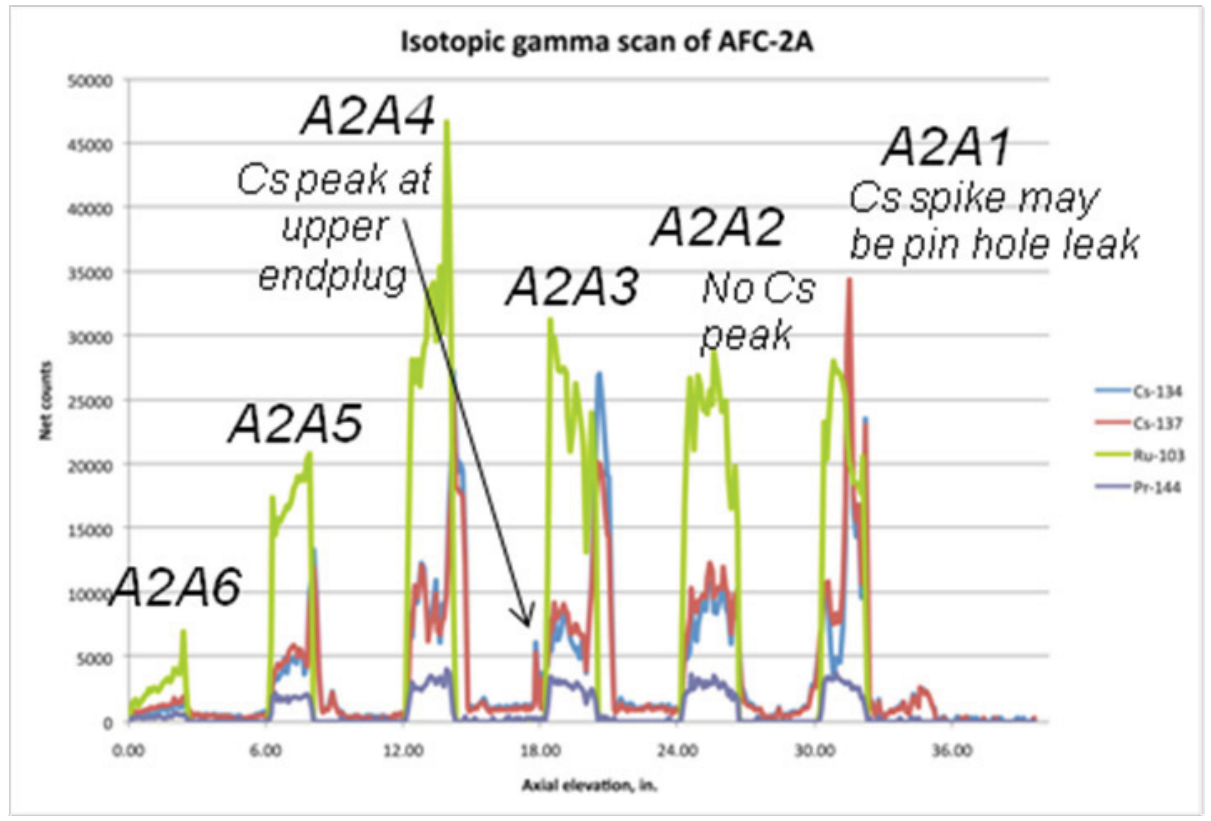

Figure 75. Isotopic gamma scan of AFC-2A. 
Due to NRAD reactor fuel conversion and equipment modifications to upgrade the fission gas capture system and metallography sample preparation, destructive PIE of AFC-1D, 1G, 1H, and 2A was deferred to FY 2011.

Initial non-destructive PIE of fuel experiments AFC-2B and 2C were conducted in FY 2010. Neutron radiography and gamma scanning results are currently under analysis.

\section{References}

1. Bruce A. Hilton, "Postirradiation Examination Plan for FFTF MFF-x, IFR-1, FO-2, ACO-3, 4 and ACN-1," INL/EXT-10-18248, March 2010.

2. Bruce A. Hilton, "Non-Destructive Examination of AFC-1H, AFC-1D, AFC-1G, and AFC-2A," INL/EXT-10-19191 Revision 0-DRAFT, FCRD-FUEL-2010-000067, June 2010.

\subsection{Prepare HFEF for FUTURIK-FTA Receipt}

\section{A. L. Crawford, Anthony.Crawford@inl.gov, C. J. Knight, S. L. Hayes, INL}

In preparation for shipping the FUTURIX-FTA metallic and nitride fuel pins from the Phénix site in France to the Hot Fuel Examination Facility (HFEF) at INL, several components were designed and fabricated to allow the TN-106 shipping cask to be received and handled at HFEF. The two major interface components are the cask cart adapter and the shield ring, shown in Figure 76. The cask handling procedure was drafted, and a dry run using the TN-106 cask to validate the procedure and qualify the new components was scheduled for September, but at the request of CEA (who had a higher priority need for the cask) that dry run was deferred. Due to mechanical failures at the Phénix hot cell, the actual shipment is currently anticipated during FY 2012.

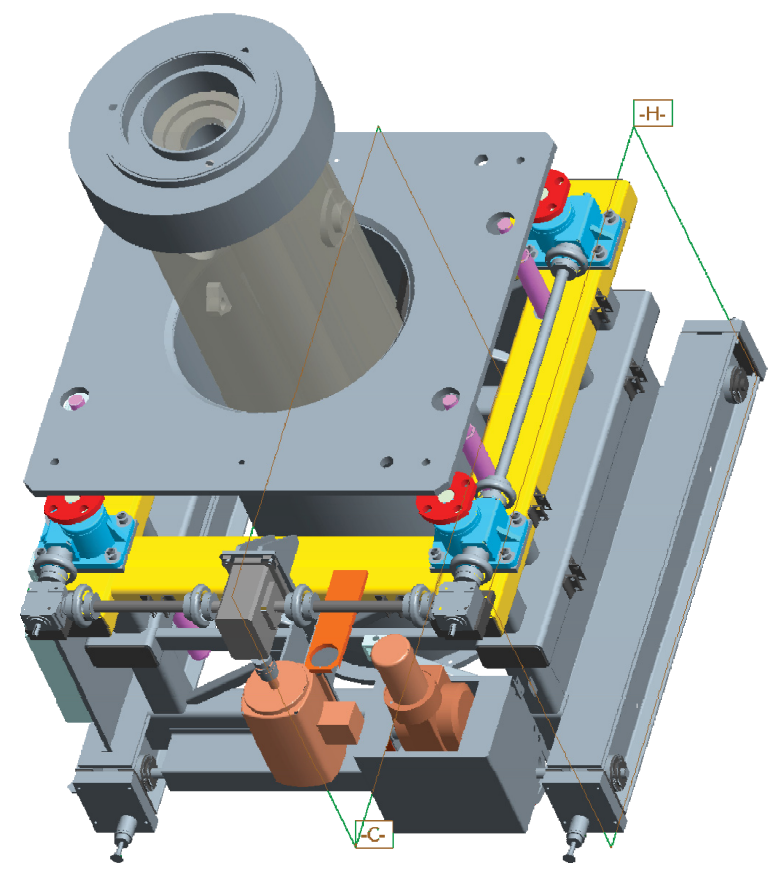

Figure 76. TN-106 shipping cask shown in HFEF cask cart with new cask cart adapter and shield ring. 


\title{
7.4 Post-Irradiation Examination Equipment Upgrade Project
}

\author{
J. A. Michelbacher, J.Michelbacher@inl.gov, INL
}

The PIE Equipment Upgrade project is a challenging and extremely important activity. It has overcome political, operational, and execution challenges since its inception in FY 2007. It has several multi-year procurement and installation activities planned through FY 2011. This project has achieved all of its milestones significantly ahead of schedule.

The microscale x-ray diffractomer (MXRD), FIB, Thermal Ionization Mass Spectrometer (TIMS), and STDM were all installed and accepted in FY 2009. The electron probe micro-analyzer (EPMA) was delivered in FY 2010 and will be installed and operational in its temporary location in the MFC Analytical Laboratory in FY 2011. The fresh fuel thermo-physical properties characterization line enhancement will install a new inert glovebox as well as a wet preparation glovebox in the MFC AL in FY 2011. Installation of these instruments at MFC will enhance PIE capabilities that support the INL in the establishment of a state-of-the-art capability for the development and qualification of transmutation fuels. The conceptual design was developed for the new Irradiated Material Characterization Laboratory (IMCL) to host some of these instruments. This shielded facility is scheduled for design/construction beginning in FY 2011, and will house the EPMA, MXRD, and FIB to allow PIE of irradiated materials.

\subsection{HFIR Irradiation Testing}

\author{
G. Bell, bellgl@ornl.gov, ORNL
}

The objective of this effort is to design and fabricate rabbit capsules and perform the safety analyses required to secure approval for irradiation experiments supporting fuel, target, and materials development for the FCRD AFC. Low fluence irradiation experiments are needed to examine (1) the early stages of microstructural evolution in metallic fuels, (2) radiation enhanced diffusion (RED) and FCCI, (3) constituent redistribution, and (4) historical EBR-II fuel irradiated in various facilities (e.g. fast and thermal spectra). The microstructural evolution will primarily be followed utilizing standard TEM disks. $\mathrm{RED} / \mathrm{FCCI}$ will be analyzed with diffusion couples and multiples. Constituent redistribution evolution will be followed with small fuel slugs. The comparison of the historical EBR-II fuel can take the form of TEM disks and/or small slugs.

The desired irradiation conditions are

- Temperatures of $550-750^{\circ} \mathrm{C}$ in the samples,

- Doses of $10^{-5}$ to $5 \mathrm{dpa}$,

- Linear heat generation rate equivalents of 300-350 W/cm.

The flux trap hydraulic rabbit facility in the HFIR at ORNL offers the unique capability to irradiate samples for very low doses (as short as 1 minute or as long as 23 days). Figure 77 contains a photograph of the HFIR core and a schematic showing the various flux trap irradiation facilities. Figure 78 is a sketch showing the location of the 9 rabbits in the standard rabbit train relative to the HFIR core. To obtain the desired irradiation conditions, shielded rabbits must be employed; however, insertion and ejection of shielded (or "black") rabbits causes a reactivity response in the reactor that has the potential to engage the HFIR safety response system which could result in an unplanned shutdown. Unplanned reactor shutdowns must be avoided. The following sections summarize the activities performed in FY 2010 in preparation for HFIR irradiation testing to begin in FY 2011 using the hydraulic rabbit facility. Work 
performed includes reactivity testing, core physics modeling and the design of shielded-rabbits to irradiate TEM specimens.

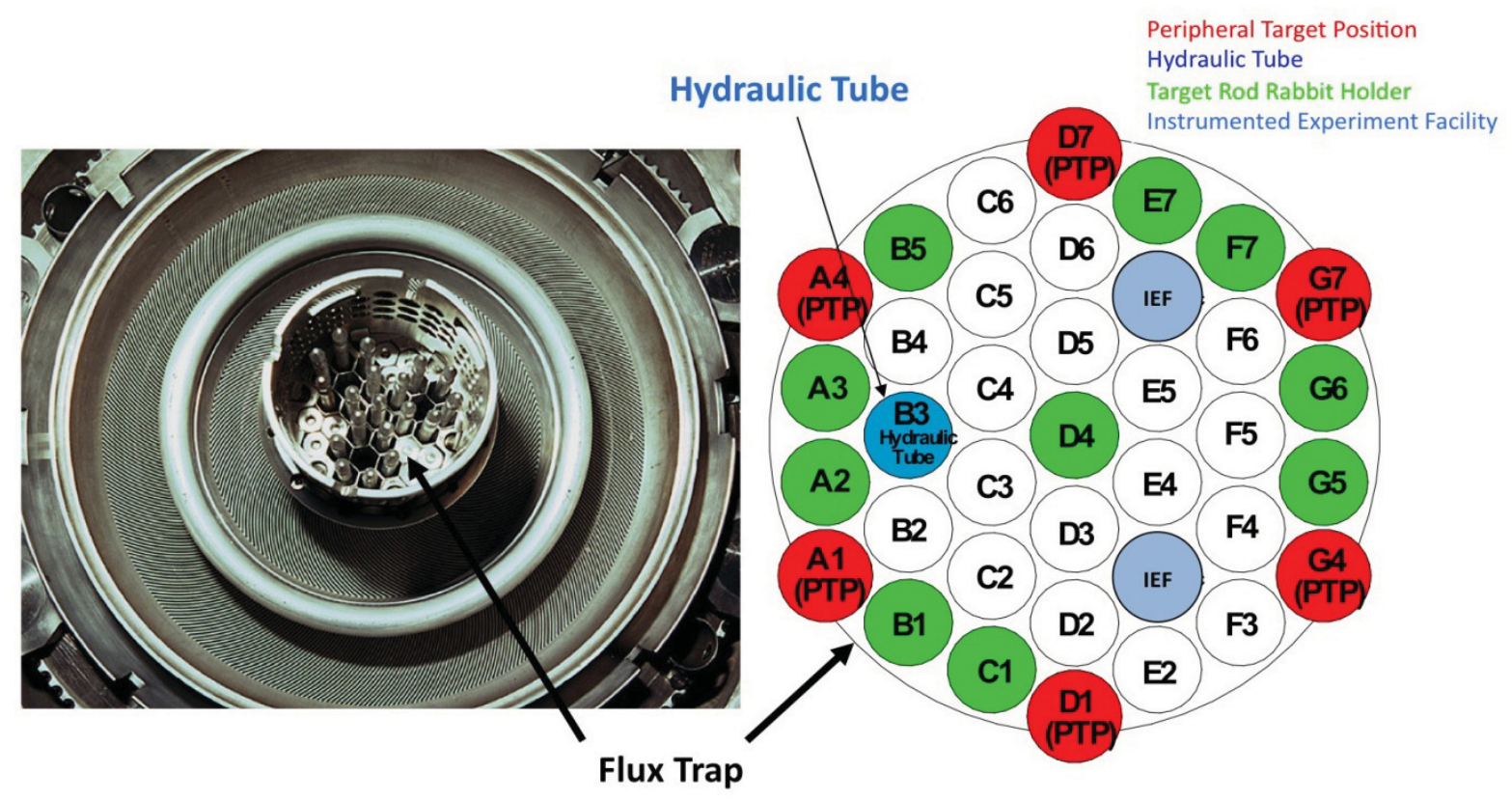

Figure 77. Photograph of HFIR core showing central flux trap (left) and schematic showing the location of the various irradiation facilities within the flux trap region (right). The diameter of the flux trap is $12.7 \mathrm{~cm}$. 


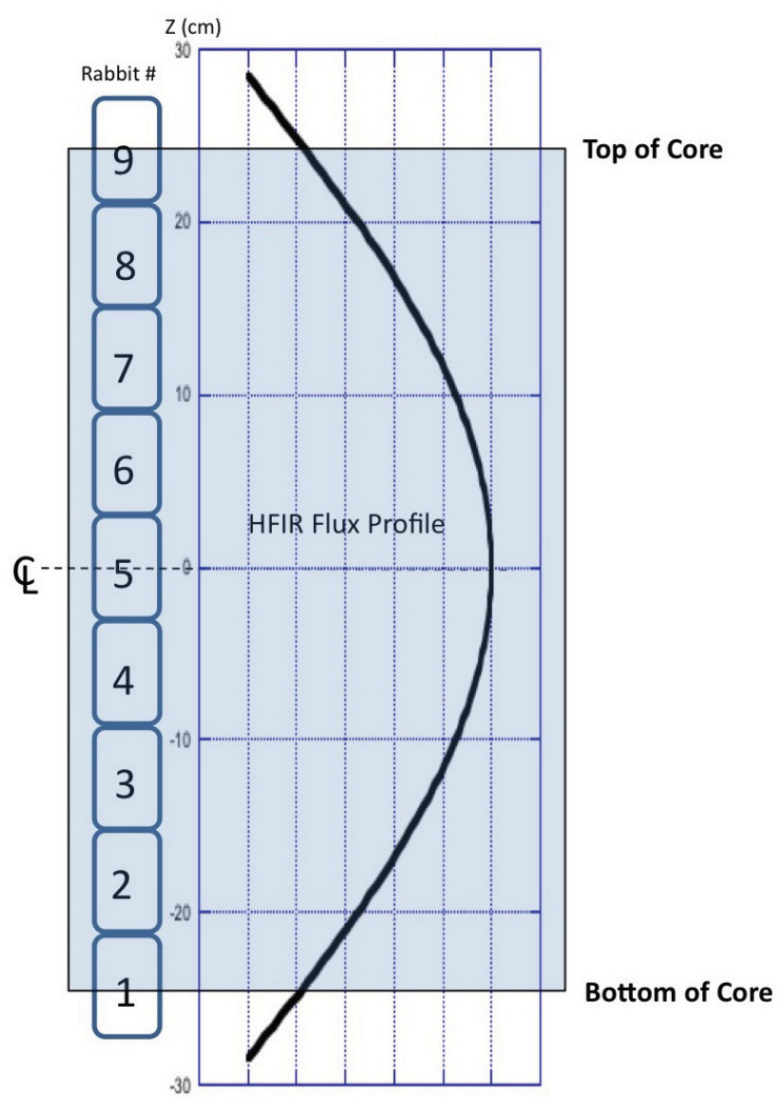

Figure 78. Sketch showing the location of the 9 rabbits in the standard rabbit train relative to the HFIR core. The fuel core height is $50.8 \mathrm{~cm}$.

\subsubsection{Reactor Reactivity Testing}

Prior to irradiating test articles, tests to measure the margin to reactor trip at low power (and at full power) are required to demonstrate that the risk of unplanned reactor shutdown is small and to define the acceptable operating space (i.e., rabbit worth, vertical position in the rabbit train, and number of rabbits housing test articles). An initial test employing a "gray" rabbit (similar to a test conducted in the 1960's [T.M. Sims, ORNL Intra-Laboratory Correspondence, 3/31/1967] and approved for operation at low reactor power, $\sim 12 \mathrm{MW}$ ) was conducted at the beginning of cycle (BOC) 429 in June 2010. The purpose of this "dry run" was to test the data collection system using a $\mathrm{Cd}$ lined rabbit $(\sim 8 \phi)$, familiarize the operators with the testing procedures, and identify any potential problems. The dry run was very successful with the "gray" rabbit being inserted and ejected into/from the fifth, seventh and ninth axial positions. The data was acquired from the servo control system channels, not the safety system channels. The reproducibility of the tests was very good and all the transients were terminated by small movements $(<1.3 \mathrm{~mm})$ of the control cylinder with movement of the cylinders starting 35-50 ms after the initiation of the rabbit ejection. It was also found that the level of noise on the power and the rate of rise of power signals was greater than expected. The source of the noise is unknown, but was judged to be real owing to the reproducible power spectrum. Figure 79 shows the reactor power signal (normalized and smoothed), the rate of rise of power signal (smoothed), and the numerical derivative (calculated using MatLab) of the reactor power signal with respect to time for the $\mathrm{Cd}$ rabbit ejected from position 5 . It should be noted that the rate of rise of power signal is actually a $\mathrm{RC}$-circuit conditioned power signal, not a true time rate of change of power signal. Preliminary analysis of the test results indicates the maximum rabbit worth that 
can be ejected from position 5 without initiating reactor shutdown is approximately 7.1 $\varnothing$. Test data using a range of rabbit worths ejected from various rabbit positions are needed to definitively map out the actual value of rabbit worth as a function of rabbit location that can be ejected without tripping the reactor.

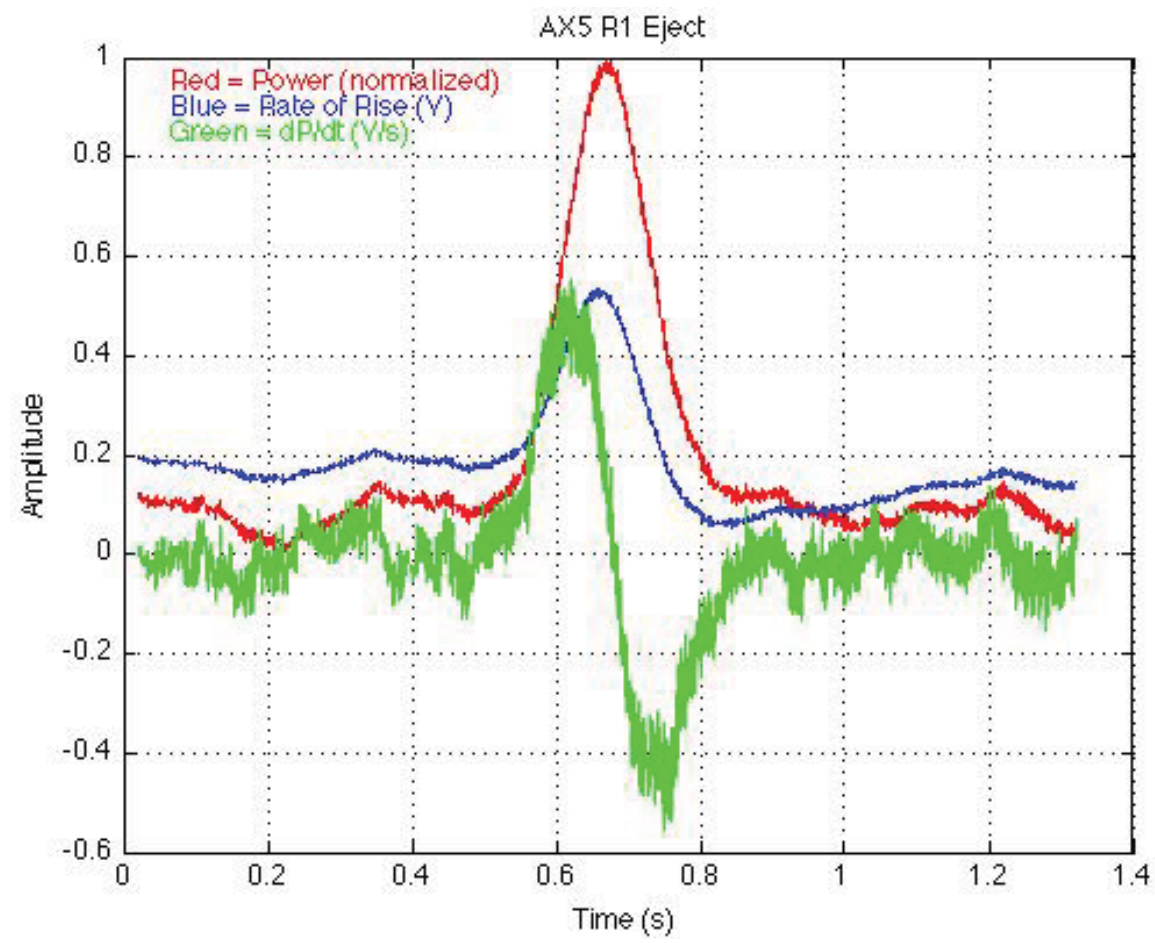

Figure 79. Plots of the reactor power signal (normalized, red), the rate of rise of power signal (actually a $R C$-circuit conditioned power signal, not a true time rate of change of power signal, blue), and the derivative of the reactor power signal with respect to time (green) for the $\sim 8 \phi C d$ rabbit ejected from position 5 .

The "black" rabbit tests, planned for early FY 2011, will involve insertion/ejection of rabbits (of various worths, $3-18 \phi$ ) while monitoring the resultant transient power level and rate-of-rise of power on a data recorder connected to one of three HFIR safety channels. These tests will be performed at reactor startup at low power and throughout the operating cycle at full power. These reactivity insertions will start at low rabbit worths not capable of causing reactor trip and then incrementally increased in a manner that ensures adequate margin to reactor trip. The testing sequence will be controlled via special operating procedures. To date, the physics calculations for the "black" design have been finished and the safety documentation completed and under review. The thermal/hydraulic safety calculations and documentation for the "black" rabbits are complete, pending approval of the physics calculations. The operating procedures, white paper and HFIR Safety Basis Supplement are being prepared and will be submitted to DOE for their review and approval. Pending DOE-HQ approval, testing of "black" rabbits could occur as early as cycle 432 (November-December 2010). If DOE approval is not received in time for cycle 432, then the testing will have to be performed in the first cycle following receipt of DOE approval (e.g., cycle 433 (1/5-1/28/2011), cycle $434(2 / 16-3 / 11 / 2011)$, etc.).

\subsubsection{HFIR Gore Reactivity Model Development}

The HFIR core reactivity model, employing point kinetics equations with best estimate temperature feedback, utilized both the PARET and COMSOL computer codes and modeled the rate-of-rise circuitry 
as an RC circuit. The model has been completed and calibrated via the low power "dry" run results. It has been used to provide best-estimate rabbit maximum reactivity worth for the hydraulic tube positions ( 5 through 8) as listed in Table 9.

Table 9. Estimated maximum rabbit reactivity worth for hydraulic rabbit tube positions

\begin{tabular}{|c|c|}
\hline Hydraulic Tube Vertical Position & Rabbit Reactivity (cents at HFIR midplane) \\
\hline 5 & 7.1 \\
\hline 6 & 7.7 \\
\hline 7 & 9.9 \\
\hline 8 & 16.2 \\
\hline
\end{tabular}

\subsubsection{Design of Shielded Rabbits for Irradiating TEM Samples}

Two conceptual TEM rabbit designs were evaluated prior to selection of the final design. These evaluations consisted of physics and thermal calculations investigating multiple configurations, shield designs and shield materials. Configurations that employed an external shield had multiple gas gaps, which resulted in excessive heat loads and internal temperatures. A final design has been chosen, which employs an internal thermal-neutron shield that also acts as a specimen holder/spacer and as a heat conduit to maintain the specimen temperature within the desired ranges (see Figure 80). This design also has an acceptable total heat generation rate (for the safety case). It should be noted that the number of Gd spacers can be reduced to adjust the reactivity of the rabbit. Removing a gadolinium (Gd) spacer simply requires using a longer spring. The physics calculations for the TEM rabbit design are in the final stages; preliminary results have been employed in the thermal/mechanical ANSYS assessment. The final thermal safety calculations and documentation for the TEM rabbit will be completed upon approval of the physics calculation in FY 2011. 


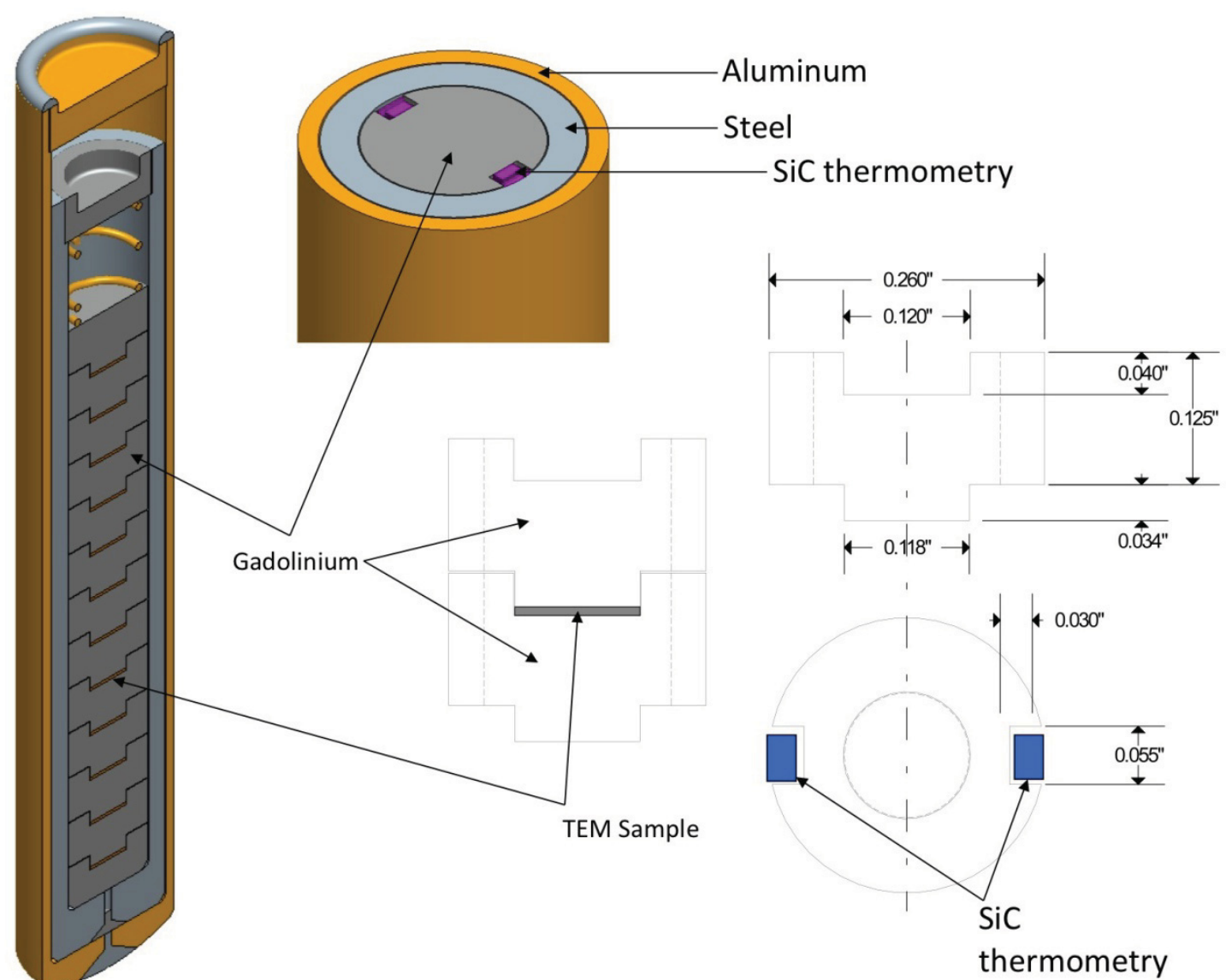

Figure 80. TEM rabbit design features the use of Gd spacers that also serve as the thermal neutron shield. Space is provided for a maximum of 12 TEM disks samples, however flux monitors will displace some of the TEM disks as needed. The number of Gd spacers can be reduced to adjust the reactivity of the rabbit. 